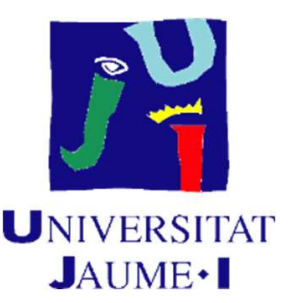

\title{
Sexualidad en hombres y mujeres con lesión medular traumática
}

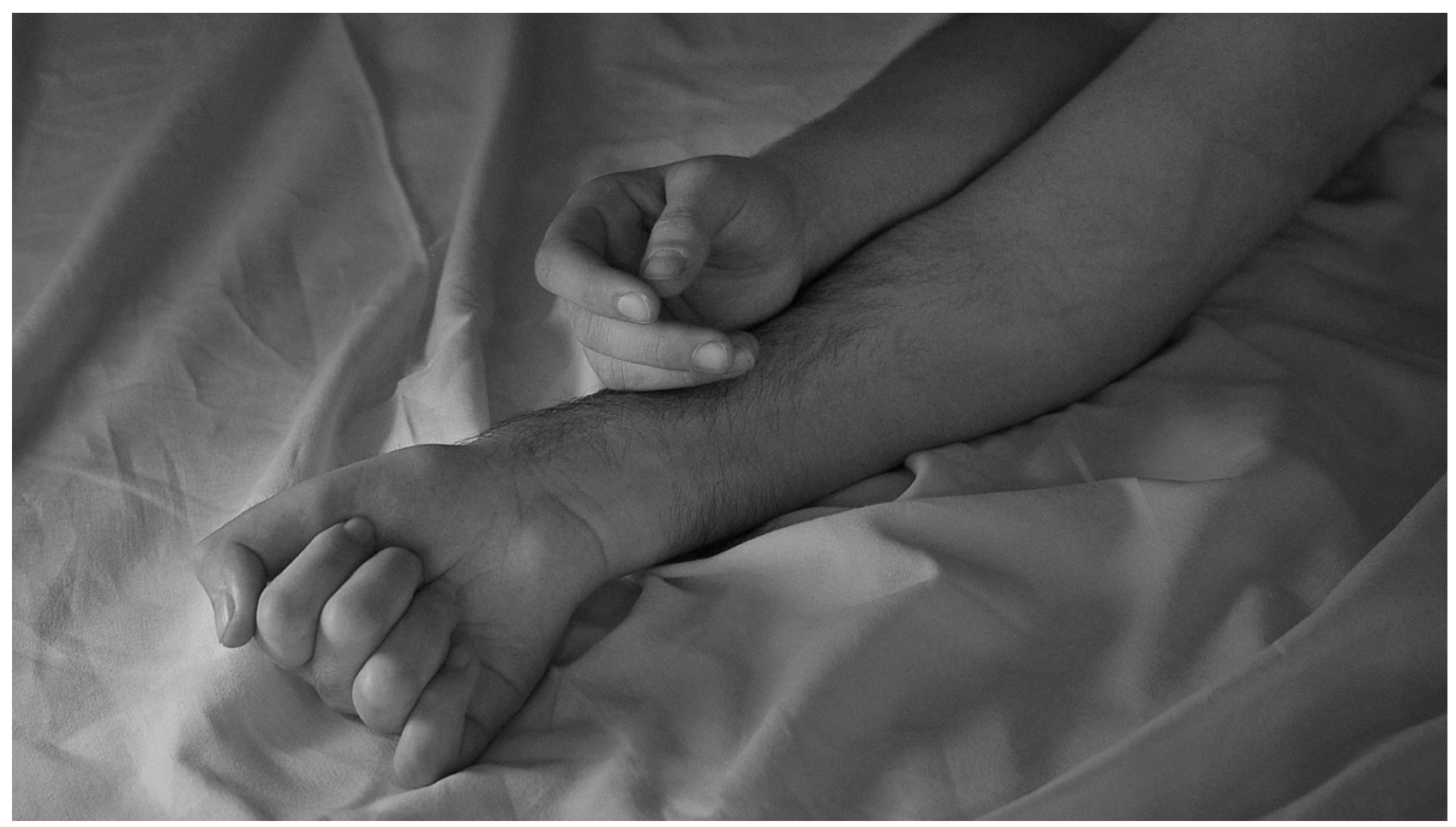

Andrea Rodríguez Alonso

Castellón, octubre, 2021

\section{Director:}

Dr. Enrique Oltra Rodríguez 


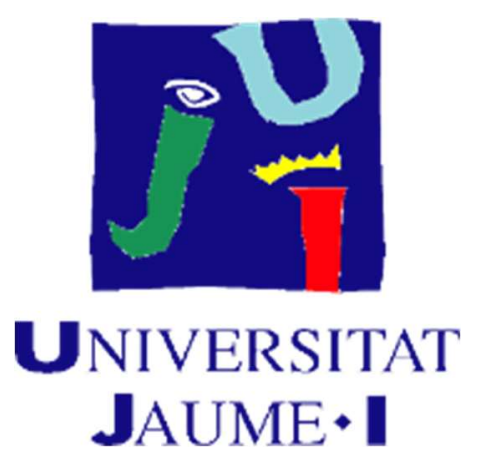

Programa de Doctorado en Ciencias de la Enfermería

Escuela de Doctorado de la Universidad Jaume I

Sexualidad en hombres y mujeres con lesión medular traumática

Memoria presentada por Andrea Rodríguez Alonso para optar al grado de doctora por la Universidad Jaume I

Doctoranda:

Andrea Rodríguez Alonso

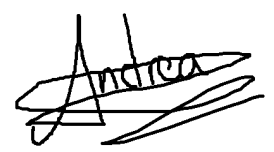

Castellón de la Plana, octubre de 2021.
Director:

Dr. Enrique Oltra Rodríguez

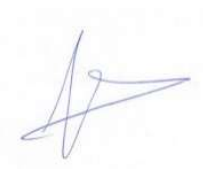


Licencia CC Reconocimiento - No comercial - Compartir igual (BY-NC-SA).

Financiación de la Cátedra de Enfermería Familiar y Comunitaria por la beca otorgada al "Mejor Proyecto de Tesis Doctoral en Enfermería Familiar y Comunitaria" 


\section{Resumen}

\section{Introducción}

La lesión medular es todo proceso patológico (conmoción, contusión, laceración, compresión o sección), de cualquier etiología (traumática y no traumática) que afecta a la médula espinal originando alteraciones motoras, sensitivas y/o autonómicas por debajo de la lesión. Cualquier persona, en cualquier momento del ciclo vital es población de riesgo de una lesión sobrevenida. En la actualidad, no hay tratamiento reparador de la lesión medular, por lo que el foco de la atención se encuentra en la calidad de vida.

Las personas con lesión medular consideran la recuperación de su sexualidad entre sus principales prioridades, teniendo que realizar procesos de adaptación a su nueva realidad, tanto en su identidad, como en su erótica y amatoria. Además, la atención a la salud sexual es un derecho y un deber profesional. Sin embargo, los profesionales ponen el foco en la rehabilitación física y psicológica, relegando la atención a la sexualidad al último lugar.

\section{Objetivos}

Conocer el estado de la salud sexual de los hombres y mujeres con lesión medular traumática.

\section{Método}

El estudio tiene tres partes diferenciadas. En la primera parte, la población a estudio estuvo conformada por las personas con lesión medular traumática ingresadas en el Hospital Universitario Central de Asturias por cualquier causa en el período del 1 de enero de 2005 al 31 de enero de 2015. Se realizó una revisión de las historias clínicas electrónicas, tanto de atención especializada como de atención primaria, con el fin de conocer las características epidemiológicas, así como identificar las complicaciones secundarias, los apoyos existentes en torno a la lesión medular y como objetivo principal, el registro en las historias clínicas sobre sexualidad.

En la segunda parte, la población a estudio estuvo conformada por las personas con lesión medular traumática pertenecientes a la muestra antes citada. Para alcanzar el 
mayor número de respuestas posibles, se ha recurrido a la Asociación de Parapléjicos y Grandes Minusválidos del Principado de Asturias para que apoyase y difundiese el proyecto. Esta segunda parte se llevó a cabo mediante cuestionarios autoinformados, tres cuestionarios validados complementados por ítems diseñados por el equipo investigador y revisados con la técnica Delphi por un comité de expertos. Se exploró y analizó un análisis sobre la calidad de vida percibida, la salud sexual, las fuentes de información utilizadas, las necesidades percibidas de atención de la sexualidad desde el entorno sanitario y la valoración del asistente sexual.

En la tercera parte, la población estuvo conformada por personas con lesión medular traumática seleccionadas mediante informantes clave con un muestreo intencionado. A través de entrevistas en profundidad se analizaron las vivencias de las personas con lesión medular traumática respecto a los cambios acontecidos en su sexualidad a raíz de la lesión. Se siguió el esquema analítico de la teoría fundamentada.

\section{Resultados}

En la parte I, el número de casos fue 92 . Un 76,9\% eran hombres. Las causas más frecuentes de lesión fueron: los accidentes de tráfico (30,3\%), accidentes laborales $(25,9 \%)$ y accidentes fortuitos $(20,2 \%)$. Las lesiones más frecuentes fueron: según la afectación de miembros, la paraplejia (38,5\%); según la extensión, la lesión completa (52,6\%); según el nivel neurológico, la lesión dorsal $(45,4 \%)$ y según el ASIA al alta, la lesión ASIA A (50,7\%). Las complicaciones secundarias más frecuentes recogidas en las historias clínicas electrónicas son: un 68,7\% presentó vejiga neurógena, un 62,7\% dolor, un $60,2 \%$ intestino neurógeno, un $46,4 \%$ espasticidad muscular y un $43,4 \%$ úlceras por presión. Un 87,3\% utiliza productos de apoyo en su vida cotidiana. En el 50,6\% de las historias clínicas estaba reflejada alguna anotación sobre sexualidad.

En la fase II, el número de casos fue 88. En la calidad de vida percibida los resultados más satisfactorios fueron: en la relación con los amigos, la vida familiar y la situación económica. Los aspectos con los que hay una mayor insatisfacción fueron: la vida sexual, la relación con la pareja y la situación laboral. Respecto a la sexualidad, un 62,8\% consideran la sexualidad como igual de importante o más que antes de la lesión. Un $75,4 \%$ ha disminuido la satisfacción con su vida sexual tras la lesión medular. La imagen 
corporal percibida empeora en un $36,4 \%$ de los casos y un $68,5 \%$ considera que ha disminuido su capacidad de seducción. El deseo se encuentra conservado o aumentado en un $54 \%$ de los lesionados. Un $85,3 \%$ de los hombres tienen disfunción eréctil y un $57,1 \%$ utiliza fármacos para la erección. Un 45,4\% de las mujeres tienen dificultades para excitarse. Un 85,1\% siente que no ha recibido suficiente información y apoyo por parte del sistema sanitario. La principal fuente de información es Internet, seguido de los profesionales sanitarios y los compañeros, amigos o pareja.

Un 53,4\% está a favor de la figura del asistente sexual con el fin de acceder al propio cuerpo y un $48,86 \%$ está a favor del mismo entendido como una persona con la que mantener relaciones eróticas.

En la parte III, las categorías que emergieron fueron: impacto inicial de la lesión medular, percepción respecto a la atención de los profesionales, vivencias de la corporalidad tras la lesión medular, proceso de sexuación tras la lesión medular, vivencias de la erótica, vivencias de la amatoria, percepciones sobre las limitaciones derivadas de la lesión medular, experiencias sobre el reaprendizaje erótico, percepciones sobre las potencialidades en la erótica, vivencias sobre la procreación, vivencias en el ámbito de la pareja, experiencias de asesoramiento y opinión sobre las figuras de apoyo en la sexualidad tras la lesión medular.

\section{Conclusiones}

El registro sobre sexualidad en las historias clínicas electrónicas es escaso, cuantitativa y cualitativamente.

Tras la lesión medular la sexualidad se modifica en varias dimensiones: la sexuación, la vivencia de la sexualidad, la erótica, la amatoria, la pareja y la vivencia de la procreación necesitan ser readaptadas.

Las limitaciones en la interacción erótica son derivadas de la lesión medular per se y de las complicaciones secundarias derivadas de la misma. Se identifican como recursos adaptativos los fármacos para la erección, los juguetes eróticos adaptados y la erotización de los productos de apoyo. 
Las potencialidades en la interacción erótica son derivadas de la adaptación a un modelo sexual conceptualmente más amplio.

Internet es la primera fuente de información sobre sexualidad tras una lesión medular traumática. 


\section{Abstract \\ Introduction}

Spinal cord injury is any pathological process (shock, contusion, laceration, compression or section) of any etiology (traumatic and non-traumatic) that affects the spinal cord, causing motor, sensory and / or autonomic alterations as a result of the injury. Anyone, throughout their lifecycle is at risk of spinal cord injury. Currently, there is no remedial treatment for spinal cord injury, so the focus is on quality of life.

People with spinal cord injury consider the recovery of their sexuality among their main priorities, having to carry out processes of adaptation to their new reality, both in their identity, as well as in their erotic and love affairs. In addition, sexual healthcare is a professional right and duty. However, professionals focus on physical and psychological rehabilitation, relegating attention to sexuality a secondary issue.

\section{Aim}

Know the state of sexual health of men and women with traumatic spinal cord injury.

\section{Method}

The study has three different parts. In the first part, the study population was made up of people with traumatic spinal cord injury admitted to the Central University Hospital of Asturias for any cause in the period from January 1, 2005 to January 31, 2015. A review of the electronic medical records of specialized care and primary care was carried out, in order to know the epidemiological characteristics, as well as to identify secondary complications, the existing support around spinal cord injury and as the main objective, the registration in medical records about sexuality.

In the second part, the study population was made up of people with traumatic spinal cord injury belonging to the aforementioned sample. In order to reach as many answers as possible, the "Asociación de personas con lesion medular y otras discapacidades físicas (Aspaym)" of the Principality of Asturias has been called upon to support and disseminate the project. This second part was carried out using self-reported questionnaires, three validated questionnaires complemented by items designed by the 
research team and reviewed with the Delphi technique by a committee of experts. An analysis of perceived quality of life, sexual health, sources of information used, perceived needs for sexuality care from the health environment and the assessment of the sexual assistant were explored and analyzed.

In the third part, the study population consisted of people with traumatic spinal cord injury selected by key informants with an intentional sampling. Through in-depth interviews, the experiences of people with traumatic spinal cord injury were analyzed regarding the changes that occurred in their sexuality as a result of the injury. The analytical scheme of grounded theory was followed.

\section{Results}

In part I, the number of cases was $92.76,9 \%$ of the cases were men. The most frequent causes of injury were: traffic accidents (30.3\%), occupational accidents (25.9\%) and fortuitous accidents (20.2\%). The most frequent injuries were: according to limb involvement, paraplegia (38.5\%); according to the extension, the complete lesion (52.6\%); according to the neurological level, the dorsal lesion (45.4\%) and according to the ASIA at discharge, the ASIA A lesion (50.7\%). The most frequent secondary complications recorded in the electronic medical records are: $68.7 \%$ presented neurogenic bladder, $62.7 \%$ pain, $60.2 \%$ neurogenic bowel, $46.4 \%$ muscle spasticity and 43.4\% Pressure ulcers. $87.3 \%$ use support products in their daily lives. In $50.6 \%$ of the medical records some remarks on sexuality were reflected.

In phase II, the number of cases was 88 . In the perceived quality of life, the most satisfactory results were: in the relationship with friends, family life and economic situation. The aspects with a greater dissatisfaction were: sexual life, the relationship with the partner and the work situation. Regarding sexuality, $62.8 \%$ consider sexuality as equally or more important than before the injury. $75.4 \%$ have decreased satisfaction with their sexual life after spinal cord injury. Perceived body image worsens in $36.4 \%$ of cases and $68.5 \%$ consider that their capacity for seduction has decreased. The desire is preserved or increased in $54 \%$ of the injured. $85.3 \%$ of men have erectile dysfunction and $57.1 \%$ use medical treatment for erection. $45.4 \%$ of women have difficulty getting aroused. $85.1 \%$ feel that they have not received enough information and support from 
the health system. The main source of information is the Internet, followed by health professionals and colleagues, friends or partner. $53.4 \%$ are in favor of the figure of the sexual assistant in order to access their own body. $48,96 \%$ are in favor of the figure understood as a person with whom to maintain erotic relationships.

In part III, the categories that emerged were: initial impact of spinal cord injury, perception regarding the care of professionals, corporality experiences after spinal cord injury, sexing process after spinal cord injury, erotic experiences, experiences of lovemaking, perceptions of the limitations derived from spinal cord injury, experiences of erotic relearning, perceptions of potentialities in eroticism, experiences of procreation, experiences in the sphere of the couple, experiences of counseling and opinions on the figures of support in sexuality after spinal cord injury.

\section{Conclusions}

The record on sexuality in electronic medical records is scarce, quantitatively and qualitatively.

After the spinal cord injury, sexuality is modified in several dimensions: sexuality, the experience of sexuality, eroticism, lovemaking, the couple and the experience of procreation need to be readapted.

The limitations in the erotic interaction are derived from the spinal cord injury as such and the secondary complications derived from it. Erection drugs, adapted erotic toys, and eroticization of assistive products are identified as adaptive resources.

The potentialities in erotic interaction are derived from adaptation to a conceptually broader sexual model.

The Internet is the first source of information on sexuality after a traumatic spinal cord injury. 


\section{Agradecimientos}

A todas las personas que han hecho posible este trabajo:

Al Dr. Enrique Oltra, por ser el mejor director de tesis que he podido tener, por enseñarme el camino y por acompañarme en su tránsito, por su ejemplo, por su sabiduría, por su perfeccionismo y su minuciosidad, por enseñarme que las cosas hay que hacerlas bien, aunque a veces no sea sencillo. También por su amistad, por su cariño y por su siempre estar ahí.

A Rosi, por su ánimo, por estar siempre disponible, por su cariño y confianza.

A Sofía, gracias por ir delante, por estar pendiente y por su generosidad.

A Tania, gracias por su trabajo, por su amabilidad y su disponibilidad.

A todas las personas que han colaborado: a Aspaym, Ana y Lara, a todas las personas con lesión medular que han participado, que han abierto su casa y su alma para ayudar. Gracias por lo que habéis aportado no solo para la tesis, sino para mi vida. Os admiro profundamente.

A Dios por la vida y por su amor.

A mis padres, especialmente a mi madre, por enseñarme a ser persistente, a no desfallecer, a siempre luchar y a hacerlo con una sonrisa.

A Jose, por haber estado siempre a mi lado en este camino, por haberme cuidado cada día, por sus ánimos, por su amor y por haber comprendido todas las renuncias, sobre todo de tiempo.

A Jman, por enseñarme que tenía que hacerlo, que era capaz y que era mi camino.

A mi familia y amigos, gracias por quererme, por aguantarme en estos años, por excusar mis ausencias y entenderlas, por escuchar las quejas, las dudas, los agobios y las ilusiones. Laura, Edurne, Lou, Elías, Patri, Sylvie, en especial para vosotros. 


\section{A Jose y a Olivia}


Sin ninguna intención sexista o excluyente, y en las ocasiones en las que no se han encontrado soluciones lingüísticas que no impliquen expresiones forzadas o artificiosas se han utilizado los siguientes términos:

Lesionado medular o persona con lesión medular para referirse tanto a hombres como a mujeres.

Enfermera o médico para hacer referencia a los profesionales sanitarios ya sean hombres o mujeres.

Así mismo, se han respetado literalmente las expresiones utilizadas por los informantes entrevistados sin entrar en juicios $u$ otras consideraciones. 


\section{Índice}

Resumen

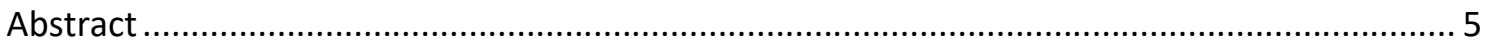

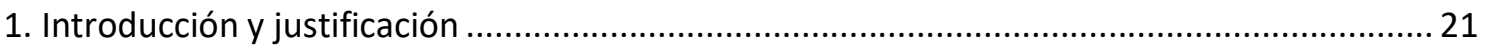

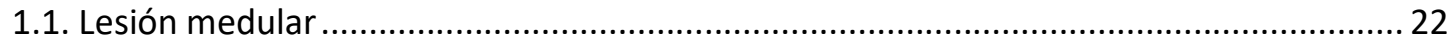

1.1.1. Definición, anatomía y fisiología de la médula espinal ............................................. 22

1.1.2. Definición y tipos de lesión medular............................................................................ 24

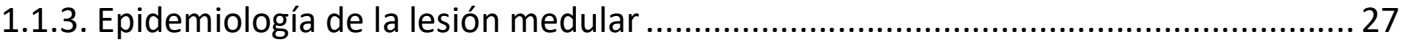

1.2. Marco filosófico-conceptual sobre la discapacidad ..................................................... 31

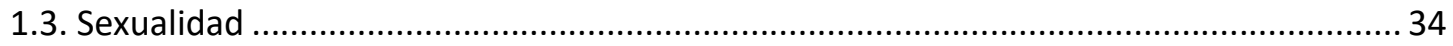

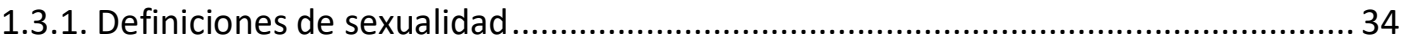

1.3.2. Modelo del Hecho Sexual Humano ........................................................................ 35

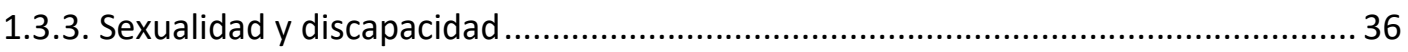

1.3.4. Respuesta sexual humana e implicaciones de la lesión medular .............................. 38

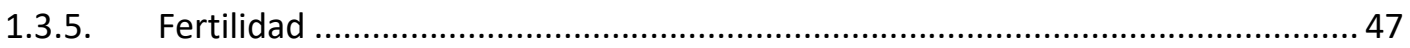

1.3.6. Derechos y leyes referentes a la sexualidad y la discapacidad ...........................5 50

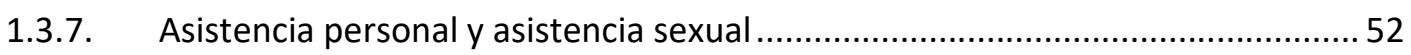

1.3.8. Atención de la sexualidad en la lesión medular por parte de los profesionales. 54

1.3.9. Antecedentes en la investigación sobre la sexualidad en la lesión medular .......55

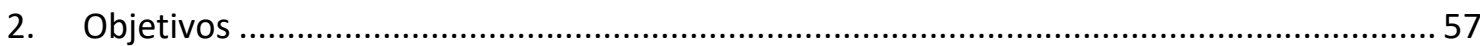

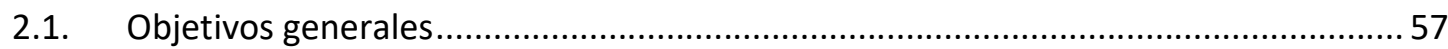

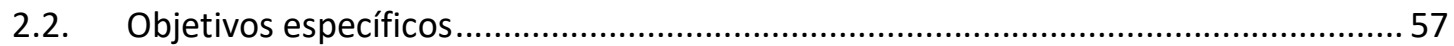

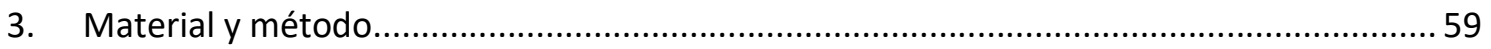

3.1. Aspectos comunes a todas las fases de la investigación............................................. 59

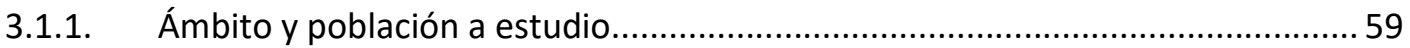

3.1.2. Fases para el desarrollo del estudio ................................................................ 59

3.2. Fase I: Epidemiología de la lesión medular, complicaciones secundarias y apoyos en

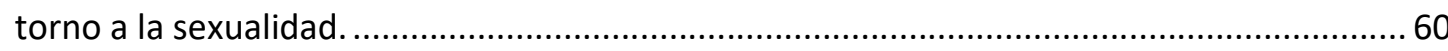

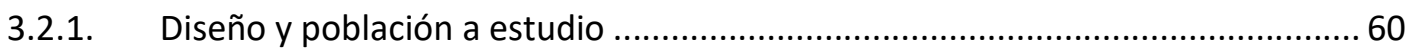

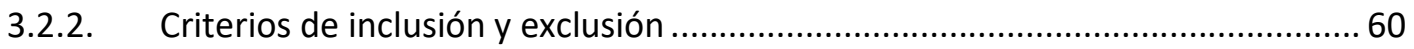

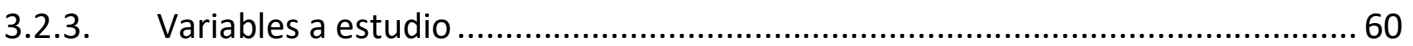

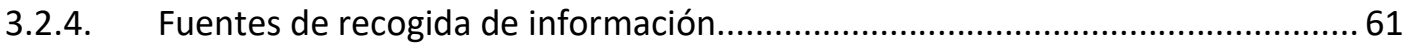

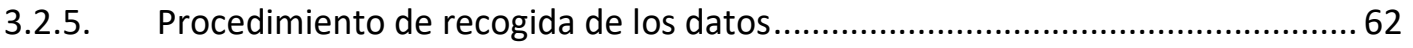

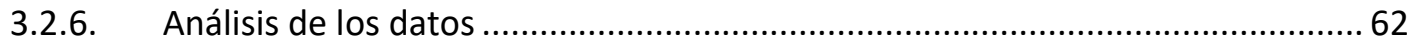

3.3. Fase II: Calidad de vida, salud sexual, fuentes de información utilizadas y necesidades percibidas de atención de la sexualidad desde el entorno sanitario .....................................62 


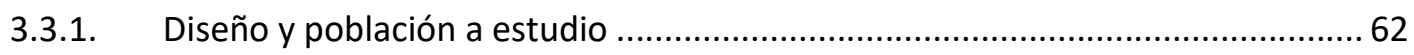

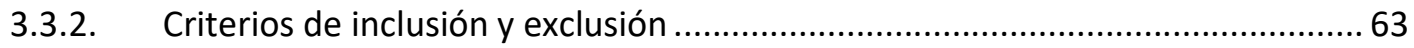

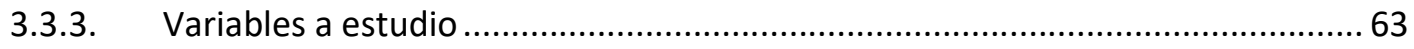

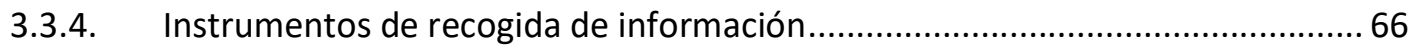

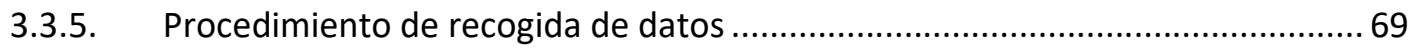

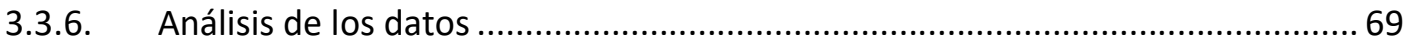

3.4. Fase III: Vivencias percibidas en personas con lesión medular traumática respecto a los cambios acontecidos en la sexualidad a raíz de la lesión medular ................................... 70

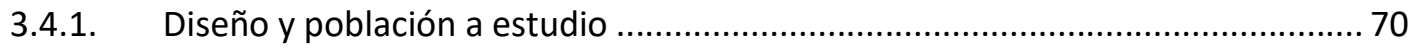

3.4.2. Instrumento de recogida de información ............................................................ 70

3.4.3. Procedimiento de recogida de los datos.......................................................... 71

El muestreo ha sido intencional o muestreo por conveniencia. El acceso a los participantes se realizó a través de la asociación Aspaym.................................................................. 71

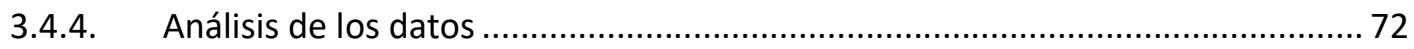

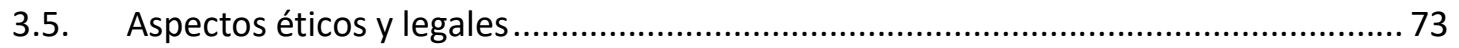

3.5.1. Confidencialidad de los datos y permisos de los responsables .......................... 73

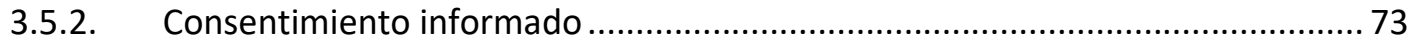

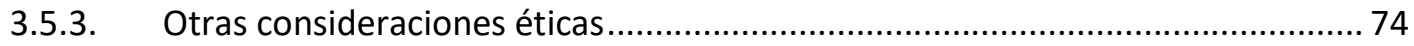

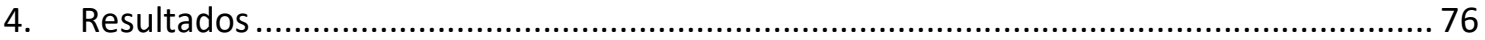

4.1. Fase I: Resultados sobre epidemiología de la lesión medular, complicaciones secundarias y apoyos en torno a la sexualidad....................................................................... 76

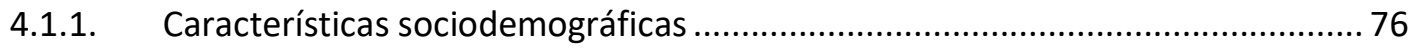

4.1.2. Resultados relacionados con la lesión medular ................................................... 77

4.1.3. Variables relacionadas con la hospitalización ........................................................ 83

4.1.4. Complicaciones secundarias derivadas de la lesión medular .............................. 84

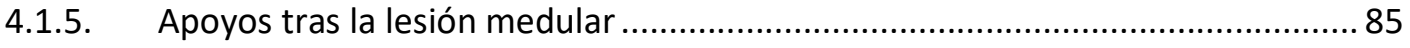

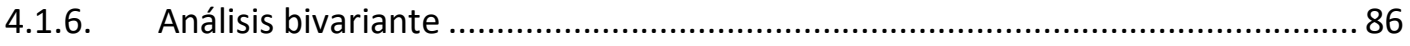

4.1.7. Abordaje de la sexualidad por parte de los profesionales sanitarios .................. 91

4.1.8. Aspectos registrados sobre sexualidad en las HCE ........................................... 94

4.2. Fase II: Calidad de vida, salud sexual, fuentes de información utilizadas y necesidades percibidas de atención de la sexualidad desde el entorno sanitario ........................................ 95

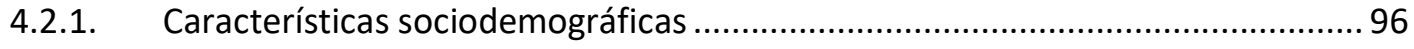

4.2.2. Resultados relacionados con la lesión.............................................................. 97

4.2.3. Resultados referentes a la calidad de vida...................................................... 100

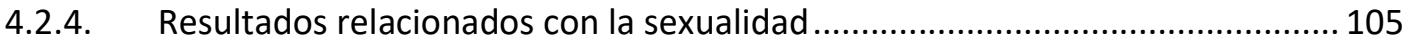

4.2.5. Percepción sobre si el sistema de salud le ha dado suficiente información y apoyo respecto a cómo enfrentar la sexualidad 
4.2.6. Fuentes de información o consejo utilizadas sobre sexualidad tras la lesión medular

4.2.7. Temas relacionados con la sexualidad tratados por los profesionales de la salud

4.2.8. Temas sobre los que se hubiera precisado información

4.2.9. Resultados relacionados con la valoración de la figura del asistente sexual.... 131

4.3. Fase III: Vivencias percibidas en personas con lesión medular adquirida respecto a los cambios acontecidos en su sexualidad a raíz de la lesión medular ..................................... 132

4.3.1. Impacto inicial de la lesión medular.................................................................. 134

4.3.2. Percepción respecto a la atención de los profesionales ................................... 137

4.3.3. Vivencias durante el ingreso y en el momento del alta hospitalaria ................. 140

4.3.4. Vivencias de la corporalidad tras la lesión medular......................................... 143

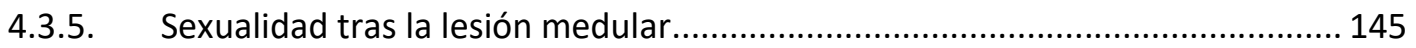

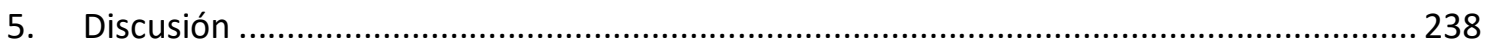

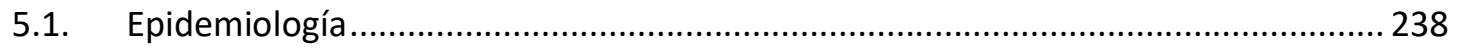

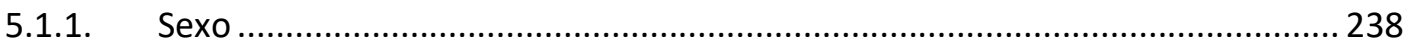

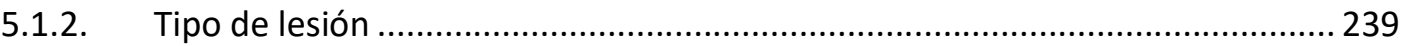

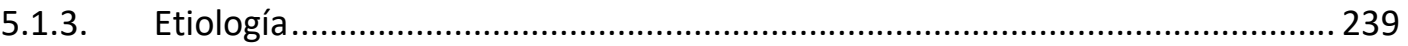

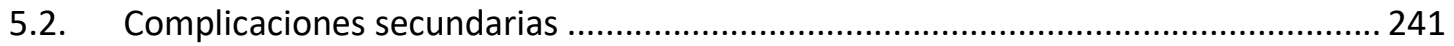

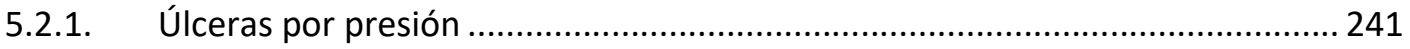

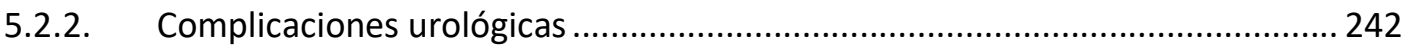

5.2.3. Complicaciones gastrointestinales ............................................................... 243

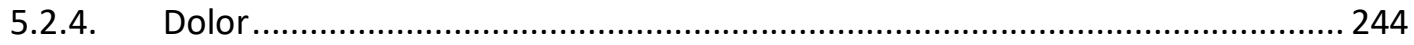

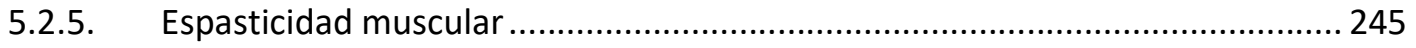

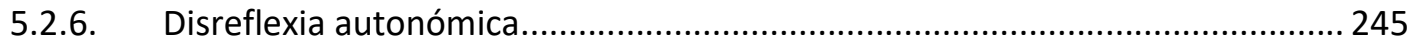

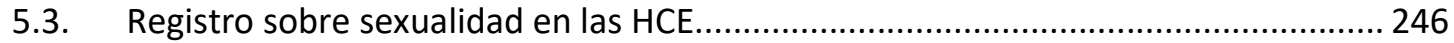

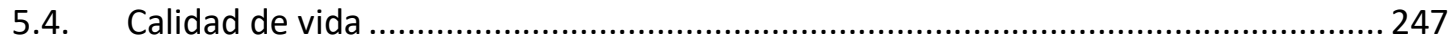

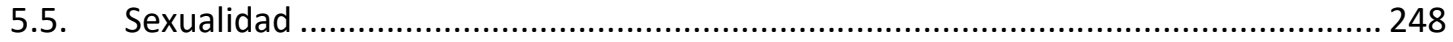

5.5.1. Instrumentos de medida de la sexualidad ................................................... 249

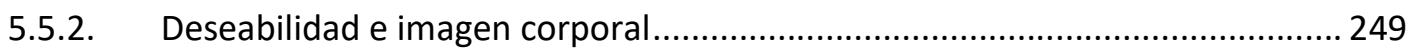

5.5.3. Cambios en la respuesta sexual humana ........................................................... 251

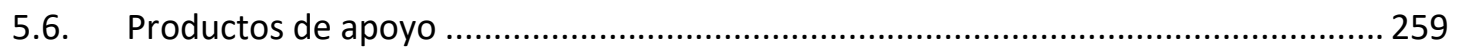

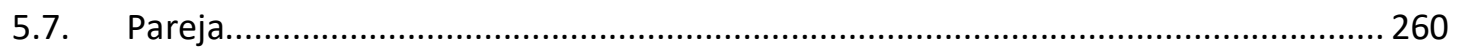

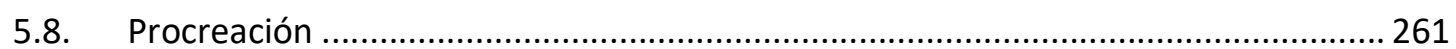

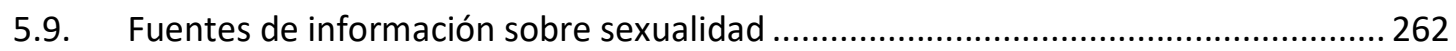

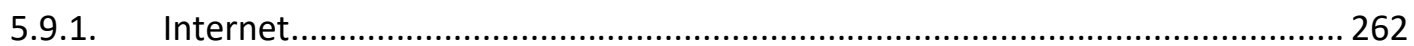

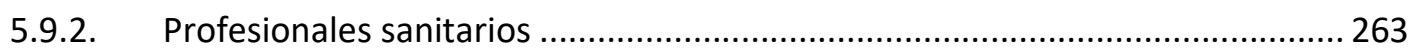




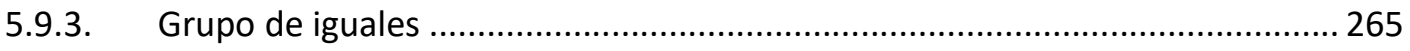

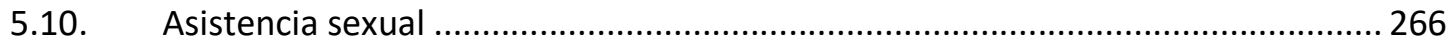

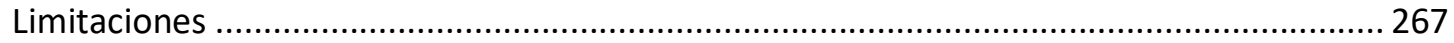

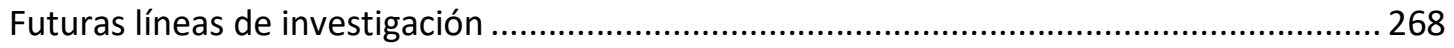

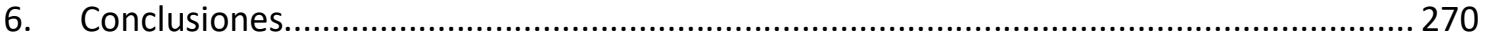

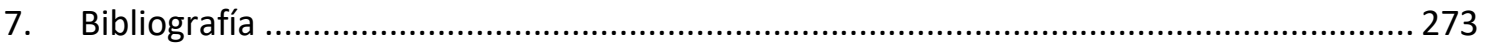

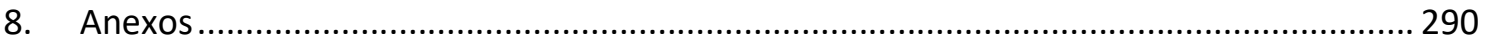

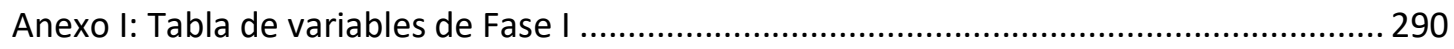

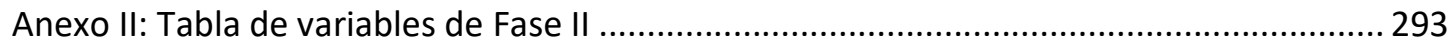

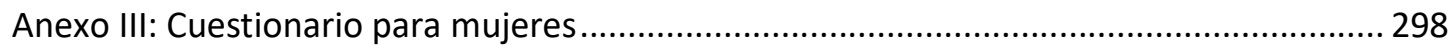

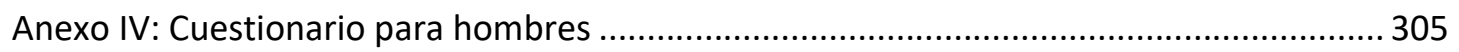

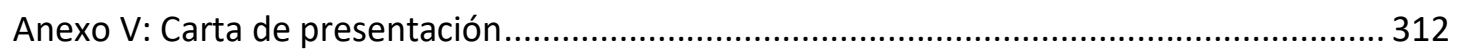

Anexo VI: Autorización del Comité de Ética de la Investigación del Principado de Asturias 313

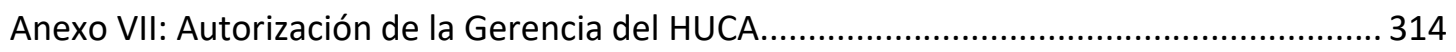

Anexo VIII: Acta Beca al Mejor Proyecto de Tesis Doctoral en Enfermería Familiar y 


\section{Índice de tablas}

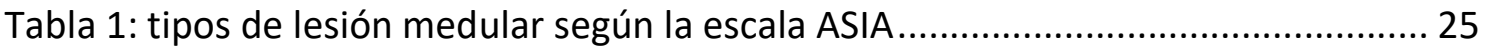

Tabla 2: síndromes clínicos definidos en lesiones parciales ....................................... 27

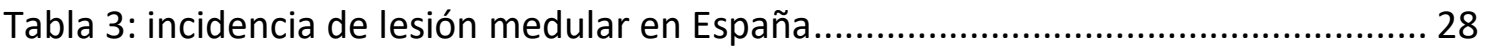

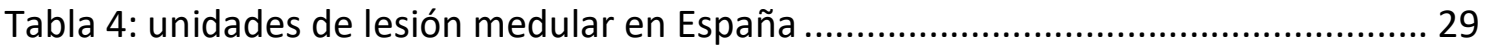

Tabla 5: cambios físicos producidos durante la fase de excitación .............................. 40

Tabla 6: cambios físicos producidos durante la fase de meseta .................................. 43

Tabla 7: cambios físicos producidos durante la fase de orgasmo............................... 44

Tabla 8: cambios físicos producidos en la fase de resolución ........................................ 47

Tabla 9: distribución sobre la ocupación previa a la lesión medular .............................. 77

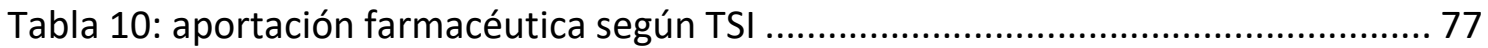

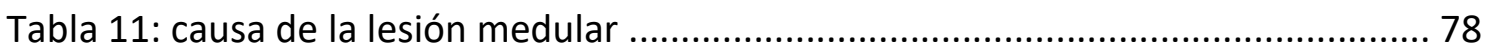

Tabla 12: datos sobre la edad al lesionarse (en años) y el tiempo de lesión (en meses)

Tabla 13: distribución del tipo de lesión medular según el nivel neurológico................. 80

Tabla 14: distribución de frecuencias según el nivel óseo de la lesión medular ............ 81

Tabla 15: distribución de la lesión medular según síndromes clínicos específicos......... 82

Tabla 16: tiempo de estancia en días en $\mathrm{UCI}$, unidad de hospitalización y tiempo total

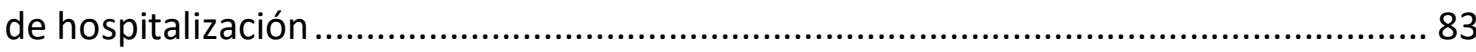

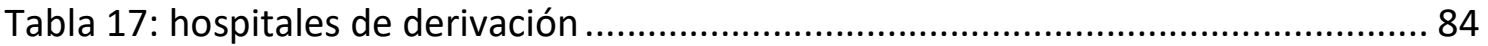

Tabla 18: relación entre el tiempo en días de hospitalización en $\mathrm{UCl}$, en unidad de hospitalización y tiempo de hospitalización total y tipos de lesión medular

Tabla 19: complicaciones secundarias y tipo de lesión medular según afectación de miembros.

Tabla 20: complicaciones secundarias y tipo de lesión medular según extensión. 89

Tabla 21: complicaciones secundarias y tipo de lesión medular según nivel neurológico

Tabla 22: relación entre aportación farmacéutica y uso de productos de apoyo ..........90

Tabla 23: relación entre aportación farmacéutica y utilización de ayudas para la movilidad personal 
Tabla 24: relaciones entre el tipo de lesión medular y las alteraciones de la marcha y la

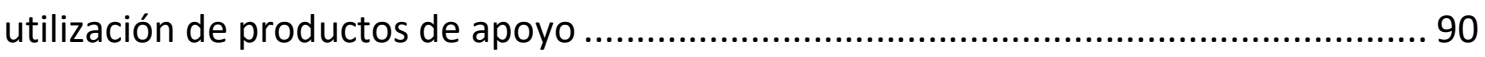

Tabla 25: relación de TSI y registro sobre sexualidad en HCE.................................... 91

Tabla 26: relación entre el tipo de lesión medular según afectación de miembros y el registro sobre sexualidad en la HCE

Tabla 27: relación entre el tipo de lesión medular según nivel neurológico y registro sobre sexualidad en la HCE.

Tabla 28: relación entre el tipo de lesión medular según extensión y registro sobre sexualidad en la HCE.

Tabla 29: complicaciones secundarias y registro sobre sexualidad en las HCE .....

Tabla 30: presencia de complicaciones secundarias: úlceras por presión, espasticidad muscular y dolor crónico.....

Tabla 31: métodos de vaciamiento vesical.

Tabla 32: métodos de vaciamiento intestinal ......................................................... 100

Tabla 33: resultados de los ítems del LISAT-8 sobre calidad de vida .......................... 101

Tabla 34: resultados agrupados de los ítems del LISAT-8 sobre calidad de vida .......... 102

Tabla 35: resultados de las dimensiones (sexual, social y económica) y sumatorio total

del cuestionario LISAT-8 102

Tabla 36: relación entre el estado civil y LISAT-8

Tabla 37: relación entre el tipo de lesión medular según afectación de miembros y

LISAT-8 103

Tabla 38: relación entre la presencia de dolor crónico y LISAT-8 104

Tabla 39: relación entre la preocupación por el escape de orina durante las relaciones eróticas y el LISAT-8 104

Tabla 40: significación estadística del LISAT-8 con el estado civil, el tipo de lesión medular, la presencia de dolor crónico y la preocupación por el escape de orina ..... 105 Tabla 41: distribución de uso de libros, películas, música o arte con contenido erótico 106

Tabla 42: grado de importancia sobre la vida erótica en relaciones de pareja 108 Tabla 43: relaciones entre el grado de placer durante la relación sexual y el orgasmo, y la presencia de sensibilidad en el área genital y anal y la preocupación por el escape de orina y heces durante la relación sexual 110 
Tabla 44: percepción sobre el grado de satisfacción a la pareja.

Tabla 45: uso de apoyos para tener hijos

Tabla 46: deseo sexual ahora comparado con la situación previa a la lesión medular117 Tabla 47: importancia dada a la sexualidad en comparación con la situación previa a la lesión medular

Tabla 48: relación entre el sumatorio SIS y el estado civil

Tabla 49: relación entre el sumatorio SIS y la preocupación por el escape de orina y heces durante las relaciones eróticas

Tabla 50: grado de confianza de tener y mantener una erección 120

Tabla 51: frecuencia de erecciones con suficiente dureza para la penetración 120

Tabla 52: frecuencia de mantenimiento de la erección tras la penetración 120 Tabla 53:grado de dificultad en el mantenimiento de la erección hasta el final del acto sexual

Tabla 54: frecuencia de relaciones sexuales satisfactorias

Tabla 55: relación entre grado de disfunción eréctil y tipo de lesión medular según afectación de miembros

Tabla 56: relación entre grado de disfunción eréctil y tipo de lesión medular según nivel neurológico

Tabla 57: relación entre grado de disfunción eréctil y presencia de úlceras por presión

Tabla 58: relación entre grado de disfunción eréctil y presencia de sensibilidad genital

Tabla 59: relación entre grado de disfunción eréctil y presencia de sensibilidad anal 123 Tabla 60: relación entre grado de disfunción eréctil y tipo de vaciamiento intestinal 123 Tabla 61: distribución de la frecuencia de la capacidad de eyacular. 124 Tabla 62: distribución sobre la frecuencia de consecución de excitación y pérdida de interés

Tabla 63: distribución sobre la frecuencia de lubricación vaginal satisfactoria durante la actividad sexual

Tabla 64: relación entre las fuentes de información sobre sexualidad tras la LM y sexo

Tabla 65: resumen sobre fuentes de información utilizadas y variables relacionadas 130 


\section{Índice de gráficos}

Gráfico 1: distribución del tipo de lesión medular según afectación de miembros ....... 79

Gráfico 2: distribución del tipo de lesión medular según ASIA al alta .......................... 82

Gráfico 3: distribución de la derivación de otros hospitales al HUCA............................ 83

Gráfico 4: distribución de la causa de la lesión medular............................................. 97

Gráfico 5: tipo de lesión medular según afectación de miembros ............................... 98

Gráfico 6: tipo de lesión medular según extensión de la lesión ................................... 98

Gráfico 7: nivel de la lesión medular según nivel neurológico..................................... 99

Gráfico 8: distribución sobre el grado de placer o disfrute de pensar y fantasear acerca

del sexo

Gráfico 9: distribución sobre el grado de placer o disfrute obtenido con la relación

sexual en general y con el orgasmo

Gráfico 10: percepción de la imagen corporal previa a la lesión medular y actual ..... 112

Gráfico 11: cambio sobre la percepción de capacidad de seducción tras la lesión

medular

Gráfico 12: cambios en la satisfacción con la vida sexual tras la lesión medular

Gráfico 13: satisfacción con el deseo de procreación.

Gráfico 14: satisfacción con las relaciones eróticas de pareja antes de la LM y en la actualidad

Gráfico 15: posibilidades y habilidades para satisfacer su propia sexualidad y la de su

pareja

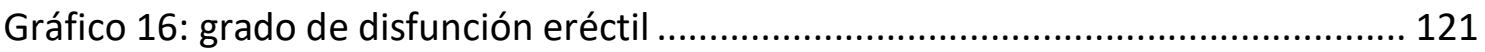

Gráfico 17: frecuencia de excitarse con facilidad con las cosas que le gustan 126

Gráfico 18: fuentes de información utilizadas sobre sexualidad tras la lesión medular 


\section{Índice de figuras}

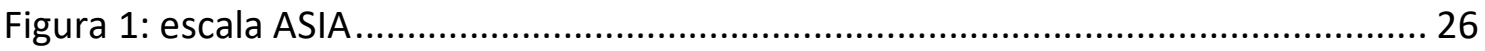

Figura 2: vivencias tras el diagnóstico de lesión medular ......................................... 137

Figura 3: percepción respecto a la atención de los profesionales ................................ 140

Figura 4: vivencias durante el ingreso y en el momento del alta hospitalaria............. 143

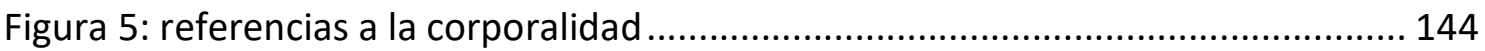

Figura 6: proceso de sexuación tras la lesión medular ............................................... 149

Figura 7: vivencias de la erótica tras la lesión medular............................................ 157

Figura 8: vivencias en el proceso de ligar tras la lesión medular ................................. 164

Figura 9: vivencias en las primeras relaciones eróticas post-lesionales ...................... 170

Figura 10: vivencias de los cambios en el ciclo de respuesta sexual humana ............. 180

Figura 11: percepciones sobre las limitaciones derivadas de la lesión medular ......... 192

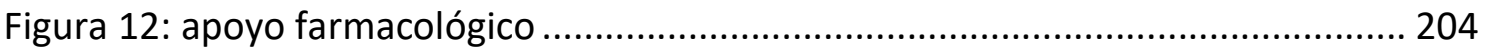

Figura 13: percepciones sobre las potencialidades derivadas de la lesión medular ... 210

Figura 14: vivencias sobre la procreación tras la lesión medular ................................ 216

Figura 15: vivencias de la pareja tras la lesión medular.............................................. 224

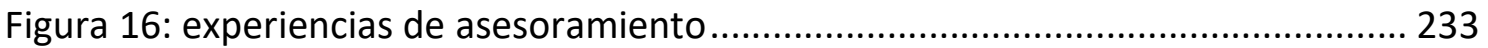

Figura 17: opinión sobre las figuras de apoyo en la sexualidad tras la lesión medular236 


\section{Siglas y acrónimos}

Aspaym: Asociación de Parapléjicos y Grandes Minusválidos Físicos

CIF: Clasificación Internacional del Funcionamiento, de la Discapacidad y de la Salud Cocemfe: Confederación Española de Personas con Discapacidad Física y Orgánica

DE: desviación estándar

HCE: Historia clínica electrónica

HUCA: Hospital Universitario Central de Asturias

IEEF-5: Sexual Health Inventory for Men

IMSERSO: Instituto de Mayores y Servicios Sociales

LISAT-8: Cuestionario de Valoración de la Satisfacción con la Vida

LM: Lesión medular

LMT: Lesión medular traumática

OMI-AP: Oficina Médica Informatizada de Atención Primaria

OMS: Organización Mundial de la Salud

PED-5: Inhibidores de la fosfodiesterasa tipo 5

Predif: Plataforma Representativa Estatal de Personas con Discapacidad Física

RAE: Real Academia Española

SIS: Sexual Interest and Satisfaction Scale

TSI: Tarjeta sanitaria individual

UCl: Unidad de Cuidados Intensivos

UPP: Úlceras por presión

WOMI: Viewer OMI 
Introducción y justificación 


\section{Introducción y justificación}

\subsection{Lesión medular}

\subsubsection{Definición, anatomía y fisiología de la médula espinal}

La médula espinal es una estructura cilíndrica, ligeramente aplanada en sentido anteroposterior, de calibre no uniforme, blanda y blanca que se inicia en la unión bulbomedular y finaliza en la carilla superior de L2; la parte final con forma cónica se conoce como "cono medular". El filum terminal es la extensión del cono medular hacia el cóccix y la cola de caballo es la extensión de las raíces nerviosas espinales a nivel caudal, desde el cono en el interior del espacio subaracnoideo lumbar $(1,2)$.

La médula espinal se encuentra en el conducto raquídeo, protegida por una estructura ósea, la columna vertebral y por unas envolturas membranosas, las meninges. La capa más interna, la piamadre, se adhiere a la superficie de la médula. La aracnoides permanece muy adherida a la capa externa, la duramadre. Entre la aracnoides y la piamadre, aparece un espacio lleno de líquido cefalorraquídeo, el espacio subaracnoideo. Entre la duramadre y la aracnoides se crea un espacio virtual denominado espacio subdural(2).

La médula espinal es un componente del sistema nervioso central indispensable para la transmisión sensitiva hacia las estructuras cerebrales y para la consecuente regulación de la función motora y autónoma, recibe información de los receptores somáticos y viscerales a través de las raíces dorsales, y la transmite a través de los haces ascendentes a los centros cerebrales superiores; por otro lado, envía a través de los haces descendentes la información de los centros cerebrales superiores hacia los órganos somáticos y viscerales $(1,3)$.

El mielómero es el segmento medular del que es tributario el correspondiente par de nervios raquídeos. La médula está constituida por 31 mielómeros: 8 cervicales, 12 dorsales, 5 lumbares, 5 sacros y 1 coccígeo(1,2).

Si se realiza un corte transversal de la médula espinal se visualiza la sustancia gris en la zona central, al contrario que la del encéfalo que se encuentra en la periferia, con forma de alas de mariposa: dos astas anteriores y dos astas posteriores. La sustancia blanca se 
encuentra alrededor de la sustancia gris, conteniendo paquetes ascendentes y descendentes de axones mielínicos y amielínicos: son los tractos o fascículos. Los paquetes formados por uno o más tractos se conocen como "funículos o cordones" $(1,2)$.

En cada mitad de la médula espinal existen tres cordones(1):

- Cordón dorsal: localizado entre el asta posterior y la línea media (septo medio posterior)

- Cordón lateral: dispuesto entre el asta posterior y el asta anterior

- Cordón ventral: situado entre el asta anterior y la línea media anterior (fisura media anterior)

La sustancia gris de una mitad medular se conecta con la contralateral a través de la comisura gris. La comisura blanca se encuentra ventralmente a la comisura gris. En la zona central de la sustancia gris está el canal medular o epéndimo(1).

La sensibilidad que penetra en la médula adopta caminos ascendentes para llevar la información a centros superiores(1):

- Haz espinotalámico lateral: recoge la sensibilidad termoalgésica

- Haz espinotalámico anterior: recoge la sensibilidad superficial grosera

- Haz espinocerebeloso: recoge la sensibilidad propioceptiva inconsciente, el tono muscular.

- Haces de los cordones posteriores: recogen la sensibilidad profunda: táctil discriminativa y propioceptiva consciente.

Las vías descendentes, son vías motoras, en ellas encontramos(1):

- Haces piramidales o corticoespinales: el haz corticoespinal lateral o cruzado (debido a su mayoría de axones heterolaterales) y el haz corticoespinal medial o anterior.

- Haces estáticoposturales

La función del sistema autónomo es el mantenimiento de la homeostasis a través de la regulación de funciones involuntarias: presión sanguínea, frecuencia cardíaca, respiración, digestión, secreción glandular, reproducción y temperatura corporal. Las neuronas preganglionares del sistema simpático se localizan en la columna 
intermediolateral entre T1 y L2, mientras que las neuronas preganglionares parasimpáticas se encuentran en el tronco del encéfalo y la región sacra medular, entre S2 y $S 4(1)$.

La irrigación medular se produce a partir de tres ejes arteriales que la recorren de craneal a caudal: la arteria espinal anterior, situada en el surco medular anterior, irriga los dos tercios anteriores de la médula, y las dos arterias espinales posteriores, situadas en la entrada de las raíces posteriores, irrigan el tercio dorsal. La arteria espinal anterior y las dos posteriores nacen de las arterias vertebrales y las van alimentando arterias que entran con las raíces (radiculomedulares) a diversos niveles en número variable(4).

El drenaje venoso de la médula espinal se produce a través de una serie de canales que se extienden longitudinalmente y que se conectan con las venas espinales anterior y posterior en la superficie de la médula(5).

\subsubsection{Definición y tipos de lesión medular}

La LM puede definirse como todo proceso patológico (conmoción, contusión, laceración, compresión o sección), de cualquier etiología (traumática y no traumática), que afecta la médula espinal, y puede originar alteraciones de las funciones neurológicas por debajo de la lesión: motoras, sensitivas y autonómicas (2). La complejidad del déficit neurológico, y por tanto del cuadro clínico resultante, depende del nivel y la completitud de la lesión, la extensión transversal o longitudinal del tejido lesionado, y la afectación de sustancia blanca o gris(6).

Las lesiones medulares se denominan de acuerdo con el último nivel intacto, es decir, aquella metámera que preserva todas las funciones neurológicas: motoras, sensitivas y autonómicas. En este sentido, pueden clasificarse de acuerdo con la funcionalidad clínica del paciente como cervicales ( $\mathrm{C} 1$ a C8), torácicas altas (T1 a T6), torácicas bajas (T7 a T12), lumbosacras (L1 a S1) y del cono medular (sacro coccígeas). Cuanto más alta sea la lesión mayor será el compromiso funcional del paciente(6). Si el compromiso es superior a C4, la persona será dependiente de ventilación mecánica(7).

De acuerdo con la extensión de la lesión, estas pueden considerarse como transversales y longitudinales; en la mayoría de los pacientes existe una combinación de ambas. La 
primera hace referencia a la extensión transversal de la metámera, produciendo secciones completas o incompletas donde el compromiso de las distintas vías descendentes y ascendentes determina el cuadro clínico del paciente. La extensión longitudinal se refiere a la lesión en los planos verticales y se determina por el número de metámeras lesionadas por el proceso patológico; el cuadro clínico del paciente se manifiesta principalmente por el compromiso de sustancia blanca o gris(6).

El nivel neurológico de la lesión se define como el segmento más distal de la médula espinal con función sensitiva y sensitiva normal en ambos lados del cuerpo(7).

La escala más utilizada a nivel internacional para evaluar la gravedad de la lesión medular es la ASIA Impairment Scale (AIS) que sigue los estándares para clasificación neurológica de la American Spinal Injury Association (ASIA). Esta escala clasifica la LM de acuerdo con cinco grados determinados por la ausencia o preservación de la función motora y sensitiva(6,8,9). Ver tabla 1 y figura 1.

Tabla 1: tipos de lesión medular según la escala ASIA

\begin{tabular}{ccc}
\hline ASIA & $\begin{array}{c}\text { Tipo de } \\
\text { lesión }\end{array}$ & Alteraciones motoras y sensitivas \\
\hline A & Completa & Sin función sensitiva o motora en los niveles sacros S4-S5 \\
\hline B & Incompleta & $\begin{array}{r}\text { Función sensitiva pero no motora por debajo del nivel } \\
\text { neurológico incluyendo S4-S5 }\end{array}$ \\
\hline C & Incompleta & $\begin{array}{r}\text { Función motora conservada por debajo del nivel } \\
\text { neurológico e incluyendo niveles sacros S4-S5 o por lo } \\
\text { menos la mitad de los músculos clave tienen fuerza menor }\end{array}$ \\
\hline D & Incompleta & $\begin{array}{r}\text { Función motora conservada debajo del nivel neurológico y } \\
\text { por lo menos la mitad de los músculos clave tienen fuerza } \\
\text { igual o mayor a 3. }\end{array}$ \\
\hline E & Normal & Funciones motoras y sensitivas normales \\
\hline
\end{tabular}


Figura 1: escala ASIA

ASIA STANDARD NEUROLOGICAL CLASSIFICATION OF SPINAL CORD INJURY

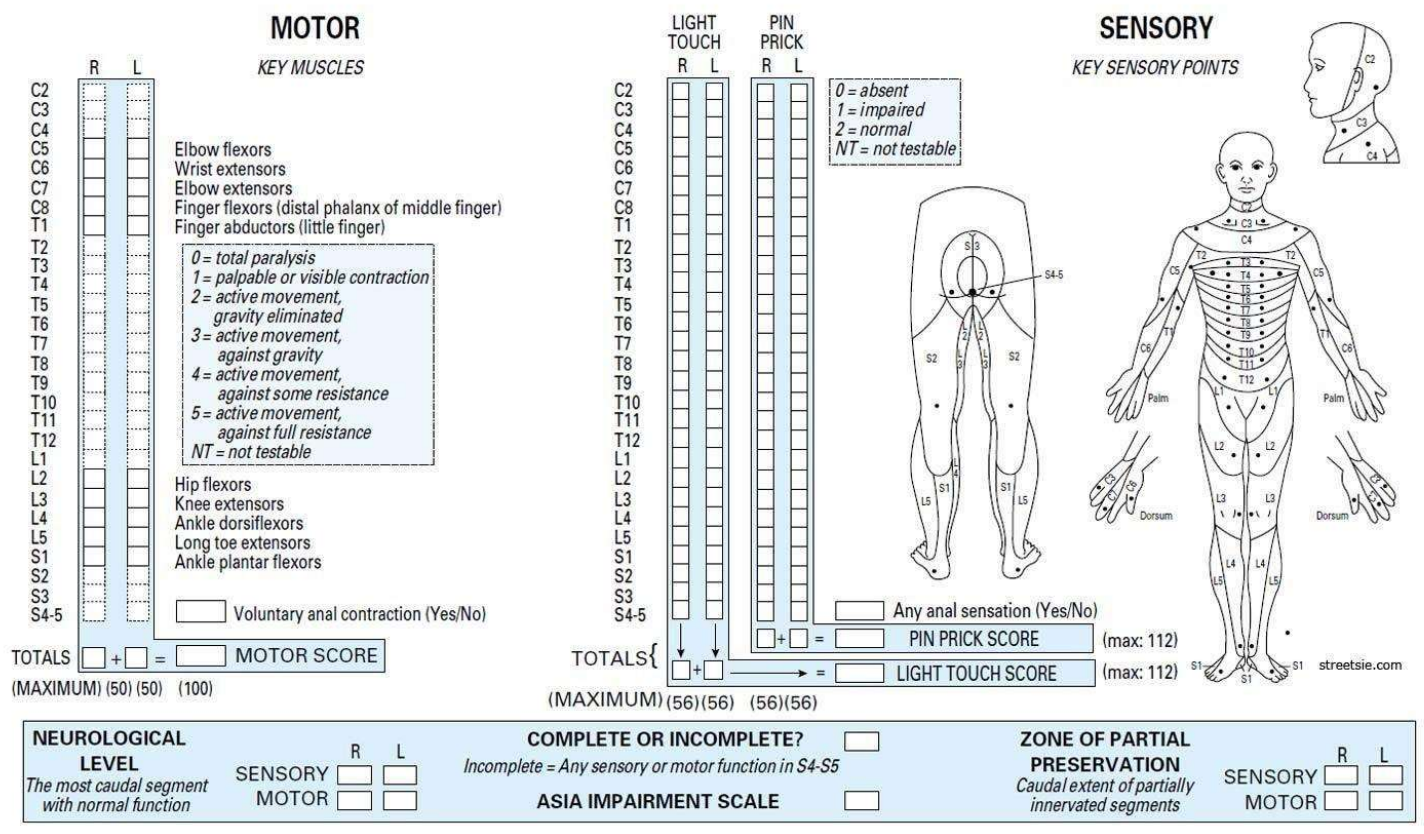

Para explorar la lesión medular, se deben identificar los niveles sensitivos, motores y el nivel neurológico, que se corresponden con los últimos miotomas (niveles motores), dermatomas (niveles sensitivos) y metámeras (nivel neurológico) indemnes(9).

En las lesiones medulares completas, no hay función sensorial, motora ni autónoma por debajo de la lesión, encontrándose la médula completamente seccionada y/o gravemente comprimida(1,7).

En las lesiones medulares incompletas, se preservan funciones sensitivas, motoras y/o autónomas. La mayoría de las lesiones incompletas no tiene cuadros clínicos ni patrones definidos de recuperación. Sin embargo, algunas lesiones parciales dan como consecuencia síndromes clínicos definidos. Estos se describen en la Tabla 2(1): 
Tabla 2: síndromes clínicos definidos en lesiones parciales

\begin{tabular}{|c|c|c|}
\hline SÍNDROME & IMAGEN & CARACTERÍSTICAS \\
\hline $\begin{array}{l}\text { Brown-Séquard o } \\
\text { hemisección } \\
\text { medular }\end{array}$ & & $\begin{array}{l}\text { Parálisis de neurona motora inferior ipsolateral } \\
\text { al nivel de la lesión. } \\
\text { Pérdida de sensibilidad en el dermatoma } \\
\text { Destrucción ipsolateral del haz corticoespinal: } \\
\text { pérdida función motora, aumento tono, de los } \\
\text { reflejos, espasticidad y signo de Babinski. }\end{array}$ \\
\hline $\begin{array}{l}\text { Centromedular o } \\
\text { síndrome de } \\
\text { Scheneider }\end{array}$ & & $\begin{array}{l}\text { Producido por compresión medular. Daño debido } \\
\text { a un compromiso microvascular de la región } \\
\text { central medular. } \\
\text { Mayor pérdida de función motora en miembros } \\
\text { superiores que en los inferiores. } \\
\text { Hay variabilidad en la pérdida sensitiva. }\end{array}$ \\
\hline $\begin{array}{l}\text { Síndrome } \\
\text { medular } \\
\text { anterior }\end{array}$ & & $\begin{array}{l}\text { Afecta a la arteria espinal anterior y asta anterior. } \\
\text { Pérdida de la función motora y de la sensibilidad } \\
\text { del dolor y de la temperatura por debajo del nivel } \\
\text { de la lesión. Columnas posteriores conservadas: } \\
\text { preservación sensibilidad propioceptiva y vibratoria. }\end{array}$ \\
\hline $\begin{array}{l}\text { Síndrome } \\
\text { medular } \\
\text { posterior }\end{array}$ & & $\begin{array}{l}\text { Afectación de los cordones posteriores. } \\
\text { Pérdida bilateral de la sensibilidad propioceptiva. } \\
\text { Conservación función motora y sensibilidad } \\
\text { termoalgésica. }\end{array}$ \\
\hline $\begin{array}{c}\text { Lesiones del cono } \\
\text { medular }\end{array}$ & & $\begin{array}{l}\text { Afectación de los segmentos sacros S1 a S4. } \\
\text { Alteración esfínter anal, del reflejo rectal, } \\
\text { erección y disfunción vesical. }\end{array}$ \\
\hline $\begin{array}{c}\text { Lesiones de cauda } \\
\text { equina }\end{array}$ & & $\begin{array}{l}\text { Cuadros clínicos variables. } \\
\text { Afectación sensibilidad en silla de montar y } \\
\text { variabilidad de la afectación motora. } \\
\text { Parálisis flácida intestinal y vesical y alteración } \\
\text { función sexual. }\end{array}$ \\
\hline
\end{tabular}

\subsubsection{Epidemiología de la lesión medular}

Todas las personas, en cualquier momento del ciclo vital son población de riesgo de una lesión medular sobrevenida(10).

La epidemiología de la lesión medular es difícil de descifrar, ya que no existe ningún registro regional ni nacional sobre lesión medular. La incidencia y la prevalencia que se 
conocen son derivadas de los estudios existentes, con su consecuente variabilidad. El conocimiento de la epidemiología de la lesión medular es esencial para la organización de los servicios sanitarios y planificación de las campañas preventivas.

Ante la variabilidad de estudios, se han realizado diversas revisiones sistemáticas que intentan estimar la incidencia mundial. Wyndaele(11) en su revisión de 17 estudios calcula una incidencia mundial de entre 10,4 y 83 casos/millón de habitante/año entre 1995 y 2005; Fitzharris(12) utilizando 31 estudios publicados, estima que en 2007 la incidencia mundial es de 23 casos/millón de habitante/año.

Si se realiza una división de los distintos estudios por continentes, en Europa la incidencia varía entre 10,4 y 29,7 casos/millón de habitante/año; en Norteamérica la cifra varía entre 27,1 y 83 casos/millón de habitante/año; en Asia la incidencia se mueve entre 18 y 40,2 casos/millón de habitante/año y en Australia se estima en 14,5 casos/millón de habitante/año(1).

En la tabla 3 se muestra la incidencia calculada a través de diferentes estudios realizados en España, todos ellos regionales(10,13-17).

Tabla 3: incidencia de lesión medular en España

\begin{tabular}{cccc}
\hline Autores & Lugar & Año & $\begin{array}{c}\text { Incidencia } \\
\text { (casos/millón habitantes/año) }\end{array}$ \\
\hline Den Berg et al. & Aragón & $1972-2008$ & 15,5 \\
\hline Montoto-Marqués et al. & Galicia & $1995-2014$ & 2,17 \\
\hline Álvarez-Pérez & Asturias & $2000-2012$ & $9,2-21,3$ \\
\hline Bárbara-Bataller et al. & Gran Canaria & $2000-2014$ & 12 \\
\hline Sebastiá-Alcácer et al. & Valencia & $2001-2013$ & 9,1 \\
\hline
\end{tabular}

La expectativa de vida de las personas con lesión medular traumática (LMT) se ha venido incrementando en las últimas décadas gracias a los avances tecnológicos y científicos en aspectos de prevención, atención prehospitalaria y manejo de complicaciones en el trascurso de la enfermedad que exige proveer a esta población de procesos de atención y rehabilitación multidimensionales(6). 


\subsubsection{Atención de la lesión medular en España}

La rehabilitación de la LM en los servicios sanitarios españoles se realiza en los dos Centros de Referencia Estatal acreditados por el Ministerio de Sanidad, Consumo y Bienestar Social: el Hospital Nacional de Parapléjicos de Toledo y el Hospital de Neurorrehabilitación Instituto Guttmann $(18,19)$.

Debido a la descentralización de la atención sanitaria, existen Unidades de Lesión Medular en nueve de las 17 comunidades autónomas. En la tabla 4 se muestran las existentes en la actualidad(19):

Tabla 4: unidades de lesión medular en España

\begin{tabular}{cc}
\hline Comunidad Autónoma & Centro hospitalario \\
\hline Andalucía & Hospital Universitario Virgen del Rocío \\
\hline Andalucía & Hospital San Juan de Dios \\
\hline Andalucía & Hospital Universitario Puerta del Mar \\
\hline Andalucía & Hospital Virgen de las Nieves \\
\hline Aragón & Hospital Universitario Miguel Servet \\
\hline Asturias & Hospital Universitario Central de Asturias \\
\hline Cataluña & Hospital Universitario Vall d'Hebron \\
\hline Galicia & Complejo Universitario A Coruña \\
\hline Galicia & Complejo Hospitalario Universitario de Vigo \\
\hline Islas Baleares & Hospital San Juan de Dios \\
\hline Islas Canarias & Complejo Hospitalario Universitario Insular \\
País Vasco & Materno Infantil de Canarias \\
\hline Valencia & Hospital de Cruces \\
\hline
\end{tabular}

En la actualidad no hay ningún tratamiento de reparación de la médula espinal que haya sido eficaz en el ser humano, aunque existen numerosos estudios al respecto(20).

Es por ello que el foco de la atención a la lesión medular debe centrarse en su prevención y en la mejora de la calidad de vida de las personas con lesión medular(20).

La lesión medular es la discapacidad física adquirida que más atención ha recibido siendo este grupo de pacientes el que ha sido objeto de mayor investigación(18). Sin embargo, esto no se ha producido en todas las esferas por igual: se ha puesto el foco en la 
superación física, menos en la superación emocional, relegando la vida sexual al último plano(21).

La rehabilitación integral es definida como aquel proceso asistencial clínico complejo dirigido a restituir, minimizar y/o compensar las alteraciones funcionales aparecidas en la persona afectada por una LM(10). Este tratamiento debe basarse en la coordinación de un grupo multidisciplinar de profesionales, teniendo la enfermera un papel destacado en proporcionar cuidados óptimos y dar una continuidad de cuidados desde el momento de adquisición de la LM y a lo largo de toda la vida(1). Este tratamiento multidisciplinar debe tener como objetivos la prevención de complicaciones, poniendo la educación como elemento central del tratamiento(20).

\subsubsection{Complicaciones secundarias derivadas de la lesión medular}

La lesión medular puede acarrear un compromiso vital a corto plazo por complicaciones propias como el shock neurógeno o derivadas de las lesiones asociadas. A medio y largo plazo, las secuelas neurológicas pueden provocar complicaciones secundarias que pueden producir alteraciones en la calidad de vida y en la participación social $(9,20)$.

Según los cambios fisiopatológicos, la fase aguda temprana se encuentra en las primeras 48 horas, la fase subaguda entre las 48 horas y las dos semanas y la fase intermedia en los primeros seis meses(22).

Algunas de las complicaciones que pueden presentarse a medio y largo plazo son las alteraciones vesico-esfinterianas, las alteraciones cutáneas, la espasticidad, la presencia de dolor neuropático, la disreflexia autonómica y las alteraciones en la esfera sexual(20). La aparición de estas complicaciones es frecuente y va a precisar una atención específica tras el alta hospitalaria(23). Además, estas complicaciones pueden interferir en el proceso de rehabilitación, ser las causantes de reingresos hospitalarios, de un aumento de la mortalidad y de una menor participación social(23).

En el estudio realizado con métodos mixtos de Callaway(24), la disfunción sexual se identifica como uno de los problemas crónicos más frecuentes o significativos encontrados, junto con el dolor crónico, la espasticidad muscular, los problemas circulatorios y las contracturas. 


\subsection{Marco filosófico-conceptual sobre la discapacidad}

Según el Informe Mundial sobre Discapacidad de la OMS(25), la discapacidad forma parte de la condición humana, constatando que casi todas las personas sufrirán algún tipo de discapacidad transitoria o permanente en algún momento de su vida. Más de mil millones de personas en el mundo se encuentran en situación de discapacidad y de ellos aproximadamente 200 millones de individuos presentan situaciones severas de funcionamiento.

Reflexiona de la Cruz(26) que "la sociedad sigue sin tener respuestas efectivas para la aceptación de la diferencia de los miembros, a pesar de que la diferencia es inherente a la propia existencia del ser humano". Esto enlaza con la idea de Aguado Díaz (27) que destaca como "desde tiempos antiguos hasta la actualidad han existido y existen grandes contradicciones en el tratamiento otorgado a las mujeres y hombres con cuerpos y órganos que funcionan de manera diferente a la habitual". A estos hombres y mujeres se les sigue clasificando como héroes, capaces de lo inverosímil, con una capacidad de superación exacerbada, o parias, personas desgraciadas, con una vida considerada como poco digna, sin acabar de aceptarlos como ciudadanos de pleno derecho(28,29). Centeno(29) expresa que "en medio de estos extremos, la nada".

Esto responde a las diferentes concepciones de las que son objeto las personas con discapacidad. Pueden distinguirse tres modelos de tratamiento, que a lo largo del tiempo se han dispensado a los hombres y mujeres con diversidad funcional y que coexisten en mayor o menor medida en el presente(30):

- Modelo de prescindencia: dentro de este modelo existen dos submodelos, el submodelo eugenésico y el submodelo de marginación.

- Submodelo eugenésico: el origen de la discapacidad tiene un origen religioso (pecaminoso u originado por los dioses). La vida de la persona con discapacidad es considerada una carga familiar y social, que no aporta nada a la comunidad. Esta vida se considera desgraciada, que no merece ser vivida y, por tanto, la sociedad decide prescindir de ella. Históricamente, se sitúa en la antigüedad clásica, aunque han quedado vestigios hasta nuestro tiempo. 
- Submodelo de marginación: muchas características de este modelo son una constante histórica. Se considera a las personas con discapacidad como objeto de compasión, de temor o de rechazo. La respuesta social ante ellos es la exclusión.

- Modelo rehabilitador: las causas que originan la discapacidad son científicas, no religiosas. La discapacidad se sitúa en el continuo salud-enfermedad. Las personas con discapacidad son valiosas para la sociedad en tanto en cuanto sean rehabilitadas o "normalizadas". El objetivo que persigue este modelo es la "normalización", y el éxito es valorado por la cantidad de destrezas o habilidades que se logren realizar. La mirada se centra en el déficit o en lo que no se puede hacer. El tratamiento social otorgado está basado en una actitud paternalista.

- Modelo social: el origen de este modelo se sitúa a finales de la década de los años 60-70 del siglo XX en Estados Unidos e Inglaterra. Las causas que originan la discapacidad son sociales. Se considera a los individuos con discapacidad como valiosos para la sociedad, aunque desde el reconocimiento y respeto de la diferencia. Este modelo promueve la autonomía y busca la eliminación de las barreras, no solo las arquitectónicas, para que la participación social sea real y efectiva. Las soluciones se dirigen a la sociedad, para que esté pensada y diseñada para hacer frente a las necesidades de todos los ciudadanos.

En la actualidad los modelos presentes en la sociedad son una dialéctica entre el modelo rehabilitador y el social, con restos del modelo de prescindencia.

Un ejemplo concreto del modelo subyacente, es el lenguaje empleado para nombrar a los individuos con un funcionamiento corporal diferente: en el pasado cercano se utilizaban términos peyorativos como subnormal, inútil o inválido. Otros como minusválido o discapacitado son términos utilizados en la actualidad.

Cabría pensar que pensamiento y lenguaje no guardan relación entre sí, como creían las escuelas psicológicas de Wurtburgo y la escuela behaviorista(31). Vigotsky describe la "teoría simultánea" que define que pensamiento y lenguaje están ligados entre sí, no siendo posibles el uno sin el otro, formando una unidad dialéctica. Las palabras utilizadas llevan asociadas ideas y conceptos. Esta correspondencia no es debida al azar, sino que 
representa valores culturalmente aceptados. Es por ello, que cuando se quiere modificar ese valor, a veces es necesario cambiar la palabra utilizada $(30,31)$.

Según la Real Academia Española(32):

- Minusválido: del latín minus "menos" y válido. Adj. Discapacitado.

- Discapacitado: del inglés disabled. Dicho de una persona: que padece una disminución física, sensorial o psíquica que la incapacita total o parcialmente para el trabajo o para otras tareas ordinarias de la vida.

- Diversidad: del latín diversĭtas, -ātis. Variedad, desemejanza, diferencia.

- Funcional: 1. Perteneciente o relativo a la función o las funciones. 4. Perteneciente o relativo a las funciones biológicas o psíquicas.

- Función: del latín functio, -ōnis. Capacidad de actuar propia de los seres vivos y de sus órganos y de las máquinas o instrumentos.

En la actual sociedad del rendimiento, se clasifica a los individuos utilizando un criterio de capacidad, de eficacia y de eficiencia. De esta manera, según la eficacia un individuo puede ser inválido o minusválido; según la eficiencia, puede ser deficiente; según la capacidad, puede resultar discapacitado, todo ello con el prisma de la productividad y del mercado(33). Todos estos términos definen a la persona por aquello que no puede hacer(34).

La OMS publica en 1980 la “Clasificación Internacional de Deficiencias, Discapacidades y Minusvalías" con la utilización de los términos comentados anteriormente(35). En 2001 se produce una revisión de esta guía, la “Clasificación Internacional del Funcionamiento, de la Discapacidad y de la Salud (CIF)", proponiendo una nueva terminología(36):

- Déficit en el funcionamiento: pérdida o anormalidad (en términos estadísticos) de una parte del cuerpo o de una función fisiológica o mental.

- Limitación en la actividad: son las dificultades que una persona puede tener en la ejecución de las actividades.

- Restricción en la participación: son problemas que una persona puede experimentar en su implicación en situaciones vitales.

- Barrera: son todos aquellos factores ambientales en el entorno de una persona que condicionan el funcionamiento y crean discapacidad. 
La discapacidad en la CIF, es un término que abarca los déficits, las limitaciones en la actividad y las restricciones a la participación. A pesar de haber intentado un cambio en la terminología, ninguno de estos términos es positivo o neutro(30).

El término diversidad funcional fue acuñado por el Foro de Vida Independiente en 2005. Este término pretende eliminar la negatividad utilizada para nombrar a este colectivo y hacer hincapié en la diversidad. El término diversidad funcional sustituye a los términos "discapacidad" y "minusvalía" (30). Bajo las maneras de nombrar, emergen las cuestiones sociales y políticas subyacentes(34).

El movimiento de vida independiente surge en California cuando un alumno con diversidad funcional, Ed Roberts ingresa en la universidad de Berkeley. Durante sus años de formación universitaria, tuvo que vivir en la enfermería por ser el único espacio adaptado, sin barreras arquitectónicas. Tras su graduación se crea el Centro de Vida Independiente en 1972. Este movimiento se va extendiendo y cuando llega a España en se crea en 2001 una comunidad virtual, el "Foro de Vida Independiente" como espacio de debate y reivindicación y se comienzan a crear las Oficinas de Vida Independiente, obviando la palabra "centro" debido a su asociación con la institucionalización(30). En la actualidad, en España existen cuatro oficinas de vida independiente: la Oficina de Vida Independent de Barcelona(37), VIgalicia(38), OVIAndalucía(39) y la Oficina de Vida Independiente de Madrid(40). También existen proyectos de creación en otras comunidades autónomas(41).

\subsection{Sexualidad}

\subsubsection{Definiciones de sexualidad}

Según la OMS(42), la sexualidad se refiere a "una dimensión fundamental del hecho de ser un ser humano: basado en el sexo, incluye al género, las identidades de sexo y género, la orientación sexual, el erotismo, la vinculación afectiva y el amor, y la reproducción. Se experimenta o se expresa en forma de pensamientos, fantasías, deseos, creencias, actitudes, valores, actividades, prácticas, roles y relaciones. La sexualidad es el resultado de la interacción de factores biológicos, psicológicos, socioeconómicos, culturales, éticos y religiosos o espirituales. Si bien la sexualidad puede abarcar todos estos aspectos, no es necesario que se experimenten ni se 
expresen todos. Sin embargo, en resumen, la sexualidad se experiencia y se expresa en todo lo que somos, sentimos, pensamos y hacemos."

La Asociación Mundial de Sexología junto con la OMS(42), define en el año 2000 la salud sexual como: "la experiencia del proceso permanente de consecución de bienestar físico, psicológico y sociocultural relacionado con la sexualidad. La salud sexual se observa en las expresiones libres y responsables de las capacidades sexuales que propician un bienestar armonioso personal y social, enriqueciendo de esta manera la vida individual y social. No se trata simplemente de la ausencia de disfunción o enfermedad o de ambos. Para que la salud sexual se logre es necesario que los derechos sexuales de las personas se reconozcan y se garanticen".

\subsubsection{Modelo del Hecho Sexual Humano}

Desde la perspectiva de la sexología sustantiva, se describe el "Hecho Sexual Humano" $(26,43-46)$ :

- El sexo: está constituido por una sucesión compleja de acontecimientos biológicos, psicológicos y sociales que hacen que seamos seres sexuados: hombres o mujeres. El proceso de sexuación, es un proceso que se inicia en la fecundación y dura hasta la muerte. En este proceso hay acontecimientos sexuantes que van sexuando al individuo. Estos se dividen en múltiples niveles: prenatales (cromosómicos, gonadales, hormonales), neonatales (asignación de sexo, asignación de nombre, primera crianza), en la adolescencia (pubertad, percepción de orientación del deseo, redefinición de la identidad), etapa adulta (afectividad, maternidad-paternidad, deseo erótico, climaterio). Al final el resultado es la identidad del sujeto en función de la suma de todos los niveles que componen la sexuación del sujeto.

- La sexualidad: es la manera que cada persona tienen de vivir el "hecho de ser sexuado", hace referencia al modo de sentir esta condición sexuada y a la vivencia subjetiva de esta condición. Es la forma peculiar de ser el hombre o la mujer que se es, a nivel personal y en relación con los otros hombres y mujeres de los que uno se encuentra rodeado: cómo se vive la propia realidad de ser 
hombre o mujer (el hombre o la mujer que se es), y cómo se siente orientado hacia el resto de hombres o mujeres.

- La erótica: se refiere a la forma concreta de expresar lo anterior, lo que se es y lo que se vive, tiene múltiples formas en su expresión y es personal y particular. Este concepto da cuenta de los deseos de los sujetos como sujetos sexuados, y por lo tanto eróticos, es decir, atractivos. La erótica alude a los deseos. Se podría definir como el conjunto de afectos, sensaciones, sentimientos, deseos y emociones que los sujetos sexuados tienen y viven como tales sujetos sexuados.

- La amatoria: da cuenta de los fenómenos de la expresión de la atracción, seducción y encuentros entre los sexos en su pragmática o conducta.

La lesión medular sobrevenida, por su carácter abrupto y todos los cambios que va a suponer actúa como un acontecimiento sexuante. Tras la lesión medular, la vivencia del hombre y mujer que se es, debido al cambio corporal, funcional, etc., puede producir cambios importantes en la vivencia de la sexualidad de la persona.

\subsubsection{Sexualidad y discapacidad}

Todas las personas somos diversas, como decía Marañón "la diversidad es la norma" en todos los aspectos constitutivos del hecho sexual humano: en cómo somos, nos vivimos, nos expresamos, etc.(26).

Sin embargo, hay ideas que subyacen en las características otorgadas sobre la sexualidad y la discapacidad:

Tradicionalmente, la sexualidad en la discapacidad ha sido un tema tabú, oculto, del que poco se sabe, incluso por las propias personas con discapacidad que pueden incluso llegar a apartar el tema de sus vidas por múltiples razones $(47,48)$.

Las personas con discapacidad tienen menos información y posiblemente de peor calidad que el resto de sus iguales(26).

Es frecuente que se les perciba como seres asexuales, como ángeles inocentes, como niños eternos. Por el contrario, a veces se les percibe como personas obsesas o desenfrenadas sexualmente. Esta última idea suele ir más asociada a la discapacidad mental $(21,29,49)$. 
Otra idea frecuente es que la sexualidad de las personas con diversidad funcional no es algo ni urgente ni importante, ya que tienen otras problemáticas de las que han de ocuparse previamente, por ser, estas sí, urgentes o importantes. La sexualidad suele quedar relegada al último lugar, tras la recuperación física, psíquica y social $(26,33,50)$.

Las personas con diversidad funcional a veces tienen cuerpos que no encajan con el modelo imperante, asociado a la juventud, la fuerza, la belleza o la salud, lejos del modelo de cuerpos productivos, capaces, reproductivos y deseables; esto sumado a la falta de referentes y modelos positivos con los que identificarse, puede llevar a la no construcción de un autoconcepto favorable(26,34,49).

También aparece la idea de que existe una sexualidad "normal" y una sexualidad "discapacitada". Reflexiona Allué(21) que "la sexualidad de las personas con discapacidad ha sido convertida en algo especial como consecuencia de la visión de los "normales" que la contemplan".

El sexólogo Díez Arrese(33), llega a señalar que "tampoco sería muy exagerado decir incluso que han sido excluidos de su propia condición de sujetos".

Todo ello se enmarca en la idea social de sexualidad imperante: penetrativa, coitocéntrica, falocéntrica, genitalizada, capacitista y competitiva. Este modelo, en el que gran parte de la población tiene dificultades para encajar, se torna aún más difícil en la diversidad funcional $(46,48)$.

Diversos autores señalan que la sexualidad de las mujeres con diversidad funcional sufre una invisibilización mayor, siendo su deseo aún más silenciado, siendo minoría de minorías. Hay que destacar, que en los últimos años han surgido más estudios sobre este tema, aunque la literatura sigue siendo limitada(50-52).

Si se centra el tema en la lesión medular adquirida, esta población presenta necesidades sanitarias y sociales muy específicas. Las múltiples consecuencias que subyacen de una lesión medular hacen que su salud sexual no sea habitualmente considerada(53).

La sexualidad puede afectarse en tres niveles: un primer nivel vinculado a las consecuencias directas de la lesión, a veces amplificado con las complicaciones secundarias de la lesión, que pueden generar una pérdida de autoestima u otros 
problemas psicológicos que constituyen el segundo nivel. Esto puede acarrear disminución de las relaciones interpersonales y de la vida social, acarreando un efecto terciario(50).

Por otro lado, al ser una discapacidad sobrevenida, puede haber un cambio de identidad, teniendo que aceptar una nueva imagen corporal, en un proceso lento y complejo(26).

Sin embargo, las personas con lesión medular consideran la recuperación de su sexualidad entre sus principales prioridades para mejorar su calidad de vida $(54,55)$.

La realización de estudios científicos sobre la sexualidad de la mujer en la lesión medular no comienza hasta finales de la década de 1980, ya que la mujer no estaba incapacitada para realizar el coito (entendido como sujeto pasivo de la recepción peneana) y su función reproductiva estaba preservada(50).

\subsubsection{Respuesta sexual humana e implicaciones de la lesión medular}

La comprensión sobre la fisiología de la respuesta sexual humana proviene de los estudios realizados por William H. Masters y Virginia E. Johnson publicados en 1966 en "Human Sexual Response". A pesar de que, desde hace siglos ya se conocía la fisiología de casi todas las funciones del ser humano, no es hasta este momento cuando se estudia de forma sistemática y desde un prisma científico este tema $(56,57)$.

La respuesta sexual humana es la respuesta integral del organismo a un estímulo sexual efectivo. Estos cambios fisiológicos naturales se dividen en cuatro fases: excitación, meseta, orgasmo y resolución. Posteriormente, Kaplan y los escritos menores de Masters y Johnson agregan el deseo como primera fase. Es importante reconocer que la respuesta sexual no se produce solo en el reino de lo físico, sino que los reflejos y sensaciones sexuales se activan y experimentan dentro de una matriz psicosociológica $(56,57)$.

\subsubsection{Deseo sexual}

El deseo sexual es un impulso psicobiológico. Se alimenta de dos fuentes: la exógena, producida durante la interacción sexual, por una adecuada excitación física percibida a través de los órganos de los sentidos, y la endógena, a través del desarrollo de fantasías e ideas sexuales(58). 
El deseo sexual se encuentra influido por(56,57):

- Factores físicos: estado de las hormonas sexuales, estado general, cansancio.

- Factores emocionales: grado de ansiedad, percepción de seguridad, estado anímico.

- Factores cognitivos: actitudes, creencias, expectativas sexuales, atracción hacia la otra persona, preocupaciones y experiencias eróticas anteriores.

- Aspectos circunstanciales: ambiente (ruido o silencio), grado de comodidad o estar en público o en privado.

- Compañero erótico: existencia de experiencias pasadas con esa persona y cómo se han desarrollado, tipo de vínculo existente con esa persona.

- Otros factores: necesidad de sentirse conectado, amado, deseo de ser abrazado, deseo de sentirse seguro, etc.

La motivación sexual de una mujer es más compleja que la mera presencia o ausencia de deseo. Para poder iniciar una relación sexual, la mujer debe incrementar su acercamiento emocional con su pareja, incrementar su bienestar y su propia imagen. Ella debe sentirse atractiva, femenina, apreciada, amada y / o deseada(58).

\subsubsection{Fase de excitación}

Los cambios producidos durante la fase de excitación se muestran en la tabla $5(56,57,59)$ : 
Tabla 5: cambios físicos producidos durante la fase de excitación

\section{Fase de excitación}

Erección tumescente del pene

Hombre Alargamiento de la uretra y aumento de su diámetro al doble

Elevación de las bolsas escrotales hacia el perineo. Engrosamiento de la piel del escroto y desaparición de los pliegues escrotales

Lubricación de las paredes vaginales

Distensión del túnel y del orificio vaginal

El color de la pared vaginal se torna más oscuro

Adelgazamiento y desplazamiento lateral de los labios mayores

Mujer Tumefacción de los labios menores

Aumento del tamaño del clítoris

El cérvix y el útero se desplazan hacia arriba

Aumento del tamaño de las mamas

Aparición del rubor sexual

Posible erección de los pezones

Comunes Tensión neuromuscular incrementada

Aumento del ritmo cardiaco y presión arterial

\section{Erección}

La erección en hombres y mujeres es un proceso dinámico que involucra la coordinación de circuitos neuronales resultando un evento vascular final, produciendo la erección del pene en los hombres y la tumescencia del clítoris en las mujeres(54).

Este evento neuro-vasculo-tisular complejo, se encuentra principalmente bajo el control nervioso vegetativo, predominando la actividad parasimpática, dando como resultado la relajación del músculo liso cavernoso. El neurotransmisor principal responsable de la erección de pene y clítoris es el óxido nitroso(54).

Se distinguen tres tipos de erecciones(58):

- Refleja: ocurre en respuesta a la estimulación local. Es comandada por el centro medular sacral situado en los niveles S2-S4 y generada por estímulos táctiles producidos en los órganos genitales o en zonas próximas. 
- Psicogénica: la erección psicogénica es controlada por el centro medular toracolumbar, en los niveles T11-L2 y es generada por un estímulo que causa excitación o deseo, es decir, que parte del cerebro.

- Nocturna: se produce durante el sueño REM, acompaña las fases del sueño paradójico y es sensible a la impregnación de andrógenos. No se ha estudiado el impacto de la lesión medular en las erecciones nocturnas.

En hombres con LM, cuando el centro S2-S4 es inaccesible debido a una LM sacra, el centro toracolumbar se convierte en la vía dominante para la transmisión, aunque estas erecciones psicógenas son a menudo de peor calidad(54).

Las personas con LM incompleta suelen presentar un mantenimiento de la erección, sea psicogénica o refleja. Sin embargo, en LM altas completas solo la erección refleja suele estar presente(54).

\section{Apoyos farmacológicos a la erección}

Existen en el mercado, diversos fármacos para la disfunción eréctil en general, válidos para la población con lesión medular.

Los inhibidores orales de la fosfodiesterasa tipo 5 (PED-5) son una opción de tratamiento de primera línea para los pacientes con disfunción eréctil(60). Los mecanismos vasculares básicos suelen estar intactos, por lo que los lesionados medulares pueden responder a la administración de estos fármacos para el tratamiento de la disfunción eréctil, al igual que la población general. En España, están disponibles en la actualidad: citrato de sildenafilo, vardenafilo, tadalafilo y avanafilo.

Los fármacos inyectados en el pene, que tradicionalmente fueron utilizados como primera opción, pasaron a una segunda línea al surgir los fármacos orales(60). Se administran por inyección intracavernosa directa. En España, el fármaco disponible es el alprostadil.

Los dispositivos de vacío o los implantes de pene son opciones de tratamiento de tercera línea(60). 


\section{Lubricación en la mujer}

La fase de excitación se caracteriza por un fenómeno de lubricación vaginal, congestión del clítoris y labios menores, extensión de los labios mayores y alargamiento de la parte posterior superior de la vagina. Esta fase implica un reflejo a partir de la médula espinal. Se estimulan las zonas erógenas primarias (labios menores, clítoris, unidad neurovascular vaginal anterior, senos, etc.) y la información sensorial genital se transmite a través en particular de los nervios pudendos y la médula para integrarse a nivel cortical. El reclutamiento de eferencias parasimpáticas que pasan a través de los nervios pélvicos y luego cavernosos conduce a la congestión del clítoris, los labios y la vagina. Esta ingurgitación permitirá la aparición de una lubricación correspondiente al aumento del trasudado resultante de la vasodilatación de los capilares de las paredes de la vagina(58).

En la mujer con LM, la capacidad de tener una lubricación psicógena o refleja depende del nivel de afectación. Es preciso una sensibilidad intacta a nivel de T11-L2 para permitir una lubricación psicógena. Puede producirse una lubricación refleja si los segmentos sacros están intactos(20).

\subsubsection{Fase de meseta}

Los cambios físicos producidos durante la fase de meseta se encuentran en la tabla $6(56,57,59)$ : 
Tabla 6: cambios físicos producidos durante la fase de meseta

\section{Fase de meseta}

\begin{tabular}{|c|c|}
\hline Hombre & $\begin{array}{l}\text { Aumenta la rigidez de la erección } \\
\text { Aumento del diámetro de la corona del glande y ligero cambio en su tonalidad } \\
\text { Los testículos incrementan su tamaño y se acercan más al periné } \\
\text { Emisión de líquido mucoide lubricante procedente de las glándulas de Cowper }\end{array}$ \\
\hline Mujer & $\begin{array}{l}\text { La lubricación vaginal continúa } \\
\text { Aumento mínimo de la profundidad y el ancho de los dos tercios internos del túnel } \\
\text { vaginal } \\
\text { Se forma la plataforma orgásmica en el tercio exterior de la vagina: intensa reacción } \\
\text { vasomotriz en el tercio externo, en el cual aumenta considerablemente la } \\
\text { vasocongestión, con sangre venosa, estrechándose de forma importante su luz } \\
\text { Cambio de color de los labios menores del rosado al rosa oscuro o rojo brillante } \\
\text { El clítoris se retira bajo el capuchón clitorídeo } \\
\text { El cuerpo y cuello del útero se elevan aún más } \\
\text { Mayor incremento del tamaño de las mamas, la areola se hace más grande, } \\
\text { ocultando parcialmente el pezón }\end{array}$ \\
\hline Comunes & $\begin{array}{l}\text { Erección de los pezones } \\
\text { Rubor sexual } \\
\text { Aceleración de ritmo cardiaco, respiratorio y aumento de presión arterial } \\
\text { Mayor aumento de la tensión neuromuscular } \\
\text { Disminución de la agudeza visual y auditiva }\end{array}$ \\
\hline
\end{tabular}

\subsubsection{Fase de orgasmo}

Los cambios físicos producidos en la fase de orgasmo se muestran en la tabla $7(56,57,59)$ : 
Tabla 7: cambios físicos producidos durante la fase de orgasmo

\section{Fase de orgasmo}

\begin{tabular}{ll}
\hline Se cierra el esfínter vesical \\
El esfínter externo de la uretra se contrae y relaja (se cierra y se abre) \\
alternativamente para posibilitar el goteo del semen a la uretra \\
Contracciones automáticas de los músculos lisos de los conductos y vasos \\
deferentes, de las vesículas seminales y de la próstata, que provocan la descarga de \\
sus líquidos seminales respectivos en la uretra prostática. \\
Contracciones automáticas del esfínter uretral e involuntarias de la musculatura \\
perineal, de los músculos isquiocavernoso y bulbocavernoso que impelen el semen \\
hacia el exterior (eyaculación)
\end{tabular}

El orgasmo es un proceso neuropsicofisiológico complejo que suele marcar el pico de la respuesta sexual. El orgasmo se manifiesta, tanto en mujeres como en hombres, por una fuerte activación de determinadas zonas del cerebro acompañada de un conjunto de respuestas fisiológicas periféricas. La sensación de intenso placer inherente al orgasmo, en parte subjetivo, se genera en las zonas activadas del cerebro. De forma periférica, el orgasmo se caracteriza por contracciones rítmicas de los músculos pelviperineales, activación más o menos pronunciada del sistema nervioso autónomo y tensión muscular generalizada $(54,58)$.

Las vías nerviosas que controlan los eventos fisiológicos periféricos que caracterizan el orgasmo están formadas por los sistemas autónomo (parasimpático y simpático) y somático (motor y sensorial). La organización de estas vías incluye en el ser humano los centros toracolumbar, parasimpático y motor sacro. La activación máxima de estos centros medulares durante el orgasmo también resulta en la estimulación de todos los 
sistemas autónomos y somáticos que inervan otros órganos como el corazón, los vasos sanguíneos de la piel, las glándulas sudoríparas y los músculos del suelo pélvico. Por tanto, este fenómeno da lugar a una respuesta generalizada que contribuye a la sensación paroxística(58).

En la mayoría de los hombres, el orgasmo acompaña a la eyaculación, aunque estos dos eventos activan distintos circuitos neurofisiológicos complejos, por lo que puede darse un evento sin el otro, darse de forma separada y darse ambos eventos sin erección peneana $(54,58)$

El orgasmo producido genitalmente, parece requerir un reflejo sacro intacto, aunque puede experimentarse por estimulación no genital o incluso solo con fantasía psicógena. Una vez producido se produce modulación por varios factores, siendo especialmente importante los psicológicos y emocionales(54).

La mayoría de estudios del orgasmo en personas con LM se basan en autoinformes del sujeto, medidas fisiológicas (sobre todo frecuencia cardíaca y presión arterial) o experiencias documentadas(54).

\section{Eyaculación}

La eyaculación se puede definir como una serie de eventos fisiológicos que resultan en la expulsión de semen por el meato uretral. La eyaculación es una función compleja que involucra eventos secretores y musculares en una secuencia perfectamente definida que requiere la coordinación de los componentes simpático, parasimpático y somático (sensorial y motor) del sistema nervioso. La eyaculación tiene dos fases distintas: emisión y expulsión. Estas fases de la eyaculación están mediadas por reflejos organizados en las etapas espinal toracolumbar y sacra(34).

La fase de emisión incluye la secreción de líquido seminal de las glándulas accesorias, la contracción del tracto seminal desde el epidídimo a la próstata, asegurando el transporte de los espermatozoides y el cierre del cuello de la vejiga que previene la eyaculación retrógrada. Esta fase está controlada por estimulación tanto simpática 
como parasimpática, con fibras nerviosas que surgen de los segmentos espinales de T10 a L2 y S2 a S4 respectivamente $(58,61)$.

La fase de expulsión corresponde a las contracciones rítmicas de la musculatura lisa uretral y de la musculatura perineal estriada, y en particular del músculo bulboesponjoso, resultando en la expulsión de los espermatozoides. La fase de expulsión está controlada por fibras nerviosas simpáticas que surgen de S2 a S4(58,61).

La dificultad de lograr la eyaculación después de una lesión de la médula espinal está ampliamente documentada. Sin embargo, cuando los segmentos lumbosacros de la médula espinal no sufren la lesión, se puede inducir la eyaculación. Estas observaciones muestran que el sistema motor que causa las contracciones estereotipadas de los músculos estriados pelviperineales está en la médula espinal. Además, la emisión refleja, el cierre del cuello de la vejiga y las contracciones rítmicas del músculo bulboesponjoso implicado en la expulsión de los espermatozoides son todos reflejos espinales muy probablemente provocados por el reclutamiento de aferentes sensoriales del nervio pudendo. Este hecho se ha aprovechado con éxito para recolectar esperma de pacientes con lesión de la médula espinal en respuesta a una estimulación de tipo vibratoria aplicada al glande(58).

En las ratas la sincronía entre ambas fases es controlada por un generador espinal de eyaculación. Se está investigando la probable existencia de este generador en humanos, en los que se encontraría situado en los segmentos medulares L3-L5(54,62,63).

Un bajo número de hombres con lesión medular pueden eyacular mediante estimulación sexual, en torno a un 10-15\% según la literatura y a veces se requiere estimulación vibratoria del pene. Debido a la disinergia en la eyaculación, es frecuente la eyaculación retrógrada $(61,63)$.

\subsubsection{Fase de resolución}

Los cambios físicos producidos en la fase de resolución se muestran en la tabla $8(56,57,59)$ : 
Tabla 8: cambios físicos producidos en la fase de resolución

\section{Fase de resolución}

\begin{tabular}{ll}
\hline Pérdida de la erección del pene \\
Relajación del escroto, disminución del tamaño de los testículos y de las bolsas \\
escrotales a su tamaño y posición habitual \\
Pérdida de la erección de los pezones \\
Desaparición de la miotonía \\
Período refractario, donde no es posible otra eyaculación y hay una intensa \\
resistencia psicofisiológica a la estimulación sexual
\end{tabular}

En la literatura no hay cambios respecto a esta fase en la LM.

\subsubsection{Fertilidad}

En las mujeres, la fertilidad tras la LMT suele mantenerse, no teniendo influencia el nivel lesional $(64,65)$. Sin embargo, puede haber un factor de infertilidad presente como en cualquier pareja, es por ello que es necesario que ante la aparición de dificultades en la concepción, la mujer también sea evaluada(66).

Es frecuente un período de amenorrea tras la lesión, reanudándose la menstruación entre 6 meses y un año(65). Es necesario informar sobre la capacidad fértil y realizar una planificación familiar. 
El embarazo, parto y posparto van a requerir un control y seguimiento estrechos, debido a tasas más altas de infecciones del tracto urinario, mayor riesgo de eventos tromboembólicos y mayor riesgo de disreflexia autonómica $(64,65)$.

En los hombres, tras una LM, en la mayoría de ellos se produce una afectación de su fertilidad debido a tres consecuencias comunes: disfunción eréctil, disfunción eyaculatoria y calidad anormal del semen $(66,67)$.

El perfil de semen característico de los hombres con lesión medular incluye una concentración normal de espermatozoides, pero una motilidad y viabilidad espermática anormalmente bajas. La causa es un área actual de investigación y parece estar relacionado con factores en el plasma seminal y con una disfunción de las glándulas accesorias $(65,67)$.

La calidad del semen generalmente permanece estable durante la fase crónica de la lesión medular, sin que exista relación entre el tiempo de duración de la lesión medular y la calidad del mismo(66).

\subsubsection{Técnicas de reproducción asistida}

Cuando es posible, se recomienda la eyaculación mediante masturbación, siendo la técnica más sencilla y la que más espermatozoides móviles recupera respecto a otras formas de obtención de semen más tecnificadas $(66,68)$. Cuando existe aneyaculación, existen diversas técnicas para lograr el eyaculado:

Vibroestimulación o estimulación vibratoria del pene: se recomienda como primera línea de tratamiento para la extracción del semen en hombres con aneyeculación. Se trata de un dispositivo vibratorio aplicado en el dorso del pene, que activa el nervio dorsal del pene. Al realizar una estimulación continua, el arco reflejo eyaculatorio se activa a nivel medular y se produce la eyaculación. Existen dos dispositivos en el mercado aprobados por la FDA: el Ferti Care $^{\circledR}$ y el Viberect-X3 ${ }^{\circledR}(65,69)$. La vibroestimulación puede realizarse en el propio domicilio solo o con ayuda de la pareja con fines eróticos o de inseminación en casa y también se puede realizar en un centro sanitario(66,69). 
Electroeyaculación: se coloca un estimulador dentro del recto orientado hacia las vesículas seminales y la glándula prostática. La corriente eléctrica se aplica con diversos patrones de voltaje hasta que se produce la eyaculación. Gracias a ello, no es necesario la estimulación del reflejo espinal para provocar la eyaculación. La motilidad de los espermatozoides es más baja y la probabilidad de eyaculación retrógrada es mayor con esta técnica, pero puede ser exitosa cuando la vibroestimulación ha fallado. La electroeyaculación requiere asistencia médica, por lo que son candidatos los pacientes que no responden a la vibroestimulación y cuyos fines son reproductivos más que eróticos $(65,66,69-71)$.

Masaje de próstata: método alternativo para la extracción de semen indicado para pacientes sin acceso a centros que realizan vibroestimulación o electroeyaculación, o para pacientes en los que fracasa la vibroestimulación y no quieren someterse a electroeyaculación. Con este método hay una baja producción de espermatozoides(66)

Extracción quirúrgica de espermatozoides: punción o biopsia de tejido de las estructuras reproductivas, como el testículo o el epidídimo para obtener espermatozoides. Debe considerarse como último recurso cuando los demás métodos fallan(66).

Posteriormente, la elección de la terapia de reproducción asistida se basará principalmente en la cantidad de espermatozoides móviles disponibles. La complejidad de la técnica a realizar irá en aumento, cuanto menor sea el recuento total de espermatozoides móviles(66):

- Inseminación intravaginal: es la técnica menos costosa y más parecida a la concepción natural. Se debe recolectar el semen e introducirlo en la vagina mediante una jeringa sin aguja, estimando la ovulación de la mujer. Si se realiza con vibroestimulación, debe instruirse a la pareja en este procedimiento(66).

- Inseminación intrauterina

- Fertilización in vitro o inyección intracitoplasmática de espermatozoides 


\subsubsection{Derechos y leyes referentes a la sexualidad y la discapacidad}

La Declaración Universal de los Derechos Humanos de Organización de Naciones Unidas de 1948, en su Artículo 1 declara que "todos los seres humanos nacen libres e iguales en dignidad y derechos y, dotados como están de razón y conciencia, deben comportarse fraternalmente los unos con los otros"(72).

En el año 1972, en el Congreso Mundial de Rehabilitación, son abordados por primera vez los derechos sexuales de las personas con discapacidad(73).

En el año 1993, se aprueba en la Conferencia Mundial de Derechos Humanos, la Declaración y Programa de Acción de Viena(74), que establece dar una especial atención que asegure "la no discriminación y el disfrute, en igualdad de condiciones, por parte de los discapacitados de todos los derechos humanos y las libertades fundamentales, incluida su participación activa en todos los aspectos de la sociedad".

El 26 de agosto de 1999, son aprobados en la Asamblea General de la Asociación Mundial de Sexología (WAS), la Declaración Universal de los Derechos Sexuales, expuestos a continuación(75):

- Derecho a la libertad sexual

- Derecho a la autonomía sexual, a la integridad sexual y a la seguridad sexual del cuerpo

- Derecho a la privacidad sexual

- Derecho a la igualdad sexual (equidad sexual)

- Derecho al placer sexual

- Derecho a la expresión sexual emocional

- Derecho a la libre asociación sexual

- Derecho a tomar decisiones reproductivas, libres y responsables

- Derecho a la información basada en conocimiento científico, sin censura religiosa o política

- Derecho a la educación sexual general

- Derecho a la atención clínica de la salud sexual 
En el 2006, en la Convención Internacional sobre los Derechos de las Personas con Discapacidad de la ONU(76) se refleja la igualdad en derechos de las personas con discapacidad, entre ellos, el de la vivencia de la sexualidad. Es considerado el primer tratado de derechos humanos del siglo XXI, destinado a proteger y asegurar los derechos humanos y libertades fundamentales de las personas con discapacidad(34).

En el año 2010, en la Carta de los Derechos Fundamentales de la Unión Europea, aparecen artículos relativos a la vida privada y familiar, el derecho a fundar una familia y a la igualdad ante la ley(77). La Unión reconoce y respeta el derecho de las personas discapacitadas a beneficiarse de medidas que garanticen su autonomía, su integración social y profesional y su participación en la vida de la comunidad(34).

En la legislación española, los artículos 14 y 18 de la Constitución Española, reflejan el derecho a la libertad y a la intimidad(78).

Unos años más tarde, en la Ley 51/2003 de Igualdad de Oportunidades, No Discriminación y Accesibilidad Universal de las personas con discapacidad: "la condición que deben cumplir los entornos, procesos, bienes, productos y servicios, así como los objetos o instrumentos, herramientas y dispositivos, para ser comprensibles, utilizables y practicables por todas las personas en condiciones de seguridad y comodidad y de la forma más autónoma y natural posible" (79). Años más tarde, en el artículo 4 de la Ley 39/2006, de Promoción de la Autonomía Personal y Atención a las Personas en situación de dependencia, se encuentra reflejado el derecho a "disfrutar de los derechos humanos y libertades fundamentales, con pleno respeto de su dignidad e intimidad"(80).

La "eliminación de toda forma de discriminación, con especial atención a las personas con algún tipo de discapacidad, a las que se les garantizará su derecho a la salud sexual y reproductiva, estableciendo para ello los apoyos necesarios en función de su discapacidad" se encuentra recogido en la Ley Orgánica 2/2010 de Salud Sexual y Reproductiva y de la Interrupción Voluntaria del Embarazo. Por otro lado, en el Artículo 8 de esta misma ley se hace mención a la formación de los profesionales de la salud: "en los aspectos formativos de los profesionales de la salud se tendrá en cuenta la realidad y las necesidades de los grupos o sectores sociales más vulnerables, como el de las personas con discapacidad"(81). 


\subsubsection{Asistencia personal y asistencia sexual}

El término "asistencia sexual" se utiliza como un paraguas bajo el que conviven diferentes realidades, servicios y demandas $(82,83)$.

Para enmarcar esta figura, es necesario hablar previamente, de la asistencia personal. En España, esta figura nace con el nacimiento del “Foro de Vida Independiente" en 2001. Según Romañach(84), un asistente personal es "aquella persona que realiza o ayuda a realizar las tareas de la vida diaria a otra persona que, por su situación, bien sea por una diversidad funcional o por otros motivos, no puede realizarlas por sí misma. Esta ayuda está regulada por un contrato profesional. La existencia del asistente personal se basa en el deseo y derecho de las personas con diversidad funcional a controlar su propia vida y a vivirla con la dignidad que conlleva estar en igualdad de oportunidades con el resto de la ciudadanía"

La asistencia personal es un recurso humano que permite la vida independiente aportando los apoyos necesarios, aportando alternativas al cuidado familiar o a la institucionalización(29).

Es un derecho personal reconocido por la ONU en la Convención Internacional de las Personas con Discapacidad(76), considerado como una de las mejores herramientas para fomentar la inclusión en la comunidad.

En España la Ley 51/2003 de Igualdad de Oportunidades, No Discriminación y Accesibilidad Universal(79) define en su artículo 2 la Vida Independiente como principio inspirador. Este principio también aparece reflejado en el Plan Nacional de Accesibilidad 2004-2012 del Instituto de Migraciones y Servicios Sociales (IMSERSO)(85). La figura del asistente personal está reconocida dentro del Catálogo de Prestaciones de la Ley 39/2006, de 14 de diciembre de Promoción de la Autonomía Personal y Atención a las Personas en Situación de Dependencia(80) como prestación económica. Sin embargo, según el informe de la Plataforma Representativa Estatal de Personas con Discapacidad Física (Predif)(86) el número de prestaciones asociadas a esta figura en 2015, suponía un 0,29\% del total de prestaciones para la autonomía y atención de la dependencia. 
Esta figura se considera como una "necesidad básica de primer orden" y con carácter universal, debiendo llegar a todas las personas que la requieran(34).

Sobre la asistencia sexual, no existe una única visión(87). Se identifican dos corrientes de pensamiento principales asociadas a esta figura:

Por un lado, según define Santesmases(83), en la que se produce un encuentro íntimo entre asistente y asistido, existiendo una "conexión erótica" entre ambos. Un ejemplo de esta propuesta es la asociación "Tándem Team", que selecciona a los asistentes sexuales según las necesidades y peculiaridades del asistido, y que entiende este acto como altruista, aunque pueda haber un pago por "dietas y desplazamiento", pero no por la actividad en sí. Entiende la experiencia como enriquecedora para ambos. Recientemente han modificado la terminología de asistencia sexual por la de acompañamiento íntimo(88).

Otra propuesta diferente es la asistencia sexual entendida como "un apoyo instrumental para acceder sexualmente al propio cuerpo y/o para tener prácticas sexuales con otra persona que no sea el asistente". Este último caso puede ser necesario cuando existe un encuentro erótico de varias personas con diversidad funcional, que pueden necesitar apoyos para articular ciertas posiciones o movimientos(34). Según Centeno(49), la reivindicación del derecho a la sexualidad en personas con diversidad funcional solo puede realizarse desde la vertiente autoerótica, ya que el mantenimiento de relaciones eróticas con otras personas son "acuerdos" y no "derechos". En esta definición, la asistencia personal y sexual parten de la misma idea en el planteamiento, la justificación, y la configuración como derecho y distinta en las tareas a realizar. Ambas reconocen la forma de autonomía consistente en hacer las cosas con las manos de otra persona y las propias decisiones, y en el caso de la asistencia sexual con la idea de alcanzar el derecho a la vida independiente en materia de sexualidad(29,34). El proyecto "Asistenciasexual.org"(89), que pone en contacto a asistentes y asistidos, concuerda con esta visión. 
En Europa, la asistencia sexual se encuentra consolidada en distinto grado, en países como Alemania, Dinamarca, Holanda, Países Bajos, Suiza, Austria, Bélgica, en general asociándolos dentro de la cartera de servicios sociales $(83,90)$.

En España, la figura del asistente sexual y su configuración se encuentran en proceso de construcción, tanto desde lo teórico como desde la práctica(49).

\subsubsection{Atención de la sexualidad en la lesión medular por parte de los profesionales}

Cuando se habla de personas con discapacidad, se puede poner el énfasis en la persona o en la discapacidad. Muchos profesionales enfocan sus actuaciones en la discapacidad, en la carencia, en la limitación o la dificultad, más que en la persona, en su potencialidad y en sus posibilidades(91).

El personal sanitario tiene entre sus objetivos la promoción de la salud. Este enfoque no puede ser ajeno al abordaje de la sexualidad en general, ni a la educación sexual en particular(26).

Esta educación sexual junto con el acompañamiento, se tornan piezas claves de la rehabilitación de la sexualidad. Estas recaen principalmente, aunque no de forma exclusiva, en la enfermera. Las enfermeras necesitan incluir en la planificación de sus cuidados un abordaje sobre la sexualidad de las personas con LM, teniendo en cuenta las necesidades del individuo y realizando las intervenciones de enfermería necesarias(92).

En el estudio de Rodríguez(93) sobre el abordaje sexual de las enfermeras en pacientes con discapacidad, las enfermeras identifican que trabajar este tema es algo muy importante, sin embargo, encuentran barreras como la falta de tiempo, la falta de formación y la presencia de falsos mitos y creencias que hacen que no se lleve a la práctica.

Independientemente del tipo de lesión medular y de la gravedad de la misma, el derecho a la vida sexual no puede ser puesto en cuestión, ni su asistencia negada por parte de los profesionales sanitarios, ni por parte de las instituciones(21). 


\subsubsection{Antecedentes en la investigación sobre la sexualidad en la lesión medular}

La investigación sobre sexualidad en diversidad funcional en general y sobre lesión medular en particular, ha aumentado en los últimos años(26). A pesar de ello, las investigaciones se han continuado centrando en lo referente a lo físico y más en concreto, en lo referente a los genitales y sus usos.

En la revisión de Rodríguez(94) que analizaba las palabras clave utilizadas en los artículos publicados, el sexo al cual eran dirigidos y las partes del hecho sexual humano abordadas, se concluyó que la mayoría de estudios se enfocan desde un paradigma rehabilitador, enfatizando "lo que les falta", la limitación o dificultad. Por otra parte, la mayoría de estudios pivotan sobre los genitales y las dificultades sexuales, sobre todo centradas en: la erección, la eyaculación y la reproducción.

La revisión de García Carenas(73) concluye que los varones son más estudiados en estas investigaciones, sobre todo en lo referente a la actividad sexual y satisfacción sexual y que en las mujeres los temas prioritarios de estudio son la fertilidad y la reproducción.

Parece que existe una concordancia entre la idea social sobre sexualidad, los objetivos de las investigaciones científicas y lo abordado en los servicios de rehabilitación tras una lesión medular. 


\section{Objetivos}




\section{Objetivos}

\subsection{Objetivos generales}

- Conocer el estado de la salud sexual de los hombres y mujeres con lesión medular traumática.

\subsection{Objetivos específicos}

- Conocer el registro en la historia clínica electrónica de aspectos relacionados con la sexualidad en personas con lesión medular traumática en el Principado de Asturias.

- Explorar las vivencias de la sexualidad en hombres y mujeres que presenten lesión medular traumática.

- Describir y analizar las dificultades y potencialidades en la interacción sexual tras la lesión medular traumática.

- Identificar los recursos adaptativos utilizados tras la lesión medular traumática.

- Identificar los agentes de información y consejería sobre la sexualidad y la lesión medular. 
Material y método 


\section{Material y método}

\subsection{Aspectos comunes a todas las fases de la investigación}

\subsection{1. Ámbito y población a estudio}

El estudio se ha realizado en el Principado de Asturias. El mapa sanitario asturiano se divide en 8 áreas de salud. En el área IV, Oviedo, se encuentra el Hospital Universitario Central de Asturias (HUCA), donde se aloja la Unidad de Lesionados Medulares, centro de referencia regional.

La población a estudio estuvo conformada por personas con lesión medular traumática ingresadas por cualquier causa en el HUCA en el período de 1 de enero de 2005 a 31 de diciembre de 2015.

\subsubsection{Fases para el desarrollo del estudio}

Para lograr los objetivos planteados, el estudio ha sido diseñado en tres fases diferenciadas:

- Primera fase: se realizó una revisión de las historias clínicas electrónicas (HCE), tanto de atención especializada como de atención primaria, con el fin de realizar un análisis epidemiológico de las personas con LMT, así como identificar las complicaciones secundarias, los apoyos existentes en torno a la lesión medular y el registro en la HCE sobre sexualidad.

- Segunda fase: se realizó mediante cuestionarios autoinformados a personas con LMT. Se realizó un análisis sobre la calidad de vida percibida, la salud sexual, las fuentes de información utilizadas, las necesidades percibidas de atención de la sexualidad desde el entorno sanitario y la valoración de la figura del asistente sexual.

- Tercera fase: a través de entrevistas en profundidad se analizaron las vivencias de las personas con LMT respecto a los cambios acontecidos en su sexualidad a raíz de la lesión. 
Para facilitar la lectura, se presentan por separado el método y los resultados de las tres partes.

\subsection{Fase I: Epidemiología de la lesión medular, complicaciones secundarias y apoyos en torno a la sexualidad.}

\subsubsection{Diseño y población a estudio}

Se ha realizado un estudio descriptivo, retrospectivo de corte transversal.

La población a estudio estuvo conformada por las personas con lesión medular traumática ingresadas en el HUCA por cualquier causa en el periodo del 1 de enero de 2005 al 31 de diciembre de 2015.

\subsubsection{Criterios de inclusión y exclusión}

Los criterios de inclusión utilizados fueron: tener como diagnóstico una lesión medular traumática y tener una edad comprendida entre los 18 y los 65 años.

No se ha considerado ningún criterio de exclusión.

\subsubsection{Variables a estudio}

Las variables a estudio fueron seleccionadas y definidas previamente a la recogida de datos.

\subsubsection{Variables sociodemográficas}

Se establecieron como variables sociodemográficas: el sexo, la edad, el estado civil, el número de hijos, el nivel de estudios, la ocupación previa a la lesión y la aportación farmacéutica según tarjeta sanitaria individual (TSI).

\subsubsection{Variables relacionadas con la lesión medular}

Como variables relacionadas con la lesión medular se establecieron: la etiología, la presencia de antecedentes en la salud mental, la edad al lesionarse, el tiempo de lesión, la estación del año en la que se produjo, el tipo de lesión según afectación de miembros, 
según extensión, y según nivel neurológico, nivel óseo, ASIA al alta, síndromes clínicos específicos y realización de intervención quirúrgica para estabilización de la lesión.

\subsubsection{Variables relacionadas con la hospitalización}

Como variables relacionadas con la hospitalización se establecieron: los ingresos en Unidad de Cuidados Intensivos (UCI), el tiempo de estancia: en $\mathrm{UCl}$, en unidad de hospitalización y el tiempo total de hospitalización, la derivación de otros hospitales de la región y la derivación a otros hospitales de referencia.

\subsubsection{Variables relacionadas con las complicaciones secundarias relacionadas con la lesión medular}

Las variables relativas a las complicaciones secundarias relacionadas con la LMT fueron: la presencia de úlceras por presión (UPP), las alteraciones urológicas, las alteraciones gastrointestinales, la presencia de dolor, la espasticidad muscular, la presencia de algún episodio de disreflexia autonómica, las complicaciones respiratorias, las alteraciones en la salud mental y las alteraciones de la marcha.

\subsubsection{Variables relacionadas con los apoyos tras la lesión medular}

Las variables relacionadas con los apoyos tras la lesión medular fueron: el uso de productos de apoyo, la utilización de ayudas para la movilidad personal y el asociacionismo relacionado con la lesión.

\subsubsection{Variables relacionadas con la atención a la sexualidad por parte de los profesionales}

Las variables relacionadas con el trato de la sexualidad por parte de los profesionales fueron la presencia o ausencia de algún registro sobre sexualidad en la HCE y los aspectos registrados por los profesionales cuando abordan la sexualidad.

\subsubsection{Fuentes de recogida de información}

Para la recogida de los datos se utilizó la HCE. En el HUCA se encuentra implantado el programa Millenium y en todas las áreas sanitarias del Principado de Asturias la "Oficina Médica Informatizada de Atención Primaria (OMI-AP)". Se accedió a las historias clínicas de atención primaria a través de la plataforma WOMI (Viewer OMI), que permite acceder a los datos desde cualquier centro de salud de la región. 
Se ha realizado una base de datos construida ad hoc donde se volcaron los datos extraídos de los diferentes registros.

\subsubsection{Procedimiento de recogida de los datos}

Para identificar a los pacientes, se solicitó un listado al servicio de codificación del HUCA de las personas con lesión medular traumática ingresadas por cualquier causa durante el periodo de estudio establecido.

\subsubsection{Análisis de los datos}

Se realizó un análisis descriptivo de cada variable, proporcionando las distribuciones absolutas y relativas para las variables cualitativas, y medidas de tendencia central tales como la media, mediana, mínimo, máximo o medidas de dispersión como la desviación típica en el caso de variables cuantitativas.

Las relaciones entre variables cualitativas se valoraron con el test Chi Cuadrado de Pearson o con el test de Fisher, según se verificase o no la hipótesis de frecuencias esperadas. Las diferencias entre las medias de las variables cuantitativas entre dos grupos se evaluaron a través del test $t$ de Student para muestras independientes, con la corrección de Welch ante la no igualdad de varianzas. Cuando los grupos eran 3 o más, se emplearon el test Anova o el test de Kruskal-Wallis ante el cumplimiento o no de la hipótesis de normalidad y homocedasticidad.

El nivel de significación empleado fue 0,05.

El análisis estadístico se efectuó mediante el programa R ( $R$ Development Core Team), versión 3.4.4 con el apoyo de la Unidad de Consultoría de los Servicios CientíficoTécnicos de la Universidad de Oviedo.

\subsection{Fase II: Calidad de vida, salud sexual, fuentes de información utilizadas y necesidades percibidas de atención de la sexualidad desde el entorno sanitario}

\subsubsection{Diseño y población a estudio}

Se realizó un estudio observacional, descriptivo y transversal. 
La población a estudio estuvo conformada por las personas con LMT pertenecientes a la muestra obtenida en los registros del HUCA. Con la intención de captar el mayor número posible de personas con LMT de Asturias y para completar la muestra obtenida a través del HUCA, se ha recurrido a la Asociación de Parapléjicos y Grandes Minusválidos del Principado de Asturias (Aspaym). Se ha realizado una comparación entre ambos grupos no existiendo diferencias estadísticamente significativas en ninguna de las variables sociodemográficas.

\subsubsection{Criterios de inclusión y exclusión}

Los criterios de inclusión y exclusión utilizados fueron los siguientes:

Criterios de inclusión:

- Diagnóstico de lesión medular traumática.

- Edad comprendida entre los 18 y 65 años.

Criterios de exclusión:

- Enfermedad mental grave que pudiera afectar a la cumplimentación del cuestionario.

\subsubsection{Variables a estudio}

Las variables incluidas fueron seleccionadas y definidas previamente a la recogida de datos, y fueron variables: sociodemográficas, relacionadas con la lesión, relacionadas con la calidad de vida, relacionadas con la sexualidad, relacionadas con las fuentes de información utilizadas, relacionadas con las necesidades sanitarias percibidas en relación a la sexualidad y relacionadas con la valoración de la figura del asistente sexual.

Se aporta una descripción más detallada de las mismas en el Anexo II.

\subsubsection{Variables sociodemográficas}

Las variables sociodemográficas estudiadas fueron: sexo, edad, estado civil, número de hijos, orientación sexual, núcleo de convivencia y nivel de estudios. 


\subsubsection{Variables relacionadas con la lesión medular}

Las variables relacionadas con la lesión fueron: causa de la lesión medular, tiempo de lesión, tipo de hospitales donde se produjo la primera atención, tipo de lesión según afectación de miembros, según extensión y según nivel neurológico, presencia de úlceras por presión, espasticidad muscular, dolor crónico asociado a la lesión, presencia de sensibilidad en el área genital y anal, método de vaciamiento vesical y método de vaciamiento intestinal.

\subsubsection{Variables relacionadas con la calidad de vida}

Las variables relacionadas con la calidad de vida fueron: satisfacción con la vida en general, satisfacción con la vida sexual, satisfacción con la relación en pareja, satisfacción con la vida familiar, satisfacción con la relación con amigos y conocidos, satisfacción con la vida de ocio, satisfacción con la situación laboral, satisfacción con la situación económica, dimensión sexual, dimensión social, dimensión económica y sumatorio de calidad de vida global. Estas variables se han explorado a través del “Cuestionario de valoración de Satisfacción con la vida" (LISAT-8).

\subsubsection{Variables relacionadas con la sexualidad}

Las variables relacionadas con la sexualidad se dividen en: comunes para ambos sexos, variables relacionadas con la sexualidad en hombres y variables relacionadas con la sexualidad en mujeres.

\subsection{Variables relacionadas con la sexualidad comunes para ambos sexos}

Las variables relacionadas con la sexualidad comunes para ambos sexos fueron: preocupación por el escape involuntario de orina durante las relaciones eróticas, preocupación por el escape involuntario de heces durante las relaciones eróticas, presencia de crisis de disreflexia autonómica durante las relaciones eróticas, uso de libros, películas o arte con contenido erótico, grado de placer o disfrute al pensar y fantasear acerca del sexo, grado de importancia de la vida erótica en las relaciones de pareja, frecuencia de obtención de orgasmo, grado de placer o disfrute obtenido durante el orgasmo, grado de placer o disfrute a lo largo de la relación erótica, percepción de la imagen corporal previa a la lesión, percepción de la imagen corporal 
en la actualidad, percepción sobre el cambio en la capacidad de seducción tras la lesión medular, cambios en la satisfacción con la vida erótica tras la lesión medular, percepción sobre el grado de satisfacción a la pareja, satisfacción sobre el deseo de procreación, uso de ayudas para tener hijos.

Se ha utilizado el cuestionario validado "Sexual interest and satisfaction scale" (SIS) para explorar: deseo sexual actual comparado con la situación previa a la lesión, importancia dada a la sexualidad en comparación con la situación previa a la lesión, satisfacción con las relaciones sexuales de pareja tras la lesión, satisfacción con las relaciones sexuales de pareja previas a la lesión, posibilidades y habilidades para satisfacer sexualmente a la pareja, posibilidades y habilidades para disfrutar de su propia sexualidad y sumatorio total.

\subsection{Variables relacionadas con la sexualidad en hombres}

Las variables relacionadas con la sexualidad incluidas para los hombres fueron: uso de ayudas para conseguir o mantener la erección, frecuencia de capacidad de eyacular cuando se encuentra muy excitado y uso de ayudas para facilitar la eyaculación.

Se ha utilizado el cuestionario validado "Sexual Health Inventory for men" (IIEF-5) para explorar: confianza en poder tener y mantener una erección, frecuencia de erecciones con dureza suficiente para la penetración, frecuencia de mantenimiento de erección tras la penetración, dificultad en mantenimiento de erección hasta el final del acto sexual, frecuencia de relaciones sexuales satisfactorias, todo ello referido a los últimos 6 meses, sumatorio de IIEF-5 y grado de disfunción eréctil.

\subsection{Variables relacionadas con la sexualidad en mujeres}

Las variables relacionadas con la sexualidad en las mujeres fueron: grado de excitabilidad, frecuencia en consecución de excitación y pérdida posterior de interés, frecuencia de lubricación vaginal satisfactoria durante las relaciones sexuales y uso de ayudas para la lubricación vaginal. 


\subsubsection{Variable relacionada con las fuentes de información utilizadas}

La variable relacionada con este apartado es los medios de obtención de la información sobre sexualidad tras la lesión medular.

\subsubsection{Variables relacionadas con las necesidades sanitarias percibidas en relación a la sexualidad}

Las variables relacionadas con las necesidades sanitarias percibidas en relación a la sexualidad fueron: percepción sobre la adecuación de información por parte del sistema de salud, temas sobre los que se ha informado sobre la sexualidad por parte de los profesionales de la salud y temas sobre los que se hubiera precisado información.

\subsubsection{Variables relacionadas con la valoración de la figura del asistente sexual.}

Las variables relacionadas con la valoración de la figura del asistente sexual fueron: opinión sobre la asistencia sexual entendida como un apoyo para poder acceder sexualmente al propio cuerpo o al de una pareja y opinión de la asistencia sexual entendida como alguien con quien mantener relaciones sexuales.

\subsubsection{Instrumentos de recogida de información}

Para decidir los instrumentos que se utilizarían para la recogida de información se ha recurrido a la realización de una profunda revisión bibliográfica, se han realizado consultas: a un catedrático de psicología experto en psicometría de la Universidad de Oviedo, a la junta directiva de la Asociación Estatal de Profesionales de Sexología (Aeps) y a un sexólogo experto en sexualidad y diversidad funcional, miembro de la única asociación española existente por el momento sobre este tema.

Para la medición de la salud sexual en hombres y mujeres con lesión medular traumática y su evaluación previa y posterior a la lesión se han utilizado los siguientes instrumentos:

- Cuestionario de Valoración de Satisfacción con la Vida (LISAT-8)

- Sexual Health Inventory for Men (SHIM o IIEF-5)

- Sexual Interest and Satisfaction Scale (SIS)

- Se ha completado con un cuestionario de elaboración propia 
Tras diseñar el cuestionario de elaboración propia, se ha realizado una revisión mediante el Método Delphi de consenso. Se solicitó la colaboración a siete expertos en el tema: una enfermera con amplia experiencia en sexualidad, dos enfermeras y sexólogas, una pedagoga y sexóloga, una filóloga y sexóloga, un psicólogo, sexólogo y experto en diversidad funcional y un sexólogo con lesión medular traumática. Su colaboración consistió en comprobar si las preguntas estaban redactadas de forma correcta e inteligible, si era necesario realizar alguna modificación en alguna de ellas, si alguna era redundante o si, por el contrario, era necesario la inclusión de alguna nueva. Si existían discrepancias en las opiniones, se planteó el realizar una segunda vuelta solo con las discrepancias para elegir entre las opciones planteadas por el grupo. Esta segunda vuelta no fue necesaria debido al consenso de las opiniones.

A continuación, se describen las características de los cuestionarios validados utilizados:

\subsubsection{Cuestionario de Valoración de Satisfacción con la Vida:LISAT-8(95-98):}

El cuestionario de Valoración de Satisfacción con la Vida es un cuestionario autoadministrado que consta de 8 ítems, los cuales se valoran con una escala tipo Likert con valores entre el 1 y el 6: 1-muy insatisfactoria, 2-insatisfactoria, 3-un poco insatisfactoria, 4-un poco satisfactoria, 5-satisfactoria y 6-muy satisfactoria. Los dominios medidos son la satisfacción con diferentes aspectos de la vida: vida en general, vida sexual, relación de pareja, vida familiar, relación con amigos y conocidos, vida de ocio, situación laboral y situación económica.

Estos ítems se agrupan en 3 dimensiones: satisfacción con la vida social (ítem 1, 4,5 y 6), satisfacción con la vida afectiva y sexual (ítems 2 y 3) y satisfacción con la vida laboral o económica (ítem 7 y 8). Se calcula una puntuación total como sumatorio de todos los ítems (rango entre 0 y 48).

Este cuestionario validado en población española, ha demostrado ser un buen instrumento para medir la satisfacción con la vida de personas y posee buenas condiciones psicométricas: el análisis de la curva ROC mostró una sensibilidad del 81,7\%, especificidad del 79,2\% y un índice Kappa de concordancia de 0,60. 


\subsubsection{Sexual Health Inventory for Men (SHIM o IIEF-5)}

Es una versión abreviada de 5 preguntas del Índice Internacional de Función Eréctil (IIEF) que se encuentra formado por 15 preguntas para diagnosticar la presencia y gravedad de disfunción eréctil. Esta versión abreviada consta de cuatro ítems que exploran el dominio de la función eréctil y un ítem que explora la satisfacción sexual. Cada ítem se valora del 1 al 5, por lo que el rango de resultados está entre 5 y 25. Según la puntuación total se clasifica la presencia y gravedad de la disfunción eréctil: de 5 a 7 , disfunción eréctil grave; de 8 a 11, disfunción eréctil moderada; de 12 a 16, disfunción eréctil de leve a moderada; de 17 a 21, disfunción eréctil leve y de 22 a 25, ausencia de disfunción eréctil(99-101).

Se ha utilizado el cuestionario en versión española. A pesar de no estar validado para población con lesión medular, se ha utilizado en numerosos estudios y los autores lo consideran adecuado para evaluar la respuesta sexual en hombres con lesión medular(65,102).

\subsubsection{Sexual interest and satisfaction scale (SIS)}

Cuestionario autoadministrado creado por Siösteen en 1990, es una de las pocas escalas específicas para el estudio de la sexualidad en personas con una lesión medular. Está compuesto por 6 ítems que miden el ajuste sexual antes y después de la lesión medular en dos dominios: interés y satisfacción. Estos ítems son valorados de 0 a 3 según una escala Likert: deseo sexual actual, importancia de la sexualidad, satisfacción general con sexualidad después de la lesión, satisfacción general con la sexualidad antes de la lesión, satisfacción personal y satisfacción al compañero(103,104).

Posee una buena consistencia interna (alfa de Cronbach=0,96). Sus propiedades psicométricas solo han sido informadas por un estudio, pero son de las escasas escalas desarrolladas para población con lesión medular adquirida(102). No ha sido validada para población española, por lo que se ha realizado la técnica de traducciónretrotraducción para poner utilizarla, debido a su especificidad para este tipo de población. 


\subsubsection{Procedimiento de recogida de datos}

Los cuestionarios se enviaron por correo postal a toda la población a estudio que cumplía los criterios de inclusión. Previo al envío, y tras la entrada en vigor de la Ley Orgánica 3/2018, de 5 de diciembre, de Protección de Datos Personales y Garantía de los Derechos Digitales, y tras la consulta a los Servicios Jurídicos del Servicio de Salud del Principado de Asturias (SESPA), se ha llamado a los profesionales sanitarios de atención primaria que habitualmente atienden a estas personas, para que se pusieran en contacto con ellos y recogiesen la autorización para el envío de los cuestionarios a su domicilio.

En la carta enviada se incluían: los cuestionarios comentados en el anterior punto (Anexo III y IV), una carta de presentación (Anexo V) donde se explicaban los objetivos del estudio, la voluntariedad de participar en el mismo y un contacto de correo electrónico y de teléfono por si necesitaban realizar alguna consulta o querían información adicional. Así mismo, se les ofrecía que, si estaban interesados en un informe con los resultados de la investigación, podían solicitarlo escribiendo al correo electrónico que se les facilitaba. Se adjuntaba un sobre prefranqueado para la devolución de las respuestas.

A las cuatro semanas de enviar la primera carta, se envió un recordatorio. Posteriormente, se comprobó a través de los datos sociodemográficos que no hubiese duplicidades de respuesta.

También se contactó con la Asociación Aspaym y se realizó un envío a los que tenían correo electrónico por esta vía y por correo postal a los que no tenían email.

Con el objeto de ampliar la muestra lo máximo posible y recabar el mayor número de realidades, se ha difundido el cuestionario a través de todas las asociaciones de Aspaym de España y también se difundió a otros contactos clave mediante la utilización de la herramienta Google Forms.

\subsubsection{Análisis de los datos}

Se realizó un análisis descriptivo proporcionando distribuciones de frecuencias relativas y absolutas para variables cualitativas, y medidas de posición y dispersión para las cuantitativas. 
Las relaciones entre variables cualitativas se valoraron con el test Chi Cuadrado de Pearson y el test de Fisher, según se verificase o no la hipótesis sobre frecuencias esperadas. Cuando se comparan variables cuantitativas entre dos grupos se empleó el test t de Student para muestras independientes si se verificó la hipótesis de normalidad y el test de Wilcoxon en el caso contrario.

Cuando los grupos a comparar eran 3 o más, se empleó el test de Kruskal-Wallis.

El nivel de significación empleado fue de 0,05.

El análisis estadístico se efectuó con la ayuda de la Unidad de Consultoría Estadística de la Universidad de Oviedo. Como apoyo se utilizó el programa R, versión 3.6.0.

\subsection{Fase III: Vivencias percibidas en personas con lesión medular traumática respecto a los cambios acontecidos en la sexualidad a raíz de la lesión medular}

\subsubsection{Diseño y población a estudio}

Se ha realizado un estudio cualitativo, mediante el método de la Teoría Fundamentada (Ground Theory). Esta teoría fue desarrollada por Glasser y Strauss(105) y está basada en el interaccionismo simbólico.

En la investigación participaron personas con lesión medular traumática.

\subsubsection{Instrumento de recogida de información}

Para recoger la información se ha utilizado la entrevista en profundidad. Se realizaron entrevistas no estructuradas o conversacionales en las que se plantearon las siguientes líneas a abordar:

- Cambios en la sexualidad a raíz de la lesión medular

- Dificultades y potencialidades en la interacción sexual

- Abordaje de la sexualidad desde el sistema sanitario

- Recursos adaptativos utilizados 


\subsubsection{Procedimiento de recogida de los datos}

El muestreo ha sido intencional o muestreo por conveniencia. El acceso a los participantes se realizó a través de la asociación Aspaym.

En primer lugar, se establecieron las características que debía tener la muestra a entrevistar: representación de ambos sexos, pertenencia a diferentes franjas etarias, personas con pareja estable y sin pareja estable en la actualidad, con LMT reciente y antigua (menor de 5 años y superior a 15 años), con diferentes causas de la LMT y con LMT a distintos niveles.

A pesar de que en la fase I del estudio, hubiera un grupo significativo de pacientes cuya etiología de la LMT fue el intento autolítico, no se ha considerado oportuno incluir esa variable para las entrevistas en profundidad, debido a que el $100 \%$ de los mismos tenían antecedentes de salud mental. Esto abre una línea de investigación sobre la relación entre prevención del suicidio y la prevención de lesión medular traumática.

Posteriormente, se recurrió a informantes claves conocedores de las características de las personas con LMT, profesionales y técnicos que trabajan en Aspaym y su junta directiva. Ya se les había informado del proyecto y se les informó de las características buscadas para los sujetos a entrevistar.

En las entrevistas se dio libertad para que su pareja estuviera o no presente durante la misma.

El protocolo utilizado fue el siguiente:

Tras un primer contacto, la investigadora principal se ponía en contacto telefónico con los participantes propuestos, con aquellos que aceptaban participar se acordaba fecha, hora y lugar, adaptándose a las condiciones del entrevistado.

Previo al inicio de la entrevista, el entrevistador se presentaba (indicando formación, experiencia, lugar de trabajo y aportando un teléfono y mail de contacto a los entrevistados), explicaba el marco de la investigación, los objetivos y el tema que se quería abordar, la voluntariedad de la entrevista y la posibilidad de terminarla en cualquier momento si la persona entrevistada así lo decidía, sin necesidad de justificar la decisión. Se explicaba que la entrevista iba a ser grabada en audio pero que en el 
procesamiento y uso de la información se garantizaba el anonimato y la confidencialidad. También se le ofrecía que, si era de su interés, al finalizar la investigación se le podía enviar un resumen de la misma.

Se procuró que el ambiente establecido fuese amable y cómodo para facilitar la expresión en libertad.

Tras la presentación y explicación del objetivo del estudio se les solicitaba información sobre su lesión medular: edad a la que fue producida, causa, edad actual y tipo de lesión. Se iniciaba la entrevista con una pregunta abierta general del tipo: ¿Qué cambios se han producido en tu sexualidad a raíz de la lesión medular? Posteriormente, si no salían espontáneamente, se lanzaban preguntas abiertas para presentar las líneas de profundización ya expuestas.

Tras cada entrevista y tras asignárseles un código, estas fueron transcritas de forma literal, incluyendo el discurso y anotaciones sobre la comunicación no verbal. Se han transcrito asimismo elementos paralingüísticos. Se ha anonimizado cualquier referencia que pudiera identificar a otras personas con lesión medular o profesionales.

Se realizaron entrevistas hasta que se produjo la saturación de la información. No fue precisa la repetición de ninguna entrevista para ahondar en la información.

\subsubsection{Análisis de los datos}

El análisis de los datos se realizó siguiendo el esquema analítico de la Teoría Fundamentada (Grounded Theory).

El análisis se fue realizando desde el inicio de forma simultánea a la recogida de datos, realizando un análisis espiral como simboliza Creswell(106), volviendo atrás de los últimos datos a los primeros, de forma que, en las siguientes entrevistas se pudieran abordar temas surgidos en las anteriores.

Posteriormente, se analizó el discurso de cada entrevista observando las categorías conceptuales emergentes y en su caso las subcategorías, codificando en cada una de ellas los segmentos significativos que fueron apareciendo, estableciéndose posteriormente relaciones entre ellas. 
Al final del análisis se han realizado unos mapas conceptuales para visualizar de forma gráfica los principales conceptos y sus conexiones.

Para la organización de la información y como ayuda al análisis de los datos se ha utilizado el programa informático MAXQDA versión 2018.

Para la presentación del presente informe se han utilizado los criterios consolidados para la presentación de investigación cualitativa (COREQ)(107).

\subsection{Aspectos éticos y legales}

\subsubsection{Confidencialidad de los datos y permisos de los responsables}

Se cuenta con la aprobación del Comité de Ética de la Investigación del Principado de Asturias (Anexo VI) y de la Directora de Enfermería del Área IV (Oviedo) por delegación del Gerente a quien se le había solicitado (Anexo VII).

Los datos obtenidos fueron tratados confidencialmente conforme a lo que establece la Ley Orgánica 157/1999 de 13 de Diciembre de Protección de Datos de Carácter Personal y posteriormente según la Ley Orgánica 3/2018, de 5 de diciembre, de Protección de Datos Personales y Garantías de los Derechos Digitales que entró en vigor a lo largo de la elaboración de la investigación. Para ello, los listados de pacientes, datos de historias clínicas y entrevistas han sido codificados, disgregando los datos investigados de la identidad de las personas. Los listados han estado custodiados exclusivamente por la doctoranda en un soporte electrónico no conectado a la red de Internet.

Dada la naturaleza de las bases de datos generadas en el estudio, que en ningún caso son nominales, no fue necesaria su inscripción en el registro oficial de bases de datos.

\subsubsection{Consentimiento informado}

En la Fase I del estudio, fue suficiente el permiso de la Gerencia del HUCA ya que se realizó con anterioridad a la promulgación de la Ley Orgánica 3/2018, de 5 de Diciembre, de Protección de Datos Personales y Garantía de los Derechos Digitales, por lo que no fue necesario solicitar permiso a los titulares de las HCE para su revisión.

En la Fase II del estudio se les solicitó autorización por vía telefónica a través de sus médicos o enfermeras de atención primaria para realizar el envío de los cuestionarios a 
su domicilio por correo postal. Posteriormente, se les facilitó a través de una carta de presentación enviada junto con los cuestionarios, la información sobre la finalidad del estudio y el carácter voluntario de la participación. Así mismo, se les proporcionó un correo electrónico y un teléfono de contacto, por si precisaban aclarar o comentar cualquier aspecto de la investigación. Para esta fase no fue preciso el consentimiento informado, ya que se produjo un consentimiento explícito recogido en su HCE para el envío de los cuestionarios a su domicilio y la contestación y reenvío de los mismos fue voluntaria.

En la Fase III del estudio, al comienzo de las entrevistas en profundidad, se explicitó verbalmente toda la información necesaria relativa a las características de la entrevista, la solicitud de su consentimiento y la aceptación de que la entrevista fuese grabada. Todo ello quedó registrado al inicio de cada grabación.

\subsubsection{Otras consideraciones éticas}

Se han tomado las medidas necesarias para minimizar los posibles perjuicios que se hayan podido originar de la participación en el estudio, tanto en cuanto a desplazamientos y horarios de los encuentros, como a cuidados de personas que pudiesen tener a su cargo u otros.

La información obtenida con la investigación se hará revertir de forma adecuada y adaptada tanto en los participantes de la misma, como en la asociación Aspaym, como en la gerencia del HUCA para poder establecer medidas que ayuden a mejorar los servicios ofertados a este colectivo. Así mismo, será publicada en los medios de comunicación oportunos para compartir los resultados con toda la comunidad científica.

No existen conflictos de interés en la realización de la investigación.

El estudio no ha sido financiado por ninguna entidad que pudiese condicionar la objetividad e independencia del mismo, solamente ha obtenido financiación a través de la beca otorgada por la Cátedra de Enfermería Familiar y Comunitaria (Anexo VIII). 


\section{$\underline{\text { Resultados }}$}




\section{Resultados}

\subsection{Fase I: Resultados sobre epidemiología de la lesión medular, complicaciones secundarias y apoyos en torno a la sexualidad}

El servicio de codificación del HUCA aportó un total de 137 registros, tras aplicar los criterios de inclusión, el número de casos fue de 92.

\subsubsection{Características sociodemográficas}

\subsubsection{Sexo y edad}

El $76,9 \%$ eran hombres $(n=70)$ y el $23,1 \%(n=21)$ mujeres. Hay un valor perdido en esta variable.

La edad media a 1 de enero de 2018 fue de 48,49 años, con una desviación estándar (DE) de 11,04, siendo la mediana de 50 años.

\subsubsection{Estado civil y número de hijos}

El estado civil se encuentra registrado en el 58,7\% ( $n=54)$ de las HCE. El 57,4\% ( $n=31)$ se encuentra casado o en pareja, el $29,6 \%(n=16)$ soltero y el $13 \%(n=7)$ separado o divorciado.

El número de hijos se encuentra registrado en $44,6 \%(n=41)$ de las HCE. Dentro de este valor, el 39\% ( $n=16)$ no tiene hijos, el 41,5\% ( $n=17)$ tiene 1 hijo, el 14,6\% ( $n=6)$ tiene dos hijos y el $4,9 \%(n=2)$ tiene 3 hijos.

\subsubsection{Nivel de estudios y ocupación previa a la lesión}

El nivel de estudios se encuentra registrado en el $14,1 \%(n=13)$ de las HCE. El 76,9\% $(n=10)$ tiene estudios universitarios, el $15,4 \%(n=2)$ estudios básicos y el $7.7 \%(n=1)$ estudios secundarios.

Los resultados sobre la ocupación previa a la lesión pueden verse en la Tabla 9. En 24 casos $(26,1 \%)$ no había registro sobre la ocupación en la HCE. 
Tabla 9: distribución sobre la ocupación previa a la lesión medular

\begin{tabular}{lcc}
\hline Ocupación previa & $\mathbf{n}$ & $\mathbf{\%}$ \\
\hline Trabajador & 52 & 76,5 \\
\hline Jubilado & 7 & 10,3 \\
\hline Estudiante & 6 & 8,8 \\
\hline Desempleado & 2 & 2,9 \\
\hline Labores del hogar & 1 & 1,5 \\
\hline Total & 24 & 100 \\
\hline
\end{tabular}

\subsubsection{Aportación farmacéutica según tarjeta sanitaria individual}

Los resultados de la aportación farmacéutica según TSI, basados en la renta anual percibida se muestran en la tabla 10. En el $16,3 \%(n=15)$ casos no estaba registrada la TSI en la HCE.

Tabla 10: aportación farmacéutica según TSI

\begin{tabular}{lcc}
\hline TSI & $\mathbf{n}$ & $\mathbf{\%}$ \\
\hline $\mathbf{1}$ (exentos de aportación) & 9 & 11,7 \\
\hline $\mathbf{2}$ (aportación del $\mathbf{1 0 \% )}$ & 59 & 76,6 \\
\hline $\mathbf{3}$ (aportación del $\mathbf{4 0 \% )}$ & 5 & 6,5 \\
\hline $\mathbf{4}$ (aportación del $\mathbf{5 0} \%)$ & 1 & 1,3 \\
\hline $\mathbf{5}$ (aportación del $\mathbf{6 0 \% )}$ & 0 & 0,0 \\
\hline $\mathbf{6}$ (pertenecientes a mutualidades, aportación $\mathbf{3 0 \% )}$ & 3 & 3,9 \\
\hline Total & $\mathbf{7 7}$ & 100 \\
\hline
\end{tabular}

\subsubsection{Resultados relacionados con la lesión medular}

\subsubsection{Causa de la lesión medular}

En la tabla 11 se puede observar la etiología de la lesión. Los accidentes de tráfico (agrupando accidentes de coche, moto y otros) son la causa más frecuente con un $30,3 \%$ $(n=27)$, seguidos de los accidentes laborales con un $25,9 \%(n=23)$ y los accidentes fortuitos con un $20,2 \%(n=18)$. Hay 5 casos perdidos en esta variable. 
Tabla 11: causa de la lesión medular

\begin{tabular}{lcc}
\hline Etiología & $\mathbf{n}$ & $\mathbf{\%}$ \\
\hline Laboral & 23 & 25,9 \\
\hline Fortuitos & 18 & 20,2 \\
\hline Tráfico coche & 17 & 19,1 \\
\hline Intento autolisis & 10 & 11,2 \\
\hline Tráfico moto & 9 & 10,1 \\
\hline Deportivos & 5 & 5,7 \\
\hline Zambullida & 3 & 3,4 \\
\hline Agresión & 1 & 1,1 \\
\hline Otros tráficos & 1 & 1,1 \\
\hline Traumatismo directo & 1 & 1,1 \\
\hline Desconocido & 1 & 1,1 \\
\hline Total & 89 & 100 \\
\hline
\end{tabular}

\subsubsection{Presencia de antecedentes en la salud mental}

El $25,8 \%(n=23)$ presentaba antecedentes previos a la lesión de alteraciones en la salud mental: el 6,7\% $(n=6)$ presentaba un trastorno ansioso-depresivo, un 6,7\% $(n=6)$ un trastorno de la personalidad, un 5,6\% ( $n=5)$ adicción a drogas, el 3,4\% (n=3) esquizofrenia, el 1,1\% $(n=1)$ trastorno bipolar, el 1,1\% $(n=1)$ enolismo crónico y el 1,1\% $(n=1)$ otras enfermedades mentales. Hay un total de 3 casos perdidos en esta variable.

4.1.2.2.1. Relación entre etiología de la lesión medular y presencia de antecedentes en la salud mental

Existe una relación estadísticamente significativa ( $p$ valor $<0,001)$ entre la causa de la lesión y los antecedentes de salud mental. Se observa que ninguno de los lesionados por accidente deportivo o laboral tenían antecedentes en la salud mental, tampoco los tenían el $76 \%$ de los lesionados en accidente de tráfico y el $73,7 \%$ de los de causa fortuita. Sin embargo, tenían antecedentes de salud mental todos los lesionados por intento autolítico.

\subsubsection{Edad al lesionarse y tiempo de lesión}

Los datos sobre la edad al lesionarse y el tiempo de lesión en meses vienen resumidas en la tabla 12. 
Tabla 12: datos sobre la edad al lesionarse (en años) y el tiempo de lesión (en meses)

\begin{tabular}{lccccccccc}
\hline & & & & \multicolumn{5}{c}{ Percentiles } \\
\cline { 6 - 10 } & $\mathbf{n}$ & Media & $\mathbf{D T}$ & $\mathbf{0}$ & $\mathbf{2 5}$ & $\mathbf{5 0}$ & $\mathbf{7 5}$ & $\mathbf{1 0 0}$ \\
\hline Edad al lesionarse & 89 & 40,2 & 12,1 & 0 & 31 & 41 & 48 & 61 \\
\hline Tiempo con lesión & 89 & 109 & 160 & 0 & 50 & 76 & 122 & 1412 \\
\hline
\end{tabular}

\subsubsection{Estación del año en la que se produjo la lesión medular}

Un $33,7 \%(n=31)$ de las lesiones fueron producidas en verano, un $23,9 \%(n=22)$ en invierno, un $21,7 \%(n=20)$ en otoño y un $17,4 \%(n=16)$ en primavera. Hay 3 casos perdidos en esta variable.

No se han encontrado diferencias estadísticamente significativas que relacionen la causa de la lesión con la estación del año en la que se produjo.

\subsubsection{Tipo de lesión}

\subsection{Según afectación de miembros}

La distribución del tipo de lesión según afectación de miembros se desglosa en el gráfico 1. En 14 casos no había registro en la HCE sobre el tipo de lesión según afectación miembros.

Gráfico 1: distribución del tipo de lesión medular según afectación de miembros

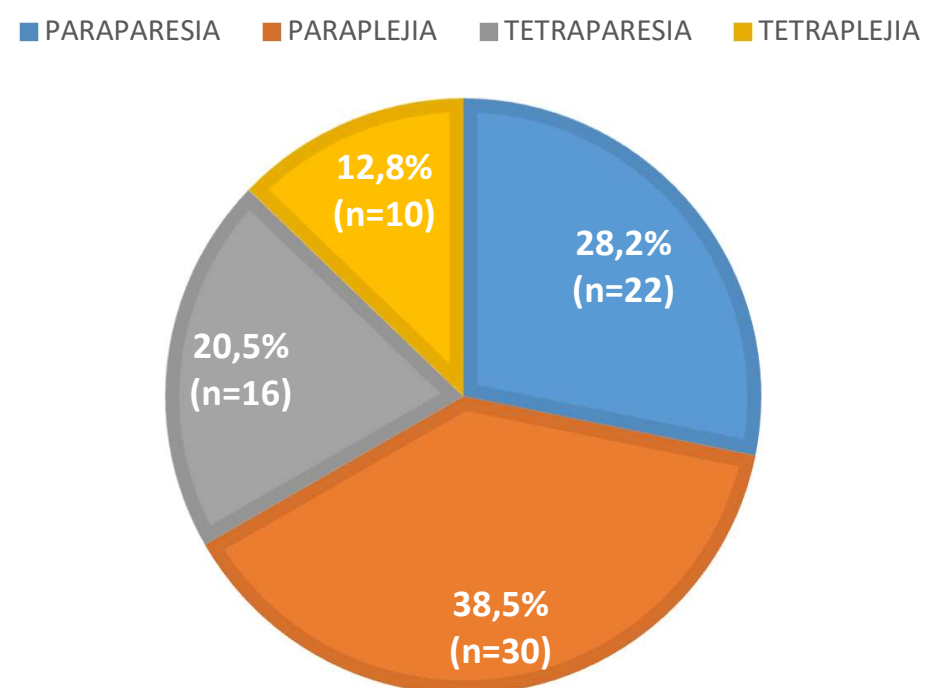




\subsection{Según extensión}

En la distribución del tipo de lesión según la extensión se obtiene que el 52,6\% ( $n=41)$ posee una lesión completa. En 14 casos no se obtiene este dato en la HCE.

\subsection{Según nivel neurológico}

La distribución de frecuencias según el nivel neurológico viene recogida en la tabla 13. Hay un total de 6 casos perdidos en esta variable.

Tabla 13: distribución del tipo de lesión medular según el nivel neurológico

\begin{tabular}{lcc}
\hline Nivel neurológico & $\mathbf{n}$ & $\mathbf{\%}$ \\
\hline Cervical & 26 & 30,2 \\
\hline Dorsal & 39 & 45,4 \\
\hline Lumbar & 21 & 24,4 \\
\hline Total & 86 & 100 \\
\hline
\end{tabular}

\subsubsection{Nivel óseo}

Las lesiones más frecuentes se encuentran a nivel de la D12 (15,6\%), L1 (13,5\%) y C6 $(11,2 \%)$, seguidas ya con diferencia considerable por el resto como se puede observar en la tabla 14. Hay 3 casos perdidos para esta variable. 
Tabla 14: distribución de frecuencias según el nivel óseo de la lesión medular

\begin{tabular}{|c|c|c|c|c|}
\hline Zona & & Vértebra & $\mathbf{n}$ & $\%$ \\
\hline \multirow{7}{*}{ Cervical } & \multirow{7}{*}{$27(30,3 \%)$} & $\mathrm{C} 1$ & 1 & 1,1 \\
\hline & & $\mathrm{C2}$ & 0 & 0,0 \\
\hline & & C3 & 3 & 3,4 \\
\hline & & C4 & 5 & 5,6 \\
\hline & & C5 & 7 & 7,9 \\
\hline & & $\mathrm{C} 6$ & 10 & 11,2 \\
\hline & & C7 & 1 & 1,1 \\
\hline \multirow{12}{*}{ Dorsal } & \multirow{12}{*}{$42(47,2 \%)$} & D1 & 0 & 0,0 \\
\hline & & D2 & 0 & 0,0 \\
\hline & & D3 & 1 & 1,1 \\
\hline & & D4 & 4 & 4,5 \\
\hline & & D5 & 7 & 7,9 \\
\hline & & D6 & 5 & 5,6 \\
\hline & & D7 & 2 & 2,3 \\
\hline & & D8 & 2 & 2,3 \\
\hline & & D9 & 2 & 2,3 \\
\hline & & D10 & 2 & 2,3 \\
\hline & & D11 & 3 & 3,4 \\
\hline & & D12 & 14 & 15,6 \\
\hline \multirow{6}{*}{ Lumbar } & \multirow{6}{*}{$20(22,5 \%)$} & L1 & 12 & 13,5 \\
\hline & & L2 & 4 & 4,5 \\
\hline & & L3 & 2 & 2,2 \\
\hline & & L4 & 1 & 1,1 \\
\hline & & L5 & 1 & 1,1 \\
\hline & & Total & 89 & 100 \\
\hline
\end{tabular}

\subsubsection{7. $\quad$ ASIA al alta}

La distribución de frecuencias del ASIA al alta se detalla en el gráfico 2. En un total de 23 HCE no se encuentra reflejado este dato. 
Gráfico 2: distribución del tipo de lesión medular según ASIA al alta

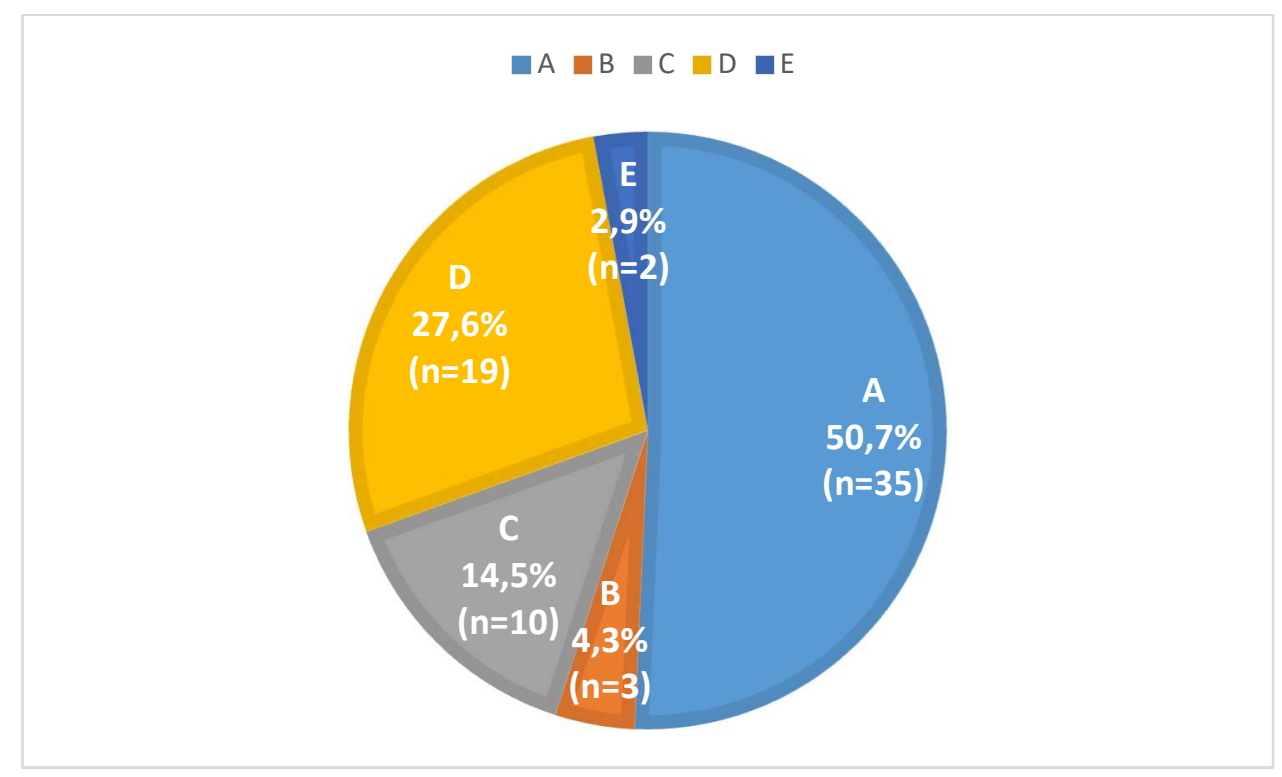

\subsubsection{Síndromes clínicos específicos}

Un $74,3 \%$ de los lesionados no presentan ningún síndrome clínico asociado. La distribución se observa en la tabla 15. Hay una pérdida de 14 casos en esta variable.

Tabla 15: distribución de la lesión medular según síndromes clínicos específicos

\begin{tabular}{lcc}
\hline Síndromes clínicos & $\mathbf{n}$ & $\mathbf{\%}$ \\
\hline Síndrome de Brown-Séquard & 8 & 10,3 \\
\hline Síndrome centro medular & 6 & 7,7 \\
\hline Síndrome de cola caballo & 2 & 2,6 \\
\hline Síndrome de cono medular & 4 & 5,1 \\
\hline No Síndrome & 58 & 74,3 \\
\hline Total & 78 & 100 \\
\hline
\end{tabular}

\subsubsection{Intervención quirúrgica}

El $81,6 \%(n=71)$ fue sometido a una intervención quirúrgica para estabilización de su lesión. 


\subsubsection{Variables relacionadas con la hospitalización}

\subsubsection{Proporción de ingresados en $\mathrm{UCl}$ y duración de la estancia hospitalaria}

Respecto a la estancia hospitalaria, el $62,5 \%(n=57)$ ha precisado ingreso en la UCl. Los distintos tiempos de estancia vienen detallados en la tabla 16.

Tabla 16: tiempo de estancia en días en $\mathrm{UCl}$, unidad de hospitalización y tiempo total de hospitalización

\begin{tabular}{lccccccccc}
\hline & & & & \multicolumn{5}{c}{ Percentiles } \\
\cline { 6 - 10 } & $\mathbf{n}$ & Media & DT & $\mathbf{0}$ & $\mathbf{2 5}$ & $\mathbf{5 0}$ & $\mathbf{7 5}$ & $\mathbf{1 0 0}$ \\
\hline Tiempo en UCl & 92 & 12,1 & 21,9 & 0 & 0 & 3 & 12 & 147 \\
\hline Tiempo en planta & 92 & 93,8 & 81,8 & 0 & 22,3 & 75 & 149,5 & 312 \\
\hline Tiempo de hospitalización & 92 & 106 & 83,4 & 0 & 38,3 & 88 & 161,5 & 314 \\
\hline
\end{tabular}

\subsubsection{Derivación de otro hospital de la región}

El $58,6 \%$ ha sido atendido de forma directa en el HUCA sin ser derivado de otros hospitales. El 41,4\% ha sido derivado de otros hospitales de la región, su distribución se encuentra detallada en el gráfico 3:

Gráfico 3: distribución de la derivación de otros hospitales al HUCA

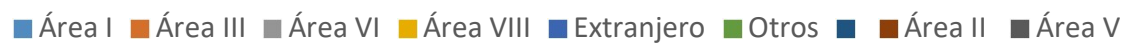

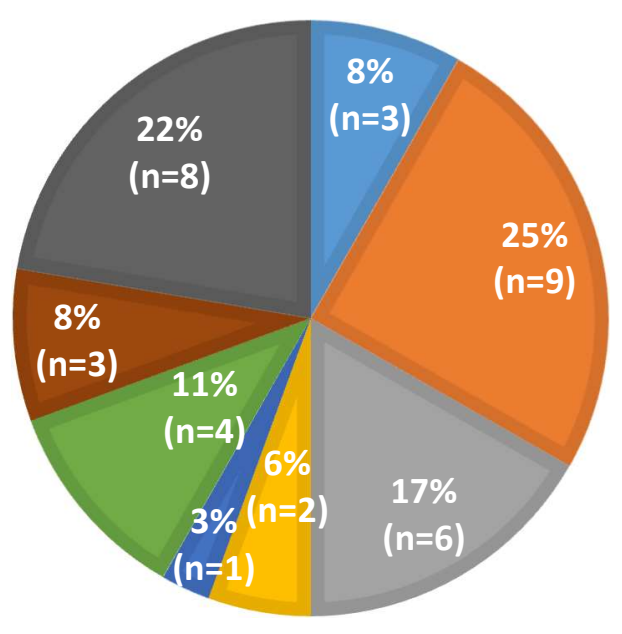




\subsubsection{Derivación a otro hospital de referencia}

El $38,7 \%(n=33)$ ha sido derivado a otros hospitales en el primer ingreso para completar el tratamiento. La distribución de hospitales de derivación se muestra en la tabla 17. Se produce una pérdida de 6 casos en esta variable.

Tabla 17: hospitales de derivación

\begin{tabular}{lcc}
\hline Hospitales de derivación & $\mathbf{n}$ & $\mathbf{\%}$ \\
\hline Hospital Nacional de Parapléjicos de Toledo & 20 & 23,3 \\
\hline Institut Guttman & 2 & 2,3 \\
\hline Hospital de origen & 2 & 2,3 \\
\hline Mutuas & 2 & 2,3 \\
\hline Otros & 7 & 8,2 \\
\hline No derivación & 53 & 61,6 \\
\hline Total & 86 & 100 \\
\hline
\end{tabular}

\subsubsection{Complicaciones secundarias derivadas de la lesión medular}

\subsubsection{1. Úlceras por presión}

En el $43,4 \%(n=39)$ de las HCE consta la presencia de UPP, de las cuales el $26,2 \%(n=22)$ fueron en múltiples zonas del cuerpo, un $7,1 \%(n=6)$ eran úlceras sacras, un $3,6 \%(n=3)$ en los dedos del pie, un $2,4 \%(n=2)$ en los talones, un $1,2 \%$ en el isquion $(n=1)$ y un $1,2 \%$ en el trocánter $(n=1)$.

\subsubsection{Complicaciones urológicas}

Dentro de las complicaciones urológicas, en un $68,7 \%(n=57)$ consta la presencia de vejiga neurógena, de los cuales el 31,3 \% $(n=26)$ presentó esta afección sumada a infecciones del tracto urinario (ITUS) de repetición. Un 2,4\% ( $n=2)$ presentó ITUS de repetición sin vejiga neurógena. El 4,8\% $(n=4)$ presentó urgencia miccional y el 2,4\% $(n=2)$ incontinencia urinaria.

\subsubsection{Complicaciones gastrointestinales}

Respecto a las complicaciones gastrointestinales, se obtiene el registro de que el $60,2 \%$ $(n=50)$ presentó intestino neurógeno, un 8,4\% ( $n=7)$ estreñimiento, un $1,2 \%(n=1)$ incontinencia fecal y un $1,2 \%(n=1)$ incontinencia a gases. 


\subsubsection{Presencia de dolor}

En el 30,1\% ( $n=25)$ consta la presencia de dolor neuropático, en el 19,3\% ( $n=16)$ de dolor nociceptivo y en el $13,3 \%(n=11)$ de ambas afecciones.

\subsubsection{Presencia de espasticidad muscular}

En el $46,4 \%(n=39)$ consta la presencia de espasticidad muscular como complicación secundaria.

\subsubsection{Crisis de disreflexia autonómica}

El 3,6\% (n=3) presentó alguna crisis de disreflexia autonómica.

\subsubsection{Complicaciones respiratorias}

En cuanto a las complicaciones respiratorias un $10,7 \%(n=9)$ presentó complicaciones respiratorias.

\subsubsection{Alteraciones de la salud mental}

Respecto a las complicaciones en la salud mental tras la lesión medular: el 30,1\% ( $n=25)$ ha sufrido síndrome ansioso-depresivo, un 3,6\% $(n=3)$ un intento autolítico posterior a la lesión, un 1,2\% ( $n=1)$ tiene insomnio, el $16,9 \%(n=14)$ tiene las enfermedades mentales que tenía previas a la lesión, y un 2,4\% $(n=2)$ tiene otras enfermedades de la esfera mental. Un 45,8\% ( $n=47)$ no presenta complicaciones en la salud mental. En un total de 9 HCE no aparecía ningún dato registrado sobre el estado de la salud mental.

\subsubsection{Alteraciones de la marcha}

En cuanto a las alteraciones de la marcha: un $58 \%(n=47)$ presenta imposibilidad para caminar, un 7,4\% ( $n=6)$ es capaz de caminar pequeños trayectos con apoyos, un $7,4 \%$ $(n=6)$ presenta marcha pareto-espástica y un 1,2\% $(n=1)$ marcha en steppage. El $25,9 \%$ $(n=21)$ presenta otras alteraciones en la marcha no definidas.

\subsubsection{Apoyos tras la lesión medular}

\subsubsection{Productos de apoyo}

Un $87,3 \%$ ( $n=69$ ) utiliza productos de apoyo en su vida cotidiana.

Si nos centramos en las ayudas para la movilidad personal, un $59,3 \%(n=48)$ se desplaza en silla de ruedas, un $28,4 \%(n=23)$ con muletas o bastón inglés, un 3,7\% ( $n=3)$ con otras ayudas y un $8,6 \%(n=7)$ no precisa ayudas para el desplazamiento. En un total de 12 
historias no se encuentra registrado ningún dato sobre el uso de ayudas al desplazamiento.

\subsubsection{Asociacionismo}

En un $16,3 \%$ de las historias aparece reflejada la pertenencia o no a una asociación. Dentro de este porcentaje, el 73,3\% $(n=11)$ pertenece a Aspaym, el 6,7\% $(n=1)$ a la Confederación Española de Personas con Discapacidad Física y Orgánica (Cocemfe) y el $20 \%(n=3)$ no pertenece a ninguna asociación.

\subsubsection{Análisis bivariante}

\subsubsection{Relación entre variables sociodemográficas y variables relacionadas con} la lesión medular

Según el nivel neurológico de la lesión, existe una diferencia de sexo: en hombres la lesión más frecuente es la dorsal con un $45,6 \%(n=31)$, seguida de la cervical con un $35,3 \%(n=24)$ y de la lumbar con un 19,1\% ( $n=13)$. En mujeres las lesiones más frecuentes son la dorsal y la lumbar con un $44,4 \%(n=8)$, seguidas de la cervical con un $11,1 \%(n=2)$. Existe una relación estadísticamente significativa entre el sexo y la altura de la lesión con una $p=0,045$.

No se encuentra relación estadísticamente significativa entre el estado civil, ni el número de hijos, ni la edad al lesionarse, ni el tiempo de lesión y las variables relacionadas con la lesión medular.

Se encuentra relación estadísticamente significativa entre la ocupación previa a la lesión y el grado de la lesión con un p valor=0,043; el 86,2\% ( $n=25)$ de las lesiones completas y el $63,6 \%(n=21)$ de las lesiones incompletas se dieron en trabajadores en activo. No se encuentra relación con el resto de variables relacionadas con la lesión.

\subsubsection{Relación entre variables relacionadas con la lesión medular y variables relacionadas con la hospitalización}

En la tabla 18 se muestran las principales relaciones entre los tiempos de hospitalización y los tipos de lesión: según afectación de miembros, según extensión y según nivel neurológico. 
Tabla 18: relación entre el tiempo en días de hospitalización en $\mathrm{UCl}$, en unidad de hospitalización y tiempo de hospitalización total y tipos de lesión medular

\begin{tabular}{|c|c|c|c|c|c|c|c|c|c|c|c|}
\hline \multirow[b]{2}{*}{ Lesión } & & \multicolumn{4}{|c|}{$\begin{array}{c}\text { Tiempo } \\
\text { hospitalización UCI }\end{array}$} & \multicolumn{3}{|c|}{$\begin{array}{l}\text { Tiempo en unidad } \\
\text { de hospitalización }\end{array}$} & \multicolumn{3}{|c|}{$\begin{array}{c}\text { Tiempo de } \\
\text { hospitalización total }\end{array}$} \\
\hline & & $\mathbf{n}$ & Media & DE & $\begin{array}{c}\mathbf{p} \\
\text { valor }\end{array}$ & Media & DE & $\begin{array}{c}\mathbf{p} \\
\text { valor }\end{array}$ & Media & DE & $\begin{array}{c}\mathbf{p} \\
\text { valor }\end{array}$ \\
\hline \multirow{4}{*}{$\begin{array}{l}\text { Según } \\
\text { afectación } \\
\text { miembros }\end{array}$} & Paraparesia & 22 & 9 & 13 & \multirow{4}{*}{0,368} & 132,1 & 84,3 & \multirow{4}{*}{$<0,001$} & 141,1 & 84,6 & \multirow{4}{*}{$<0,001$} \\
\hline & Paraplejia & 30 & 12 & 18,3 & & 133,9 & 78,6 & & 145,9 & 85,8 & \\
\hline & Tetraparesia & 16 & 7 & 15,7 & & 67,3 & 44,1 & & 74,3 & 44,5 & \\
\hline & Tetraplejia & 10 & 35,1 & 44,9 & & 13,7 & 21,4 & & 48,8 & 37,5 & \\
\hline \multirow{2}{*}{$\begin{array}{l}\text { Según } \\
\text { extensión }\end{array}$} & Completa & 37 & 18,3 & 29,3 & \multirow{2}{*}{0,094} & 110,9 & 85,9 & \multirow{2}{*}{0,714} & 129,2 & 86,1 & \multirow{2}{*}{0,392} \\
\hline & Incompleta & 41 & 9,2 & 14,5 & & 104,1 & 77,4 & & 113,3 & 77 & \\
\hline \multirow{3}{*}{$\begin{array}{l}\text { Según } \\
\text { nivel } \\
\text { neurológico }\end{array}$} & Cervical & 26 & 17,9 & 32,7 & \multirow{3}{*}{0,063} & 50 & 45,6 & \multirow{3}{*}{$<0,001$} & 67,9 & 42,8 & \multirow{3}{*}{$<0,001$} \\
\hline & Dorsal & 39 & 13,6 & 17,8 & & 149,2 & 73,7 & & 162,8 & 77,4 & \\
\hline & Lumbar & 21 & 5,4 & 10,9 & & 67,4 & 80,3 & & 72,8 & 78,9 & \\
\hline
\end{tabular}

\subsubsection{Relación entre variables sociodemográficas y complicaciones} secundarias

No existe una relación estadísticamente significativa entre el sexo y las complicaciones secundarias derivadas de la LMT.

Se encuentra relación estadísticamente significativa entre el estado civil y las complicaciones mentales derivadas de la $\operatorname{LMT}(p=0,045)$ : de las personas con una patología mental tras la LMT: el 63,3\% ( $n=19)$ estaban casadas, el 20\% ( $n=6)$ separadas o divorciadas y el $16,7 \%(n=5)$ solteras. De las personas sin patología mental posterior a la lesión: el 47,6\% ( $n=10)$ estaban casadas, el 47,6\% $(n=10)$ solteras y un $4,7 \%(n=1)$ separadas o divorciadas. No aparece relación estadísticamente significativa entre el estado civil y el resto de complicaciones secundarias.

La presencia de antecedentes mentales tiene una relación estadísticamente significativa con la presencia de UPP $(p=0,01)$ : de las personas con antecedentes en la esfera de la salud mental, el 70\% ( $n=14$ ) sufren UPP, de las personas sin antecedentes en esta esfera, un $37,1 \%(n=23)$ tienen UPP. También una relación entre la presencia previa de 
antecedentes mentales y tener complicaciones mentales posteriores a la lesión con un $p$ valor $<0,001$. No existe relación con el resto de complicaciones secundarias.

\subsubsection{Relación entre variables relacionadas con la lesión medular $y$ complicaciones secundarias}

En las tablas 19,20 y 21 , se presentan las relaciones más importantes entre las complicaciones secundarias a las LMT y el tipo de lesión según afectación de miembros, según extensión y según nivel neurológico. Puede observarse que la mayoría de las complicaciones secundarias tienen relación estadísticamente significativa con el tipo de lesión, tanto según la afectación de los miembros como con la extensión de la misma y con el nivel neurológico.

Tabla 19: complicaciones secundarias y tipo de lesión medular según afectación de miembros

\begin{tabular}{|c|c|c|c|c|c|c|c|}
\hline & & Paraparesia & Paraplejia & Tetraparesia & Tetraplejia & Total & p valor \\
\hline \multirow{2}{*}{ UPP } & Sí & $5(13,9 \%)$ & $24(66,7 \%)$ & $3(8,3 \%)$ & $4(11,1 \%)$ & $36(100 \%)$ & \multirow{2}{*}{$<0,001$} \\
\hline & No & $16(40 \%)$ & $6(15 \%)$ & $13(32,5 \%)$ & $5(12,5 \%)$ & $40(100 \%)$ & \\
\hline \multirow{2}{*}{$\begin{array}{l}\text { Complicaciones } \\
\text { urológicas }\end{array}$} & Sí & $17(26,6 \%)$ & $30(46,9 \%)$ & $9(14 \%)$ & $8(12,5 \%)$ & $64(100 \%)$ & \multirow{2}{*}{$<0,001$} \\
\hline & No & $4(36,4 \%)$ & $0(0 \%)$ & $7(63,6 \%)$ & $0(0 \%)$ & $11(100 \%)$ & \\
\hline \multirow{2}{*}{$\begin{array}{l}\text { Complicaciones } \\
\text { gastrointestinales }\end{array}$} & Sí & $14(24,6 \%)$ & $28(49,1 \%)$ & $7(12,3 \%)$ & $8(14 \%)$ & $57(100 \%)$ & \multirow{2}{*}{$<0,001$} \\
\hline & No & $7(38,9 \%)$ & $2(11,1 \%)$ & $9(50 \%)$ & $0(0 \%)$ & $18(100 \%)$ & \\
\hline \multirow{2}{*}{ Espasticidad } & Sí & $7(18 \%)$ & $19(48,7 \%)$ & $5(12,8 \%)$ & $8(20,5 \%)$ & $39(100 \%)$ & \multirow{2}{*}{0,007} \\
\hline & No & $14(37,9)$ & $11(29,7)$ & $11(29,7)$ & $1(2,7)$ & $37(100 \%)$ & \\
\hline \multirow{2}{*}{$\begin{array}{l}\text { Disreflexia } \\
\text { autonómica }\end{array}$} & Sí & $0(0 \%)$ & $0(0 \%)$ & $0(0 \%)$ & $3(100 \%)$ & $3(100 \%)$ & \multirow{2}{*}{0,001} \\
\hline & No & $21(29,2 \%)$ & $30(41,7 \%)$ & $16(22,2 \%)$ & $5(6,9 \%)$ & $45(100 \%)$ & \\
\hline \multirow{2}{*}{$\begin{array}{l}\text { Complicaciones } \\
\text { respiratorias }\end{array}$} & Sí & $0(0 \%)$ & $1(11,1 \%)$ & $3(33,3 \%)$ & $5(55,6 \%)$ & $9(100 \%)$ & \multirow{2}{*}{$<0,001$} \\
\hline & No & $21(31,3 \%)$ & $29(43,3 \%)$ & $13(19,4 \%)$ & $4(6 \%)$ & $67(100 \%)$ & \\
\hline
\end{tabular}


Tabla 20: complicaciones secundarias y tipo de lesión medular según extensión

\begin{tabular}{|c|c|c|c|c|c|}
\hline & & Completa & Incompleta & Total & $\mathrm{p}$ valor \\
\hline \multirow{2}{*}{ UPP } & Sí & $28(73,7 \%)$ & $10(26,3 \%)$ & 38 (100\%) & \multirow{2}{*}{$<0,001$} \\
\hline & No & $8(21 \%)$ & $30(79 \%)$ & 38 (100\%) & \\
\hline \multirow{2}{*}{$\begin{array}{l}\text { Complicaciones } \\
\text { urológicas }\end{array}$} & Sí & $36(58 \%)$ & $26(42 \%)$ & $62(100 \%)$ & \multirow{2}{*}{$<0,001$} \\
\hline & No & $0(0 \%)$ & $13(100 \%)$ & $13(100 \%)$ & \\
\hline \multirow{2}{*}{$\begin{array}{l}\text { Complicaciones } \\
\text { gastrointestinales }\end{array}$} & Sí & $34(61,8 \%)$ & $21(38,2 \%)$ & $55(100 \%)$ & \multirow{2}{*}{$<0,001$} \\
\hline & No & $2(10 \%)$ & $18(90 \%)$ & $20(100 \%)$ & \\
\hline \multirow{2}{*}{ Espasticidad } & Sí & $26(66,7 \%)$ & $13(33,3 \%)$ & $39(100 \%)$ & \multirow{2}{*}{0,001} \\
\hline & No & $10(27 \%)$ & $27(73 \%)$ & $37(100 \%)$ & \\
\hline
\end{tabular}

Tabla 21: complicaciones secundarias y tipo de lesión medular según nivel neurológico

\begin{tabular}{|c|c|c|c|c|c|c|}
\hline & & Cervical & Dorsal & Lumbar & Total & p valor \\
\hline \multirow{2}{*}{ UPP } & Sí & $7(18 \%)$ & $24(61,5 \%)$ & $8(20,5 \%)$ & $39(100 \%)$ & \multirow{2}{*}{0,032} \\
\hline & No & $18(43,9 \%)$ & $15(36,6 \%)$ & $8(19,5 \%)$ & $41(100 \%)$ & \\
\hline \multirow{2}{*}{$\begin{array}{l}\text { Complicaciones } \\
\text { urológicas }\end{array}$} & Sí & $18(28,1 \%)$ & $36(56,3 \%)$ & $10(15,6 \%)$ & $64(100 \%)$ & \multirow{2}{*}{0,014} \\
\hline & No & $6(40 \%)$ & $3(20 \%)$ & $6(40 \%)$ & $15(100 \%)$ & \\
\hline \multirow{2}{*}{ Espasticidad } & Sí & $13(33,3 \%)$ & $24(61,6 \%)$ & $2(5,1 \%)$ & 39 (100\%) & \multirow{2}{*}{0,004} \\
\hline & No & $12(29,3 \%)$ & $15(36,6 \%)$ & $14(34,1 \%)$ & $41(100 \%)$ & \\
\hline \multirow{2}{*}{$\begin{array}{l}\text { Disreflexia } \\
\text { autonómica }\end{array}$} & Sí & $3(100 \%)$ & $0(0 \%)$ & $0(0 \%)$ & $3(100 \%)$ & \multirow{2}{*}{0,032} \\
\hline & No & $21(27,6 \%)$ & $39(51,3 \%)$ & $16(21,1 \%)$ & 76 (100\%) & \\
\hline \multirow{2}{*}{$\begin{array}{l}\text { Complicaciones } \\
\text { respiratorias }\end{array}$} & Sí & $8(88,9 \%)$ & $1(11,1 \%)$ & $0(0 \%)$ & $9(100 \%)$ & \multirow{2}{*}{$<0,001$} \\
\hline & No & $17(23,9 \%)$ & $38(53,5 \%)$ & $16(22,6 \%)$ & 71 (100\%) & \\
\hline
\end{tabular}

\subsubsection{Relación entre variables sociodemográficas $y$ uso de productos de} apoyo.

La aportación farmacéutica según TSI se encuentra relacionada significativamente con el uso de productos de apoyo ( $p$ valor $<0,001$ ) y en concreto, con la utilización de ayudas para la movilidad personal ( $p$ valor $=0,019$ ).

En la tabla 22 y 23 respectivamente se muestran las relaciones entre la aportación farmacéutica y el uso de productos de apoyo, y la utilización de ayudas para la movilidad personal. 
Tabla 22: relación entre aportación farmacéutica y uso de productos de apoyo

\begin{tabular}{lcccccr}
\hline & \multicolumn{2}{c}{ No uso } & \multicolumn{2}{c}{ Sí uso } & Total & p valor \\
\hline & $\mathbf{n}$ & $\%$ & $\mathbf{n}$ & $\%$ & & \\
\cline { 1 - 6 } Exento & 1 & 14,3 & 6 & 85,7 & $7(100 \%)$ & \\
\cline { 1 - 6 } Pensionista & 2 & 3,6 & 54 & 96,4 & $56(100 \%)$ & $<0,001$ \\
\cline { 1 - 5 } En activo & 5 & 62,5 & 3 & 37,5 & $8(100 \%)$ & \\
\hline
\end{tabular}

Tabla 23: relación entre aportación farmacéutica y utilización de ayudas para la movilidad personal

\begin{tabular}{|c|c|c|c|c|c|c|c|c|}
\hline & \multicolumn{2}{|c|}{ Silla ruedas } & \multicolumn{2}{|c|}{ Otras ayudas } & \multicolumn{2}{|c|}{ No ayudas } & \multirow[t]{2}{*}{ Total } & \multirow[t]{2}{*}{$p$ valor } \\
\hline & $\mathbf{n}$ & $\%$ & $\mathbf{n}$ & $\%$ & $\mathrm{n}$ & $\%$ & & \\
\hline Exento & 5 & 71,4 & 1 & 14,3 & 1 & 14,3 & 7 (100\%) & \\
\hline Pensionista & 33 & 56,9 & 23 & 39,7 & 2 & 3,4 & $58(100 \%)$ & 0,019 \\
\hline En activo & 4 & 50 & 1 & 12,5 & 3 & 37,5 & $8(100 \%)$ & \\
\hline
\end{tabular}

\subsubsection{Relación entre variables relacionadas con la lesión medular y productos} de apoyo.

En la tabla 24 se muestran las relaciones entre el tipo de lesión según afectación de miembros y las alteraciones de la marcha y el uso de productos de apoyo. Puede observarse que el tipo de lesión medular tiene relación estadísticamente significativa con las alteraciones de la marcha, el uso de productos de apoyo y el uso de ayudas al desplazamiento.

Tabla 24: relaciones entre el tipo de lesión medular y las alteraciones de la marcha y la utilización de productos de apoyo

\begin{tabular}{|c|c|c|c|c|c|c|c|}
\hline & & Paraparesia & Paraplejia & Tetraparesia & Tetraplejia & Total & $\begin{array}{c}\mathbf{p} \\
\text { valor }\end{array}$ \\
\hline \multirow{3}{*}{$\begin{array}{l}\text { Alteraciones } \\
\text { marcha }\end{array}$} & $\begin{array}{l}\text { Trayectos } \\
\text { cortos }\end{array}$ & $3(50 \%)$ & $1(16,7 \%)$ & $2(33,3 \%)$ & $0(0 \%)$ & $6(100 \%)$ & \multirow{3}{*}{$<0,001$} \\
\hline & No Marcha & $6(13 \%)$ & $28(60,9 \%)$ & $2(4,4 \%)$ & $10(21,7 \%)$ & $46(100 \%)$ & \\
\hline & Otras & $11(47,8 \%)$ & $0(0 \%)$ & $12(52,2 \%)$ & $0(0 \%)$ & $23(100 \%)$ & \\
\hline \multirow{2}{*}{$\begin{array}{l}\text { Uso productos } \\
\text { apoyo }\end{array}$} & Sí & $15(23,4 \%)$ & $28(43,8 \%)$ & $13(20,3 \%)$ & $8(12,5 \%)$ & $64(100 \%)$ & \multirow{2}{*}{0,035} \\
\hline & No & $4(50 \%)$ & $0(0 \%)$ & $3(37,5 \%)$ & $1(12,5 \%)$ & $8(100 \%)$ & \\
\hline \multirow{3}{*}{$\begin{array}{l}\text { Uso ayudas } \\
\text { desplazamiento }\end{array}$} & Silla ruedas & $6(12,5 \%)$ & $29(60,4 \%)$ & $3(6,3 \%)$ & $10(20,8 \%)$ & $48(100 \%)$ & \multirow{3}{*}{$<0,001$} \\
\hline & No & $3(50 \%)$ & $0(0 \%)$ & $3(50 \%)$ & $0(0 \%)$ & $6(100 \%)$ & \\
\hline & Otras ayudas & $11(52,4 \%)$ & $0(0 \%)$ & $10(47,6 \%)$ & $0(0 \%)$ & $21(100 \%)$ & \\
\hline
\end{tabular}




\subsubsection{Abordaje de la sexualidad por parte de los profesionales sanitarios}

En el 50,6\% $(n=44)$ de las HCE aparece alguna anotación sobre sexualidad. En la valoración de enfermería, aparece valorado el dominio de sexualidad (Modelo Dominios y Clase según Taxonomía II de la NANDA) en el 18.7\% ( $n=17)$ de las historias. Dentro de las valoraciones en las que se encuentra recogida, a través de la pregunta: “¿Cree que su enfermedad puede influir en su sexualidad?" en el 64,7\% ( $n=11)$ está recogida la respuesta: "Si", en el 4,4\% $(n=4)$ la respuesta "No" y en el $11,8 \%(n=2)$ respuestas contradictorias (Cuando se encuentran realizadas varias valoraciones, "Sí" recogido en algunas de ellas y "No" en otras).

\subsubsection{Relación entre las características sociodemográficas y el registro sobre sexualidad}

Realizando un análisis bivariante entre las características sociodemográficas y el registro sobre la sexualidad en la HCE se muestra que el sexo, la edad, el estado civil, el nivel de estudios y la ocupación laboral previa a la lesión no influyen en este registro.

La presencia de antecedentes mentales se encuentra relacionado con el registro sobre sexualidad en la historia con un $\mathrm{p}$ valor=0,005.

Existe una relación entre la aportación farmacéutica según TSI y abordaje de la sexualidad con un $\mathrm{p}$ valor=0,004. Esto viene detallado en la tabla 25.

Tabla 25: relación de TSI y registro sobre sexualidad en HCE

\begin{tabular}{lccccc}
\hline & \multicolumn{2}{c}{ No registro } & \multicolumn{2}{c}{ Sí registro } & p valor \\
\cline { 2 - 5 } & $\mathbf{n}$ & $\mathbf{\%}$ & $\mathbf{n}$ & $\mathbf{\%}$ & \\
\hline TSI 1 & 3 & 8,8 & 5 & 11,9 & \\
\hline TSI 2 & 22 & 64,8 & 37 & 88,1 & \\
\hline TSI 3 & 5 & 14,7 & 0 & 0,0 & \multirow{2}{*}{0,004} \\
\hline TSI 4 & 1 & 2,9 & 0 & 0,0 & \\
\hline TSI 5 & 0 & 0,0 & 0 & 0,0 & \\
\hline TSI 6 & 3 & 8,8 & 0 & 0,0 \\
\hline Total & 34 & 100 & 42 & 100 & \\
\hline
\end{tabular}




\subsubsection{Relación entre las variables relacionadas con la lesión medular y el registro sobre sexualidad}

Realizando un análisis bivariante entre las variables relacionadas con la lesión medular y el abordaje de la sexualidad se muestra que el tiempo de lesión, la edad al lesionarse, la etiología, la derivación de otros hospitales de la región y la derivación a otros hospitales de referencia no influyen en este registro.

Existe una relación estadísticamente significativa entre el tiempo de hospitalización en unidad de hospitalización (con un p valor $<0,001$ ), el tiempo de hospitalización total (con un $\mathrm{p}$ valor=0,001) y el registro sobre sexualidad en la historia clínica, existiendo un mayor registro a mayor tiempo de hospitalización (en unidad de hospitalización y total). No existe relación estadísticamente significativa entre tiempo de estancia en $\mathrm{UCl}$ y registro sobre sexualidad en la HCE.

El tipo de lesión según afectación de miembros, según el nivel neurológico y según la extensión de la lesión se encuentran estadísticamente relacionados con el registro sobre sexualidad en la HCE. Esto se encuentra detallado en las tablas 26, 27 y 28 respectivamente.

Tabla 26: relación entre el tipo de lesión medular según afectación de miembros y el registro sobre sexualidad en la HCE

\begin{tabular}{lccccc}
\hline Tipo lesión & \multicolumn{2}{c}{ No registro } & \multicolumn{2}{c}{ Sí registro } & p valor \\
\hline & $\mathbf{n}$ & $\mathbf{\%}$ & $\mathbf{n}$ & $\mathbf{\%}$ & \\
\hline Paraparesia & 11 & 31,4 & 11 & 25,6 & \\
\cline { 1 - 5 } Paraplejia & 7 & 20,0 & 23 & 53,5 & \\
\cline { 1 - 5 } Tetraparesia & 9 & 25,7 & 7 & 16,3 & 0,007 \\
\cline { 1 - 5 } Tetraplejia & 8 & 22,9 & 2 & 4,6 & \\
\cline { 1 - 4 } Total & 35 & 100 & 43 & 100 & \\
\hline
\end{tabular}


Tabla 27: relación entre el tipo de lesión medular según nivel neurológico y registro sobre sexualidad en la HCE

\begin{tabular}{|c|c|c|c|c|c|}
\hline \multirow[t]{2}{*}{ Nivel neurológico } & \multicolumn{2}{|c|}{ No registro } & \multicolumn{2}{|c|}{ Sí registro } & \multirow[t]{2}{*}{ p valor } \\
\hline & $\mathbf{n}$ & $\%$ & $\mathbf{n}$ & $\%$ & \\
\hline Cervical & 17 & 43,6 & 9 & 20,4 & \multirow{4}{*}{0,017} \\
\hline Dorsal & 12 & 30,8 & 27 & 61,4 & \\
\hline Lumbar & 10 & 25,6 & 8 & 18,2 & \\
\hline Total & 39 & 100 & 44 & 100 & \\
\hline
\end{tabular}

Tabla 28: relación entre el tipo de lesión medular según extensión y registro sobre sexualidad en la HCE

\begin{tabular}{lccccc}
\hline Tipo lesión & \multicolumn{2}{c}{ No registro } & \multicolumn{2}{c}{ Sí registro } & p valor \\
\hline & $\mathbf{n}$ & $\mathbf{\%}$ & $\mathbf{n}$ & $\%$ & \\
\cline { 1 - 5 } Completa & 12 & 34,3 & 25 & 58,1 & \\
\cline { 1 - 5 } Incompleta & 23 & 65,7 & 18 & 41,9 & 0,036 \\
\cline { 1 - 5 } Total & 35 & 100 & 43 & 100 & \\
\hline
\end{tabular}

No existe relación entre la realización de intervención quirúrgica para estabilizar la lesión, ni con el ASIA al alta.

\subsubsection{Relación entre las variables relacionados con las complicaciones secundarias y el registro sobre sexualidad}

Las principales relaciones entre las variables relacionadas con las complicaciones secundarias y el registro sobre sexualidad en la HCE, se encuentran en la tabla 29. Se encuentra una relación estadísticamente significativa con la espasticidad y el dolor, estando cercana a la significación estadística las complicaciones urológicas. 
Tabla 29: complicaciones secundarias y registro sobre sexualidad en las HCE

\begin{tabular}{|c|c|c|c|c|c|c|c|c|}
\hline \multirow[t]{2}{*}{ Complicaciones } & & \multicolumn{2}{|c|}{ No registro } & \multicolumn{2}{|c|}{ Sí registro } & \multicolumn{2}{|c|}{ Total } & \multirow[t]{2}{*}{ p valor } \\
\hline & & $\mathbf{n}$ & $\%$ & $\mathbf{n}$ & $\%$ & $\mathbf{n}$ & $\%$ & \\
\hline \multirow{2}{*}{ Espasticidad } & No & 26 & 57,8 & 19 & 42,2 & 45 & 100 & \multirow{2}{*}{0,045} \\
\hline & Sí & 14 & 35,9 & 25 & 64,1 & 39 & 100 & \\
\hline \multirow{2}{*}{$\begin{array}{l}\text { Disreflexia } \\
\text { autonómica }\end{array}$} & No & 36 & 45,0 & 44 & 55,0 & 70 & 100 & \multirow{2}{*}{0,099} \\
\hline & Sí & 3 & 100 & 0 & 0,0 & 3 & 100 & \\
\hline \multirow{2}{*}{$\begin{array}{l}\text { Complicaciones } \\
\text { respiratorias }\end{array}$} & No & 33 & 44,0 & 42 & 56,0 & 75 & 100 & \multirow{2}{*}{0,079} \\
\hline & Sí & 7 & 77,8 & 2 & 22,2 & 9 & 100 & \\
\hline \multirow{4}{*}{ Dolor } & Ambos & 2 & 18,2 & 9 & 81,8 & 11 & 100 & \multirow{4}{*}{0,045} \\
\hline & Mecánico & 7 & 43,7 & 9 & 56,3 & 16 & 100 & \\
\hline & Neuropático & 10 & 40,0 & 15 & 60,0 & 25 & 100 & \\
\hline & No & 20 & 64,5 & 11 & 35,5 & 31 & 100 & \\
\hline \multirow{2}{*}{ UPP } & No & 25 & 62,5 & 15 & 37,5 & 40 & 100 & \multirow{2}{*}{0,118} \\
\hline & Sí & 20 & 45,4 & 24 & 54,6 & 44 & 100 & \\
\hline Complicaciones & No & 12 & 30,8 & 27 & 69,2 & 39 & 100 & \multirow{2}{*}{0,059} \\
\hline Urológicas & Sí & 6 & 13,6 & 38 & 86,4 & 44 & 100 & \\
\hline Complicaciones & No & 15 & 38,5 & 24 & 61,5 & 39 & 100 & \multirow{2}{*}{0,071} \\
\hline Gastrointestinales & Sí & 9 & 20,4 & 35 & 79,6 & 44 & 100 & \\
\hline
\end{tabular}

4.1.7.4. Relación entre las variables relacionadas con los apoyos de la lesión medular y el registro sobre sexualidad

No existe relación estadísticamente significativa entre la pertenencia a alguna asociación y el registro sobre sexualidad en la HCE.

Existe una relación estadísticamente significativa entre el uso de productos de apoyo y el registro de este dato, con un $p$ valor $=0,004$.

\subsubsection{Aspectos registrados sobre sexualidad en las HCE}

\subsubsection{Aspectos registrados en torno a la sexualidad de las mujeres en las HCE}

- Temas relacionados con la menstruación: aparecen en un 23,8\% de las HCE, en todos los casos asociados a cambios o síntomas: amenorrea 9,5\% $(n=2)$, oligoamenorrea $4,8 \%(n=1)$, dismenorrea $4,8 \%(n=1)$ y climaterio $4,8 \%(n=1)$.

- Las revisiones ginecológicas se encuentran reflejadas en el 38\% $(n=8)$ de las HCE. 
- Alteraciones ginecológicas: reflejadas en el $28,6 \%(n=6)$ de las HCE: leiomioma uterino $9,5 \%(n=2)$, leucorrea no infecciona $9,5 \%(n=2)$, vaginitis infecciosa $4,8 \%$ $(n=1)$ y estenosis vaginal $4,8 \%(n=1)$.

- No aparece ninguna anotación sobre anticoncepción en las HCE de las mujeres.

\subsubsection{Aspectos registrados en torno a la sexualidad de los hombres en las HCE}

- Temas relacionados con la erección: registrado en el 44,9\% ( $n=31)$ de las HCE. De los registros realizados, el 93,5\% ( $n=29)$ presentaba disfunción eréctil frente a un $6,5 \%(n=2)$ que aparecía reflejado no tener problemas con la erección. De los hombres con disfunción eréctil registrada, en el 65\% ( $n=19)$ estaba registrado algún tratamiento: en un $36,8 \%(n=7)$ alprostadil, en un $31,6 \%(n=6)$ sildenafilo, en un $10,5 \%(n=2)$ vardenafilo, en un $10,5 \%(n=2)$ tadalafilo, un $5,3 \%(n=1)$ avalafilo y en un $5,3 \%(n=1)$ prótesis peneana.

- Ayudas para la eyaculación: en un 4,3\% $(n=3)$ de las HCE aparecen vibradores relacionados con la ayuda para conseguir la eyaculación.

- Alteraciones genitales: en un $15,9 \%(n=11)$ aparecen alteraciones en los genitales: en un $8,7 \%(n=6)$ lesiones en el pene y en un $7,2 \%(n=5)$ problemas testiculares.

- En el 2,9\% $(n=2)$ de las historias masculinas aparece algo relacionado con la anticoncepción, en ambas sobre la vasectomía.

\subsubsection{Aspectos registrados en torno a ambos sexos}

- En el 5,5\% $(n=5)$ de las historias se encuentra registrado si la persona convive o no con su pareja.

- En aspectos relacionados con la fertilidad, en un 6,6\% (n=6) existe derivación o tratamiento a la unidad de fertilidad.

\subsection{Fase II: Calidad de vida, salud sexual, fuentes de información utilizadas y necesidades percibidas de atención de la sexualidad desde el entorno sanitario}

El número de casos fue 88. 


\subsubsection{Características sociodemográficas}

\subsubsection{Sexo y edad}

El $72,7 \%(n=64)$ eran hombres y el $27,3 \%(n=24)$ eran mujeres. La edad media a 29 de febrero de 2020 fue de 45,8 años, con una $D E=12,4$ y una mediana de 46 .

\subsubsection{Estado civil y número de hijos}

En cuanto al estado civil actual se obtiene que el $52,9 \%(n=46)$ de las personas con LMT están casadas o en pareja, el 33,3\% ( $n=29)$ solteras, el 6,9\% ( $n=6)$ separadas o divorciadas, el $4,6 \%(n=4)$ viudas y el $2,3 \%(n=2)$ se encuentran en otro tipo de relación de pareja. Se produce un valor perdido en esta variable.

Respecto al número de hijos se obtiene que el $48,7 \%(n=37)$ no tiene hijos, el $23,7 \%$ tiene un hijo, el $21,1 \%(n=16) 2$ hijos y el 6,6\% $(n=5) 3$ hijos. Se producen 12 valores perdidos en esta variable.

\subsubsection{Orientación sexual}

Respecto a la orientación sexual, se obtiene que el 94,3\% ( $n=83$ ) es heterosexual, el 3,4\% $(n=3)$ es bisexual, el 1,1\% ( $n=1)$ es homosexual y el 1,1\% $(n=1)$ tiene otra orientación del deseo.

\subsubsection{Núcleo de convivencia}

En cuanto al núcleo de convivencia, se obtiene que el $50 \%(n=44)$ convive con su pareja, el $25 \%(n=22)$ vive solo, el $19,3 \%(n=17)$ vive con sus padres, el $2,3 \%(n=2)$ vive en una institución residencial y el 3,4\% ( $n=3)$ presenta otras situaciones de convivencia.

\subsubsection{Nivel de estudios}

Respecto al nivel de estudios el 45,2\% ( $n=38)$ tiene estudios universitarios (diplomatura, grado o licenciatura), el $32,1 \%$ ( $n=27$ ) estudios medios y el $22,6 \%(n=19)$ tiene estudios primarios. Se producen 4 valores perdidos en esta variable. 


\subsubsection{Resultados relacionados con la lesión}

\subsubsection{Causa de la lesión}

La distribución de la causa de la lesión medular viene detallada en el gráfico 4.

Gráfico 4: distribución de la causa de la lesión medular

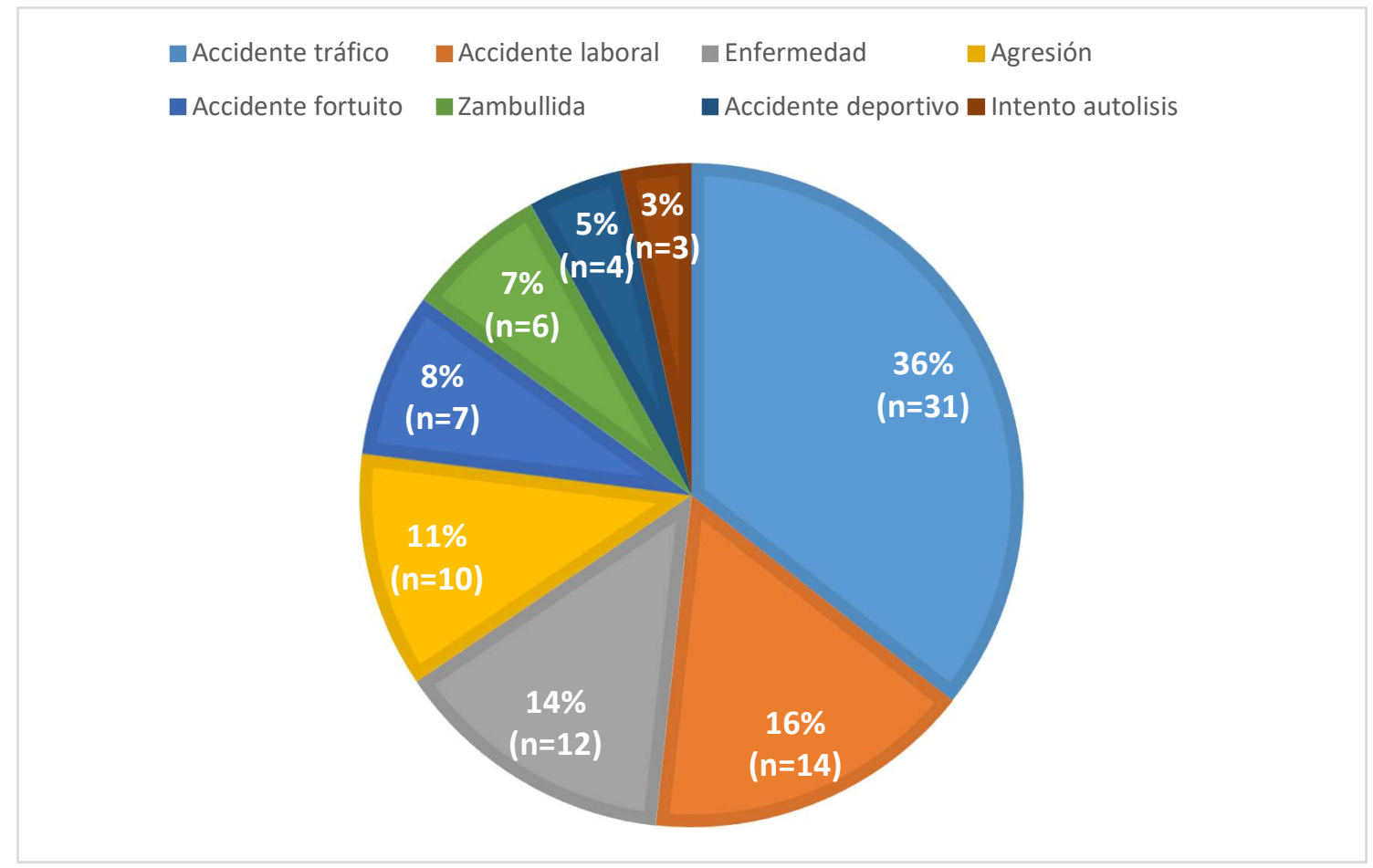

\subsubsection{Tiempo de lesión}

El tiempo medio de lesión desde que se produjo la lesión hasta el momento del estudio es de 15 años, con una $\mathrm{DE}=10,9$ y una mediana de 11.

\subsubsection{Tipo de hospitales donde se produjo la primera atención}

Respecto al tipo de hospital donde se produjo la primera atención tras la adquisición de la lesión, se presenta la siguiente distribución: el $57,1 \%(n=48)$ fue atendido en un hospital regional, el $19 \%(n=16)$ en un hospital nacional de referencia, el $17,9 \%(n=15)$ en ambos dispositivos (regional y hospital nacional de referencia), un $2,4 \%(n=2)$ en el extranjero y un $3,6 \%(n=3)$ en otros dispositivos. Hay 4 valores perdidos en esta variable. 


\subsubsection{Tipo de lesión según afectación de miembros, según extensión y según nivel neurológico.}

La distribución del tipo de lesión según afectación de miembros, según la extensión y según nivel neurológico viene especificado en los gráficos 5,6 y 7 respectivamente:

Gráfico 5: tipo de lesión medular según afectación de miembros

-Tetraplejia $\square$ Tetraparesia $\square$ Paraplejia $\square$ Paraparesia $\square$ No sabe su tipo de lesión

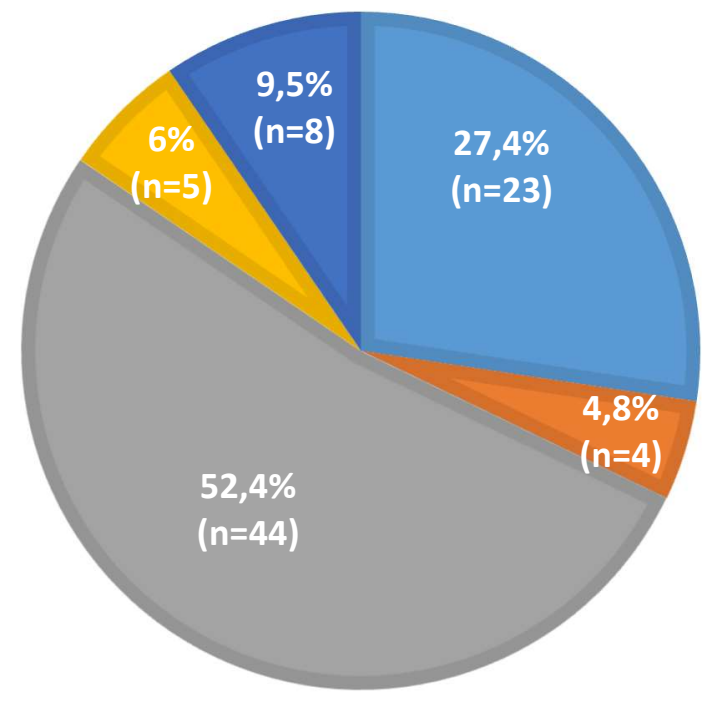

Gráfico 6: tipo de lesión medular según extensión de la lesión

- Completa Incompleta No sabe tipo de lesión

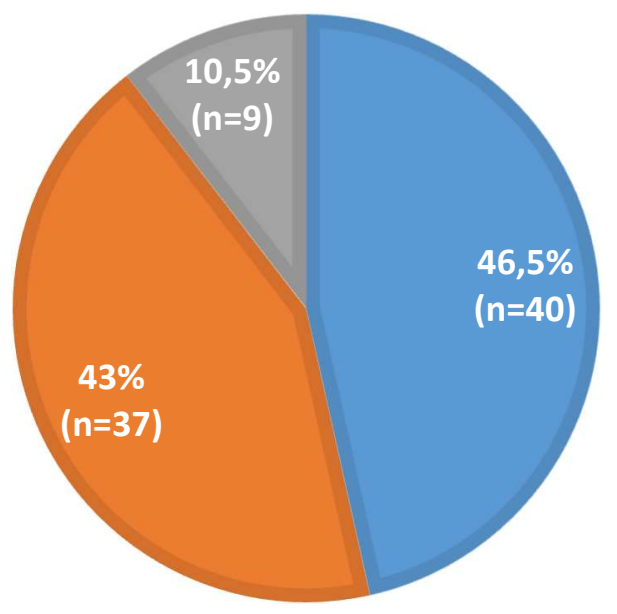


Gráfico 7: nivel de la lesión medular según nivel neurológico

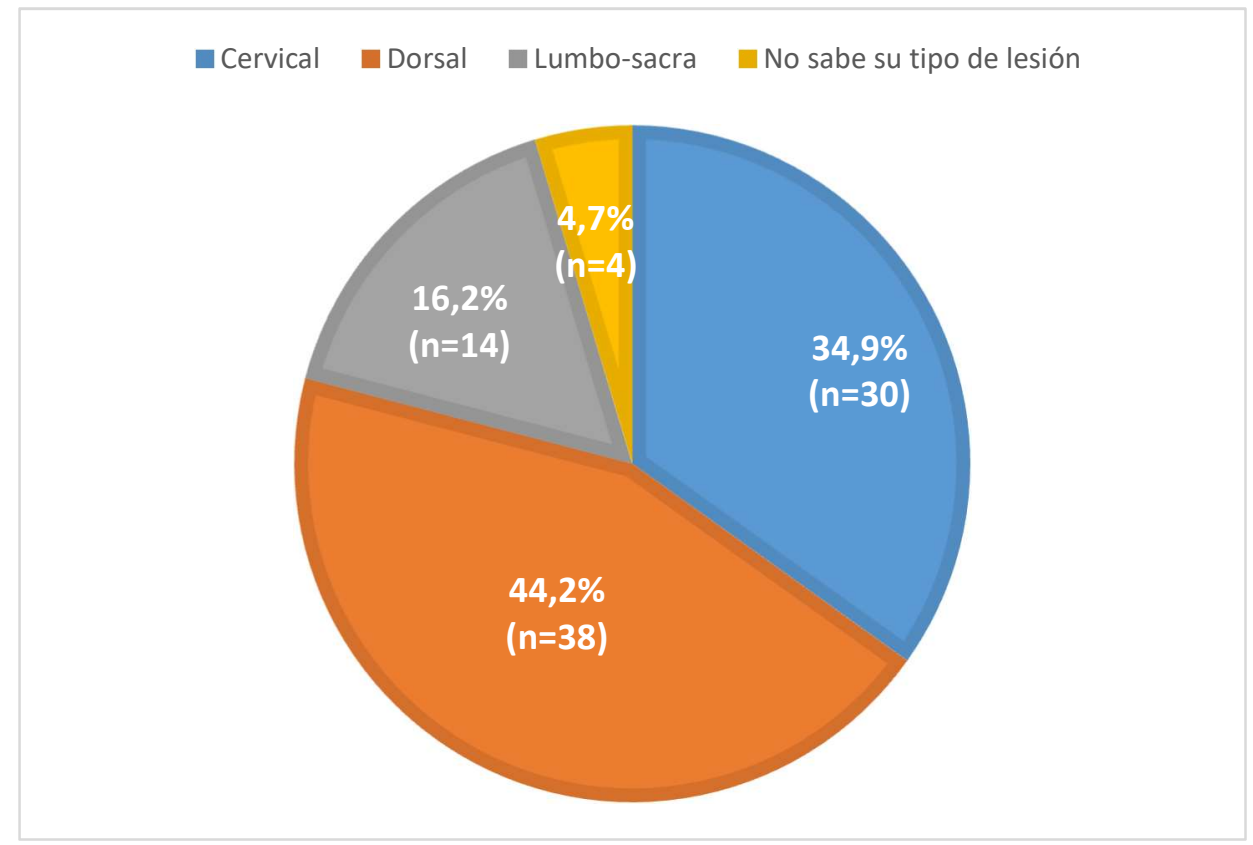

\subsubsection{Presencia de úlceras por presión, espasticidad muscular y dolor crónico asociado a la lesión medular}

La distribución sobre la presencia anterior o actual de úlceras por presión, la presencia de espasticidad muscular y la presencia de dolor crónico asociado a la lesión medular se muestran en la tabla 30. Hay un valor perdido en la presencia de UPP y dos valores perdidos en la presencia de espasticidad muscular y dolor crónico.

Tabla 30: presencia de complicaciones secundarias: úlceras por presión, espasticidad muscular y dolor crónico

\begin{tabular}{llll}
\hline & Sí & No & Total \\
\hline UPP & $41,4 \%(n=36)$ & $58,6 \%(n=51)$ & $100 \%(n=87)$ \\
\hline Espasticidad & $67,4 \%(n=58)$ & $32,6 \%(n=28)$ & $100 \%(n=86)$ \\
\hline Dolor crónico & $52,3 \%(n=45)$ & $47,7 \%(n=41)$ & $100 \%(n=86)$ \\
\hline
\end{tabular}

\subsubsection{Presencia de sensibilidad en el área genital y anal}

El 39,8\% ( $n=35)$ no presentan sensibilidad en el área genital, el 26,1\% ( $n=23)$ sí presentan sensibilidad y el $34,1 \%(n=30)$ la presentan parcialmente. 
El $40,9 \%(n=36)$ no presenta sensibilidad en el área anal, el $22,7 \%(n=20)$ sí presentan sensibilidad y el $36,4 \%(n=32)$ la presentan parcialmente.

\subsubsection{Método de vaciamiento vesical e intestinal}

La distribución del método de vaciamiento vesical e intestinal empleado habitualmente, se encuentra desglosado en las tablas 31 y 32 respectivamente. Hay un valor perdido en el método de vaciamiento vesical.

Tabla 31: métodos de vaciamiento vesical

\begin{tabular}{lcc}
\hline Método de vaciamiento vesical & $\mathbf{n}$ & $\mathbf{\%}$ \\
\hline Sondaje vesical intermitente & 42 & 47,7 \\
\hline Espontáneo & 28 & 31,8 \\
\hline Maniobra de Credé & 7 & 8,0 \\
\hline Sondaje vesical permanente & 5 & 5,7 \\
\hline Pañal & 3 & 3,4 \\
\hline Sonda suprapúbica & 2 & 2,3 \\
\hline Otros & 1 & 1,1 \\
\hline Total & 88 & 100 \\
\hline
\end{tabular}

Tabla 32: métodos de vaciamiento intestinal

\begin{tabular}{lcc}
\hline Método de vaciamiento intestinal & $\mathbf{n}$ & $\mathbf{\%}$ \\
\hline Enema/ supositorios & 36 & 40,9 \\
\hline Voluntario & 22 & 25,0 \\
\hline Estimulación digital & 21 & 23,9 \\
\hline Pañal & 1 & 1,1 \\
\hline Otros & 8 & 9,1 \\
\hline Total & 88 & 100 \\
\hline
\end{tabular}

\subsubsection{Resultados referentes a la calidad de vida}

Los resultados sobre percepción en la calidad de vida de las personas con LMT se recogieron a través del cuestionario validado LISAT-8. Ver tablas 33, 34 y 35. En los ítems sobre vida general, vida sexual, relación con amigos, situación económica y vida de ocio ha habido 1 valor perdido, en el ítem de vida familiar 5 y en los ítems de relación de pareja y situación laboral 11 valores perdidos. 
Tabla 33: resultados de los ítems del LISAT-8 sobre calidad de vida

\begin{tabular}{lcccccc}
\hline & $\begin{array}{c}\text { Muy } \\
\text { insatisfactoria }\end{array}$ & Insatisfactoria & $\begin{array}{c}\text { Un poco } \\
\text { insatisfactoria }\end{array}$ & $\begin{array}{c}\text { Un poco } \\
\text { satisfactoria }\end{array}$ & Satisfactoria & $\begin{array}{c}\text { Muy } \\
\text { satisfactoria }\end{array}$ \\
\hline $\begin{array}{l}\text { Vida } \\
\text { en general }\end{array}$ & $4,6 \%(n=4)$ & $6,9 \%(n=6)$ & $10,3 \%(n=9)$ & $11,5 \%(n=10)$ & $50,6 \%(n=44)$ & $16,1 \%(n=14)$ \\
\hline $\begin{array}{l}\text { Vida } \\
\text { sexual }\end{array}$ & $20,7 \%(n=18)$ & $16,1 \%(n=14)$ & $9,2 \%(n=8)$ & $17,2 \%(n=15)$ & $33,3 \%(n=29)$ & $3,4 \%(n=3)$ \\
\hline $\begin{array}{l}\text { Relación } \\
\text { en pareja }\end{array}$ & $10,4 \%(n=8)$ & $20,8 \%(n=16)$ & $5,2 \%(n=4)$ & $14,3 \%(n=11)$ & $31,2 \%(n=24)$ & $18,2 \%(n=14)$ \\
\hline $\begin{array}{l}\text { Vida } \\
\text { familiar }\end{array}$ & $1,2 \%(n=1)$ & $3,6 \%(n=3)$ & $3,6 \%(n=3)$ & $15,7 \%(n=13)$ & $44,6 \%(n=37)$ & $31,3 \%(n=26)$ \\
\hline $\begin{array}{l}\text { Relación } \\
\text { amigos }\end{array}$ & $2,3 \%(n=2)$ & $3,4 \%(n=3)$ & $3,4 \%(n=3)$ & $9,2 \%(n=8)$ & $43,7 \%(n=38)$ & $37,9 \%(n=33)$ \\
\hline $\begin{array}{l}\text { Vida de } \\
\text { ocio }\end{array}$ & $2,3 \%(n=2)$ & $6,9 \%(n=6)$ & $10,3 \%(n=9)$ & $19,5 \%(n=17)$ & $44,8 \%(n=39)$ & $16,1 \%(n=14)$ \\
\hline $\begin{array}{l}\text { Situación } \\
\text { laboral }\end{array}$ & $10,4 \%(n=8)$ & $13,0 \%(n=10)$ & $5,2 \%(n=4)$ & $14,3 \%(n=11)$ & $39 \%(n=30)$ & $18,2 \%(n=14)$ \\
\hline $\begin{array}{l}\text { Situación } \\
\text { económica }\end{array}$ & $5,7 \%(n=5)$ & $3,4 \%(n=3)$ & $3,4 \%(n=3)$ & $18,4 \%(n=16)$ & $55,2 \%(n=48)$ & $13,8 \%(n=12)$ \\
\hline
\end{tabular}

$\mathrm{Si}$ en las variables se agrupan las frecuencias de "muy insatisfactoria" más "insatisfactoria" y de "satisfactoria" más "muy satisfactoria" despreciando las puntuaciones intermedias, se puede observar en la Tabla 34, que destacan positivamente la vida familiar y la relación con los amigos y destaca negativamente la vida sexual y la relación de pareja. 
Tabla 34: resultados agrupados de los ítems del LISAT-8 sobre calidad de vida

\begin{tabular}{lcc}
\hline & $\begin{array}{c}\text { Muy insatisfactoria+ } \\
\text { insatisfactoria }\end{array}$ & $\begin{array}{c}\text { Satisfactoria+ muy } \\
\text { satisfactoria }\end{array}$ \\
\hline $\begin{array}{l}\text { Vida } \\
\text { sexual }\end{array}$ & $36,8 \%(n=32)$ & $36,7 \%(n=32)$ \\
\hline $\begin{array}{l}\text { Relación } \\
\text { en pareja }\end{array}$ & $31,2 \%(n=24)$ & $49,4 \%(n=38)$ \\
\hline $\begin{array}{l}\text { Situación } \\
\text { laboral }\end{array}$ & $23,4 \%(n=18)$ & $57,2 \%(n=44)$ \\
\hline $\begin{array}{l}\text { Vida } \\
\text { en general }\end{array}$ & $11,5 \%(n=10)$ & $66,7 \%(n=58)$ \\
\hline $\begin{array}{l}\text { Vida de } \\
\text { ocio }\end{array}$ & $6,9 \%(n=8)$ & $60,9 \%(n=53)$ \\
\hline $\begin{array}{l}\text { Situación } \\
\text { económica }\end{array}$ & $9,1 \%(n=8)$ & $69 \%(n=60)$ \\
\hline $\begin{array}{l}\text { Relación } \\
\text { con amigos }\end{array}$ & $5,7 \%(n=5)$ & $81,6 \%(n=71)$ \\
\hline $\begin{array}{l}\text { Vida } \\
\text { familiar }\end{array}$ & $4,8 \%(n=4)$ & $75,9 \%(n=63)$ \\
\hline
\end{tabular}

Tabla 35: resultados de las dimensiones (sexual, social y económica) y sumatorio total del cuestionario LISAT-8

\begin{tabular}{lcccccccc}
\hline & \multicolumn{1}{c}{} & \multicolumn{8}{c}{ Percentiles (\%) } \\
\hline & $\mathbf{n}$ & Media & $\mathbf{D E}$ & $\mathbf{0}$ & $\mathbf{2 5}$ & $\mathbf{5 0}$ & $\mathbf{7 5}$ & $\mathbf{1 0 0}$ \\
\hline LISAT sexual & 88 & 6,74 & 3,17 & 0 & 4 & 6 & 10 & 12 \\
\hline LISAT social & 88 & 18,42 & 3,99 & 5 & 5,75 & 19,5 & 21 & 24 \\
\hline LISAT económico & 88 & 8,11 & 2,81 & 0 & 6 & 9 & 10 & 12 \\
\hline LISAT total & 88 & 33,27 & 7,97 & 8 & 27,75 & 36 & 39 & 47 \\
\hline
\end{tabular}

\subsubsection{Relación entre variables sociodemográficas y LISAT-8.}

No se encuentra relación estadísticamente significativa entre el sexo, la edad y el núcleo de convivencia con el LISAT-8.

Existe una relación estadísticamente significativa entre el estado civil y el LISAT sexual, social y total. No se encuentra relación estadísticamente significativa entre el estado civil y el LISAT económico. Los resultados se muestran en la tabla 36. 
Tabla 36: relación entre el estado civil y LISAT-8

\begin{tabular}{lllcccccc}
\hline LISAT & Estado Civil & $\mathbf{n}$ & Media & Mediana & DE & p25 & p75 & p valor \\
\hline \multirow{2}{*}{ SEXUAL } & Soltero/separado/viudo & 39 & 5,1 & 5 & 3,79 & 3 & 6,5 & \multirow{2}{*}{0,001} \\
& Casado/conviviente/otros & 48 & 8,08 & 9,5 & 2,88 & 6 & 10 & \\
\hline \multirow{2}{*}{ SOCIAL } & Soltero/separado/viudo & 39 & 17,38 & 17 & 4,27 & 15 & 22 & \multirow{2}{*}{0,034} \\
& Casado/conviviente/otros & 48 & 19,21 & 20 & 3,52 & 18 & 21 & \\
\hline \multirow{2}{*}{ ECONÓMICO } & Soltero/separado/viudo & 39 & 7,97 & 9 & 2,72 & 6 & 10 & \multirow{2}{*}{0,752} \\
& Casado/conviviente/otros & 48 & 8,17 & 9 & 2,9 & 6 & 10 & \\
\hline \multirow{2}{*}{ TOTAL } & Soltero/separado/viudo & 39 & 20,46 & 30 & 7,71 & 25 & 37 & \multirow{2}{*}{0,003} \\
& Casado/conviviente/otros & 48 & 35,46 & 37 & 7,58 & 33,75 & 40,25 & \\
\hline
\end{tabular}

\subsubsection{Relación entre variables relacionadas con la lesión y LISAT-8.}

No se encuentra relación estadísticamente significativa entre tipo de lesión según extensión y el tipo de lesión según nivel neurológico con el LISAT-8. Tampoco se encuentra relación estadísticamente significativa con el tiempo de lesión.

Se encuentra relación estadísticamente significativa entre el tipo de lesión según afectación de miembros agrupadas en lesiones completas e incompletas, con el LISAT sexual, social y total, no así con el económico. Los resultados se muestran en la tabla 37.

Tabla 37: relación entre el tipo de lesión medular según afectación de miembros y LISAT-8

\begin{tabular}{lllcccccc}
\hline LISAT & Tipo de lesión* & $\mathbf{n}$ & Media & Mediana & DE & p25 & p75 & p valor \\
\hline \multirow{2}{*}{ SEXUAL } & Tetraplejia (I+C) & 27 & 7,96 & 9 & 2,83 & 6 & 10 & \multirow{2}{*}{0,05} \\
& Paraplejia (I+C) & 49 & 6,41 & 6 & 3,15 & 3 & 9 & \\
\hline \multirow{2}{*}{ SOCIAL } & Tetraplejia (I+C) & 27 & 20,04 & 21 & 3,79 & 19,5 & 22 & \multirow{2}{*}{0,006} \\
& Paraplejia (I+C) & 49 & 17,94 & 19 & 3,89 & 15 & 21 & \\
\hline \multirow{2}{*}{ ECONÓMICO } & Tetraplejia (I+C) & 27 & 8,78 & 9 & 2,41 & 7 & 10,5 & \multirow{2}{*}{0,318} \\
& Paraplejia (I+C) & 49 & 8,1 & 9 & 2,78 & 6 & 10 & \\
\hline \multirow{2}{*}{ TOTAL } & Tetraplejia (I+C) & 27 & 36,78 & 38 & 7,16 & 35 & 41 & \multirow{2}{*}{0,01} \\
& Paraplejia (I+C) & 49 & 32,45 & 35 & 7,76 & 27 & 38 & \\
\hline
\end{tabular}

*I: incompleta, C: completa

No se encuentra relación estadísticamente significativa entre la presencia de UPP, la espasticidad muscular, la presencia de crisis de disreflexia autonómica, la presencia de 
sensibilidad en el área genital y anal y la preocupación por el escape de heces y las distintas dimensiones del LISAT-8. Tampoco entre los distintos tipos de vaciamiento vesical e intestinal y el LISAT-8.

Se encuentra relación estadísticamente significativa entre la presencia de dolor crónico y el LISAT social y total. Los resultados se muestran en la tabla 38 :

Tabla 38: relación entre la presencia de dolor crónico y LISAT-8

\begin{tabular}{lcccccccc}
\hline LISAT & DOLOR & $\mathbf{n}$ & Media & Mediana & DE & p25 & p75 & p valor \\
\hline \multirow{2}{*}{ SEXUAL } & No & 41 & 7,05 & 7 & 3,27 & 5 & 10 & \multirow{2}{*}{0,476} \\
& Sí & 45 & 6,56 & 6 & 3,12 & 4 & 10 & \\
\hline \multirow{2}{*}{ SOCIAL } & No & 41 & 19,8 & 21 & 3 & 18 & 22 & \multirow{2}{*}{0,002} \\
& Sí & 45 & 17,22 & 19 & 4,45 & 15 & 21 & \\
\hline \multirow{2}{*}{ ECONÓMICO } & No & 41 & 8,8 & 9 & 2,42 & 7 & 11 & \multirow{2}{*}{0,061} \\
& Sí & 45 & 7,71 & 9 & 2,87 & 6 & 10 & \\
\hline \multirow{2}{*}{ TOTAL } & No & 41 & 35,66 & 37 & 6,44 & 31 & 40 & \multirow{2}{*}{0,014} \\
& Sí & 45 & 31,49 & 34 & 8,69 & 25 & 38 & \\
\hline
\end{tabular}

Se encuentra una relación estadísticamente significativa entre la preocupación por el escape de orina durante las relaciones eróticas y el LISAT sexual. Los resultados se muestran en la tabla 39. No se encuentra relación estadísticamente significativa con la preocupación por el escape de heces.

Tabla 39: relación entre la preocupación por el escape de orina durante las relaciones eróticas y el LISAT-8

\begin{tabular}{lcccccccc}
\hline LISAT & $\begin{array}{c}\text { Preocupación } \\
\text { escape orina }\end{array}$ & $\mathbf{n}$ & Media & Mediana & DE & p25 & p75 & $\begin{array}{c}\mathbf{p} \\
\text { valor }\end{array}$ \\
\hline \multirow{2}{*}{ SEXUAL } & No & 41 & 7,61 & 8 & 2,9 & 6 & 10 & 0,033 \\
& Sí & 45 & 6,2 & 6 & 3,12 & 3 & 9 & \\
\hline \multirow{2}{*}{ SOCIAL } & No & 41 & 18,88 & 20 & 3,56 & 17 & 21 & \multirow{2}{*}{0,393} \\
& Sí & 45 & 18,13 & 19 & 4,4 & 15 & 21 & \\
\hline \multirow{2}{*}{ ECONÓMICO } & No & 41 & 8,73 & 9 & 2,33 & 7 & 10 & \multirow{2}{*}{0,06} \\
& Sí & 45 & 7,6 & 7 & 3,09 & 5 & 10 & \\
\hline \multirow{2}{*}{ TOTAL } & No & 41 & 35,22 & 37 & 7,16 & 31 & 41 & \multirow{2}{*}{0,054} \\
& Sí & 45 & 31,93 & 35 & 8,31 & 26 & 38 & \\
\hline
\end{tabular}

En la tabla 40 se puede observar un resumen con la significación estadística del LISAT- 8 en relación con las variables anteriores. 
Tabla 40: significación estadística del LISAT-8 con el estado civil, el tipo de lesión medular, la presencia de dolor crónico y la preocupación por el escape de orina

\begin{tabular}{lcccc}
\hline LISAT & Estado civil & $\begin{array}{c}\text { Tipo de } \\
\text { lesión }\end{array}$ & $\begin{array}{c}\text { Presencia } \\
\text { dolor crónico }\end{array}$ & $\begin{array}{c}\text { Preocupación } \\
\text { escape de orina }\end{array}$ \\
\hline SEXUAL & $*$ & $*$ & $* *$ & $*$ \\
\hline SOCIAL & $*$ & $*$ & $*$ & $* *$ \\
\hline ECONÓMICO & $* *$ & $* *$ & $* *$ & $* *$ \\
\hline & & & & $*$ \\
\hline
\end{tabular}

*Estadísticamente significativo $(p=<0,05)$

$* *$ Sin significación estadística $(p>0,05)$

\subsubsection{Resultados relacionados con la sexualidad}

\subsubsection{Comunes para ambos sexos}

4.2.4.1.1. Preocupación por el escape involuntario de orina y heces durante las relaciones eróticas

El $52,3 \%(n=45)$ refiere sentirse preocupado por el escape de orina durante las relaciones erótica. El 43,5\% ( $n=37)$ lo refiere por el escape de heces.

4.2.4.1.2. Aparición de crisis de disreflexia autonómica durante las relaciones eróticas

El 9,4\% ( $n=8)$ ha presentado alguna crisis de disreflexia autonómica durante las relaciones eróticas.

4.2.4.1.3. Uso de libros, películas, música o arte con contenido erótico

La distribución sobre el uso de libros, películas, música o arte con contenido erótico viene detallada en la tabla 41. 
Tabla 41: distribución de uso de libros, películas, música o arte con contenido erótico

\begin{tabular}{lcc}
\hline Uso material erótico & $\mathbf{n}$ & $\mathbf{\%}$ \\
\hline Nunca & 29 & 33,7 \\
\hline Rara vez & 29 & 33,7 \\
\hline A veces & 20 & 23,3 \\
\hline A menudo & 6 & 7,0 \\
\hline Diariamente & 2 & 2,3 \\
\hline Total & 86 & 100 \\
\hline
\end{tabular}

4.2.4.1.3.1. Relación entre el uso de contenido erótico y las características sociodemográficas

El uso de contenido erótico en forma de libros, películas, música o arte no se encuentra estadísticamente relacionado con el sexo, con la edad, ni con el estado civil. Existe una relación estadísticamente significativa ( $p$ valor=0,001) con el núcleo de convivencia, el $86,2 \%(n=50)$ de los que lo utilizan nunca o rara vez viven en pareja o solos y el $53,6 \%$ $(n=15)$ de los que lo utilizan a veces, siempre o a menudo, en relación a los que cohabitan con sus padres o en una residencia.

\subsection{Relación entre el uso de contenido erótico y variables relacionadas con la lesión medular}

El uso de contenido erótico se encuentra estadísticamente relacionado con el tipo de lesión según afectación de miembros, agrupada en tetraplejias (completas e incompletas) y paraplejias (completas e incompletas) con un p valor=0,013; el 73,5\% $(n=36)$ de los que lo utilizan rara vez o nunca tienen una lesión tipo paraplejia, el 56\% $(n=14)$ de los que lo utilizan a veces, a menudo o siempre tienen una lesión tipo tetraplejia.

No se encuentra relación entre el uso de contenido erótico y el resto de variables relacionadas con la LMT.

\subsection{Grado de placer o disfrute de pensar y fantasear acerca del sexo}

La distribución sobre el grado de placer o disfrute de pensar y fantasear acerca del sexo viene detallada en el gráfico 8. 
Gráfico 8: distribución sobre el grado de placer o disfrute de pensar y fantasear acerca del sexo

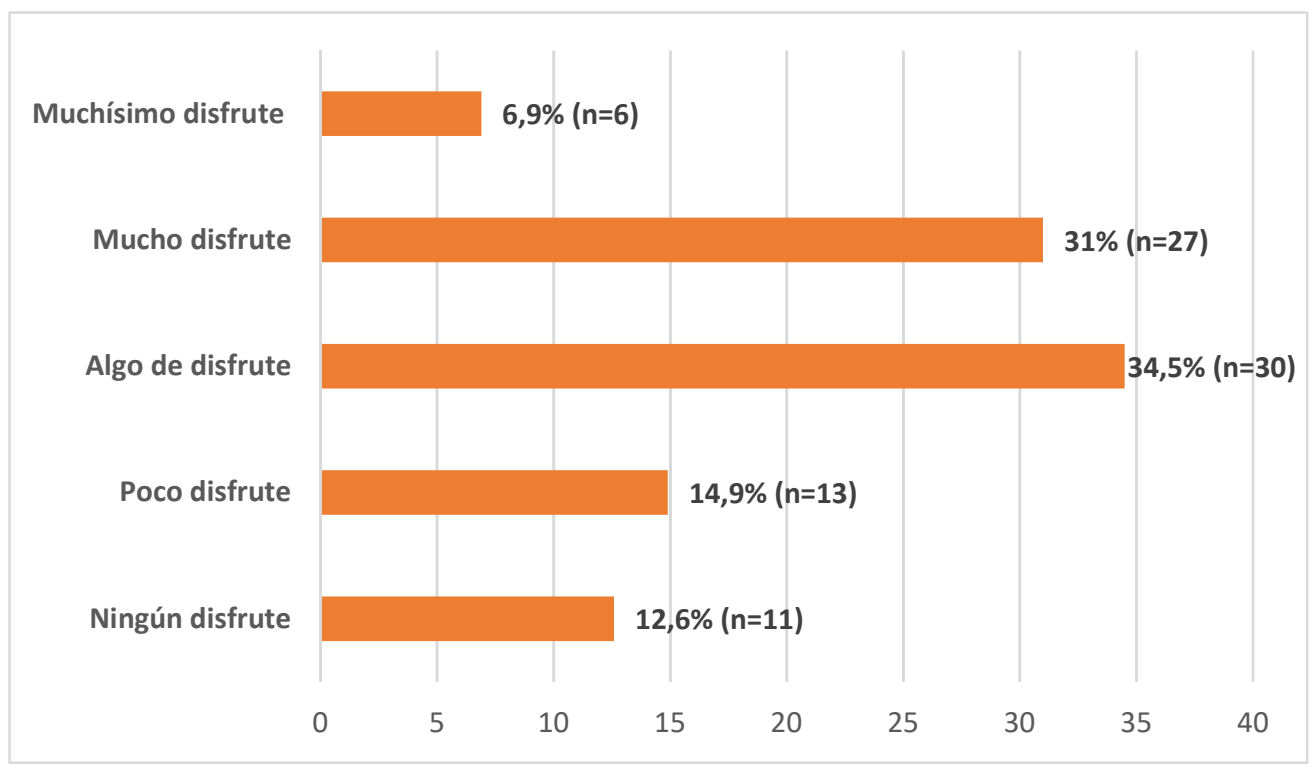

4.2.4.1.1. Relación entre grado de placer o disfrute que obtiene de pensar y fantasear acerca del sexo y variables sociodemográficas.

El grado de disfrute o placer que obtiene de pensar y fantasear acerca del sexo no se encuentra estadísticamente relacionado con el sexo, la edad, el estado civil, ni el núcleo de convivencia.

\subsection{Relación entre grado de placer o disfrute que obtiene de pensar} y fantasear acerca del sexo y variables relacionadas con la lesión

Si se analiza el grado de placer o disfrute que se obtiene de pensar y fantasear acerca del sexo y el tipo de lesión agrupada en paraplejias y tetraplejias, encontramos una relación estadísticamente significativa con un $p$ valor $=0,025$. El 88,9\% de las personas con una tetraplejia y el $65,3 \%(n=32)$ de las personas con una paraplejia tienen algo, mucho o muchísimo disfrute.

Existe una relación estadísticamente significativa entre el grado de placer o disfrute al pensar o fantasear acerca del sexo y el nivel de la lesión con un $p$ valor $=0,032$. El 89,7\% ( $n=26)$ de las personas con lesión cervical, el 65,8\% ( $n=25)$ de las que tienen una lesión dorsal y el $57,1 \%(n=8)$ de las que tienen una lesión lumbo-sacra tienen algo, mucho o muchísimo disfrute. 
Existe una relación estadísticamente significativa entre el grado de placer o disfrute al pensar o fantasear acerca del sexo y la presencia de UPP ( $p$ valor=0,049). El 83,3\% $(n=30)$ de las personas con UPP y el $64 \%(n=32)$ de las que no tienen UPP tienen algo, mucho o muchísimo placer al pensar o fantasear acerca del sexo. Con el resto de complicaciones secundarias no se encuentra relación.

Si se analiza la relación con el tipo de vaciamiento de la vejiga, el 79,4\% ( $n=27)$ de las personas con vaciamiento de la vejiga espontáneo o con maniobra de Credé, el 76,2\% $(n=32)$ de personas que realizan sondaje vesical intermitente, el $42,9 \%(n=3)$ de las personas con sonda vesical permanente o sonda suprapúbica y el $25 \%(n=1)$ de los que utilizan pañal por incontinencia tienen algo, mucho o muchísimo placer ( $p$ valor=0,035). No existe relación estadísticamente significativa con el tipo de vaciamiento intestinal.

\subsection{Grado de importancia de la vida erótica en relaciones de pareja}

La distribución sobre el grado de importancia de la vida erótica en las relaciones de pareja, se expresa en la Tabla 42.

Tabla 42: grado de importancia sobre la vida erótica en relaciones de pareja

\begin{tabular}{lcc}
\hline Importancia vida erótica & $\mathbf{n}$ & $\mathbf{\%}$ \\
\hline Muy poco importante & 6 & 6,9 \\
\hline No importante & 5 & 5,8 \\
\hline Relativamente importante & 20 & 23 \\
\hline Importante & 39 & 44,8 \\
\hline Muy importante & 17 & 19,5 \\
\hline Total & 87 & 100 \\
\hline
\end{tabular}

4.2.4.1.5.1. Relación entre grado de importancia de vida erótica en relaciones de pareja y variables sociodemográficas y relacionadas con la lesión.

No se encuentra relación estadísticamente significativa entre el grado de importancia de vida erótica y las relaciones de pareja y las variables sociodemográficas, ni relacionadas con la lesión. 


\subsection{Frecuencia de obtención de orgasmo}

La distribución sobre la frecuencia de obtención de orgasmo (cuando se produce una alta excitación) se desglosa en: el $42,9 \%(n=36)$ no tiene orgasmo nunca, el $16,7 \%(n=14)$ lo tiene a veces, un $14,3 \%(n=12)$ lo tiene a menudo, un $14,3 \%(n=12)$ siempre y un $11,9 \%$ $(n=10)$ lo tiene rara vez.

\subsection{Grado de placer o disfrute obtenido con los orgasmos y grado de placer o disfrute obtenido a lo largo de la relación erótica (no valorando exclusivamente el momento del orgasmo)}

Las distribuciones sobre el grado de disfrute o placer obtenidos tanto en el momento del orgasmo como a lo largo de la relación erótica vienen expresadas en el gráfico 9.

Gráfico 9: distribución sobre el grado de placer o disfrute obtenido con la relación sexual en general y con el orgasmo

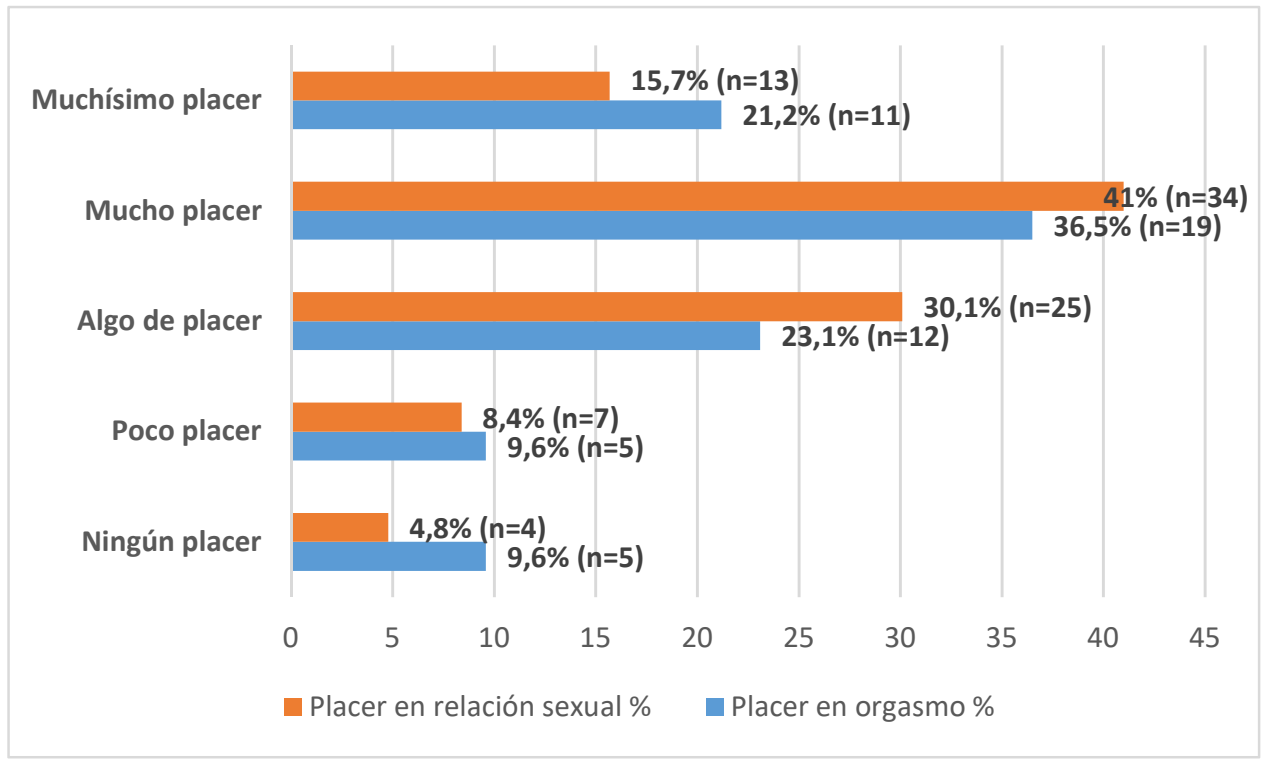

4.2.4.1.1. Relaciones entre el grado de placer durante la relación sexual y el orgasmo y variables sociodemográficas

El grado de placer sentido durante las relaciones eróticas presenta una relación estadísticamente significativa con el estado civil con un $\mathrm{p}$ valor=0,019; de los que tienen ninguno, poco o algo de placer, el $60 \%(n=21)$ son solteros, separados o viudos y el $40 \%$ 
$(n=14)$ casados o en pareja. De las personas que tienen mucho o muchísimo placer, el $66 \%(n=31)$ estaban casados o en pareja y el $34 \%(n=16)$, solteros, separados o viudos.

No se encuentra relación estadísticamente significativa con el resto de variables.

\subsection{Relaciones entre el grado de placer durante la relación sexual y el orgasmo y variables relacionadas con la lesión}

El grado de placer sentido durante el orgasmo presenta una relación estadísticamente significativa con el nivel de la lesión con un $p$ valor=0,05. De las personas que sienten mucho o muchísimo placer durante el orgasmo, un $46,4 \% \quad(n=13)$ tienen lesiones cervicales, un $46,4(n=13)$ dorsales y un $7,1 \%$ lumbosacras $(n=2)$.

En la tabla 43 se presentan las principales relaciones respecto al grado de placer durante la relación sexual y durante el orgasmo y la sensibilidad en el área genital y anal y la preocupación por el escape de orina y heces durante la relación sexual.

Tabla 43: relaciones entre el grado de placer durante la relación sexual y el orgasmo, y la presencia de sensibilidad en el área genital y anal y la preocupación por el escape de orina y heces durante la relación sexual 


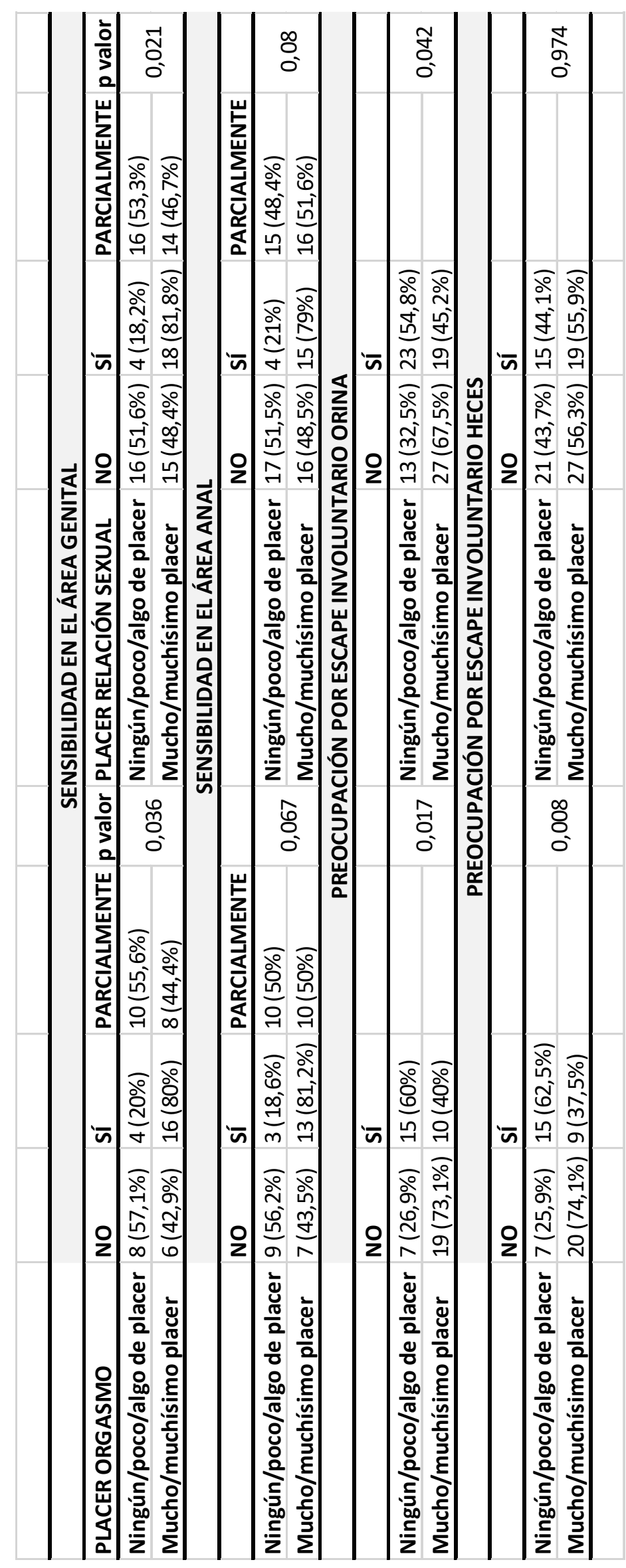




\subsection{Percepción de la imagen corporal previa a la lesión y actual.}

La distribución sobre la percepción de la imagen corporal previa a la lesión y en la actualidad se encuentra detallada en el gráfico 10.

Gráfico 10: percepción de la imagen corporal previa a la lesión medular y actual

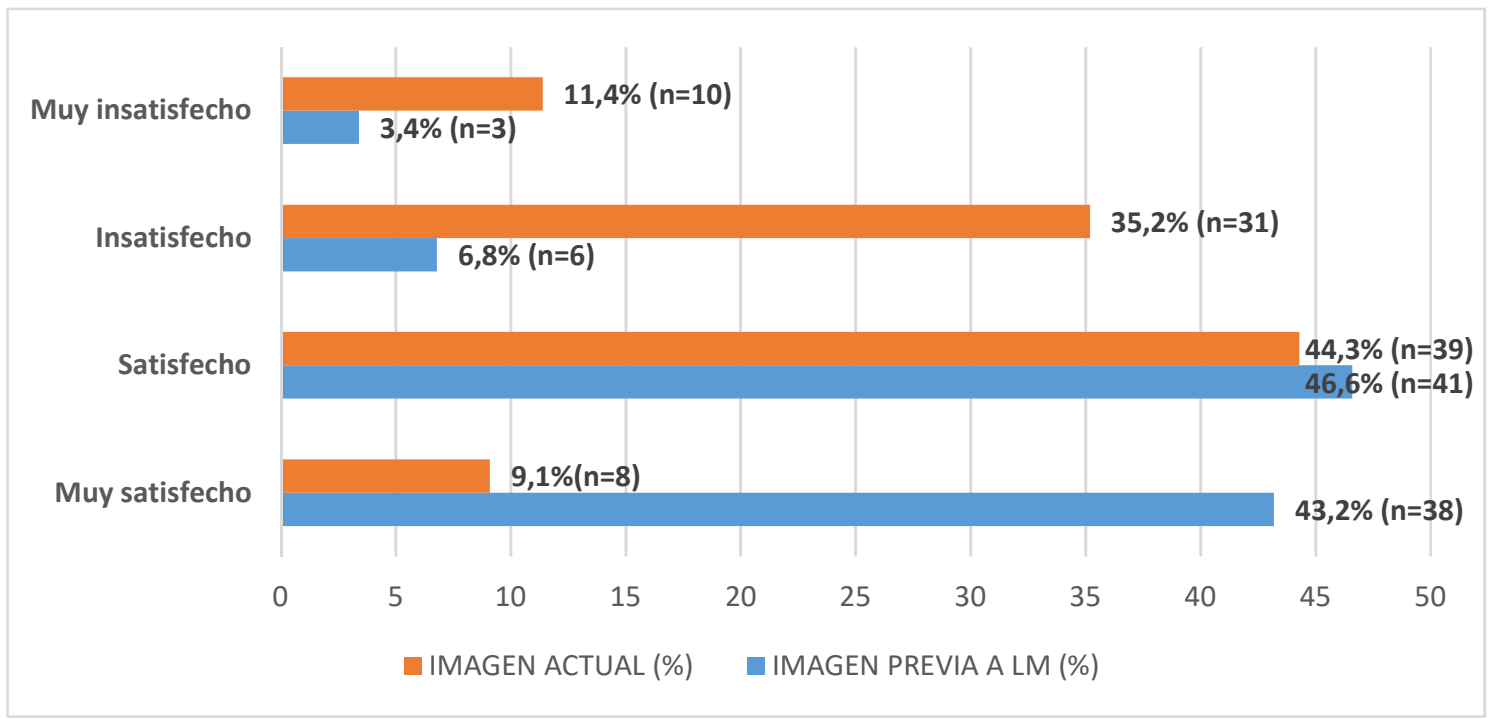

4.2.4.1.8.1. Relación entre la percepción de la imagen corporal actual y variables sociodemográficas y relacionadas con la lesión

Se encuentra una relación estadísticamente significativa entre el núcleo de convivencia y la imagen actual con un $\mathrm{p}$ valor=0,039. De las personas que viven con sus padres o en instituciones, un $68,18 \%(n=15)$ se encuentran insatisfechos o muy insatisfechos con su imagen corporal. No se encuentra relación estadísticamente significativa con el resto de variables sociodemográficas ni con las variables relacionadas con la LMT.

4.2.4.1.9. Cambio sobre percepción de capacidad de seducción tras la lesión medular

La distribución sobre el cambio sobre la percepción de la capacidad de seducción tras la lesión medular se especifica en el gráfico 11. 
Gráfico 11: cambio sobre la percepción de capacidad de seducción tras la lesión medular

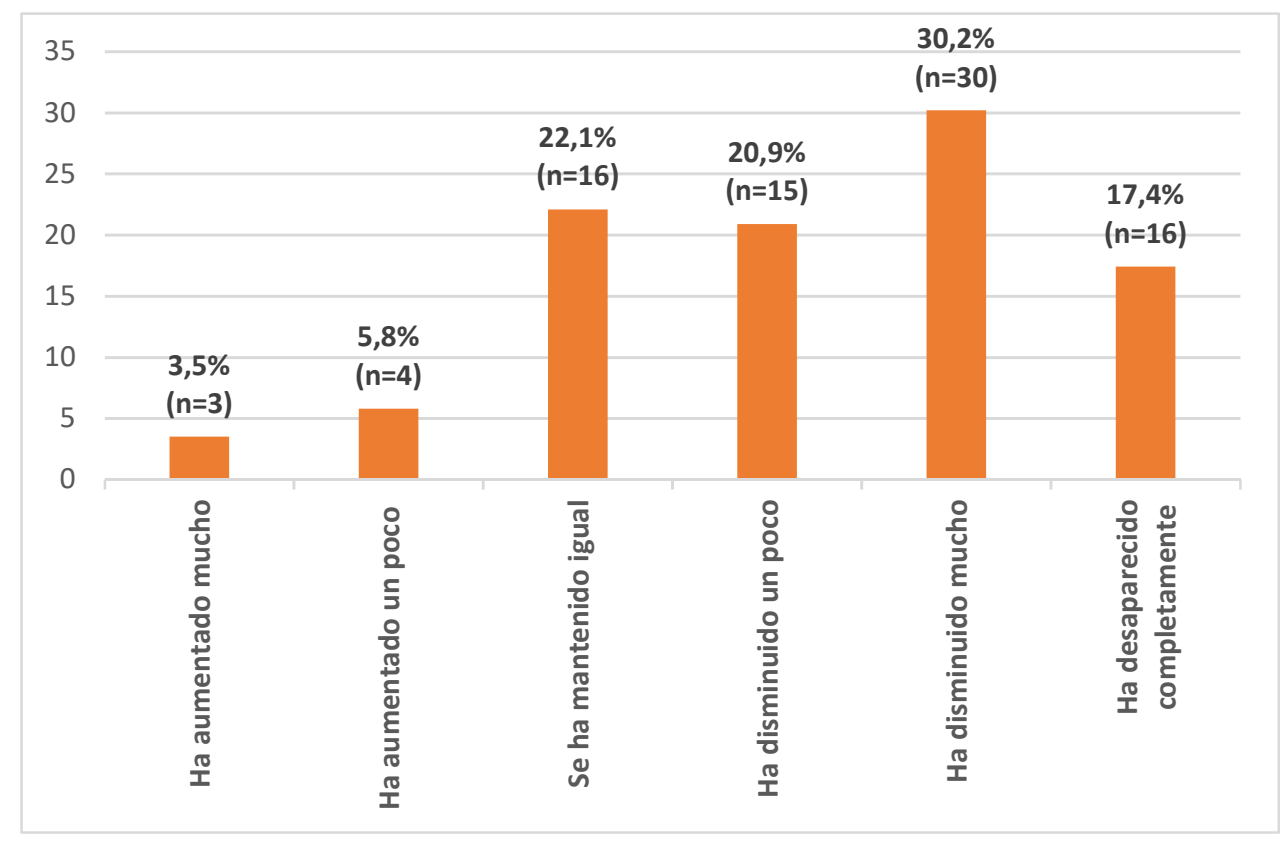

4.2.4.1.9.1. Relación entre el cambio de percepción en la capacidad de seducción y variables sociodemográficas y relacionadas con la lesión

El cambio de percepción en la capacidad de seducción se encuentra relacionado con el estado civil con una relación estadísticamente significativa ( $p$ valor=0,026) El $81,1 \%$ $(n=30)$ de las personas solteras, separadas o viudas, es decir, sin pareja en la actualidad, sienten que su capacidad de seducción se encuentra disminuida o desaparecida. El $74,1 \%(n=20)$ de las personas casadas o en pareja perciben que su capacidad de seducción se encuentra igual o aumentada.

El resto de variables sociodemográficas y relacionadas con la lesión no se encuentran estadísticamente relacionadas con el cambio de percepción en la capacidad de seducción.

\subsection{Cambios en la satisfacción con la vida sexual tras la lesión medular}

La distribución sobre los cambios en la satisfacción con la vida sexual tras la lesión medular se especifica en el gráfico 12. 
Gráfico 12: cambios en la satisfacción con la vida sexual tras la lesión medular

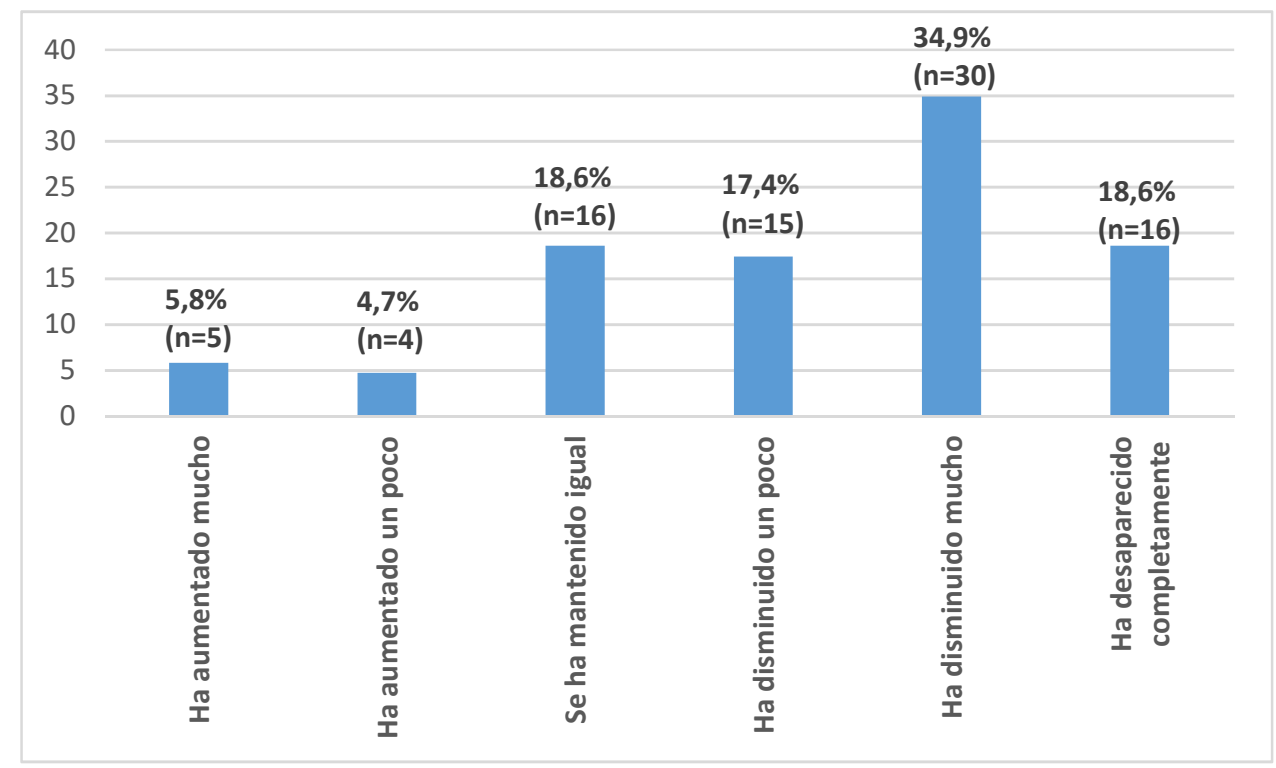

4.2.4.1.10.1. Relación entre el cambio de satisfacción con la vida sexual tras la lesión medular y variables sociodemográficas y relacionadas con la lesión

Se encuentra una relación estadísticamente significativa entre la presencia de sensibilidad en el área genital y el cambio en la satisfacción de la vida sexual: de las personas sin sensibilidad genital, el $76,5 \%(n=26)$ tiene su satisfacción disminuida en distinto grado (poco, mucho o completamente); también la tiene disminuida, un $80 \%$ $(n=24)$ de los lesionados con sensibilidad parcial y un $50 \%(n=11)$ de los lesionados medulares con presencia de sensibilidad $(p=0,041)$.

No se encuentra relación con el resto de variables sociodemográficas ni relacionadas con la LMT.

\subsection{Percepción sobre el grado de satisfacción a la pareja}

La distribución sobre el grado de satisfacción a la pareja viene detallada en la tabla 44: 
Tabla 44: percepción sobre el grado de satisfacción a la pareja

\begin{tabular}{lcc}
\hline Grado satisfacción pareja & $\mathbf{n}$ & $\mathbf{\%}$ \\
\hline Casi nunca & 8 & 12,3 \\
\hline Pocas veces & 7 & 10,8 \\
\hline Algunas veces & 11 & 16,9 \\
\hline Muchas veces & 17 & 26,2 \\
\hline Casi siempre & 22 & 33,8 \\
\hline Total & 65 & 100 \\
\hline
\end{tabular}

4.2.4.11.1. Relación entre la percepción sobre el grado de satisfacción a la pareja y variables sociodemográficas y relacionadas con la lesión

Se encuentra una relación estadísticamente significativa entre la percepción en el grado de satisfacción a la pareja y el tipo de lesión según afectación de miembros: un $84,2 \%(n=16)$ de las personas con tetraplejia (completa e incompleta) consideran satisfacen a su pareja muchas veces o casi siempre y un $52,6 \%(n=20)$ de las personas con paraplejia (completa e incompleta), con un $\mathrm{p}$ valor $=0,02$.

No se encuentra relación con el resto de variables.

\subsection{Satisfacción sobre el deseo de procreación}

La distribución sobre el deseo de procreación viene detallada en el gráfico 13:

Gráfico 13: satisfacción con el deseo de procreación

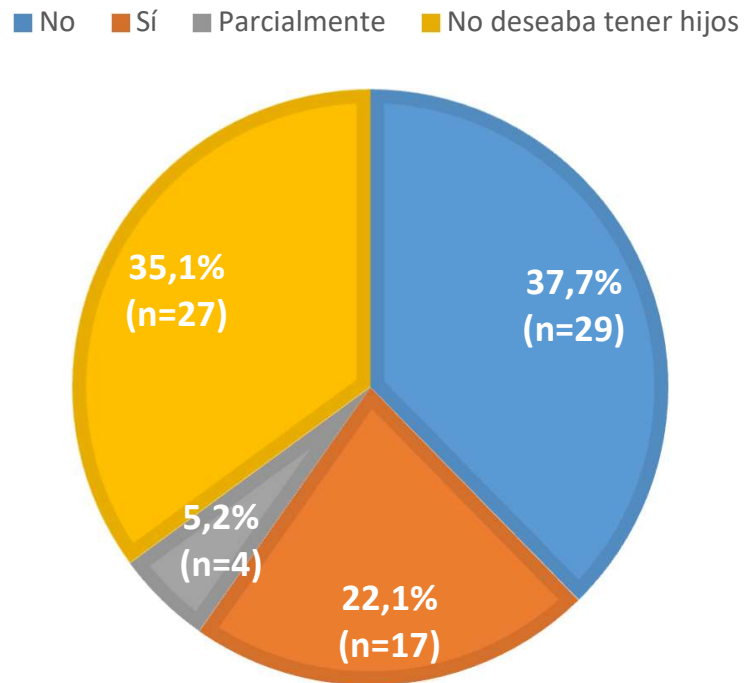


4.2.4.1.12.1. Relación entre la satisfacción con el deseo de procreación y variables sociodemográficas y relacionadas con la lesión

El deseo de procreación se encuentra relacionado con el estado civil y el núcleo de convivencia.

Respecto al estado civil, el $83,3 \%(n=30)$ de los solteros, separados o viudos no tienen su deseo de procreación resuelto, y el $62,5 \%(n=25)$ de los casados o convivientes en pareja ( $p$ valor $=0,043$ )

Respecto al núcleo de convivencia, el 64,9\% $(n=37)$ de las personas que viven en pareja o solos no tiene su deseo de procreación resuelto, y el 95\% ( $n=19)$ de los que conviven con sus padres o en un dispositivo residencial ( $p$ valor $=0,009$ ).

No se encuentra relación con el resto de variables sociodemográficas ni relacionadas con la LMT.

\subsection{Uso de ayudas para tener hijos}

La distribución del uso de apoyos para tener hijos se encuentra detallada en la tabla 45.

Tabla 45: uso de apoyos para tener hijos

\begin{tabular}{lcc}
\hline Ayudas para tener hijos & $\mathbf{n}$ & $\%$ \\
\hline Sin ayuda & 44 & 80 \\
\hline Inseminación artificial & 2 & 3,6 \\
\hline Inseminación artificial con donante & 0 & 0 \\
\hline Fertilización in vitro & 4 & 7,3 \\
\hline Fertilización in vitro con donante & 0 & 0 \\
\hline Uso de vibradores & 3 & 5,5 \\
\hline Otros & 2 & 3,6 \\
\hline Total & 55 & 100 \\
\hline
\end{tabular}

\subsection{Resultados referentes al cuestionario SIS}

Los resultados sobre deseo sexual actual comparado con la situación previa a la lesión y sobre la importancia dada a la sexualidad en comparación con la situación previa a la LM se muestra en las tablas 46 y 47. 
Tabla 46: deseo sexual ahora comparado con la situación previa a la lesión medular

\begin{tabular}{lcc}
\hline & $\mathbf{n}$ & $\mathbf{\%}$ \\
\hline Inexistente & 12 & 13,8 \\
\hline Disminuido & 28 & 32,2 \\
\hline Sin cambio & 36 & 41,4 \\
\hline Aumentado & 11 & 12,6 \\
\hline Total & 87 & 100 \\
\hline
\end{tabular}

Tabla 47: importancia dada a la sexualidad en comparación con la situación previa a la lesión medular

\begin{tabular}{lcc}
\hline & $\mathbf{n}$ & $\mathbf{\%}$ \\
\hline Inexistente & 5 & 5,8 \\
\hline Disminuida & 27 & 31,4 \\
\hline Sin cambio & 37 & 43 \\
\hline Aumentada & 17 & 19,8 \\
\hline Total & 86 & 100 \\
\hline
\end{tabular}

La satisfacción con las relaciones eróticas de pareja antes de la lesión y en la actualidad se muestra en el gráfico 14.

Gráfico 14: satisfacción con las relaciones eróticas de pareja antes de la LM y en la actualidad

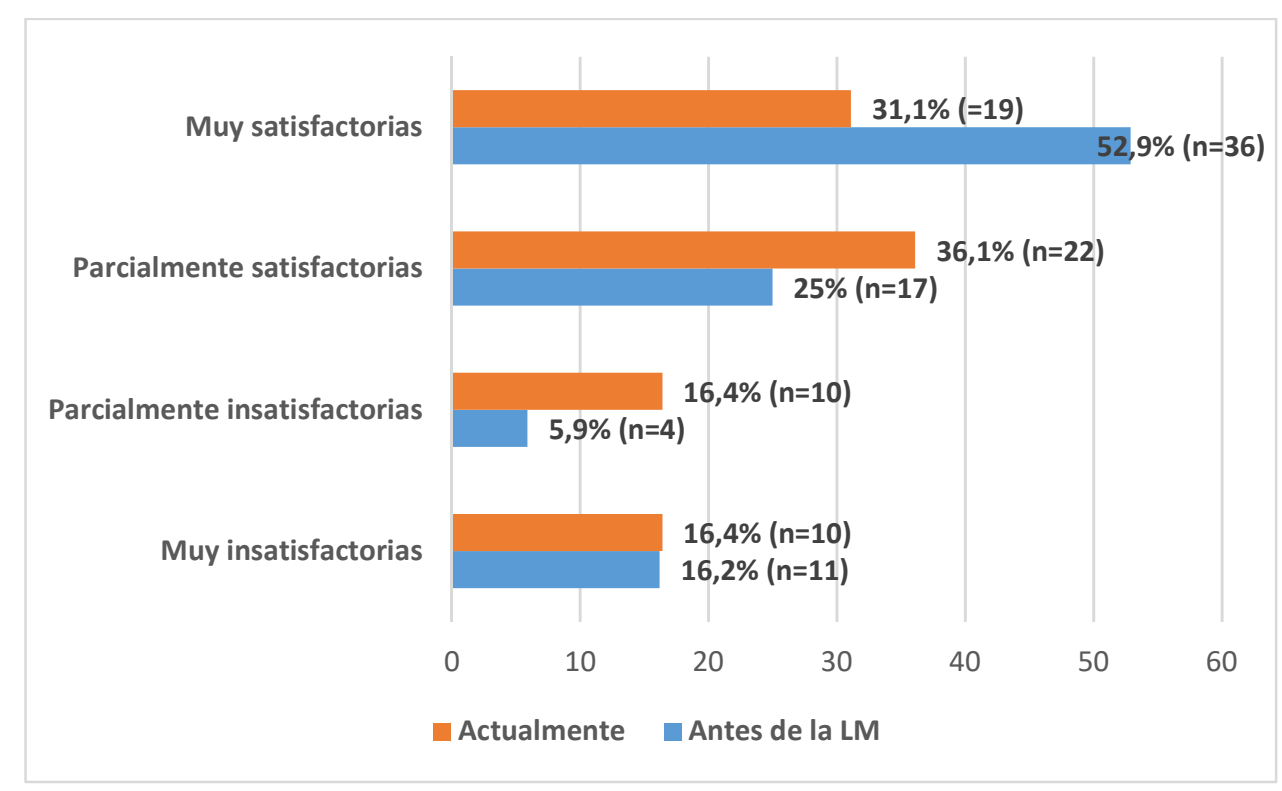

Las posibilidades y habilidades para satisfacer su propia sexualidad y la de su pareja se muestran en el gráfico 15. 
Gráfico 15: posibilidades y habilidades para satisfacer su propia sexualidad y la de su pareja

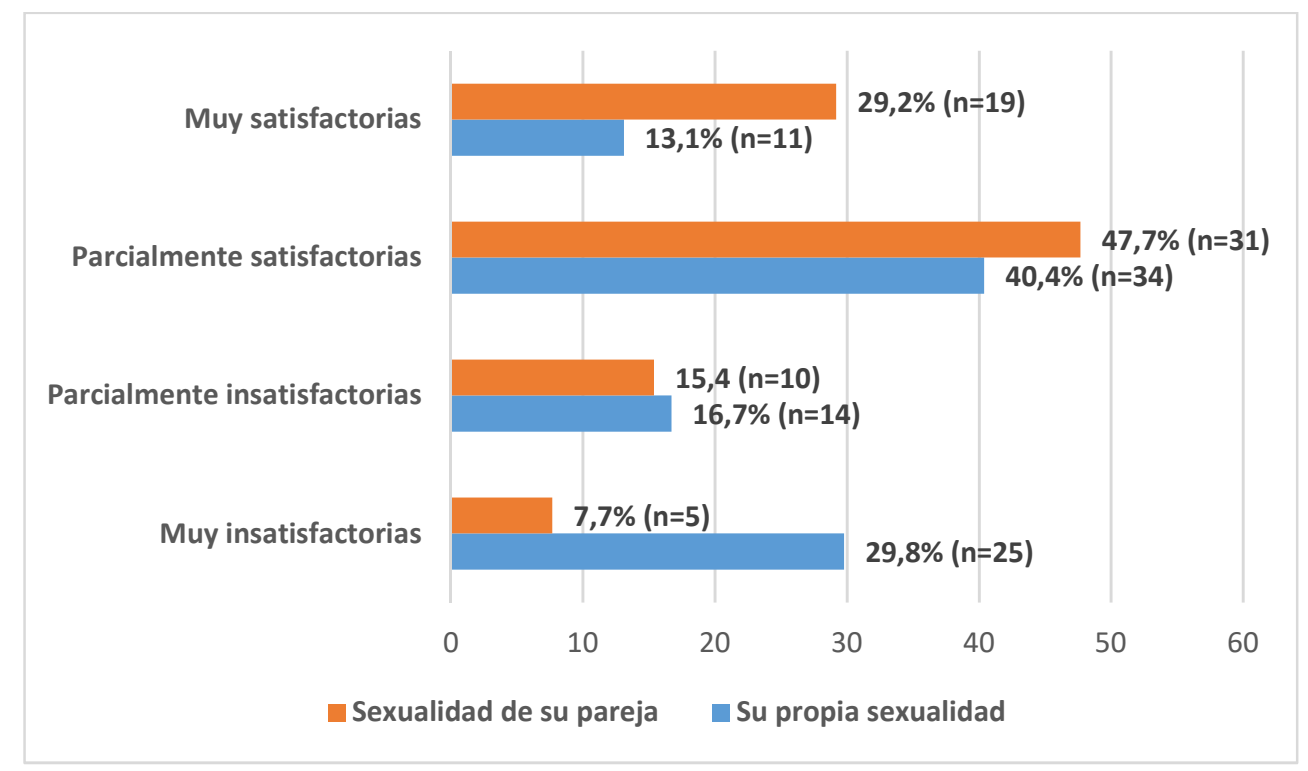

La media del sumatorio SIS es 8,93 con una $D E=4,09$ y una mediana de 8,50 .

La resta del SIS antes-después de la lesión es de 0,07 con una $D E=2,50$ y una mediana de 0.

\subsection{Relación entre sumatorio SIS y variables sociodemográficas}

Se encuentra una relación estadísticamente significativa entre el sumatorio SIS y el estado civil agrupado en soltero, separado o divorciado o viudo, es decir, sin pareja en la actualidad y en pareja o casado, es decir, con pareja en la actualidad. Esta se muestra en la tabla 48:

Tabla 48: relación entre el sumatorio SIS y el estado civil

\begin{tabular}{lccccccc}
\hline & $\mathbf{n}$ & Media & Mediana & DT & p25 & p75 & p valor \\
\hline Sin pareja & 39 & 7,13 & 7 & 4,03 & 5 & 9,5 & \multirow{2}{*}{$<0,001$} \\
\hline Con pareja & 48 & 10,42 & 11 & 3,58 & 8 & 13 & \\
\hline
\end{tabular}

No se encuentra relación estadísticamente significativa con el resto de variables sociodemográficas. 
4.2.4.1.14.2. Relación entre sumatorio SIS y preocupación por el escape de orina y heces durante las relaciones eróticas

Se encuentra una relación estadísticamente significativa entre la preocupación por el escape de orina y el sumatorio SIS, no encontrándose respecto a la preocupación por el escape de heces. Esto se muestra en la tabla 49.

Tabla 49: relación entre el sumatorio SIS y la preocupación por el escape de orina y heces durante las relaciones eróticas

\begin{tabular}{llccccccc}
\hline & & $\mathbf{n}$ & Media & Mediana & DT & p25 & p75 & p valor \\
\hline Preocupación & No & 41 & 10,44 & 11 & 3,94 & 8 & 13 & \multirow{2}{*}{0,002} \\
\cline { 2 - 10 } escape orina & Sí & 15 & 7,78 & 7 & 3,69 & 5 & 11 & \\
\hline Preocupación & No & 48 & 9,52 & 10 & 4,1 & 7 & 13 & \multirow{2}{*}{0,291} \\
\cline { 2 - 9 } escape heces & Sí & 37 & 8,59 & 8 & 3,82 & 6 & 12 & \\
\hline
\end{tabular}

\subsection{Relación entre sumatorio SIS y tiempo de lesión}

Existe una relación estadísticamente significativa entre el sumatorio SIS y el tiempo de lesión con un $\mathrm{p}$ valor=0,035.

\subsubsection{Resultados referentes a los hombres}

\subsection{Resultados referentes al Sexual Health Inventory for Men (IEEF-5)}

Los resultados del IEEF-5 sobre confianza en poder tener y mantener una erección, frecuencia en las que las erecciones tienen dureza suficiente para la penetración, frecuencia en las que se ha podido mantener la erección tras la penetración, grado de dificultad en el mantenimiento de la erección hasta el final del acto sexual y frecuencia de relaciones sexuales satisfactorias, todo ello referido a los últimos 6 meses, viene especificado en las tablas $50,51,52,53$ y 54 respectivamente: 
Tabla 50: grado de confianza de tener y mantener una erección

\begin{tabular}{lcc}
\hline Confianza tener y mantener erección & $\mathbf{n}$ & $\mathbf{\%}$ \\
\hline Muy baja & 20 & 31,2 \\
\hline Baja & 11 & 17,2 \\
\hline Moderada & 14 & 21,9 \\
\hline Alta & 12 & 18,8 \\
\hline Muy alta & 7 & 10,9 \\
\hline Total & 64 & 100 \\
\hline
\end{tabular}

Tabla 51: frecuencia de erecciones con suficiente dureza para la penetración

\begin{tabular}{lcc}
\hline Erecciones suficiente dureza penetración & $\mathbf{n}$ & $\mathbf{\%}$ \\
\hline Casi nunca & 20 & 32,3 \\
\hline Pocas veces & 7 & 11,3 \\
\hline Algunas veces & 13 & 21 \\
\hline Muchas veces & 8 & 12,8 \\
\hline Casi siempre & 14 & 22,6 \\
\hline Total & 62 & 100 \\
\hline
\end{tabular}

Tabla 52: frecuencia de mantenimiento de la erección tras la penetración

\begin{tabular}{lcc}
\hline Mantenimiento erección tras penetración & $\mathbf{n}$ & $\mathbf{\%}$ \\
\hline Casi nunca & 23 & 37,8 \\
\hline Pocas veces & 8 & 13,1 \\
\hline Algunas veces & 16 & 26,2 \\
\hline Muchas veces & 6 & 9,8 \\
\hline Casi siempre & 8 & 13,1 \\
\hline Total & 61 & 100 \\
\hline
\end{tabular}

Tabla 53:grado de dificultad en el mantenimiento de la erección hasta el final del acto sexual

\begin{tabular}{lcc}
\hline Dificultad para mantener erección & $\mathbf{n}$ & $\mathbf{\%}$ \\
\hline Extremadamente difícil & 17 & 28,3 \\
\hline Muy difícil & 13 & 21,7 \\
\hline Difícil & 9 & 15 \\
\hline Ligeramente difícil & 8 & 13,3 \\
\hline Nada difícil & 13 & 21,7 \\
\hline Total & 60 & 100 \\
\hline
\end{tabular}


Tabla 54: frecuencia de relaciones sexuales satisfactorias

\begin{tabular}{lcc}
\hline Satisfacción en relaciones sexuales & $\mathbf{n}$ & $\mathbf{\%}$ \\
\hline Casi nunca & 16 & 26,3 \\
\hline Pocas veces & 6 & 9,8 \\
\hline Algunas veces & 13 & 21,3 \\
\hline Muchas veces & 13 & 21,3 \\
\hline Casi siempre & 13 & 21,3 \\
\hline Total & 61 & 100 \\
\hline
\end{tabular}

Los resultados sobre el grado de disfunción eréctil vienen detallados en el gráfico 16.

Gráfico 16: grado de disfunción eréctil

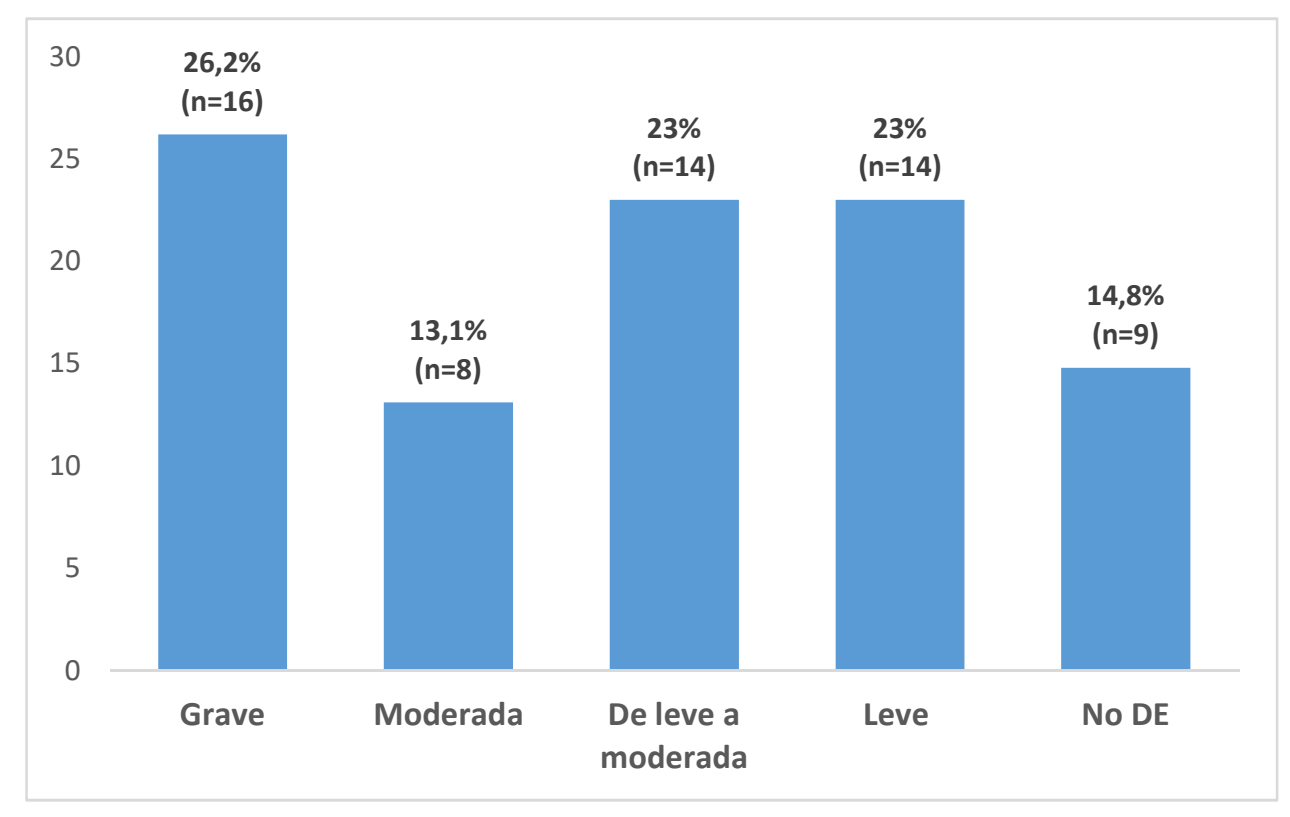

El 85,2\% ( $n=52)$ de los hombres presentan disfunción eréctil de algún grado.

La media sobre el sumatorio de IEEF-5 es de 9,59 con una $D E=8,15$, teniendo una mediana de 8.

4.2.4.2.1.1. Relación entre el grado de disfunción eréctil y variables relacionadas con la lesión

Si se compara el grado de disfunción eréctil con el tipo de lesión (según afectación de miembros y según el nivel neurológico) se encuentra una relación estadísticamente significativa. Ver tablas 55 y 56 : 
Tabla 55: relación entre grado de disfunción eréctil y tipo de lesión medular según afectación de miembros

\begin{tabular}{lccccc}
\cline { 2 - 5 } & \multicolumn{2}{c}{ Paraplejia $\left(\mathbf{C}+\mathbf{I}^{*}\right)$} & \multicolumn{2}{c}{ Tetraplejia $\left(\mathbf{C}+\mathbf{I}^{*}\right)$} & \\
\cline { 2 - 5 } & $\mathbf{n}$ & $\mathbf{\%}$ & $\mathbf{n}$ & $\mathbf{\%}$ & p valor \\
\hline Leve & 2 & 6,1 & 10 & 47,6 & \\
\cline { 1 - 5 } De leve a moderada & 8 & 24,2 & 4 & 19,1 & \multirow{2}{*}{0,012} \\
\cline { 1 - 5 } Moderada & 6 & 18,2 & 2 & 9,5 & \\
\cline { 1 - 5 } Grave & 11 & 33,3 & 3 & 14,3 & \\
\hline No DE & 6 & 18,2 & 2 & 9,5 & \\
\hline Total & 33 & 100 & 21 & 100 \\
\hline
\end{tabular}

${ }^{*} \mathrm{C}$ : completa, I: incompleta

Tabla 56: relación entre grado de disfunción eréctil y tipo de lesión medular según nivel neurológico

\begin{tabular}{|c|c|c|c|c|c|c|c|}
\hline & \multicolumn{2}{|c|}{ Cervical } & \multicolumn{2}{|c|}{ Dorsal } & \multicolumn{2}{|c|}{ Lumbo-sacra } & \multirow[b]{2}{*}{ p valor } \\
\hline & $\mathbf{n}$ & $\%$ & $\mathbf{n}$ & $\%$ & $\mathbf{n}$ & $\%$ & \\
\hline Leve & 11 & 47,9 & 1 & 3,7 & 2 & 25,0 & \multirow{5}{*}{0,021} \\
\hline De leve a moderada & 4 & 17,4 & 6 & 22,2 & 2 & 25,0 & \\
\hline Moderada & 2 & 8,7 & 5 & 18,5 & 1 & 12,5 & \\
\hline Grave & 3 & 13,0 & 9 & 33,4 & 3 & 37,5 & \\
\hline No DE & 3 & 13,0 & 6 & 22,2 & 0 & 0 & \\
\hline Total & 23 & 100 & 27 & 100 & 8 & 100 & \\
\hline
\end{tabular}

Existe una relación estadísticamente significativa entre el grado de disfunción eréctil y la presencia de UPP ( $p$ valor=0,025), no existiendo relación con el resto de complicaciones secundarias. Ver tabla 57.

Tabla 57: relación entre grado de disfunción eréctil y presencia de úlceras por presión

\begin{tabular}{|c|c|c|c|c|c|}
\hline & \multicolumn{2}{|c|}{ NO UPP } & \multicolumn{2}{|c|}{ UPP } & \multirow[b]{2}{*}{$p$ valor } \\
\hline & $\mathbf{n}$ & $\%$ & $\mathbf{n}$ & $\%$ & \\
\hline Leve & 8 & 25,8 & 6 & 20,7 & \multirow{5}{*}{0,025} \\
\hline De leve a moderada & 5 & 16,1 & 8 & 27,7 & \\
\hline Moderada & 1 & 3,2 & 7 & 24,1 & \\
\hline Grave & 9 & 29,0 & 7 & 24,1 & \\
\hline No DE & 8 & 25,9 & 1 & 3,4 & \\
\hline Total & 31 & 100 & 29 & 100 & \\
\hline
\end{tabular}


Si se analiza la relación entre el grado de disfunción eréctil y la presencia de sensibilidad genital y anal, se encuentra una relación estadísticamente significativa. Esta se muestra en las tablas 58 y 59 respectivamente.

Tabla 58: relación entre grado de disfunción eréctil y presencia de sensibilidad genital

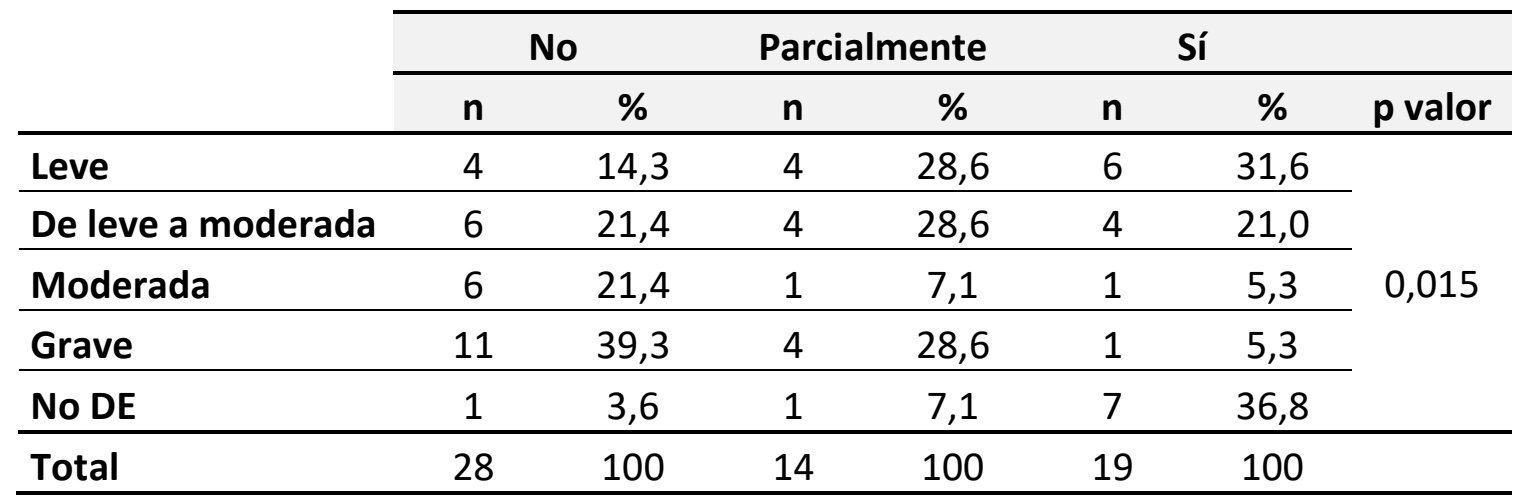

Tabla 59: relación entre grado de disfunción eréctil y presencia de sensibilidad anal

\begin{tabular}{|c|c|c|c|c|c|c|c|}
\hline & \multirow{2}{*}{\multicolumn{2}{|c|}{ No }} & \multirow{2}{*}{\multicolumn{2}{|c|}{ Parcialmente }} & \multirow{2}{*}{\multicolumn{2}{|c|}{ Sí }} & \multirow[b]{3}{*}{ p valor } \\
\hline & & & & & & & \\
\hline & $\mathbf{n}$ & $\%$ & $\mathrm{n}$ & $\%$ & $\mathbf{n}$ & $\%$ & \\
\hline Leve & 4 & 13,8 & 4 & 26,7 & 6 & 35,3 & \multirow{5}{*}{0,035} \\
\hline De leve a moderada & 6 & 20,7 & 5 & 33,2 & 3 & 17,6 & \\
\hline Moderada & 7 & 24,1 & 1 & 6,7 & 0 & 0,0 & \\
\hline Grave & 10 & 34,5 & 4 & 26,7 & 2 & 11,8 & \\
\hline No DE & 2 & 6,9 & 1 & 6,7 & 6 & 35,3 & \\
\hline Total & 29 & 100 & 15 & 100 & 17 & 100 & \\
\hline
\end{tabular}

Se encuentra una relación estadísticamente significativa entre el grado de disfunción eréctil y el tipo de vaciamiento intestinal según su control volitivo. Esto se muestra en la tabla 60.

Tabla 60: relación entre grado de disfunción eréctil y tipo de vaciamiento intestinal

\begin{tabular}{|c|c|c|c|c|c|}
\hline & \multirow{2}{*}{\multicolumn{2}{|c|}{ Voluntario }} & \multirow{2}{*}{\multicolumn{2}{|c|}{ Involuntario }} & \\
\hline & & & & & \multirow[b]{2}{*}{ p valor } \\
\hline & $\mathbf{n}$ & $\%$ & $\mathbf{n}$ & $\%$ & \\
\hline Leve & 4 & 23,6 & 10 & 22,7 & \multirow{5}{*}{0,006} \\
\hline De leve a moderada & 3 & 17,6 & 11 & 25,0 & \\
\hline Moderada & 0 & 0,0 & 8 & 18,2 & \\
\hline Grave & 3 & 17,6 & 13 & 29,5 & \\
\hline No DE & 7 & 41,2 & 1 & 4,6 & \\
\hline Total & 17 & 100 & 43 & 100 & \\
\hline
\end{tabular}




\subsection{Ayudas para conseguir o mantener la erección}

La distribución de ayudas para conseguir o mantener la erección es: el 42,6\% utiliza fármacos orales, el 6,6\% $(n=4)$ fármacos inyectados en el pene y el 1,6\% $(n=1)$ tiene una prótesis peneana. El 49,2\% no utiliza ningún fármaco para la erección.

\subsection{Relación entre el uso de ayudas para conseguir o mantener la erección y variables sociodemográficas}

Se encuentra una relación estadísticamente significativa entre el uso de ayudas para conseguir o mantener la erección y el estado civil ( $p$ valor=0,009). De las personas que utilizan fármacos para ayudar a la erección, el $61,3 \%(n=19)$ se encuentran solteros, separados o viudos. De las personas que no utilizan fármacos, el $63,6 \%(n=21)$ está casado o convive en pareja.

4.2.4.2.2. Relación entre el uso de ayudas para conseguir o mantener la erección y variables relacionadas con la lesión medular

Se encuentra una relación estadísticamente significativa entre el tipo de vaciamiento intestinal y el uso de ayudas para la erección $(p=0,038)$. De las personas que utilizan ayudas para la erección, el $83,9 \%(n=26)$ tienen un vaciamiento intestinal involuntario.

4.2.4.2.3. Frecuencia de capacidad de eyacular cuando se encuentra muy excitado y uso de ayudas para facilitar la eyaculación.

La distribución de la frecuencia de la capacidad de eyacular viene desglosada en la tabla 61.

Tabla 61: distribución de la frecuencia de la capacidad de eyacular

\begin{tabular}{lcc}
\hline Capacidad eyacular & $\mathbf{n}$ & \% \\
\hline Nunca & 34 & 54,8 \\
\hline Rara vez & 8 & 12,9 \\
\hline A veces & 4 & 6,5 \\
\hline A menudo & 8 & 12,9 \\
\hline Siempre & 8 & 12,9 \\
\hline Total & 62 & 100 \\
\hline
\end{tabular}




\subsection{Relación entre la capacidad de eyacular y el estado civil}

Se encuentra una relación estadísticamente significativa entre la frecuencia de eyacular cuando existe una alta excitación y el estado civil $(p=0,034)$. De los lesionados que eyaculan a veces, a menudo o siempre, el $75 \%(n=15)$ se encuentra casado o conviviendo en pareja.

\subsection{Relación entre la capacidad de eyacular y las variables relacionadas con la lesión}

Se encuentra una relación estadísticamente significativa entre el tipo de lesión según extensión y la frecuencia de eyacular cuando existe una alta excitación $(p=0,038)$. El $76,7 \%(n=23)$ de los hombres con lesión completa y el $50 \%(n=13)$ eyaculan rara vez 0 nunca.

Se encuentra una relación estadísticamente significativa entre la presencia de sensibilidad en el área genital y la frecuencia de eyaculación cuando se está muy excitado $(p=0,014)$. De los lesionados medulares que eyaculan a veces, a menudo o siempre, el $55 \%(n=11)$ tienen sensibilidad genital, el $25 \%(n=5)$ no la tienen y el $20 \%$ $(n=4)$ la tienen parcialmente. De los lesionados que eyaculan rara vez o nunca, el $57,1 \%$ ( $n=24)$ no tienen sensibilidad en el área genital, el $23,8 \%(n=10)$ la tienen de forma parcial y el $19,1 \%(n=8)$ no tienen sensibilidad. No existe relación estadísticamente significativa con la presencia de sensibilidad en el área anal.

Se encuentra una relación estadísticamente significativa entre el tipo de vaciamiento intestinal y la frecuencia de eyaculación $(p=0,032)$. De las personas con vaciamiento intestinal voluntario, el $52,9 \%(n=9)$ eyaculan a veces, a menudo o siempre; de las personas con vaciamiento involuntario, el $75,6 \%(n=34)$ eyaculan rara vez o nunca.

Un 11,9\% ( $n=8)$ utiliza vibradores peneanos para facilitar la eyaculación. 


\subsubsection{Resultados relacionados con la sexualidad de las mujeres}

\subsection{Grado de excitabilidad}

La distribución sobre la frecuencia de excitarse con facilidad con las cosas que le gustan viene reflejada en el gráfico 17:

Gráfico 17: frecuencia de excitarse con facilidad con las cosas que le gustan

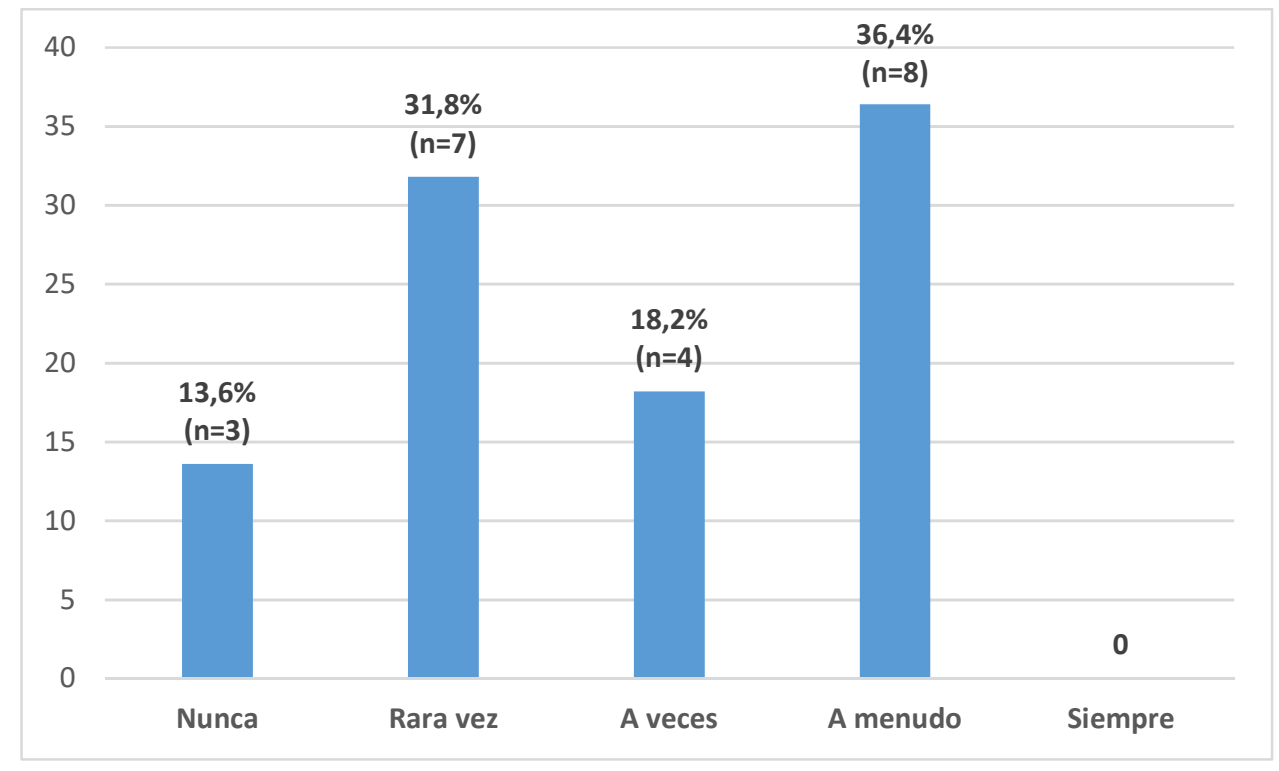

No se encuentran relaciones estadísticamente significativas entre la facilidad de excitarse con las cosas que le gustan y las variables sociodemográficas o relacionadas con la lesión.

\subsection{Frecuencia en consecución de excitación y pérdida de interés.}

La distribución sobre la frecuencia en la consecución de excitación y posterior pérdida de interés se encuentra detallada en la tabla 62. 
Tabla 62: distribución sobre la frecuencia de consecución de excitación y pérdida de interés

\begin{tabular}{lcc}
\hline Excitación y pérdida de interés & $\mathbf{n}$ & $\mathbf{\%}$ \\
\hline Nunca & 4 & 18,3 \\
\hline Rara vez & 7 & 31,8 \\
\hline A veces & 5 & 22,7 \\
\hline A menudo & 5 & 22,7 \\
\hline Siempre & 1 & 4,5 \\
\hline Total & 22 & 100 \\
\hline
\end{tabular}

Se encuentra una relación estadísticamente significativa entre el núcleo de convivencia y la frecuencia de excitación y posterior pérdida de interés. El 100\% ( $n=11)$ de las mujeres a las que esta situación les ocurre rara vez o nunca, viven solas o en pareja y el $54,5 \%(n=6)$ de las que les ocurre a veces, a menudo o siempre.

\subsection{Frecuencia de lubricación vaginal satisfactoria y uso de ayudas para la lubricación}

La distribución sobre la frecuencia de lubricación vaginal satisfactoria se encuentra detallada en la tabla 63.

Tabla 63: distribución sobre la frecuencia de lubricación vaginal satisfactoria durante la actividad sexual

\begin{tabular}{lcc}
\hline Lubricación vaginal satisfactoria & $\mathbf{n}$ & $\mathbf{\%}$ \\
\hline Nunca & 2 & 9,5 \\
\hline Rara vez & 2 & 9,5 \\
\hline A veces & 4 & 19 \\
\hline A menudo & 6 & 28,6 \\
\hline Siempre & 7 & 33,4 \\
\hline Total & 21 & 100 \\
\hline
\end{tabular}

No se encuentra relación estadísticamente significativa entre frecuencia de lubricación satisfactoria y variables sociodemográficas ni relacionadas con la lesión.

Respecto al uso de ayudas para la lubricación: el $81 \%(n=17)$ no utiliza ninguna ayuda y el $19 \%(n=4)$ utiliza hidratantes o lubricantes vaginales. 
No se encuentra relación estadísticamente significativa entre el uso de ayudas para la lubricación y las variables sociodemográficas ni relacionadas con la lesión.

\subsubsection{Percepción sobre si el sistema de salud le ha dado suficiente información y apoyo respecto a cómo enfrentar la sexualidad}

El $85,1 \%(n=74)$ siente que no ha recibido suficiente información y apoyo por parte del sistema de salud respecto a cómo enfrentar su sexualidad.

\subsubsection{Fuentes de información o consejo utilizadas sobre sexualidad tras la lesión medular}

Las fuentes de información utilizadas sobre sexualidad tras la lesión medular vienen detalladas en el gráfico 18:

Gráfico 18: fuentes de información utilizadas sobre sexualidad tras la lesión medular

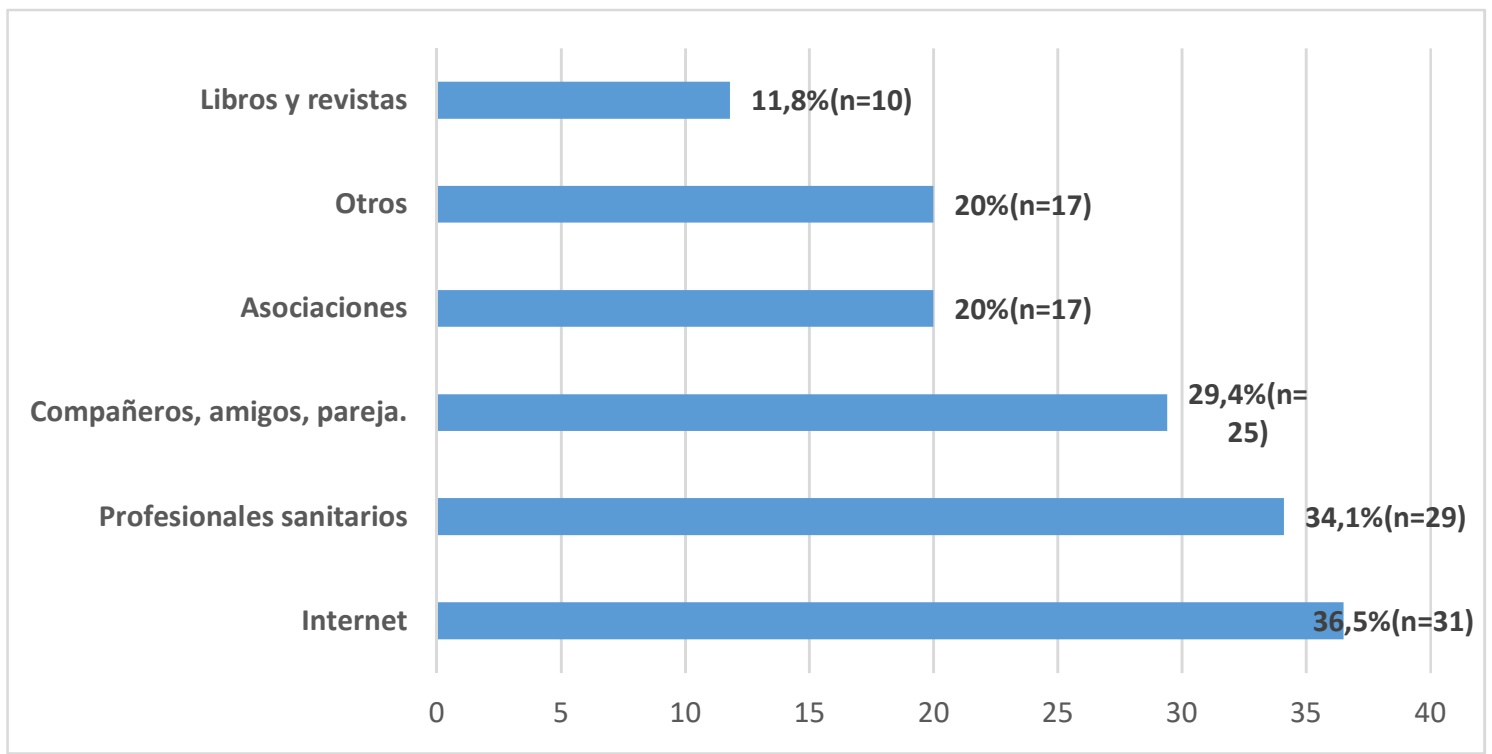

\subsubsection{Relación entre fuentes de información sobre sexualidad tras $\mathrm{LM} y$ variables sociodemográficas.}

Las relaciones entre las fuentes de obtención información sobre sexualidad tras LM y el sexo se encuentran en la tabla 64. Se observa cómo los hombres acuden a informarse más que las mujeres de forma significativa a los profesionales sanitarios, mientras que las mujeres lo hacen en mayor medida a través de compañeros, amigos o parejas. 
Tabla 64: relación entre las fuentes de información sobre sexualidad tras la LM y sexo

\begin{tabular}{|c|c|c|c|c|c|c|c|}
\hline & & \multicolumn{2}{|c|}{ Hombres } & \multicolumn{2}{|c|}{ Mujeres } & \multirow[b]{2}{*}{ Total } & \multirow[b]{2}{*}{$p$ valor } \\
\hline & & $n$ & $\%$ & $n$ & $\%$ & & \\
\hline \multirow{2}{*}{$\begin{array}{l}\text { Profesionales } \\
\text { sanitarios }\end{array}$} & No & 36 & 64,3 & 20 & 35,7 & $56(100 \%)$ & \multirow{2}{*}{0,033} \\
\hline & Sí & 25 & 86,2 & 4 & 13,8 & $29(100 \%)$ & \\
\hline \multirow{2}{*}{$\begin{array}{l}\text { Compañeros, amigos } \\
\text { o parejas }\end{array}$} & No & 48 & 80 & 12 & 20 & $60(100 \%)$ & \multirow{2}{*}{0,009} \\
\hline & Sí & 13 & 52 & 12 & 48 & 25 (100\%) & \\
\hline \multirow{2}{*}{ Asociaciones } & No & 50 & 73,5 & 18 & 26,5 & 68 (100\%) & \multirow{2}{*}{0,55} \\
\hline & Sí & 11 & 64,7 & 6 & 35,3 & 17 (100\%) & \\
\hline \multirow{2}{*}{ Internet } & No & 39 & 72,2 & 15 & 27,8 & $54(100 \%)$ & \multirow{2}{*}{0,902} \\
\hline & Sí & 22 & 71 & 9 & 29 & $31(100 \%)$ & \\
\hline \multirow{2}{*}{$\begin{array}{l}\text { Libros o } \\
\text { revistas }\end{array}$} & No & 53 & 70,7 & 22 & 29,3 & 75 (100\%) & \multirow{2}{*}{0,718} \\
\hline & Sí & 8 & 80 & 2 & 20 & $10(100 \%)$ & \\
\hline
\end{tabular}

\subsubsection{Relación entre obtención de información sobre sexualidad tras la LM y complicaciones secundarias}

Existe una relación entre la obtención de información sobre sexualidad por parte de los profesionales y la presencia de UPP $(p=0,014)$. No existe relación con el resto de complicaciones secundarias.

Si se estudia la relación entre la obtención de información sobre sexualidad por parte de profesionales y el método de vaciamiento intestinal, se ve que el $89,7 \%$ de las personas que obtienen información de los profesionales no tienen un vaciamiento voluntario, es decir, uso de irrigadores, pañal, etc. $(p=0,027)$. No existe relación con el vaciamiento vesical.

No existe ninguna relación entre la obtención de información sobre la sexualidad por parte de las asociaciones ni en internet y el resto de variables.

Esta obtención por parte de compañeros, amigos o parejas, se encuentra relacionada con el tipo de lesión según la extensión, de los que obtienen la información de compañeros, amigos o parejas, el 70,8\% $(n=17)$ tienen una lesión incompleta $(p=0,005)$.

Esta obtención también se encuentra relacionada con la presencia de sensibilidad en el área genital y anal. De los que lo obtienen el $24 \%(n=6)$ no tienen sensibilidad en el área genital, el $20 \%(n=5)$ sí la tienen y el $56 \%(n=14)$ la tiene parcialmente $(p=0,021)$. Si se 
explora la relación con la sensibilidad en el área anal, de los que sí obtienen la información por parte de compañeros, amigos o parejas, el $20 \%(n=5)$ no tiene sensibilidad, el $12 \%(n=3)$ sí la tiene y el $68 \%(n=17)$ la tiene parcialmente. $(p<0,001)$

Si se relaciona la obtención de información o consejo por parte de libros o revistas sobre el tema, con la sensibilidad en el área anal, vemos que el $70 \%(n=7)$ tiene una sensibilidad parcial, el $30 \%(n=3)$ sí tiene sensibilidad y un $0 \%(n=0)$ no tiene sensibilidad $(p=0,005)$.

Se puede resumir que se encuentra relación estadísticamente significativa entre las fuentes de información y las variables estudiadas en aquellos casos expuestos en la tabla 65:

Tabla 65: resumen sobre fuentes de información utilizadas y variables relacionadas

\begin{tabular}{llllll}
\hline & Sexo & $\begin{array}{l}\text { Tipo de lesión } \\
\text { según } \\
\text { extensión }\end{array}$ & $\begin{array}{l}\text { Presencia } \\
\text { sensación } \\
\text { genital }\end{array}$ & $\begin{array}{l}\text { Presencia } \\
\text { sensación } \\
\text { anal }\end{array}$ & $\begin{array}{l}\text { No vaciamiento } \\
\text { intestinal } \\
\text { voluntario }\end{array}$ \\
\hline $\begin{array}{lllll}\text { Profesionales sanitarios } \\
\text { Compañeros, amigos }\end{array}$ & $0,033^{*}$ & 0,797 & 0,508 & 0,391 & $0,027^{*}$ \\
\hline y pareja & $0,009^{*}$ & $0,005^{*}$ & $0,021^{*}$ & $<0,001^{*}$ & 0,08 \\
\hline $\begin{array}{lllll}\text { Asociaciones } \\
\text { Internet }\end{array}$ & 0,55 & 0,807 & 1 & 0,94 & 0,545 \\
\hline Libros y revistas & 0,902 & 0,733 & 0,587 & 0,526 & 0,859 \\
\hline 0,718 & 1 & 0,079 & $0,005^{*}$ & 0,703 \\
\hline
\end{tabular}

\subsubsection{Temas relacionados con la sexualidad tratados por los profesionales de la salud}

En la pregunta abierta sobre temas relacionados con sexualidad que han sido tratados por los profesionales de la salud, un $35,2 \%(n=31)$ dicen que no han sido informados de nada, un $10,2 \%(n=9)$ han sido informados sobre temas referentes a la erección, un $10,2 \%(n=9)$ han sido informados sobre temas relacionados con la fertilidad y la procreación y un 4,5\% ( $n=4)$ sobre temas relacionados con la sexualidad en general. A 
un 2,3\% ( $n=2)$ de las personas les informaron sobre: zonas erógenas, relaciones sexuales alternativas, medicación, satisfacción u orgasmo y manifestaron que la información fue "poca."

Hay diversos temas relacionados con la sexualidad a los que se ha informado a un $1,1 \%$ $(n=1)$ : lubricantes, eyaculación, "sobre todo", sobre fisiología, vejiga neurógena y sexualidad, anticonceptivos, suelo pélvico y masajes.

\subsubsection{Temas sobre los que se hubiera precisado información}

Un 35,2\% ( $n=31)$ dejó la pregunta en blanco, un 11,4\% $(n=10)$ considera que necesita información sobre todo, un 10,2\% ( $n=9)$ sobre la adaptación a la nueva situación y las alternativas, un $7,9 \%(n=7)$ sobre la sexualidad en general y otro $7,9 \%(n=7)$ considera que se le debe informar sobre la sexualidad pero sin concretar los temas, un $6,8 \%(n=6)$ precisa información sobre erecciones, satisfacción, placer u orgasmo, prácticas sexuales alternativas, posturas o prácticas no normativas, un 5,7\% $(n=5)$ sobre masturbación, un $4,5 \%(n=4)$ sobre sensibilidad y asesoramiento de la pareja, un $2,3 \%(n=2)$ sobre grupos de apoyo, eyaculación, autoestima, zonas erógenas y disfunciones sexuales.

Un 1,1\% ( $n=1)$ considera que precisa información sobre: congelación de esperma, sexo anal, infecciones de orina, manejo de la incontinencia, rehabilitación sexual, suelo pélvico, respuesta sexual humana, deseo, ayudas técnicas, habilidades sociales, adaptación psicológica, juguetes eróticos, libros y métodos anticonceptivos.

Un 4,5\% ( $n=4)$ considera que no se le debe informar sobre ningún tema relacionado con la sexualidad.

\subsubsection{Resultados relacionados con la valoración de la figura del asistente sexual}

La opinión sobre la figura del asistente sexual con el fin de acceder al propio cuerpo o al de una pareja: un 53,41\% ( $n=47$ ) está a favor de esta figura, un 7,95\% ( $n=7)$ no tienen opinión sobre ella, un 3,41\% ( $n=3)$ está en contra de su existencia, un 2,27\% ( $n=2)$ creen que es una figura escasa o pobre y un $1,14 \%(n=1)$ cree que no es necesaria en su caso. Un $31,81 \%(n=28)$ ha dejado la pregunta en blanco. 
Respecto a la opinión sobre la figura del asistente sexual entendida como alguien con quien mantener relaciones eróticas: un 48,86\% ( $n=43)$ está a favor, un 7,95\% ( $n=7)$ no tienen opinión sobre ello, un $2,27 \%(n=2)$ están en contra y un $4,55 \%(n=4)$ no lo considera necesario para su caso. Un $36,36 \%(n=32)$ ha dejado la pregunta en blanco.

\subsection{Fase III: Vivencias percibidas en personas con lesión medular adquirida respecto a los cambios acontecidos en su sexualidad a raíz de la lesión medular}

Se realizaron 8 entrevistas a personas con lesión medular: cuatro hombres, tres mujeres y una pareja en la que él tenía la lesión medular.

Las edades de adquisición de la lesión medular fueron: dos personas 17 años, 18, 19, 24, 35,40 y 62 años, con una media de 29, una mediana de 21,5 y una desviación estándar de 15,95 .

El tiempo con la lesión medular fue de: dos personas 2 años, 3, 5, 15, dos personas 23 y 28 años, con una media de 12,62, una mediana de 10 y una desviación estándar de 10,91 .

El estado civil en el momento de la entrevista fue: 3 personas estaban solteras, 3 casadas, 1 convivía en pareja y una divorciada.

Los tipos de lesión medular fueron: C5-C6 incompleta, C5 incompleta, C5-C7 incompleta, D6, dorsal alta, dorsal baja, D6 completa, D11 completa. Es decir, 3 personas con una tetraplejia y 5 con una paraplejia.

Como producto de apoyo para la movilidad, 7 personas utilizaban silla de ruedas y una, muletas.

Características de cada entrevistado:

- H1: hombre de 34 años, con lesión D6 completa desde hace 15 años. La causa de la lesión fue un accidente de tráfico laboral. En la actualidad tiene pareja con la que convive. 
- H2: hombre de 23 años, con lesión C5-C6 incompleta, ASIA B, sin capacidad motora y con sensibilidad parcial infralesional desde hace 5 años. La causa de la lesión fue una zambullida. En la actualidad está soltero.

- H3: hombre de 40 años, con lesión C5-C7 incompleta con movilidad parcial en la parte superior y sensibilidad parcial infralesional desde hace 17 años. La causa de la lesión fue una zambullida. En la actualidad está soltero.

- H4: hombre de 52 años, con lesión D11-D12 completa hace 28 años. La causa de la lesión fue la caída de un andamio por un accidente laboral. En la actualidad se encuentra casado.

- M1: mujer de 40 años, con lesión C5 con sensibilidad parcial infralesional hace 23 años. La causa de la lesión fue un traumatismo por el impacto de un columpio. En la actualidad se encuentra soltera.

- M2: mujer de 42 años, con lesión dorsal baja hace 2 años. La causa de la lesión fue una malformación vascular medular. En la actualidad se encuentra divorciada.

- M3: mujer de 37 años, con lesión D3-D8 hace 2 años. La causa de la lesión fue un infarto medular. En la actualidad se encuentra casada.

- P1: pareja compuesta de un hombre de 65 años con lesión completa D11 desde hace 3 años y su mujer de 64 años. La causa de la lesión fue un atropello.

Tres personas prefirieron su casa para la realización de la entrevista, una, la casa de la entrevistadora principal por proximidad, una la Facultad de Enfermería de Gijón, una el salón de un hotel, otra su centro de salud y otra una cafetería. Seis entrevistas se realizaron en Asturias, una en Vitoria y otra en Zamora.

El tiempo total de grabación fue de 8 horas, 55 minutos, con una media de 64,12 minutos, una mediana de 54 minutos y una desviación estándar de 33,05.

Los resultados del análisis se van a presentar, según las categorías que han ido emergiendo:

- Impacto inicial de la lesión medular

- Percepción respecto a la atención de los profesionales

- Vivencias durante el ingreso hospitalario y en el momento del alta hospitalaria 
- Vivencias de la corporalidad tras la lesión medular

- Proceso de sexuación tras la lesión medular

- Vivencias de la erótica tras la lesión medular

- Vivencias de la amatoria

- Percepciones sobre las limitaciones derivadas de la lesión medular y su relación con la erótica

- Experiencias de reaprendizaje erótico tras la lesión medular

- Percepciones sobre las potencialidades en la erótica derivadas de la lesión medular

- Vivencias sobre la procreación tras la lesión medular

- Vivencias en el ámbito de la pareja tras la lesión medular

- Experiencias de asesoramiento

- Opinión sobre las figuras de apoyo en la sexualidad tras la lesión medular

\subsubsection{Impacto inicial de la lesión medular}

En un primer momento, tras el diagnóstico, se identifica un desconocimiento sobre qué es una lesión medular y qué consecuencias trae asociadas:

Si te digo la verdad hasta que no pasaron...6 meses del accidente, no sabía ni qué era la lesión medular, y solo había estado una vez ingresado que era cuando me rompí el cruzado, pensé que iba a estar una semana o dos y luego para casa, como antes $(\mathrm{H} 2-21)$.

Lo primero que te planteas ahí, primero es el desconocimiento, el no saber qué le pasa a tu cuerpo (H3-6).

Yo durante los primeros, el primer mes o los primeros, no sé...yo le achacaba ciertas cosas primero, a ciertas anestesias que me podían haber inyectado y que hacían que mi cuerpo todavía no respondiese (H3-7).

Cuando se cae en la cuenta de la magnitud de la lesión surgen sentimientos de desconcierto, preocupación o miedo ante la nueva realidad. Se produce un proceso de adaptación mental o duelo. En el proceso de duelo, se llega a la aceptación, siendo consciente de que la realidad del suceso podría haber sido la muerte en vez de la lesión medular. 
Me veía muy perdida. No sabía ni por dónde iba a entrar ni por dónde iba a salir (M2-2).

24 años. Imaginaos el trauma que fue...de una vida... Yo era un tío que vivía en un pueblo, que hacía de todo...trabajaba...estaba casado, recién casado, buscándote la vida con tu, con tu piso nuevo... Me cambió completamente la vida, o sea, eso fue un varapalo impresionante (H4-27).

Puedo tener la sensación de pérdida de ánimo en general, de pérdida de...vamos a decir, de ganas de vivir incluso en algún momento, es decir, de un proceso de duelo de libro, sin más (H3-49).

Cada uno tiene lo suyo, como me dice uno: - ¿Tú eres feliz? -Sí, ¿diferente?, sí, porque lógicamente ahora tienes otra vida, pero bueno, tienes tu familia que te apoya, está contigo, no sé, vas evolucionando, aunque sea poco, chico no sé, y si no, chico, es lo que hay. Como le dije yo, en vez de celebrar el aniversario, podían estar celebrando tu funeral, suena fuerte, pero es así (M3-41).

El proceso de adaptación a la lesión medular suele darse en el hospital debido a que los ingresos derivados por este proceso son largos. En ocasiones toda la rehabilitación se da en el hospital de ingreso y otras veces es precisa la derivación a hospitales de referencia nacionales.

Estuve prácticamente casi un año en el hospital (H2-4).

Estuve como 11 días en la UVI de X, del hospital, no me acuerdo si era el hospital H o la residencia Y, ahora están unidos, además. Bueno, y después de eso me trasladaron a $T$ [hospital de referencia], un hospital de parapléjicos y estuve durante 9 meses aproximadamente (H3-4).

En este proceso de duelo, el apoyo de la familia y del grupo habitual de amigos es vivido como un gran apoyo.

Yo tuve la suerte de encontrarme con gente que me ayudó muchísimo, después una familia que me arropó en todo, eso es importantísimo y después ya tu 
capacidad (H4-13).

Ahora tienes otra vida, pero bueno, tienes tu familia que te apoya, está contigo (M3-41).

Con mis amigos también, que realmente no, si digo, -oye quiero bajar al sótanopues me bajan, no me ponen ninguna pega, ninguna traba, tanto los chicos como las chicas, el grupo en ese sentido no tengo ningún problema (H2-37).

El grupo de iguales, referido a otras personas con lesión medular, se convierte en un referente, en personas que asesoran a lo largo de todo el proceso de adaptación.

Me enseñó, pues, como hacer caballitos, subir los bordillos. Es que claro te sientas y te dicen: "ahora funciona" ¿Y? ¿Cómo hago? Es que yo no lo sé. Y yo tampoco conocía a nadie en silla de ruedas: ni mis amigas, ni ningún familiar, ni nada. Para mí era todo nuevo. Y luego lógicamente te ves con todos los impedimentos que tenemos, ¿no?, desgraciadamente (M2-2).

Me dijo: "mira, a lo mejor te viene bien hablar con este chico que te oriente y demás". Y así fue, vino a hablar conmigo. Estuvimos hablando. Y empezamos a ya tratar el tema, pero ya, la venta del coche que yo tenía que era con el embrague: - "X [nombre de la entrevistada], esto no lo vas a conducir, ¿para qué lo quieres aquí delante?" Tener un coche, además a ti te gusta conducir, te da mucha libertad; qué tipo de silla debería de comprar, una pues estrechita para mí porque así me iba a pesar menos, yo la iba a manejar más; la adaptación de la vivienda, me tuvieron que adaptar el baño porque tenía bordillo (M2-2).

Cuando estos referentes no están, se vive como una limitación, el no conocer a nadie en silla de ruedas dentro del propio entorno.

Es que claro te sientas y te dicen: "ahora funciona" ¿Y? ¿Cómo hago? Es que yo no lo sé. Y yo tampoco conocía a nadie en silla de ruedas: ni mis amigas, ni ningún familiar, ni nada. Para mí era todo nuevo (M2-2).

Sí conocía alguna chica, pero a lo mejor también ellas tenían alguna limitación mental, no era como a lo mejor en mi caso. O sea, yo una persona de mi edad, 
así en mí misma situación, yo no conozco a ninguna chica. A ninguna. Conocí a chicos, pero a ninguna chica conocí (M2-2).

Por mucho que te quieran ayudar decían bueno y el coche, ¿y ahora qué? ¿Cómo hacemos? ¿Y con ella? Claro, ahora cuando me ven cómo funciona, cómo guardo... (M2-7).

La figura 2 muestra el mapa conceptual sobre el diagnóstico de la lesión medular.

Figura 2: vivencias tras el diagnóstico de lesión medular

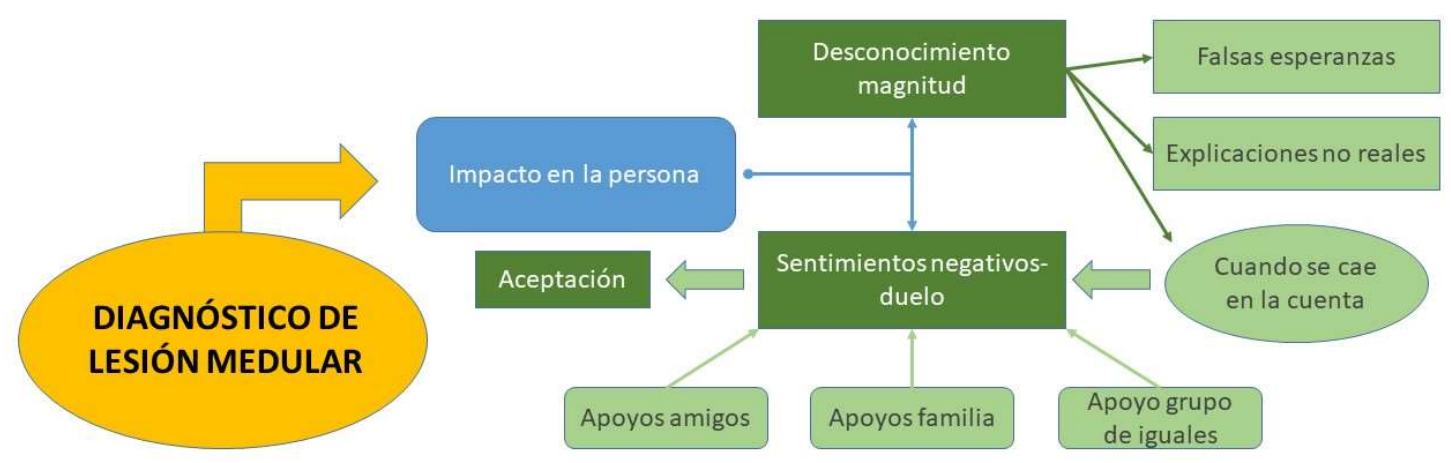

\subsubsection{Percepción respecto a la atención de los profesionales}

Existen distintas opiniones sobre los profesionales.

Se valoran como aspectos negativos: la falta de conocimiento y la actitud ante la lesión medular, frecuentemente basada en el paternalismo y la sobreprotección.

No hace falta que te diga los nombres, ¿no? Sí los digo, me la trae al pairo, ni la doctora $X$, ni la doctora $Y$, no tenían ni $p^{* * *}$ idea de lo que era una lesión medular en ninguno de los tipos. El concepto de lesión medular era un concepto de lesión medular en aquel momento, en el año 2005 cuando yo tuve el accidente, de 30 años atrás (H1-4).

Entonces, bueno, al final personalmente hablando, yo creo que hay, hay un nulo conocimiento y sobre todo hay nulas ganas de saber (H1-11). 
"No hombre, tú no puedes andar ahí porque me enteré el otro día que te compraste un quad" [médico rehabilitador]. -“Claro, sí, me gusta, ¿YY? Ando en quad, ¿pues qué problema hay?" - "A ver si te vas a caer" -"Bueno, pues si me caigo, como si caigo de la moto" Todo como muy para atrás, ¿no? (H1-5)

Se valoran como aspectos positivos: el informar de forma adecuada sobre el proceso y el interés respecto a la rehabilitación de la persona con lesión medular.

Y luego tuve suerte con la doctora que me tocó alli, $X, y$ además le gustaba mucho investigar también, siempre...nunca me decía que no si yo le decía: - "Oye, me gustaría probar tal..."-incluso ella me decía: - "oye, por qué no pruebas a hacer esta terapia, o pruebas a hacer esto y tal", eso...eso a mí me vino muy bien (H215)

A mí me tocó una terapeuta muy buena, al menos a mí me pareció muy buena, creo que era de las mayores que había ahí, pero se tomaba bastante, de una forma bastante personal el trabajo contigo, es decir, que incluso yo creo que te tomaba cariño y tú le tomabas cariño, es decir, que se empeñaba mucho en que tú sacases las cosas (H3-28).

Sí que recuerdo que en planta hubo uno de los celadores también de los mayores que no sé por qué algo vio, y se empeñaba bastante...es decir, era bastante cabroncete, pero no por llamarle cabrón, era bastante desagradable, pero era una...era su pose esa, es decir, el ser borde contigo para picarte, para que tú hicieras cosas, y con él alguna cosa más hice, pero tampoco... (H3-30)

Desde el primer día ya me iba un fisio a la habitación todos los días. La verdad que yo estoy encantada con el neurólogo, que es el doctor $X$, la verdad que muy bien. Te explicaba las cosas muy bien, es un poco serio, pero sí que es verdad que te decía todo muy bien, te lo explicaba bien (M3-15). 
Es frecuente la búsqueda de una segunda opinión médica sobre la lesión medular, bien por desconfianza sobre el diagnóstico inicial o como búsqueda de otros tratamientos alternativos no ofrecidos en el hospital de atención.

Yo más que nada a X [otro hospital] fui para que me asegurasen lo que tenía. Porque yo llegaba un día, la doctora de allí y me decía, me daba así en la rodilla y me decía: - “¿Qué? ¿Cómo vas de sensibilidad?” y yo decía: - "Hija de puta, tengo una lesión completa, solo tienes que leerte el puto informe para entrar a la habitación, que soy el único chaval de 19 años de planta que estoy aquí. Que está toda la planta volcada conmigo y no te sabes ni mi informe" (H1-16).

Yo marché para Barcelona y entré en Barcelona y le dije a la doctora que me tocó: "Tú imagínate que acabo de salir aquí volando de la hostia que me han dado en moto. Tú me revisas todo: analítica, todo, todo, todo, porque no tengo la seguridad de lo que me han contado sea cierto. Porque cada vez me cuentan una historia: un día que había aplastamiento medular, otro día que roto, otro día que no sabían. Hostia, no tienes la tranquilidad en algo tan importante (H1-17)

Estuve en Santiago de Compostela, al lado, en un pueblín de al lado, hay un centro, yo no sé lo que tardarán en cerrarlo porque la verdad es que lo han llevado muy mal, pero bueno, eso es otro asunto, de rehabilitación neurológica, utilizaban hormona de crecimiento con la intención de la regeneración, bueno, eso al final fue un cuento chino, pero bueno, yo allí me fui, ¿no? (M1-16).

Yo cuando tuve la lesión me marché a Estados Unidos a buscar el maná, después estuve en Rusia...allí me operaron...Sí, en Rusia en Moscú, sí, sí. Allí me operaron...me operaron, me quitaron. A mí me hizo el canal medular [movimiento de manos como de separación] pum...un desplazamiento, entonces lo que hicieron fue quitarme esa vértebra que sobraba, me la quitaron ¿Para qué? para descongestionar la médula. Dentro de lo que pude mejorar...y yo ahí mejoré. Bueno, claro, es que nosotros claro... mejorar, mejorar... yo mejoré uy [un poquito], pero esa mejora la tuve ¿no? Yo no vine lo mismo cuando fui a Rusia que cuando vine. Caminar eso ya sabía que no, pero el neurocirujano ruso que me operó me dijo que iba a mejorar en el control de esfínteres y en la sexualidad, 
que en el caminar. Y yo ahí sí que hubo un impasse de mejoría, sí, sí (H4-13).

La figura 3 muestra el mapa conceptual sobre las percepciones respecto a la atención de los profesionales.

Figura 3: percepción respecto a la atención de los profesionales

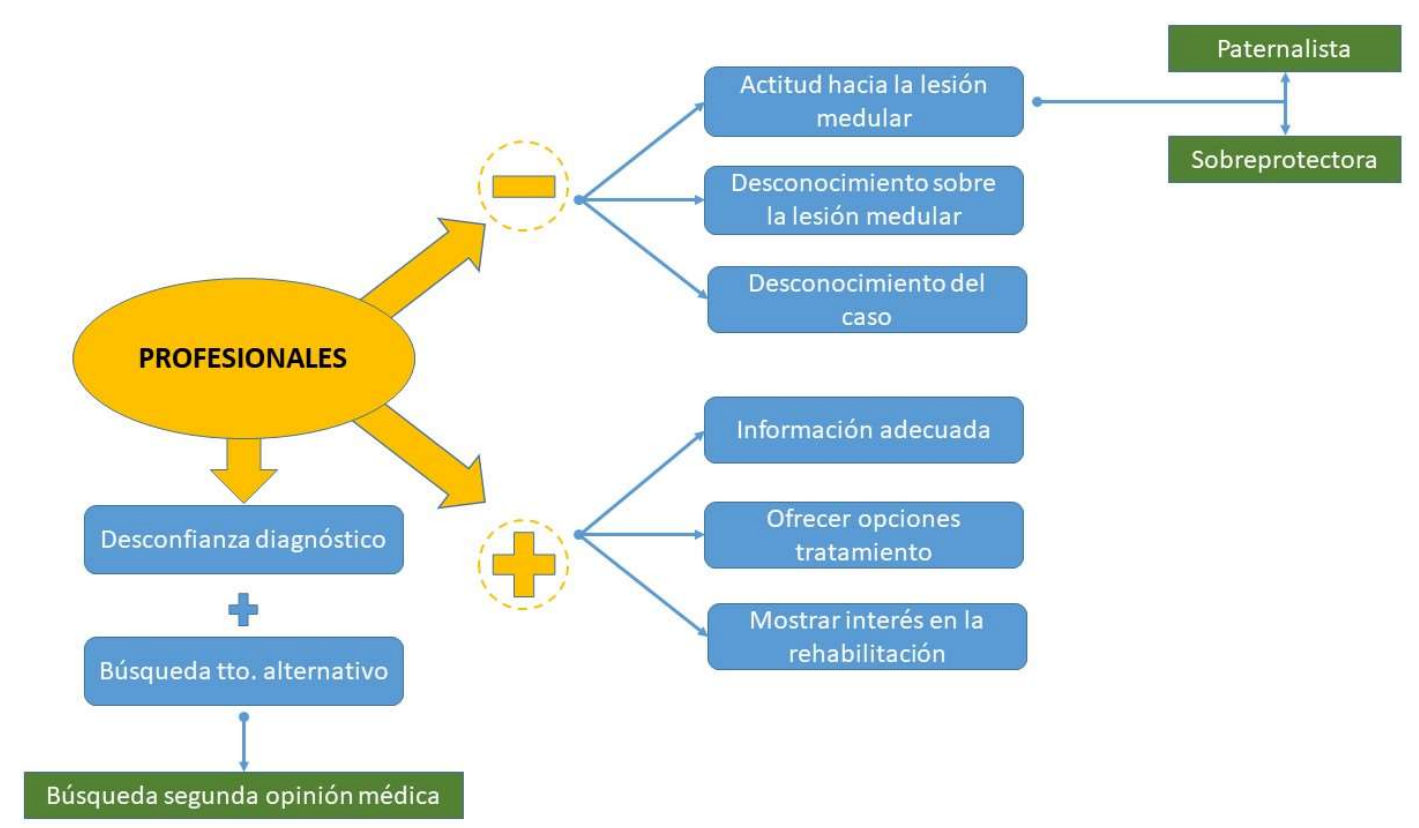

\subsubsection{Vivencias durante el ingreso y en el momento del alta hospitalaria}

Las primeras fases de la lesión se dan en el hospital. La experiencia hospitalaria se percibe como buena en general. En adultos jóvenes, el estar ingresado en la planta de hospitalización infantil se percibe como algo ventajoso, sobre todo por el mayor arropamiento por parte de los profesionales y la posibilidad de recibir un mayor de tiempo de rehabilitación, debido a la existencia de una menor masificación.

En T [hospital de referencia nacional] bien, hombre obviamente nunca se está como en casa, pero bien, bien. Además, al ser digamos el hospital de referencia de lesión medular en toda España, eso se nota (H2-11).

A mí me metieron en la planta de niños, tenía 18, hasta los 23 creo que te meten, y la verdad que mucho mejor porque claro, quieras que no, el personal de planta pues está un poco más...te arropa un poco más ¿no? (H2-12) 
Yo tenía 17 años, era menor de edad. Yo además estaba en la planta de niños, tuve la suerte de estar en la planta de niños, también te digo, o sea, pero clarísimamente. Como era menor de edad me metieron en niños, también un poco porque hicieron porque yo estuviera allí...no por nada, pero realmente era un privilegio porque había menos masificación, yo la rehabilitación que tenía yo... yo conocía a gente que era un poco más mayor que yo y que estaban en adultos, y no hacían ni la mitad de fisioterapia que hacía yo (M1-58).

Se perciben como aspectos negativos el no cuidar la intimidad y el tratar a las personas de forma desexualizada: habitaciones compartidas, no llamar a la puerta antes de entrar o el ser tratado más como un número que como una persona, y en concreto, como una persona sexuada.

Estábamos en habitaciones compartidas 3 personas, continuamente entrando y saliendo gente en un espacio bastante hostil con pues eso, con lo cual tampoco era lo más sugestivo para que a ti te apetezca... (H3-8).

En el hospital X fue el primer lugar en el que ves cómo nadie llama a la puerta, nadie, es decir, y no es que te dejen en pelotas en el pasillo, no... a mí nunca me dejaron en pelota en el pasillo, pero... digamos que hay bastante poco respeto por la... bastante respeto por ti como persona sexuada, como hombre o como mujer, en muchos casos eres un número más y como número no tienes sexo... (H3-22).

En algunas ocasiones, es en el hospital donde se dan los primeros ligues y las primeras experiencias eróticas tras la lesión. Estas primeras experiencias se dan tanto con nuevas parejas como con parejas previas. El hospital se percibe como un lugar incómodo tanto por las instalaciones en sí, como por el miedo a ser descubierto.

Yo, por ejemplo, a lo mejor tuve demasiados entre comillas ligues en el hospital: tuve dos pero bueno, claro, fue un año de hospital y no sé si es mucho, poco, ahí tampoco no hay un baremo (H2-64).

Tuve la posibilidad de volver a mantener una relación compartida con aquella 
chica con la que las había mantenido antes y fue un desastre. Fue un desastre, porque allí creo que empecé a comprender qué cosas pasaban, fue un clic muy desagradable, muy desagradable para mí, que entiendo que muy desagradable para ella, en conjunto también como muy... primero porque ni el espacio, ni el lugar, ni el modo, era cómodo, era todo muy hospitalario, evidentemente era hospitalario porque era un hospital. Eran los baños de un hospital en el que estas atento a que no entre nadie, que pueda ser nadie de tus compañeros, de los familiares de tus compañeros, nadie del personal del hospital, nadie de tu familia, que nadie te eche de menos y empiece a buscarte, bueno una situación...(H3-9). A mí iban chicas a visitarme, y aunque nadie lo hablaba, el hospital era lo que era, el hospital en algún momento se convertía en un ... no te voy a decir un putiferio, pero sí desde luego era un lugar en el que cada uno se las apañaba cómo y por donde podía, y a ciertas horas en las que no había actividades los pasillos de arriba, los baños de los pasillos, las habitaciones, los jardines... pues ahí era donde la gente tenía sus encuentros, porque eran los únicos sitios en los que se podían dar (H3-35).

El hospital también es el espacio donde se dan los primeros asesoramientos del grupo de iguales sobre sexualidad.

Yo recuerdo sobre todo una noche que, no sé por qué razón aquella noche en el pasillo, en un lugar del pasillo, había como 8 o 9 hombres, 8 o 9 hombres de diferentes edades. Y aquella noche que yo recuerdo nítidamente, uno de los temas que se habló era a quien se le ponía dura y a quién no (H3-57).

\subsubsection{Vivencias en el momento del alta hospitalaria}

El momento de salir del hospital se vivencia como una "salida a la realidad", una realidad más dura y difícil de lo esperado. Surgen reflexiones de que hubiera sido necesario un mayor conocimiento, un mejor asesoramiento o una mayor rehabilitación antes de alcanzar ese hito.

De repente pasan 8 meses y sales del hospital de alta, y sales vendido completamente ¿no?, no te han contado...de lo que tienes que saber, nada (H1- 


\section{1).}

En Navidades me dieron permiso para ir a casa. Me fui a casa, y volví, te das cuenta de que tienes que rehabilitar mucho más, el mundo fuera es más jodido (H2-62).

Realmente nadie te preparaba para lo que te ibas a encontrar en la calle, a todos los niveles, "no, no, tú puedes hacer una vida normal", pero ¿ Tú qué cojones sabes si tú caminas? Si no es verdad, empezando porque cuando salga a la calle me voy a encontrar barreras arquitectónicas, me voy a encontrar con gente que me mira con condescendencia y me habla con condescendencia (M1-7).

La figura 4 muestra el mapa conceptual sobre las vivencias durante el ingreso y en el momento del alta hospitalaria.

Figura 4: vivencias durante el ingreso y en el momento del alta hospitalaria

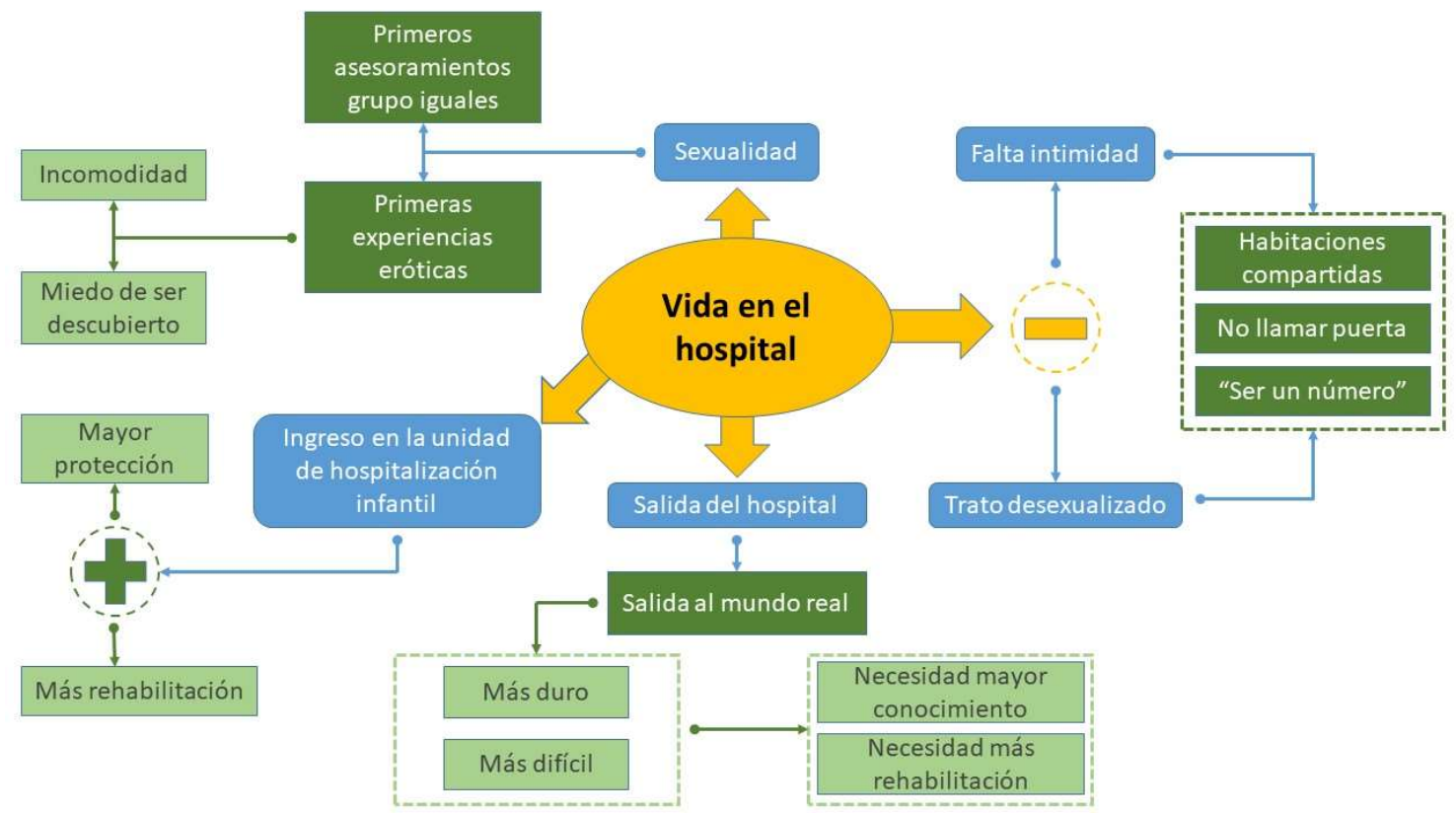

\subsubsection{Vivencias de la corporalidad tras la lesión medular}

Aparecen en los discursos referencias a la nueva realidad corporal. En ocasiones, el nuevo cuerpo se vivencia como un "otro" con el que se lucha, se pelea, o uno se comunica. Hay un conocimiento y un reconocimiento del nuevo cuerpo con una búsqueda de una buena comunicación y de un "remar hacia el mismo lado" o "seguir un mismo camino". 
Todo el tiempo que yo estuve en el Hospital de $X$, y tiempo posterior, mi cuerpo $y$ yo todavía no habíamos llegado a este punto de comunión de ir hacia el mismo sitio, de compaginar nuestras acciones, con lo cual yo ahí poco puedo decir... (H329).

Tienes unas peleas con tu cuerpo... (H4-124).

Tú te ves algo diferente, y te ves mal por eso (M1-24).

Ir conociendo tu cuerpo también lo que le pasa, tranquilizarte tú y luego tranquilizar también un poco a la gente que está contigo (M2-6).

Tenemos que ser conscientes de conocer nuestro cuerpo, no nos queda otra, amoldarnos a él como lo tenemos ahora y todo lo que mejor podamos, ser positivos y llevarlo (M3-26).

Pero bueno, te vas acostumbrando un poco al cuerpo. (M3-51).

La figura 5 muestra el mapa conceptual sobre las referencias a la corporalidad.

Figura 5: referencias a la corporalidad

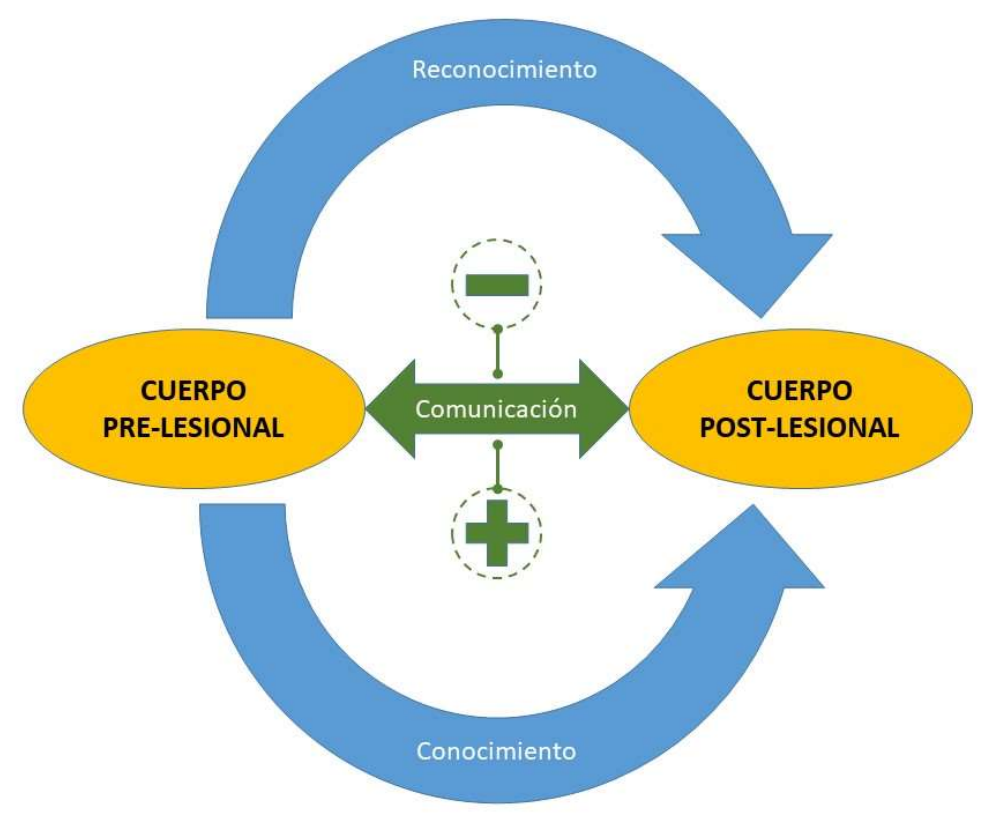




\subsubsection{Sexualidad tras la lesión medular}

\subsubsection{Proceso de sexuación tras la lesión medular}

El concepto de la identidad sexual, de ser hombre o mujer, de la masculinidad o de la feminidad se pone en duda tras la lesión medular. La construcción de este concepto se encuentra influenciada por los roles, expectativas o modelos que la sociedad asigna a cada género. En la lesión, se produce una ruptura sobre lo esperado por la sociedad y lo existente, lo que conlleva a una reconstrucción sobre la nueva feminidad o masculinidad. Se percibe una falta de acompañamiento en este proceso.

Aparece una diferencia de género en los discursos: la pérdida de masculinidad se atribuye a la disminución de la fortaleza, a la merma del poder protector respecto a la familia y a la pérdida de independencia (física, económica, etc.) y la pérdida de feminidad se achaca a una menor percepción de deseabilidad. Esta se encuentra influenciada por el cambio en la imagen corporal, influido por el cambio en la forma de vestirse y arreglarse.

El ser hombre o mujer en la sociedad actual implica cumplir ciertos cánones o ciertas expectativas, y cuando tú tienes una lesión medular hay una serie de cánones y expectativas que dejas de cumplir automáticamente (M1-7).

Yo retomé el ser mujer, el día que me permití volver a ser deseable (M1-51).

Mi accidente me hizo también reflexionar sobre muchas cosas y aprender muchas cosas. Reflexionar mucho sobre roles, modelos, imposiciones o no...pero al menos sí tradiciones...Qué es ser un hombre, cuáles son los requisitos que tienes que cumplir para considerarte tú mismo un hombre y que los demás te consideren un hombre, más allá de tener pito. Sabiendo que luego, si lo reflexionas, te das cuenta de que precisamente el pito es igual lo último a la hora de generar la construcción, la guinda es "y encima tienes pito", no te construyes a partir de que tienes pito. $Y$ yo creo que eso me sirvió bastante y me ha servido bastante a lo largo de los años para darte cuenta de que ese modelo de hombre, ese modelo de mujer, está construido sobre unas bases que tienen muy poco de sólidas. Tan sólidas que una zambullida en la playa se las puede cargar todas (H3-83). 
Desde un modelo tradicional, yo no llego a lo que es considerado un hombre de verdad en la sociedad: alguien sin vulnerabilidad o poco vulnerable, o que su vulnerabilidad sea muy poco visible, alguien que cumpla unos roles de independencia a todos los niveles y, desde luego, a nivel orgánico y físico, alguien a quien se le vea como el que realmente manda en su casa, o...claro, porque esto está muy relacionado con el tema de la dependencia. Es decir, cuesta mucho visualizar a alguien desde un paradigma tradicional me refiero. Cuesta mucho visualizar a alguien como el cabeza de familia, el que manda en casa, cuando es totalmente dependiente de que las mujeres de su casa lo acuesten, lo levanten, lo duchen...Desde ese modelo pierdes tu legitimidad como hombre, porque ya no eres el fuerte de la casa, ya no eres, en muchos casos, el que lleva el dinero a casa, el que mantiene la unidad de la familia, el que es capaz de proteger a sus mujeres de una agresión externa, por ejemplo... (H3-84).

Te planteas también el hecho, al principio, luego se me pasó un poco, pues en el tema de ser un poco como mujer a la hora de prepararte, de presumir, de comprarte ropa, de maquillarte. Madre mía, ¿y ahora? En la silla... ¿qué? no luces nada. Me quiero poner un vestido y esto tal. Si es que tampoco vas a estar de pie, unos zapatos con unos tacones o cosas así. Dices tú, no lo sé, si tampoco al principio, hubo una época que me sentía, un poco, como un poco bajita de moral en el tema de sentirme sexi o menos mujer (M2-2)

Te dan pautas de autocuidado, pero nadie te enseña a volver a ser una mujer o un hombre, ¿no? Simplemente se preocupan de mantenerte vivo y con una salud razonable (M1-7).

Esta construcción sobre la feminidad y la masculinidad, se produce también desde la mirada de los otros, desde el verse reflejado en la mirada de los demás, en especial de las personas del sexo preferente.

La verdad es que con respecto a otras cuestiones que tienen que ver con la sexualidad como un poco, que tienen que ver con la masculinidad y todo eso, puedo decir que no llegué a hacerme o a ser consciente o a darme cuenta de que 
podían haber cambiado cosas, sobre todo, hacia afuera, es decir, del exterior hacia mí y de cómo se veía, cómo se me veía a mí, supongo que hasta pasado bastante tiempo, bastante tiempo... (H3-17).

En algún momento yo me planteé la situación, y supongo que yo, el planteamiento sobre la situación [hablando de la masculinidad] tuvo que venir precisamente con el cómo yo pudiera notar que me veían las chicas que antes me veían. Es decir, cómo mi situación había cambiado...eh...su modo de verme, su modo de considerarme (H3-18)

La pérdida de masculinidad o de feminidad, tienen como consecuencia la pérdida de independencia dentro del núcleo familiar: la pérdida de unos privilegios ya ganados, produciéndose una regresión a tiempos anteriores.

Con respecto a mi masculinidad...en casa, es decir a mí me ha sucedido el accidente con 17 años, yo ya tenía cierta autonomía y autodeterminación dentro de mi casa. Mi dormitorio era, vamos a decir, mi república, no quiere decir que mi madre no, mi madre o mi familia, que siempre que quisieran entrar llamase, no, pero sí que había como más... ¿Cierto respeto? Si, "no vaya sé que me encuentre con algo que me vaya a traumatizar más a mí como madre que a él como hijo". Y en cambio, después de esto se perdió en cierta manera (H3-21).

Yo creo que eso no tiene que ver con la masculinidad en sí, pero sí tiene que ver con cómo yo pude entender o entiendo que fui ganando esa masculinidad, es decir, eso de ganar esa independencia, ganarse ese respeto a mi sitio, a mi lugar, a mis cosas, a... y como la perdí, pero no solo la perdí con mi familia ¿ंeh? (H3-22).

El considerarse menos mujer, y menos deseable, puede tener como consecuencia el no sentirse capaz de establecer vínculos erótico-amatorios. Esta relación parece ser bidireccional: existe una percepción de sentirse menos masculino o femenina, por lo que se considera que no se puede ligar, pero también el ligar o no ligar tiene impacto en cuán hombre o mujer se sienten. 
Al sentirte mujer u hombre porque como no cumples esos cánones que se supone que tienen que cumplir un hombre o una mujer, ya es como que tú mismo te quitas del mercado erótico-festivo (M1-9).

Pero no sé, tampoco yo nunca me he sentido a lo mejor menos hombre o con menos posibilidades que otro que no esté en silla. Pero igual es porque yo soy demasiado seguro en mí mismo, luego te puedes llevar la hostia o no, pero igual es depende de lo que le guste sobre todo a ella (H2-54).

Yo creo que mucha gente a lo mejor no intenta acercarse a una chica o a un chico si lo puedo entender, que la gente, que los hombres en este caso se puedan sentir un poco menos hombres (H2-53).

A principios de junio empecé a salir con ella. Digamos que esto tiene relevancia también en todo lo que puede ser este proceso mío de readecuación, reinvención, reconciliación sexual y erótica (H3-68).

$Y$ a otros niveles que tengan que ver con lo sexual, como hablamos antes un poco de la masculinidad o tal, pues también fue en paralelo. Además, fue algo que se influyó mucho mutuamente. Y a partir de la facultad, sobre todo. Empezar a salir con aquella chica en la facultad, incluso cómo comenzó la relación aquel día, aquella borrachera a sidras... (H3-82)

La figura 6 muestra el mapa conceptual sobre el proceso de sexuación tras la LMT. 
Figura 6: proceso de sexuación tras la lesión medular

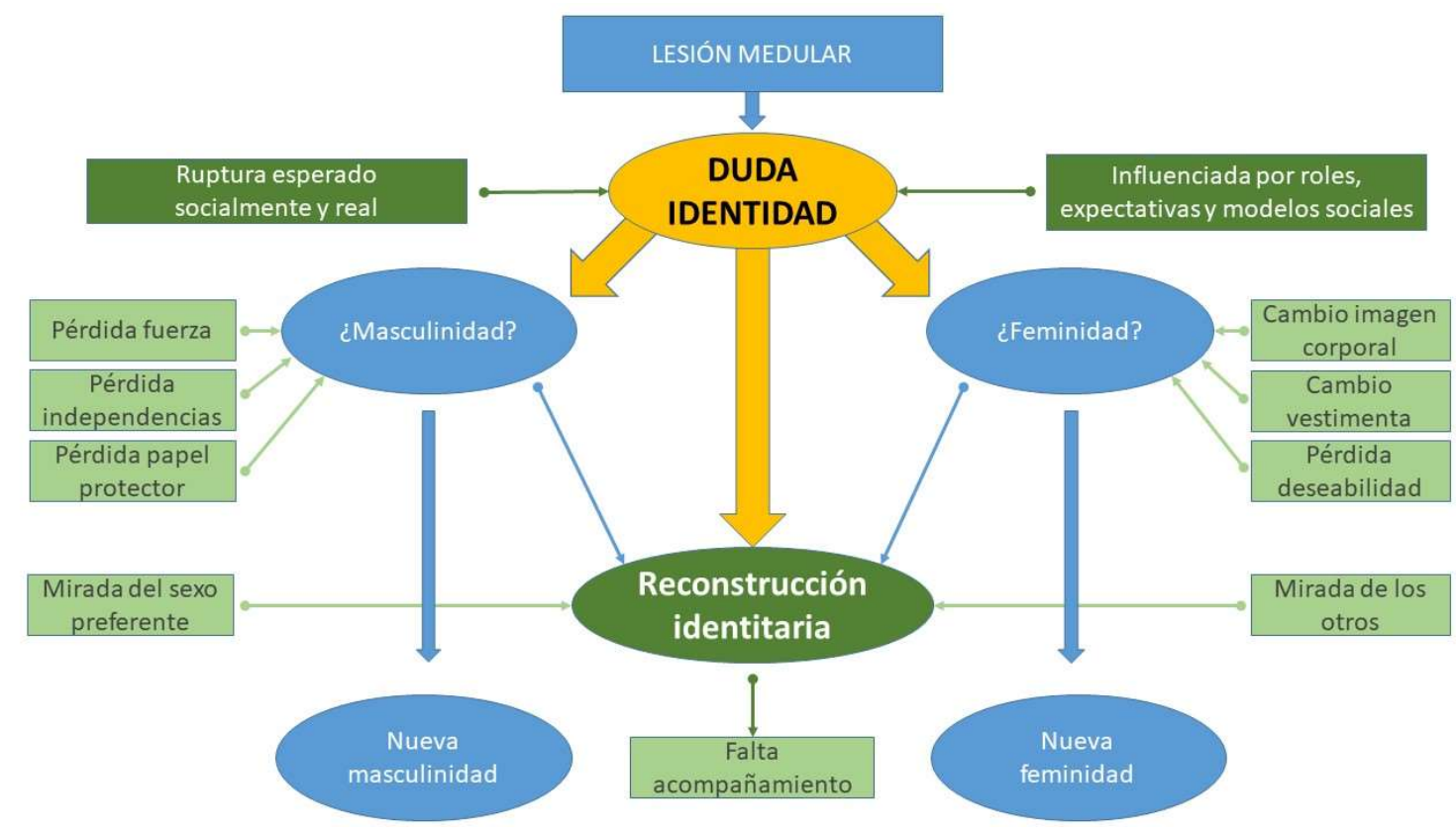

4.3.5.2. Vivencias de la erótica tras la lesión medular

\subsection{Percepciones sobre la mirada de los otros}

En la construcción de la deseabilidad, se cae en la cuenta de que la mirada de la gente ha cambiado.

Y luego en qué cambia también: en la mirada de la gente (M1-8).

No llegué a hacerme o a ser consciente o a darme cuenta que podían haber cambiado cosas, sobre todo, hacia afuera, es decir, del exterior hacia mí y de cómo se veía, cómo se me veía a mí, supongo que hasta pasado bastante tiempo, pasado bastante tiempo (H3-17).

En ocasiones la mirada va dirigida a la silla en vez de a la persona, la silla se eleva hacia algo más que un objeto que sirve para desplazarse, ocupando un lugar más simbólico, en el cual se crea un diálogo entre la "otra persona" y "la silla".

La mirada de la gente, ya va cambiando poco a poco ¿eh?, pero la mirada de la gente es a la silla, raramente ven directamente a la persona, luego hay algún rarito después, ya ven a la persona, pero lo primero que ven es la silla, pero es 
importante saber eso y que tampoco te afecte en exceso ¿no? (M1-24).

Sí que es verdad que... si puedes notar alguna mirada de... tampoco entienden por qué estás en silla, sobre todo si eres tan joven... (H2-32).

Aparecen miradas de pena, de condescendencia, de lástima. También aparecen miradas de admiración ante la capacidad de superación.

Sobre todo, más en gente mayor, de 40-45 hacia arriba, ya notas las miradas de... muchas veces yo creo que son de lástima o de pena, cada uno que las interprete como quiera. Si miran, que miren y si no también (H2-32).

Me voy a encontrar con gente que me mira con condescendencia y me habla con condescendencia, o sea, mmm...pues a nivel erótico y sexual ya ni te cuento (M17).

Pasé de ser un poco rara, a ser un poco la estrella y la superación, de qué fuerte eres y qué grande eres y que no sé qué (M2-4).

\subsection{Ser deseable}

En ocasiones no se percibe ningún cambio en la deseabilidad. Otras veces, sin embargo, se percibe un cambio importante sobre la deseabilidad actual comparada con la previa a la lesión medular.

-La gente de la calle o tus parejas o tus ligues, ¿Cómo... cómo lo ven? ¿Cómo lo interpretan el verte en silla de ruedas? ¿Te ven como objeto sexual, objeto de deseo en...?

-Como antes. No sé, no he tenido tampoco ni problemas, ni más ni menos. (H122)

Ahí sí fue cuando yo empecé a ver que había una cierta diferencia entre el éxito que yo podía tener anteriormente entre esas chicas y el ver que ahora mismo no tenía ningún éxito (H3-19).

Aparece la silla de ruedas como algo que se visualiza de forma previa a la persona, y que a veces obstaculiza el conocer a esa persona, quedándose en la parte simbólica de la 
silla. Sin embargo, en ocasiones, la silla y lo que conlleva es considerada como una característica más de la persona.

Por otro lado, también aparece como una potencialidad a la hora de escoger por parte de la persona con lesión medular, el cual ya filtra de antemano a aquellas personas que, por el mero hecho de ir en silla, ya no están interesadas en conocer a la persona. La silla se ve como una característica más dentro del conjunto de adjetivos de la persona; se entiende el no gustar tras conocer a la persona, aunque sea por el tema "de la silla", pero no el rechazo "a priori".

Tengo la suerte ahora estando en silla de ruedas que tengo una selección natural. Es decir, y además que la acepto, porque hay gente que sí estaría conmigo porque les gusto, pero en cuanto se dan cuenta de lo de la silla de ruedas es como que ya los ves que se hacen algo así [gesto despectivo]. Y tú dices: "guay, porque si tú simplemente para hablar conmigo un minuto o conocerme un poco más, no puedes porque eso te frena tanto, mejor", porque yo con una persona así no querría ni siquiera tener una amistad, porque considero que tiene demasiados prejuicios (H1-29).

Otra cosa es que empieces a hablar conmigo y digas: "joder, es un chico majo, pero bueno, yo a mí el tema de la silla..." lo respeto, lo respeto. Como si me dices que no me gustan los gordos, o los delgados, o los altos, o los bajos, lo respeto, perfectamente. Pero, y a parte... no se atreva ni siquiera a conocerte porque les dé un poco de cosa. Dices: "Guay, porque no me apetece a mí tampoco conocerte". Entonces es una selección natural que me ha hecho y que me beneficia (H1-29).

Probablemente a ver... hay gente que sí tiene problemas, pero no por...yo creo que es más por desconocimiento que por... de verdad, no sé cómo decirte, atracción no... no repelús...eh... (-como respeto)- Sí, eso. Tienen más respeto al tema de la silla, entonces por no meterse en ese fregado, pues están un poco más distantes (H2-33).

El no ver a una persona que se desplaza en silla de ruedas como alguien deseable, se encuentra imbricado con la existencia de una sociedad no inclusiva, en la que uno no se 
ha relacionado con personas con diversidad funcional, y, por tanto, no los conoce, no los ve como iguales y como consecuencia es difícil que los vea como seres deseables.

Al principio, no había negros, había un negro por ciudad, dos, tres, era la novedad, era así. Empezaron a llegar y ahora es mucho más habitual. Muchísimas cuadrillas, todas no evidentemente, pero en muchísimas cuadrillas hay un negro, hay un árabe, hay una que es lesbiana, hay uno que es gay, hay uno que es gótico... Es decir, está ahí, pero es cierto que todavía no es habitual lo otro. No es tan habitual que en todas las cuadrillas haya alguien que utilice una silla de ruedas, alguien que sea sordo, alguien que sea ciego, o alguien que tiene un trastorno de Asperger, o un grado de autismo, y mucho menos que tenga una afectación cognitiva (H3-111).

En realidad lo que ocurre es que una persona puede llegar a su edad adulta sin haber tenido nunca un contacto cercano, un contacto directo, una relación de amistad, de pareja, de compañeros de extraescolar, o de compañeros de ir a los mismos sitios a jugar al mismo parque, o lo que sea, con alguien con algún tipo de afectación orgánica, pues claro, es muy difícil que luego, cuando llega la época del ligoteo, de esa socialización, de ese plus de socialización, si no has tenido ningún tipo de contacto, ninguno, es muy difícil que tú los asimiles a que es tu gente, a que son iguales. No son tus iguales porque tus iguales son con los que has vivido, con los que has hecho la vida, con los que veías en los sitios a los que tú ibas. Si no los ves, si no están, es muy normal que te cueste (H3-110).

Existe una relación entre la imagen corporal y el concepto de deseabilidad, asociado al cambio corporal, que se vive como un cambio importante, incluso total. Este cambio de cuerpo, se intenta en ocasiones tapar o disimular con el uso de ropas flojas u oscuras. Se ve como una necesidad la existencia de un acompañamiento para la aceptación del nuevo cuerpo o de la nueva imagen corporal, ayudando a asumir las imperfecciones y haciendo reflexión o crítica sobre la no existencia del cuerpo perfecto y también ofrecer ayuda para encontrar ropa con la que uno se sienta bien.

Esto impacta en una pérdida de autoestima, incluso pueden aparecer sentimientos de vergüenza por mostrar el nuevo cuerpo. 
La imagen corporal con 17 años, es que...es un cambio total y absoluto, ¿no? (M17).

Estéticamente no te ves igual, hay una alteración muy importante de la imagen corporal (M1-7).

Y nadie te cuenta...bueno pues sí, esto pues igual no es lo...pero es que no todo el mundo es perfecto ni es un modelo, ¿no? Entonces bueno, no te preocupes, pero vamos a buscar maneras, a enseñarte maneras de que tú busques ropa de manera que te encuentres guapo, que te encuentres guapa, porque es que sí es importante, o sea, nos podemos dar de cabezazos diciendo..." Ah, la imagen no importa", imira no me jodas, sí que importa! Es que entramos por los ojos a todo el mundo, igual que nos demás nos entran... iclaro que sí! Entonces, que alguien te enseñe...o te explique...o te ayude a quitarle importancia a que tengas más barriga, simplemente eso ¿no? A aceptar el cuerpo que tienes y con eso hacer lo que puedas, como todos (M1-21).

Yo eso, vestía ancho, oscuro, cuanto más oscuro mejor porque me hacía más delgada. Escondía las formas que a mí no me gustaban, no es que ahora vaya con una cosa así apretada que se me vea lo que no me gusta, pero bueno ya no... ya me permito llevar colores, ya me permito ponerme otras cosas ¿no? (M1-52).

Te planteas también el hecho, al principio, luego se me pasó un poco, pues en el tema ¿no? De ser un poco como mujer a la hora de prepararte, de presumir, de comprarte ropa, de maquillarte. Madre mía ¿y ahora? En la silla ¿qué? no luces nada. Me quiero poner un vestido y esto tal. Si es que tampoco vas a estar de pie, unos zapatos con unos tacones o cosas así. Dices tú, no lo sé, si tampoco al principio, hubo una época, que me sentía, un poco, como un poco bajita de moral en el tema de sentirme sexi o menos mujer (M2-2).

Hay gente que no se ducha después de hacer deporte. Yo eso yo no lo entiendo. Por la vergüenza. Pero vergüenza ¿de qué? La vergüenza es una cosa importante y eso hay que tratarlo ya desde la base (H4-78).

La imagen corporal se encuentra por otro lado asociada a la vestimenta. Las recomendaciones que se le ha dado en los hospitales pasan porque las personas con 
lesión medular lleven ropa ancha y cómoda para evitar complicaciones como úlceras por presión o hinchazón de piernas, en concreto, en los discursos se ha identificado con entidad propia la recomendación de llevar chándal. Sin embargo, el llevar esta prenda todo el día se vivencia como algo asexuado, con la que se percibe tener una peor imagen corporal, tanto en hombres como en mujeres. También es utilizada como forma de tapar el "nuevo cuerpo" y disimular las partes que a uno no le gustan. El proceso de volver a ponerse otro tipo de ropa: vaqueros, vestidos, etc. se realiza con un proceso de "ensayoerror", viendo que no aparecen complicaciones asociadas a su uso. Una vez vivido este camino de prueba, el chándal queda relegado a situaciones concretas como: acudir al fisioterapeuta o realizar deporte.

Sí que es verdad que yo siempre intenté cuidar la imagen...no sé... intentar ir afeitado, con el pelo corto... Nunca me gustó ir de chándal en el hospital; es verdad que por la mañana cuando vas al fisio, vas a no sé dónde, vas a tal, vas en chándal, pero luego por la tarde siempre me cambiaba y me ponía unos vaqueros o tal. Me ponía como iba antes, pero en la silla. Y eso lo hago ahora todavía, quiero decir, solo voy a entrenar en chándal nada más o a las competiciones, pero el resto del día estoy siempre vestido, incluso por casa que podría estar cómodo de chándal, pero normalmente estoy presentable. Y yo creo que eso es importante... el tener un poco... porque claro cada vez que te miras, pues quieras que no, te sube un poco la autoestima (H2-29).

La imagen corporal con 17 años, es que...es un cambio total y absoluto, ¿no? porque además tú cuando vas a...yo estuve en T [hospital de referencia], lo que te dicen es: ropa ancha, ropa cómoda, ojo con las escaras, ojo con que se te inflamen las piernas...o sea, te dan pautas de autocuidado, pero nadie te enseña a volver a ser una mujer o un hombre, ¿no? Simplemente, se preocupan de mantenerte vivo y con una salud razonable (M1-7).

Yo recuerdo al principio de tener el accidente...llevaba siempre...bueno, para empezar, cuando vienes de Toledo, eso: mallas, chándal...o sea, dejas de ser un ser sexuado, ¿no? Y ya poco a poco...vas diciendo: bueno, pues en vez de...me voy a poner un vaquero a ver qué pasa, si no me sale una escara, pues igual...pero era eso...ropa súper ancha...porque yo me veía como mucha barriga, iclaro! tu 
cuerpo cambia, es que tu cuerpo cambia: pierdes musculatura en un lado, en otro, hay flaccideces, hay... (M1-21).

Hay un momento de aceptación del propio cuerpo y de vestirse como la persona desea. Aparece como importante el apoyo del grupo de iguales, que se identifica como referentes. A veces, no existe ese referente, y se cae en la cuenta de lo importante y necesaria que sería su presencia. Parece más difícil encontrar referentes del sexo femenino.

En ese aspecto luego en seguida ya cambié un poco el chip. ¿Por qué no? Y entonces pues nada. Sigo con las cosas pues me apetece ponerme un vestido o unos botines con un poco de tacón ¿que no me tal? Pues me quito el botín, si me hace daño, me tengo que apoyar en cualquier sitio, porque lógicamente si tiene un poco de tacón te tienes que incorporar un poco, si el pie se me va completamente con un poco de tacón, pues más todavía (M2-2).

Alguien me dijo a mí que, si yo a él lo veía diferente por estar en una silla de ruedas, si lo veía diferente hacia cualquier otro chico que pudiese caminar. Y yo como soy una persona que admiro tantísimo y lo quiero tanto y todo y dije: pero, ¿qué dices? para nada. Entonces tú ¿por qué te vas a ver diferente?, si eres una chica súper guapa. Puedes sacar partido. Si quieres poner tacones pues te los pones, y además estás sentada, no te hacen daño, no sé qué, tal. Oye ¿pues sabes qué? pues también tienes razón (M2-2).

Allí en la asociación, en $X$, son poquitas las chicas las que hay de mi edad, y que yo pueda tal... Hay más hombres y gente con más edad, que no mujeres (M2-1). Por eso considero que es muy importante la idea de conocer a mucha gente $y$ también explicarles y contarles tu caso: "oye mira, que no te hundas", a mí me daría mucha pena, yo si realmente conociese a alguna chica, a ver te digo en términos de chica porque a lo mejor, no sé, puedes empatizar más, mismamente a la hora de vestirte, de decir: pues se llevan estos botines o se llevan estas, ¿sabes? A mí me encantaría tanto poder ayudar porque como conmigo lo hicieron y me vino tan bien, ¿sabes? Porque yo creo que, si no llego a conocer a esa persona, pues no lo sé, pero mis amigas no sabrían cómo ayudarme, como 
mucho desconocen el tema. Mi familia lo mismo, nadie conocíamos a nadie que estuviera en una silla de ruedas (M2-7).

Aparece el deporte como una actividad con la que se mejora el aspecto físico y eso permite la mejora de la imagen corporal y una mayor percepción de deseabilidad.

En mi caso, es verdad que a base de hacer deporte ahora estos últimos años he recuperado mucha masa, entonces tengo otro aspecto. Pero claro, cuando estoy allí, no tengo absolutamente nada de físico, estoy en los huesos prácticamente, entonces yo creo que por eso me empecé a interesar más en volver a reactivar mi vida social con el sexo opuesto cuando empiezo a hacer deporte y vuelvo a desarrollar otra vez el músculo -no todos, pero bueno- me vuelvo a ver bien (H228).

Yo eso, hasta que no empecé a coger un poco la forma que yo tenía antes, no me planteé tampoco el tema de novia, el tema de sexo, ni nada (H2-29).

\subsection{Ser deseante}

El deseo que se siente no se encuentra modificado por la lesión. El deseo está conservado desde el principio de la lesión, ni la edad, ni la falta de sensibilidad parecen modificarlo.

Yo creo que igual [hablando del deseo], o más a veces, a lo mejor porque llevas más tiempo, llevo más tiempo, sin... sin...pero igual o más. No se me va la cabeza ni nada por el estilo, pero en ese sentido creo que estoy igual (H2-82).

Incluso estando en la UVI alguna de las personas a las que yo más deseaba ver eran alguna de estas chicas con las que yo tenía algo o había tenido algo (H3-49). No tengo menos deseo. Más tampoco, porque está así en este proceso, el cuerpo, el dolor...pero menos no, vamos, ni que desee menos ni que...el sentir es diferente, pero no, no, en ese aspecto, yo por lo menos no, no se me ha quitado la gana, vamos. Estando ingresada tampoco se me quitó la gana (M3-73).

Yo no creo que pasase siquiera un mes o quince días, vamos a poner 15, 20 días desde el momento en el que yo llegué por primera vez al hospital de X a la primera 
vez que tuve visita de alguna de las chicas con las que yo había estado anteriormente, y procuré perder el tiempo lo menos posible (H3-49).

Yo recuerdo que hubo una vez un hombre de estos, de los mayores, tendría 60 y alguno, que aquel día estábamos emocionadísimos en el corrillo de hombres porque aquel día se le había puesto dura y los demás pues estaban como un poco ojipláticos. Es decir, claro que hay interés, esos hombres estaban interesadísimos en qué pasaba, otra cuestión es que pueda haber otras prioridades... (H3-58).

Las necesidades las seguimos teniendo, las ganas nos siguen dando, independientemente del nivel de sensibilidad que tengas (M1-18).

Evidentemente el deseo permanece, las ganas permanecen, es que eso no varía, tú sigues siendo el mismo ser humano deseante (M1-9).

La figura 7 muestra el mapa conceptual sobre las vivencias de la erótica.

Figura 7: vivencias de la erótica tras la lesión medular

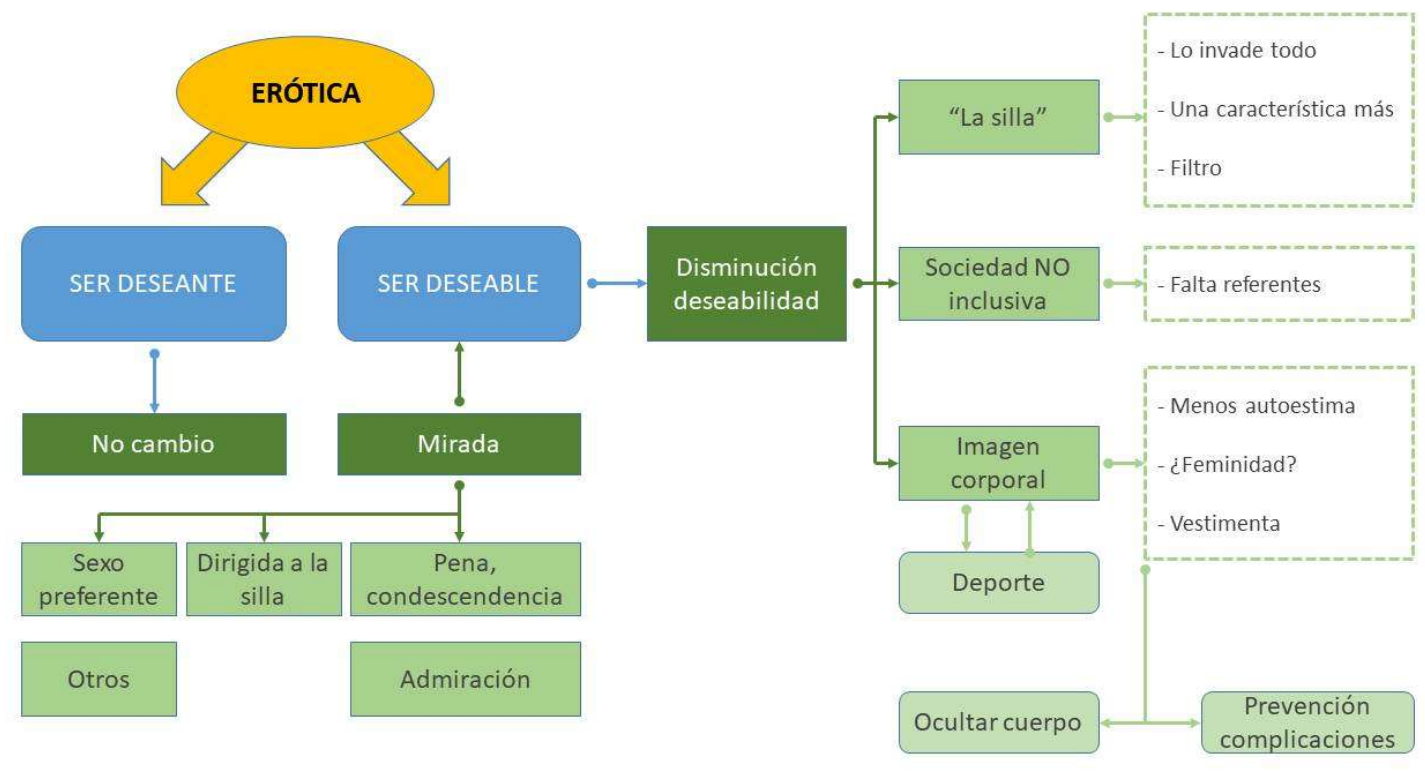

\subsection{Vivencias en el proceso de ligar}

Hasta que uno no se ve bien o se siente bien consigo mismo y acepta el poder ser un ser deseable no intenta ligar con otras personas, poniendo una barrera personal ante el posible encuentro. También se identifica cierto miedo a la práctica amatoria, a no saber apañarse. Por otro lado, a veces el acercamiento de personas del sexo preferente, se 
interpreta por parte del lesionado como un gesto condescendiente y no derivado del deseo.

Está claro que hasta que tú no te admites eso [que eres deseable], por más que vengan y te digan: "qué guapa eres", intenten ligar, es que eres tú mismo el que pone esa barrera (M1-52).

Yo eso hasta que no empecé a coger un poco otra vez la forma que yo tenía antes, no me plantee tampoco el tema de novia, el tema de sexo ni nada (H2-29).

Los primeros años después de la lesión, te podían llegar tíos y decirte, e intentar ligar contigo: pero... primero por el miedo a... hostia y ¿cómo lo hago? Porque este chico me parece mono, pero esto al final esconde... ¿y cómo lo hago? Ni tú mismo sabes muy bien, y luego, que en el fondo piensas...no, es que viene porque es majo...porque tal... hasta que ya no superas tú esa barrera... (Sí, sí) y luego ya sí, es una cosa más fluida. Pero hasta ese momento...yo creo que el trabajo, la lucha con uno mismo es la más dura ¿eh? (M1-52).

Sobre la posibilidad de ligar comparada con la previa a la lesión, hay opiniones distintas. Por un lado, se ven parecidas a las previas a la lesión medular, en las que tampoco el éxito estaba asegurado.

Tampoco es que yo fuera antes muy extrovertido, pero bueno, tampoco es que me fuera fatal con las chicas, yo creo que estaba un poco en el medio. $Y$ ahora realmente estoy igual (H2-33).

Igual es que tengo demasiada confianza en mí mismo, pero en mi caso me veo con las mismas, se dónde está mi límite, me veo con las mismas posibilidades que a lo mejor que otra persona que esté al lado y quiera ligar con una chica (H2-52). Vamos de fiesta, vamos a ligar. Para que te digan que no... Antes te decían que no... [Risas] (H4-72).

A veces la nueva condición sí que se interpreta como una dificultad para ligar por el mero hecho de ir en silla de ruedas. Esta se instaura como una barrera y en ocasiones las personas con lesión medular tienen dificultades para distinguir si las dificultades son 
debidas a la silla o a sus propias características personales. Se percibe un desconocimiento social sobre la lesión medular en general y sobre la sexualidad en particular.

Probablemente a ver... hay gente que sí tiene problemas, pero no por...yo creo que es más por desconocimiento que por... de verdad, no sé cómo decirte, atracción no... no repelús...eh... (-como respeto) Sí, eso. Tienen más respeto al tema de la silla, entonces por no meterse en ese fregado, pues están un poco más distantes (H2-34).

Me puedo ver con las mismas posibilidades, otra cosa es lo que piense la chica, si quiere una silla o no quiere una silla. Yo creo que el desconocimiento en el caso de la silla, en este caso en la lesión medular, la sexualidad, entiendo que la gente no sé si por vergüenza, no sé, sí por vergüenza yo creo que sería supongo, del rechazo por eso, yo creo que mucha gente a lo mejor no intenta acercarse (H253).

Yo ligo menos porque voy en silla de ruedas, porque la mirada de la gente, ya va cambiando poco a poco ¿eh?, pero la mirada de la gente es a la silla, raramente ven directamente a la persona, luego hay algún rarito después, ya ven a la persona, pero lo primero que ven es la silla, pero es importante saber eso y que tampoco te afecte en exceso ¿no? (M1-24).

$X$ era parapléjica, además guapísima, mira esa chica era la típica que...bueno pues pibón: rubia, guapísima, cuerpazo. Yo no la conocía antes ¿no? ni vi fotos de ella, pero es que era un bombón, era la guapísima del grupo ¿no? Y claro, imagínate pasar de ser la guapa del grupo a la que todo el mundo mira, la que liga más, la guapa de tal, a de repente ser la que menos todo el mundo mira (M141).

Hasta que no te ves reflejado en alguien en el sentido de: "no, no que tú estás buena, no te confundas, que, sino ligas más es porque la gente tiene miedo a enfrentarse a una silla, pero tú estás muy bien. Tu problema no es que seas fea, o que tengas el cuerpo así o asá, es la silla" ¿No? (M1-52).

A ver, yo creo que más difícil [conocer a alguien nuevo al ir en silla] sí que es. Pero no porque yo me... sino porque es así, tal cual. La gente entra a lo mejor por la 
vista, entonces, el momento a lo mejor a los chicos o determinados chicos, no todos, pues piensan...ay, pobre...no se fijan (M2-5).

Con el encuentro, es decir con la socialización, con el acercamiento, con el que te vean como un hombre o como una mujer, con que tú te sientas un hombre o una mujer, con que se diluyan los prejuicios, que cuando tú te acercas a ligar con una chica o entablar una conversación y, de repente, haces ver que tú tienes un interés de tipo erótico o... Que esa chica te ha despertado el deseo y tú se lo transmites de otra manera, que eso no suponga el susto que a veces supone, el impacto que supone... Sobre todo, por falta de conocimiento, por ignorancia, por incomprensión, por nunca haberse puesto en la situación y que nunca nadie le haya puesto en la hipotética situación de que esas cosas pueden ocurrir. Porque cuando tú te acercas, y parece que va todo bien porque vamos como de colegas "qué simpático", "qué tipo más simpático", "qué chica más maja", y tú sacas el tema y de repente el gesto cambia, la relación cambia, la comunicación cambia, la comunicación se corta... Eso al final entiendo que puede ser que ha ocurrido un cierto shock en la otra persona, pero, en ti, es muy duro lo que ocurre porque te das cuenta de que es tu situación y no tú, tu persona, la que ha echado para atrás, la que ha bloqueado la continuación (H3-107).

Se identifican limitaciones como la dificultad para comunicarse debido a la diferente altura (persona de pie-persona sentada) sumado al volumen elevado de la música en sitios como discotecas; se percibe una limitación en el contacto físico inicial. Esto se suple con otras potencialidades que surgen: darle una mayor importancia a la comunicación, utilizar el sentido del humor e ir a sitios donde la proxémica social sea favorable.

Al final es ligar, pero de otra manera, a ver sí que es cierto... A mí no me gusta ir a discotecas o sitios que tenga la música muy alta, sí me gusta ir de vez en cuando de copas con los amigos a un pub, o a un bar. Pero claro, si me meto en una discoteca, la música está muy alta. Yo entiendo que es incómodo estar siempre agachándose y luego encima, mi capacidad pulmonar no es la de antes, no tengo la fuerza con la voz que tenía antes, y acabo afónico, no me oyen la mitad de las 
veces, entonces prefiero calma. Eso, música tranquila, un bar normal (H2-35).

Es verdad que luego no puedes ligar como antes, el contacto físico de primeras se limita bastante, entonces nada, tienes que tirar de labia, mucha labia, y ya está (H2-34).

El miedo. Que pierdan el miedo. El miedo es importante y esa timidez que te da...Claro, claro, no, no, es verdad. Son cosas...Vamos de fiesta, vamos a ligar. Para que te digan que no... Antes te decían que no, [risas] Cuando vas sentado, cuenta chistes, se gracioso, búscate otra forma (H4-73).

En mi caso, no sé, es que he desarrollado con la lesión como tenía que hablar siempre mucho y luego me ofrecieron dar charlas a la gente, quieras que no, vas cogiendo mucha labia, mucho rollo, ya ves que no callo y eso, pues desarrollé eso... Hay chicas que les gusta eso y otras que no, igual que te pueden gustar rubias o morenas (H2-53).

Se percibe otra dificultad importante que es la proyección en el futuro a priori (antes de comenzar una relación) y el miedo a lo que pueda conllevar estar con una persona en silla de ruedas, sobre todo centrado en temas sobre el continuo independenciadependencia.

Yo intento cada vez que conozco a alguien es que queden claras varias cosas, y que si alguien tiene un cierto miedo a cuán dependiente es esta persona, qué es a lo que me voy a enfrentar, porque hay mucha gente que se flipa mucho a nivel de futuro cuando todavía no ha pasado absolutamente nada, pero se proyecta un poco en el futuro de qué es esto lo que me podría suponer, pues síque es cierto que mi idea es tratar que vean que soy autónomo para mis cosas, que si tengo cierta ayuda mejor, pero que bueno... (H3-96).

Se identifica como dificultad la falta de accesibilidad. Esta impide acceder a los lugares de moda en ese momento donde se encuentra la mayor parte de la gente, limitando las posibilidades de conocer gente, de encuentro y de establecer vínculos eróticoamatorios. Se identifica que las posibilidades de socialización tienen una influencia sobre la sexualidad en personas con discapacidad. 
A mí no me sirve para nada que estemos hablando de accesibilidad en el transporte, accesibilidad en los edificios... si eso no me lleva luego a que uno de los frutos es que mis posibilidades de relación aumenten. Yo si quiero que pongan en la discoteca una rampa es porque ahí está la gente con la que quiero estar, a la que quiero conocer, porque es el local de moda donde va todo el mundo y donde se liga, donde se hacen amigos, donde te echas unas risas, donde te lo pasas bien. Por eso yo quiero una rampa. Si ese local no tiene rampa y nadie hace nada porque tenga una rampa, a mí se me están negando unas posibilidades de socialización, y si ese es el local de moda en esta ciudad, en el que todo el mundo quiere dejarse ver pasar por ahí, y donde la gente liga, donde se generan tal, y a mí se me está negando la posibilidad, se me están negando a la vez grandes posibilidades de socialización, de relaciones eróticas, de relaciones de pareja... (H3-112).

En ocasiones, el encuentro con alguien que deje de lado la silla y se centre en la persona, produce un empoderamiento en la persona con lesión medular. En otras ocasiones, la propia lesión produce una atracción centrada en la capacidad de superación personal.

"Mira me gustas y ya está" ¿no? y eso mismo te empodera a ti, dices, bueno pues si esto no es tan difícil, no es tan complicado y tiras para delante y a partir de ahí ya sale todo ¿no?, pero, ¿y el que no tiene esa suerte? (M1-12).

Tampoco yo he sido una chica que tampoco he dejado de ligar por el hecho de estar en silla. No sé si es porque me ven como muy segura de mí misma y es por el tema de que crean como un poco de, jolín, yo la admiro ¿no? porque a lo mejor hubiese sido una amiga o mi pareja o mi novia y tal, y eso no lo iba a superar, entonces yo te veo a ti, que vas, que vienes, que haces unas cosas u otras y entonces como que les llama más la atención, ¿no? Sí, sí, se sienten como... ¿y esta chica? que sale, no sé qué, que mira cómo se maneja, cómo controla, conduce, ella vive sola, tiene su trabajo, va a natación, va a uno, a otro, entonces les llama un poco más la atención, de verdad [risas] Te escuchan como con atención, te hacen preguntas...pues mira, casi ligo más ahora que antes (M2-5). Me conoció y se fijó en mí, pero cuando me vio, jolín, que chica, qué no sé qué, y 
luego cuando me conoció un poco más, de tratar hablando con él, le parecía como muy interesante todo, pues jolín, pues yo no sería capaz si me pasa a mí, no lo superaría no sé qué, no se cuanto más...entonces pues les crea curiosidad (M26).

El deporte se encuentra muy unido al ligar, a la búsqueda de encuentro con otras personas del sexo preferente: por un lado, es útil como mejora de la imagen corporal, por otro lado, como lugar donde conocer nueva gente, como lugar de recreo, asociado también a una apertura de mente, al aumento de autoestima en uno mismo y a la vivencia de nuevas situaciones.

A partir de que empecé a hacer deporte, me empecé a mover más, me encontraba mejor, también, ya conocí a chicas (H2-24).

Yo creo que con el deporte empiezas sobre todo a conocer a más gente, a hablar con más gente y ahí también empecé, tengo más contacto con chicas, en ese momento y entonces ahí es cuando me empieza a picar un poco la curiosidad...de: ¿Volveré a estar como antes o a qué altura podré estar respecto a mi yo anterior cuando...? (H2-62).

[Con el deporte] Te desinhibes también, que es importante. O sea, el físico es importante pero aquí...esto, esto [señala a la cabeza] (H4-126).

Yo enfoqué la vida, ya te digo...por eso estoy en la Federación y seguiré ahí dando el callo y estaré hasta que me retire definitivamente de todo. Por eso, por devolver un poco lo que me dio el deporte. Porque a mí el deporte me abrió la vida, te lo juro. Yo tenía una familia maravillosa pero claro te faltaba eso. Eso de enfrentarte a la vida. Eso de irte a una competición a Londres sin tener ni pajolera idea de inglés (H4-73).

La figura 8 muestra el mapa conceptual sobre las vivencias en el proceso de ligar. 
Figura 8: vivencias en el proceso de ligar tras la lesión medular

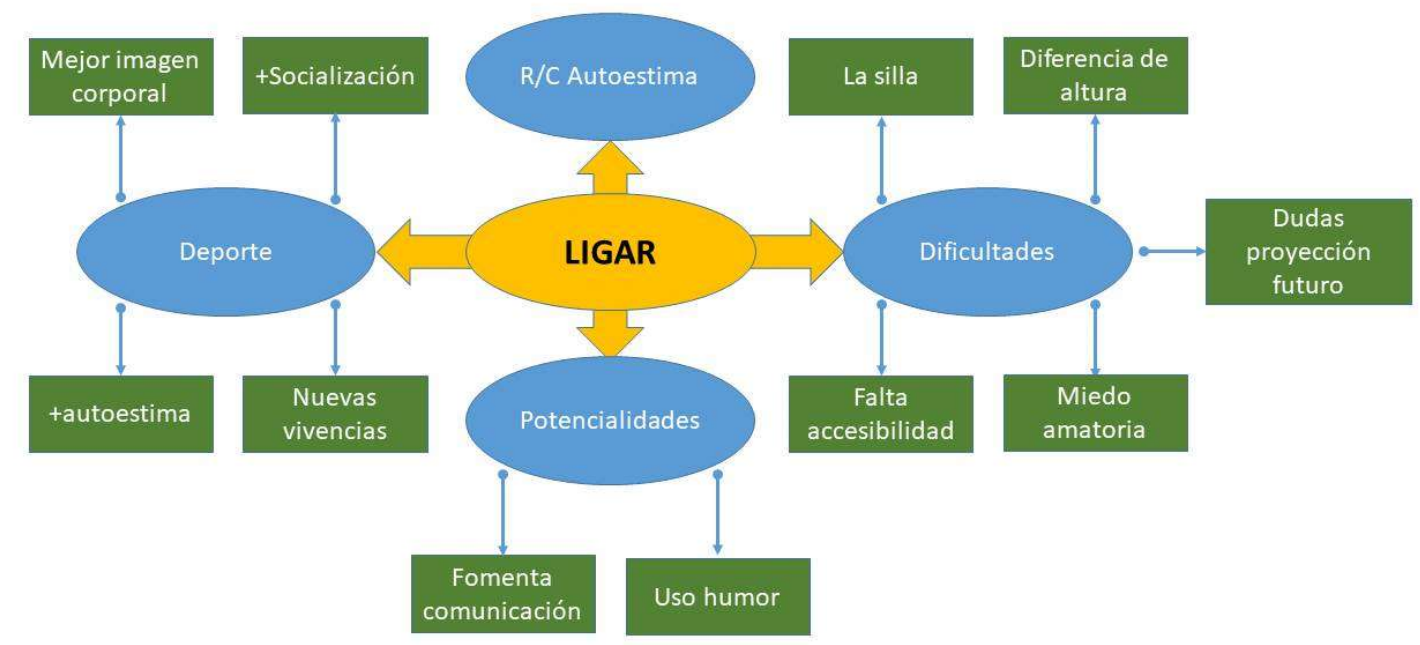

\subsubsection{Vivencias de la amatoria}

\subsection{Percepción de la amatoria como necesidad humana}

La amatoria es vista en ocasiones como una necesidad del ser humano. Esta necesidad es independiente de la edad o del nivel de sensibilidad.

Hasta que al final ves que es una necesidad también. Es una necesidad y sobre todo en lesionados medulares que pueden hacer una vida completamente normal, sin ningún tipo de problema. Tiene sus condicionantes como todo (H467).

Hay un problema ahí que hay que solucionar de alguna manera. Hay un problema bastante serio porque da para todo. Porque hay gente que está mal y claro tú tienes tus necesidades como ser humano. Tienes tus necesidades... y no encuentran cómo (H4-108).

Las necesidades las seguimos teniendo, las ganas nos siguen dando, independientemente del nivel de sensibilidad que tengas (M1-18).

Porque $X$ cuando se casó [hablando de una pareja en el cual un miembro es lesionado medular] y le ves tan enamorado, tan feliz, con una chica tan joven, yo creo que si no tuvieran sexo no estarían juntos. Eso tienes que darlo por hecho (P1-57). 
En contrapartida, a veces tras la lesión medular, la amatoria deja de ser vista como algo prioritario, quedando relegado al abandono de la misma en la pareja, estando relacionado con la falta de sensibilidad y con la carga mental derivada del cuidado.

Te digo yo que, en mi caso, el sexo sobra, para mí es como si no existiera, no me acuerdo ni de él, porque yo no voy, yo no voy para la cama relajada ni un día, ni un día [remarcándolo] (P1-2).

Bueno yo el cambio [hablando del cambio en la sexualidad a raíz de la lesión] la verdad, no volvimos más... ni a pensar en ello. Como yo tampoco sé si lo necesito o no lo necesito porque como no siento... (P1-49).

Bueno, pero yo ya te expliqué, que yo no lo necesito (P1-53).

\subsection{Experiencias en la actividad amatoria pre-lesión}

Cuando la lesión medular sucede, las personas han tenido diferentes vivencias en su actividad amatoria antes de la lesión, sobre todo dependientes de la edad en la que se produzca. Cabe destacar cuando la lesión se produce en la adolescencia, vivenciado como un momento de despertar a la sexualidad.

Yo siempre he sido una persona erotofilica desde que era pequeña, o sea, yo me masturbaba, yo no sé... cuando yo no sabía lo que era masturbarse, me masturbaba, ¿no? Les pasa a muchos niños; y que de repente, claro, con 17 años que tú estás empezando a vivir la sexualidad de una forma más activa e interactiva (M1-7)

Yo a los 17 años ya era activo se puede decir, ya había tenido varias parejas, había tenido varias experiencias sexuales y había tenido ya relaciones sexuales con coito. Para esas alturas, solamente con una persona, pero en repetidas ocasiones. Entonces lo primero que te planteas ahí, primero es el desconocimiento, el no saber qué le pasa a tu cuerpo (H3-6).

En una época en la que todo el mundo vive una actividad en general muy frenética [primera juventud], la tuya se va (M1-9).

Tras el diagnóstico de la lesión medular, una de las preocupaciones identificadas es la 
puesta en duda de la sexualidad. Se plantea la duda sobre cómo podrá afectar la lesión medular a la sexualidad y a todas las partes que la construyen.

Sabía lo que me había pasado y tenía unas ligeras nociones de que eso qué suponía, pero a nivel sexual o a nivel erótico o a nivel de todo lo que pueda afectar al cuerpo en tanto función sexual, tenía poca idea, no sabía eso de qué manera podía afectar, a mis genitales, a la sensibilidad de mis genitales, a mis erecciones, a la eyaculación, a todas esas cosas, la verdad es que no tenía mucha idea (H36).

No tenía, ahí sí que no tenía claro qué es lo que pasaba, qué es lo que iba a pasar (H3-7).

Mi cuerpo ya no respondía como respondía antes (H3-12).

Yo el tema sexual, pues te puedo decir que, aunque yo estaba casado, yo creo que, fue incluso uno de los tabúes que había porque, tú la sexualidad te cambia completamente, tú antes estabas basado en un arquetipo de...no sé cómo explicar, las palabras exactas, para explicar...pero una sexualidad normal por llamarla de alguna manera... a encontrarte que tú no tenías erecciones ni tenías sensibilidad y tú: ¿Qué pasa aquí? Eso fue el mayor trauma (H4-27).

Esa preocupación a veces surge desde el primer momento, y otras veces hay otros temas prioritarios como la rehabilitación motora, que se anteponen y es cuando estos aspectos están más enfocados, cuando aflora el tema de la sexualidad.

El tema de la sexualidad, aunque estaba casado, cuando tuve el accidente estaba casado, tampoco fue que me preocupara, lo que más buscabas era tu recuperación física (H4-25).

El primer año, año y pico, como si no hubiera ese problema (H4-28).

Tampoco me obsesionaba con el tema de la sexualidad, si iba poder hacer cosas. Tuve la suerte de que al final sí que puedo así que bueno... ni tan mal (H2-26). Yo creo que con el deporte empiezas sobre todo a conocer a más gente, a hablar con más gente y ahí también empecé, tengo más contacto con chicas, en ese momento y entonces ahí es cuando me empieza a picar un poco la curiosidad...de: 
¿Volveré a estar cómo antes o a qué altura podré estar respecto a mi yo anterior cuando...? yo creo que es un poco ahí, habrá empezado en enero, febrero... 6 meses más o menos, sí (H2-62).

\subsubsection{3. "Petición de permiso" para mostrar interés por la sexualidad} Aparece un fenómeno llamado "petición de permiso", en el cual el los lesionados medulares, por su condición de personas con una diversidad física, sienten la necesidad de que "otro", normalmente un profesional de la salud, valide el que se sigan interesando por la sexualidad, "a pesar" de su nueva condición.

Si en el personal sanitario durante un año nadie les menciona absolutamente nada, ni en el periodo agudo, ni después, nadie les menciona absolutamente nada, si tú no das pie en esto la gente no te lo dice, porque la gente tiene sus vergüenzas, tienen sus reparos, ven que las cosa no funcionan y dicen "pues será asi", y si encima no me hablan, a ver si voy a sacar yo el tema y encima me van a..., van a pensar que soy un degenerado porque en mi situación estoy pensando en esto (H3-63).

"En la situación en la que está y tiene otras prioridades, no creo que piense en esto [de la sexualidad] y si piensa en esto es que es un degenerado porque en su situación más se tendría que preocupar de esforzarse lo máximo posible por volver a andar" (H3-64).

\subsection{Experiencias de las primeras relaciones eróticas post-lesión}

Las primeras relaciones eróticas post-lesión ocurren pronto tras el accidente en muchas ocasiones, frecuentemente en el hospital donde se encuentran ingresados.

La primera vez que estuve con una chica fue...en el hospital después del accidente (H2-60).

Yo, por ejemplo, a lo mejor tuve demasiados entre comillas ligues en el hospital: tuve dos, pero bueno, claro, fue un año de hospital y no sé si es mucho, poco...ahí tampoco no hay un baremo (H2-64). 
Relativamente pronto, o yo diría que bastante pronto, tuve la posibilidad de volver a mantener una relación compartida con aquella chica con la que las había mantenido antes... (H3-9).

En las primeras relaciones eróticas post-lesión se produce un caer en la cuenta del nuevo comportamiento del cuerpo en cuanto a erótica se refiere, tanto para la persona con una lesión medular como para el compañero o compañera que las comparte.

Relativamente pronto, o yo diría que bastante pronto, tuve la posibilidad de volver a mantener una relación compartida con aquella chica con la que las había mantenido antes y fue un desastre. Fue un desastre, porque allí creo que empecé a comprender qué cosas pasaban, fue un clic muy desagradable, muy desagradable para mí, que entiendo que muy desagradable para ella (H3-9).

Fue desagradable primero porque ella estaba como, no es que estuviera reacia, porque no lo estaba, pero sí que estaba, sí que tenía pues esa, no sé si llamarlo miedo o si el estar en una situación en la que ella no había estado nunca y nunca pensaba que iba a estar (H3-11).

En algunas ocasiones, se realizan con poca preparación con la idea de "aprovechar la oportunidad" surgida.

El conjunto de elementos: desconocimiento del funcionamiento del propio cuerpo, desconocimiento del nuevo cuerpo por parte de la pareja, desconocimiento de los productos de apoyo y poca preparación del entorno, hacen que esta experiencia pueda ser vivida como frustrante o desagradable. Se abre una brecha entre: lo que sentía y lo que siento, o entre lo que debería sentir y lo que siento, lo que antes pasaba y ahora no pasa, lo que antes no pasaba y ahora pasa. Esta diferencia hace incluso plantearse el deseo de seguir manteniendo encuentros eróticos en el futuro.

Iba ser una situación de algo con muy poca preparación, con muy poco tiempo y casi al, pues al... iVenga ya! iAhora mismo! Con lo cual ya, para ser la primera vez que tú vas a mantener una relación, que vas a echar un polvo, después del accidente, con todo lo que conlleva y tal. No, no, realmente, no fue la mejor situación, igual incluso hubiera sido mejor, más satisfactorio si hubiera esperado 
a encontrar una situación más agradable, o más cómoda o más... (H3-10)

La situación que estamos viviendo, que estoy viviendo, es totalmente desagradable, esto que al menos antes me generaba una gran satisfacción pues ahora que tengo la posibilidad, que has venido, que estás aquí, que estamos aquí, pues no vamos a decir: no venga, esperamos a una próxima vez, esperamos que vuelvas a casa y estés en tu cama, no...tiene que ser ahora (H3-11).

Yo recuerdo en aquella primera situación, pues yo ya había empezado a, yo ya utilizaba colectores y sondas para mear y eso, y lo suyo, evidentemente lo suyo, era haberlo quitado y luego haber puesto uno, pero yo tenía tanto miedo a luego no saber ponerlo, que decidió que con ello puesto... lo cual yo decía [risas] si ya es complicado de por sí lo que estamos haciendo y fíjate que no estoy sondado, que tenemos esa facilidad, que no es cuestión de que haya que quitar ningún catéter ni nada, no, no, no, no.... Ahora entiendo que todavía fuese más desagradable para mí, pero para ella... (H3-12).

El tema de no haber quitado los artilugios [el colector], y el tema de que yo notaba que, bueno, yo no notaba, al revés, es decir, lo que yo debería de haber notado, que era lo que yo recordaba, bueno estaba ahí, estaba... no había pasado, yo creo que no habían pasado dos meses, o una cosa así, con lo cual yo tenía todavía muy fresco, pero eso no sucedía y no pasaba lo de siempre, había una sensación placentera pero no pasaba de ahí y no llegó hasta donde solía llegar y entiendo que para ella tampoco, pero bueno, para ella serían otras circunstancias pero también... hizo que aquella primera fuera muy frustrante, muy muy frustrante hasta el punto de plantearte, espero que esto no sea así porque si la próxima vez es así, eh..., no sé si me van a quedar ganas de que haya más veces (H3-15).

A parte de aquel momento de frustración, es decir, el momento de frustración ese que me duró tiempo, sí que es cierto, me duró tiempo, me duró en realidad hasta que volví a conocer otra chica que no conocía de nada y tuve con ella otra... (H3$60)$.

En la figura 9 se muestra el mapa conceptual sobre las vivencias en las primeras relaciones eróticas post-lesionales. 
Figura 9: vivencias en las primeras relaciones eróticas post-lesionales

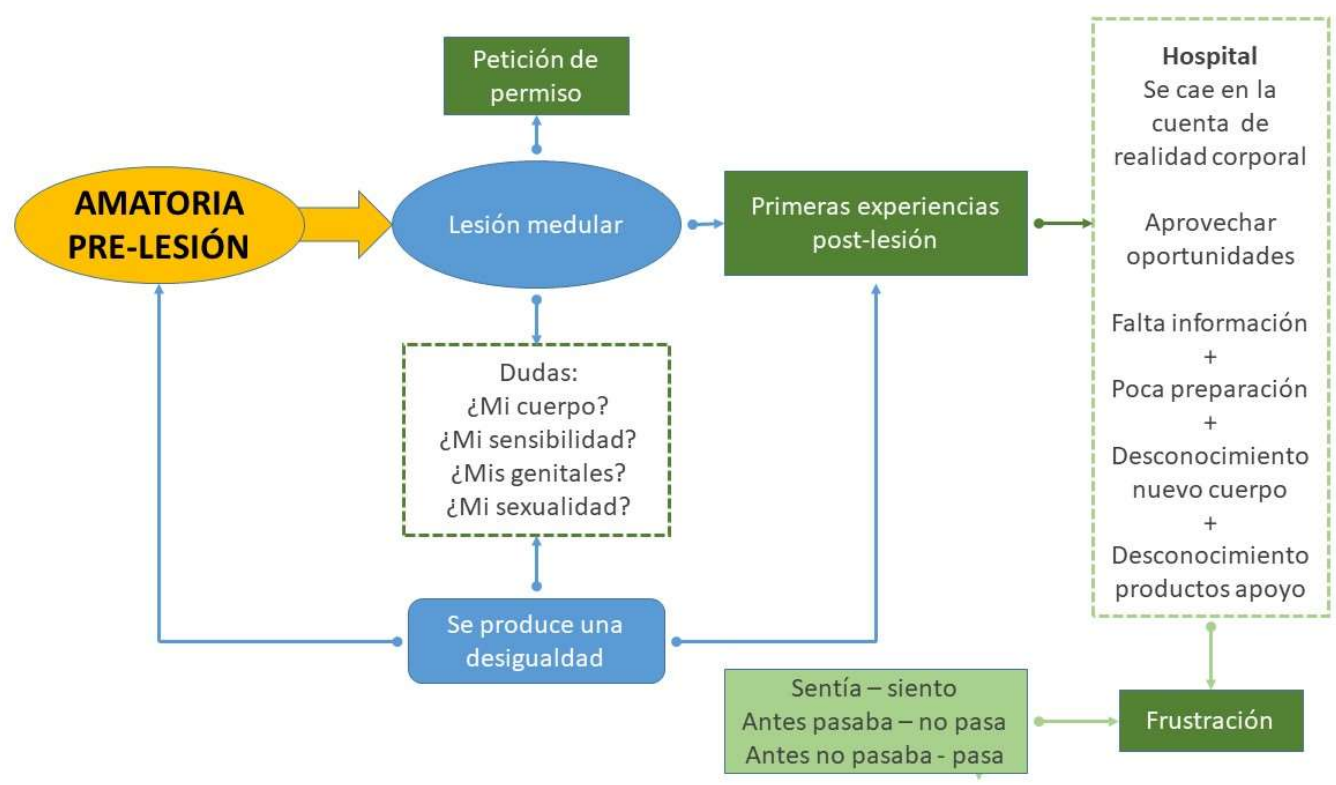

4.3.5.3.5. Vivencias de los cambios en el ciclo de respuesta sexual humana (excitación, meseta, orgasmo y resolución)

A raíz de la lesión medular, se producen cambios en el ciclo de respuesta sexual humana.

\subsection{Vivencias de la excitación}

Para lograr la excitación, se identifica como importante centrarse en las sensaciones, sentimientos y apagar el juicio sobre lo que se debería sentir o no sentir.

Aprender a apagar el cerebro en ese sentido, el cerebro racional, de lo que estoy sintiendo, no estoy sintiendo. Porque claro nos obsesionamos mucho con observarnos a ver qué sentimos (-mirar desde fuera sí) -efectivamente -y entonces te cuesta mucho realmente estar dejándote llevar y disfrutando sin más (M1-37).

Es un aprendizaje el...el... pues eso, qué bien lo estoy pasando y ya está, sin más, sin pensar (M1-37).

\subsection{1. Vivencias de la erección}

En las personas que conservan la capacidad de tener erecciones sin apoyos, el sentirlas inicialmente tras la lesión medular se vive como una tranquilidad. Sin embargo, esta se modifica en la mayoría de las ocasiones: distinta dureza, distinta duración, mayor 
período desde el comienzo de la excitación hasta que se produce la erección, no producción de erecciones siempre que se desea y pérdida de erección en ocasiones. Incluso a veces, la vivencia de falta de control es tal, que se habla del pene en tercera persona, como reseñando la "independencia" sobre esa parte del cuerpo.

Es cierto que esa parte no me preocupaba porque yo sí que veía que tenía erecciones, y que tenía tal. Y bueno, pues supongo que como todo iré aprendiendo a controlarlas, iré aprendiendo a controlar cómo, a ver qué métodos utilizo (H1-18).

Te das cuenta de que sí tienes erecciones, pero igual no las tienes tan duraderas como te gustaría y que para que el momento sexual, que es algo que te gusta, no pase a no gustarte...pues decides probar ¿no? Y entonces pruebas, en aquel caso, con una Viagra ${ }^{\circledR}$, porque es lo que siempre has oído (H1-2).

En el tema de las erecciones estoy igual que antes, misma duración... probablemente, si digo: "ahora quiero una", pues tengo que esperar cinco, diez minutos. No es tan instantánea como antes, pero bien, en ese sentido creo que tengo suerte que no me varió mucho (H2-39).

Yo también conservo erecciones supongo que tendrá que ver con conservar la sensibilidad, o por lo que sea. Conservo erecciones, no siempre que quiero, no como quiero, es decir, ni suceden cuando yo quiero o siempre que yo quiero, ni duran todo lo que yo quiero que duren cuando yo quiero (H3-14).

Digamos que hemos llegado a un acuerdo, nos llevamos más o menos bien. Pero en aquel momento también fue eso de, yo tenía una erección hace 15 segundos y ahora cuando las cosas han ido a más que se supone que la erección debería ir a más, ha ido a menos (H3-14).

De mis erecciones, que duran lo que les da la gana durar, a veces cuando no quiero, y a veces cuando quiero, nada (H3-74).

La cuestión es... Y también que yo tengo una relación con mi pene que nos llevamos bien, pero hay veces que a él no le da la gana y por mucho que me empeñe en que quieras, no vas a querer (H3-99). 
Hay hombres con lesión medular que no tienen erecciones. Esto es vivenciado con frustración. Esta frustración es apoyada por el modelo de erótica imperante muy centrada en el coitocentrismo, en el que la normalidad se define porque ocurra la triada erección-penetración-eyaculación. También se puede producir una frustración en la pareja, que intenta buscar de forma insistente la aparición de erección.

En esta situación de no erección es frecuente recurrir al apoyo farmacológico como recurso.

Tú la sexualidad te cambia completamente, tú antes estabas basado en un arquetipo de...no sé cómo explicar, las palabras exactas, para explicar...pero una sexualidad normal por llamarla de alguna manera... a encontrarte que tú no tenías erecciones ni tenías sensibilidad y tú: ¿Qué pasa aquí? Eso fue el mayor trauma (H4-27).

Hay lesionados que tienen erecciones y yo sin embargo tengo que tomar pastillas, sino no tengo erección (H4-61).

Cuestiones que han podido suceder, o que me suelan suceder, te lo comentaba antes: la frustración que puede generar en la otra persona la falta de eyaculación, la falta de orgasmo o, incluso, la falta de erección. Fastidiarle incluso más de lo que me fastidia a mí. Es que los hombres estáis obsesionados con... Pues las mujeres también os lo tenéis que mirar un poco (H3-99).

También se vivencia de forma negativa la no ocurrencia de erección cuando se espera o la pérdida de la misma, sobre todo asociado a una pareja o encuentro nuevo y a la necesidad de dar explicaciones sobre lo sucedido.

Comerte muchos marrones y salir de ahí como podías, porque si no era alguien que conocieses de mucho más, tampoco te apetecía ponerte a explicar tu vida, porque tú te acuestas una noche con alguien, no le explicas porque tienes una teta más baja que otra, o tal, sí fue que tuviste una operación o tuviste un cáncer porque bueno eso lo explicas cuando tienes más confianza (H1-7).

Lógicamente si, cuando te ocurre algo así [falta de erección], te encuentras en ese marrón, pues dices "bueno es que estoy reventado, chica. Nada, mañana será otro día." Pero al final es un marrón y eso, psicológicamente hablando además 
es muy duro, es decir, y yo me considero afortunado por la cabeza que tengo y que a mí eso me resbala, pero es muy duro (H1-8).

Existe un desconocimiento sobre lo que le ocurre al resto de lesionados medulares, suele asimilarse la situación propia como general. En ocasiones surgen puestas en común entre el grupo de iguales sobre la situación personal de cada uno.

Lo que no sabíamos era de lo que no teníamos conciencia, era de lo que pasaba el resto o no, yo no, yo la verdad es que hasta tiempo después yo no tuve conciencia de que al resto o a la mayoría del resto no tenía sensibilidad y no se les ponía dura. Yo pensaba que lo mismo que me pasaba a mí les pasaría a los demás, y los demás tampoco tenían conciencia de que había alguien que sí tenía sensibilidad y al que sí se le ponía dura (H3-57).

Yo recuerdo que hubo una vez un hombre de estos, de los mayores, tendría 60 y alguno, que aquel día estábamos emocionadísimos en el corrillo de hombres porque aquel día se le había puesto dura y los demás pues estaban como un poco ojipláticos (H3-58).

La aparición de una erección (a veces inesperada), genera un inicio de un encuentro erótico para aprovecharla. Este "aprovechar la oportunidad" también es referido a cuando surge algún contacto que puede derivar en encuentro erótico.

Entonces pues bueno, también es un esto de... bueno que toca, vamos a aprovechar [cuando hay una erección] (H3-14).

Es decir, que tenía que ser, que me he programado que hoy va a ser y hoy me voy a pinchar, con lo cual le quitaba toda la erótica, parte de la erótica al asunto de lo que era el tema de los deseos, no es que esto va a empezar porque tenemos un brote de deseo, no. Va a empezar porque yo me voy a pinchar y encima tenemos que aprovechar lo que dura esto... pues eso... (H3-33).

Había que aprovechar lo mínimo que hubiera, lo mínimo. Es decir, el contacto que tú pudieras tener no podías dejarlo pasar porque no sabías cuándo iba a venir el siguiente (H3-67). 


\subsection{Vivencias de la fase de meseta}

En las personas que no tienen orgasmo, cuando están altamente excitadas durante un tiempo prolongado, si las siguen estimulando la sensación puede pasar a ser desagradable o molesta. Otras veces, sin embargo, hay un deseo de mantener esa alta excitación durante más tiempo, dejando un sentimiento de insatisfacción si esto no se produce.

Sí que es verdad que yo he notado que cuando ya hay una estimulación muy grande, ya llevas, llevan un rato o penetrándote, o chupándote el clítoris, o lo que sea, o masturbando, llega un momento que ya que eso que notas que es como placer o por lo menos yo lo percibo así, deja de ser placer y se convierte en algo desagradable y doloroso, es como " $y a^{\prime}$ ", (molesto) supongo que se saturan los receptores y es como "hasta aqui", entonces como para un ratito y ya luego si acaso seguimos, ¿no? (M136).

Hay veces que es como que con la penetración ¿no? tú estás sintiendo placer y tú estás sintiendo que sigues sintiendo placer si te siguen penetrando. Claro, Ilega un momento que el que está contigo pues puede aguantar más, menos o si no utilizas o un juguete, utilizar los dedos o tal. Claro, yo hay veces que tal, pero con algunos tíos pues como que no me acabo de quedar satisfecha y yo identificaba eso ¿no? Todavía tengo la sensación de que si me siguen estimulando sigo teniendo placer (M1-45).

\subsection{Vivencias del orgasmo}

La información dada por los profesionales sobre el orgasmo es estándar, basada en el nivel de la lesión, pero en numerosas ocasiones es errónea. Es frecuente que personas a las que se les ha dicho que no van a tener orgasmos, los tengan.

Qué dijeron cuando a mí me da... nada, es que a partir de la D6... justo tal... no se cual, era todo como muy del libro. Entonces, de repente, cuando ya vas conociendo tu cuerpo te das cuenta de que llegas al orgasmo, de que el orgasmo te es muy placentero, que es un orgasmo muy largo y si aprendes a reconducir, lo aprendes a controlar: cuándo vas a tener un orgasmo, a cuándo no, a cómo mantenerlo más, a cómo menos (H1-9). 
Quienes no tienen orgasmos pueden sentirse frustrados, aunque es posible que con el paso del tiempo se vaya aceptando la situación y disminuyendo su impacto. En ocasiones, esta frustración no se encuentra tanto en la persona con lesión medular como en la pareja, que intenta de forma persistente que la persona obtenga ese pico de placer.

En el momento en el que sucedería el orgasmo, pueden aparecer diversas sensaciones corporales, como por ejemplo espasmos. A veces se produce una sensación de que el orgasmo está próximo y va a producirse, pero no llega, aunque se produce una sensación de no querer seguir estimulando. Si cuando aparecen los espasmos se mantiene la estimulación erótica, puede producirse una subida tensional, desencadenando una crisis de disreflexia autonómica.

Mi único problema es que yo no eyaculo, entonces digamos, yo no llego a ese clímax, ¿no? (H2-42).

Yo por aquel entonces ya había asumido que yo y los orgasmos estábamos peleados y, posiblemente, estaríamos peleados de por vida, porque lo que yo ya sabía de qué era lo que a nivel fisiológico a mí me pasaba, era bastante incompatible con sentir orgasmos del modo en el que yo los sentía antes. Si te digo la verdad es algo que, al principio, me frustraba mucho más, que luego ha dejado de frustrarme y que, en estos momentos, digamos que me puede frustrar a ratos, en alguna ocasión (H3-71).

Lógicamente sentir lo que es sentir...y el orgasmo ya no sé dónde quedaría el pobre (M3-59).

El tema de mis orgasmos y mis eyaculaciones muchas veces me frustra más por la frustración que yo veo que genera en la otra persona que lo que me genera a mí. Es decir, lo que para mí no es obsesivo hay veces que se convierte en obsesión para la otra persona. Conseguir que yo tenga un orgasmo o que yo me corra. $Y$ da igual que yo lo pueda explicar: mira, lo que ocurre es esto. Con lo cual yo me lo paso muy bien contigo, es decir, yo disfruto a tope contigo, para mí esto es muy placentero, yo no tengo ninguna queja de mis encuentros contigo. Pero no voy a tener un orgasmo como tú quieras que lo tenga, y es muy complicado que yo me corra como tú quieres que yo me corra (H3-72). 
$Y$ si es verdad que, cuando cuándo tendría que ser digamos el momento del orgasmo y de eyacular, pues ahí noto yo un espasmo en el abdomen, y entonces ahí ya noto que se acaba, porque si no, siguen los espasmos en el abdomen, ahí es cuando yo paro (H2-42).

Sí, o sea, cuando llega a ese momento de espasmos en el abdomen [con un pico de excitación sexual], muchas veces...si tengo muchos seguidos me sube la tensión, entonces me podría dar una crisis vegetativa, y entonces claro, ahí sé que ese es el punto. Ese digamos es mi orgasmo, más placentero que el otro, si y no, no me gusta que me suba la tensión, pero es cuando noto que ya no puedo más. Supongo que ese sería mi momento de eyacular, supongo. Pero bueno, ni me molesta...no es molesto, si se sigue el acto, y es continuado, entonces es molesto, pero si en ese momento paro y descanso 5, 10 minutos, puedo seguir sin ningún problema (H2-44).

Además, distinguir, cuando...Yo he llegado a identificar una cierta sensación, no es un orgasmo, pero algo muy parecido, lo que para mí es un orgasmo ahora. Entonces bueno, sé cuándo puedo seguir estimulando y voy a seguir pasándolo bien, y voy a seguir sintiendo placer, y cuando va a llegar un punto que ya no, por más que estimule, no va a llegar el orgasmo tal y como yo lo conocía (M1-37).

Todavía tengo la sensación de que si me siguen estimulando sigo teniendo placer y es como: tengo la sensación de que voy a llegar al orgasmo. Realmente nunca llegas, pero hay un punto que ya dejas de sentir esa necesidad de que te sigan estimulando (M1-45).

Algunas personas con lesión medular sí tienen orgasmos, pero estos son diferentes a como eran antes de la lesión. A veces se produce una obsesión por llegar al orgasmo, al orgasmo tal y como se había conocido previamente. A veces esta obsesión del orgasmo como meta, hace que se pierda el placer del camino.

Hay lesionados medulares, en los que no se producen cambios post-lesión en su vivencia del orgasmo.

Dentro de esto, te das mucha cuenta de que tus orgasmos no tienen nada que ver con cómo los tenías antes (H4-37). 
El orgasmo, la obsesión por conseguir un orgasmo (M1-37).

Claro, si has experimentado orgasmo antes de tener una lesión, eh...igual te obsesionas un poco con volver a tenerlo. Yes una putada, porque claro, te pierdes todo el camino hasta el orgasmo que nunca llega realmente como tú lo conociste. O sea, tienes que aprender a sentir, en el sentido de disfrutar de lo que estas sintiendo, sin obsesionarte con dónde vas a llegar. Es decir, no me voy a centrar en si llego o no llego si no y además discernir: esto creo que ya es mi punto álgido de placer ¿no? (M1-37).

Me sirvió para encontrar cosas que me gustaban, momentos, situaciones prácticas... que me llenaban, que me llenaban mucho, con las que ya empecé a dejar al coito en realidad en el lugar en el que debería haber estado siempre, que era el de otra alternativa más. No vamos a hacer la cúspide a la que vas subiendo y tienes que hacer cumbre. Lo mismo con el orgasmo, el mismo paralelismo (H378).

La entrevistadora pregunta: "orgasmo, ¿tienes orgasmo?", la informante responde: "sí, sí, si". La entrevistadora pregunta: "¿de la misma manera?, ¿el orgasmo es igual?", la informante responde: "si" (M2-5).

\subsection{Vivencias de la eyaculación}

No hay ninguna referencia a la eyaculación femenina.

En la capacidad de eyacular, existen diferencias individuales a pesar de la lesión: cada lesión medular es distinta y lesiones altas pueden tener capacidad eyaculatoria y otras más bajas no tenerla. Esto, en ocasiones, no es acogido así por los profesionales, los cuales ajustan su consejo al tipo de lesión, aportando información errónea. Cuando la información profesional es de no poder y la eyaculación se produce se vivencia como algo "raro" o "extraño".

Aparece la eyaculación como símbolo de finalización del encuentro erótico. Ante la falta de eyaculación se identifica la duda de no saber cuándo parar o acabar.

El tema de la eyaculación. Pues es cierto que yo eyaculo y además me gusta, con lo cual, genial. Pero a mí me dijeron que no, que no, que no, que no, que era 
imposible. Bueno, pues bien, chica, imposible no, es una lesión medular y ahí hay dos millones de cables y puede estar roto muchos, pocos, todos. Algo cambiará (H1-21).

Hay incluso gente que eyacula. Eso es rarísimo. No tienen ni un pijo de sensibilidad y eyaculan. Son cosas que no...y lo que te decía, cada uno es un auténtico mundo (H4-61).

Además, te da la sensación de que has eyaculado. Has sentido algo raro... pero no sabes nada, es todo muy raro... (H1-2)

Desde que me dijo el Dr. Y, de que sí que con la Viagra ${ }^{\circledR}$ que funcionaba, pero eso, funcionaba, punto. Yo no iba a sentir nada, ni a eyacular, y pienso a veces: ¿Y cómo sé cuándo acabo? Si me pusiera...llegaré yo a saber cuándo, cuando pues ¿acabé? (P1-52).

El no eyacular puede vivirse con frustración. Sin embargo, en ocasiones la no eyaculación se vive como una ventaja, el poder mantener encuentros eróticos sin posibilidad de embarazo.

En personas que no conservan la capacidad de eyacular tras la lesión, se pueden producir otros síntomas como espasmos en el abdomen o sensación de ganas de orinar que se interpretan como el momento en el que la eyaculación se produciría.

Pero aun así se sigue generando esa frustración que a veces a mí me frustra [el no eyacular], pero bueno... (H3-73).

La falta de orgasmo y la falta de eyaculación, que yo creo que es algo que visualmente es algo que a todos nos llena, nos provoca, el tema de la eyaculación, el tema del orgasmo también... a todos y a todas (H3-74).

Nosotros tenemos un problema muy grande con eyaculación, tú si quieres...yo no eyaculo sino me estimulo [con el Ferticare ${ }^{\circledR}$ ]. Y entonces ahí está el problema, por una parte, decías: "mira así no tengo, de puta madre... [Risas]...oye hablando mal y pronto...sí, sí, de puta madre... que yo voy a tener... (H4-36).

Muchas veces antes de que llegue el momento ese de los espasmos en el abdomen, a veces lo que noto es como que tengo ganas de orinar entonces 
supongo que sería el momento supongo el semen la eyaculación supongo, como nunca lo he hecho pues no sabría decirte, pero, eso es un poco lo que me ha dicho el doctor de la unidad sexual ahí en Toledo; al final es ir probando al final mucho prueba-error (H2-46).

$Y$ si es verdad que, cuando cuándo tendría que ser digamos el momento del orgasmo y de eyacular, pues ahí noto yo un espasmo en el abdomen, y entonces ahí ya noto que se acaba, porque si no, siguen los espasmos en el abdomen, ahí es cuando yo paro (H2-42).

El no eyacular produce una limitación a la hora de intentar tener descendencia. Existen métodos como la estimulación del pene por vibración o la punción testicular para ello. A veces, en las unidades de reproducción hospitalaria se realizan estas estimulaciones para valorar la fertilidad. Hay personas que compran estos estimuladores y les dan uso en el juego erótico.

Los cervicales no suelen poder eyacular, entonces hay maneras: puede ser por punción, mediante estimuladores que te sacan, sobre todo para ver si eres fértil (H2-23).

Mi único problema es que yo no eyaculo, entonces digamos, yo no llego a ese clímax, ¿no? por eso te decía antes lo de la punción, se intentó en su día con un estimulador, pero nada, creo que la única opción que queda es la punción, pero era sobre todo, no por el hecho de eyacular si no para ver si soy fértil y puedo formar una familia, y como no me corre prisa tampoco... (H2-42).

En la figura 10 se muestra el mapa conceptual sobre las vivencias de los cambios en el ciclo de respuesta sexual humana. 
Figura 10: vivencias de los cambios en el ciclo de respuesta sexual humana

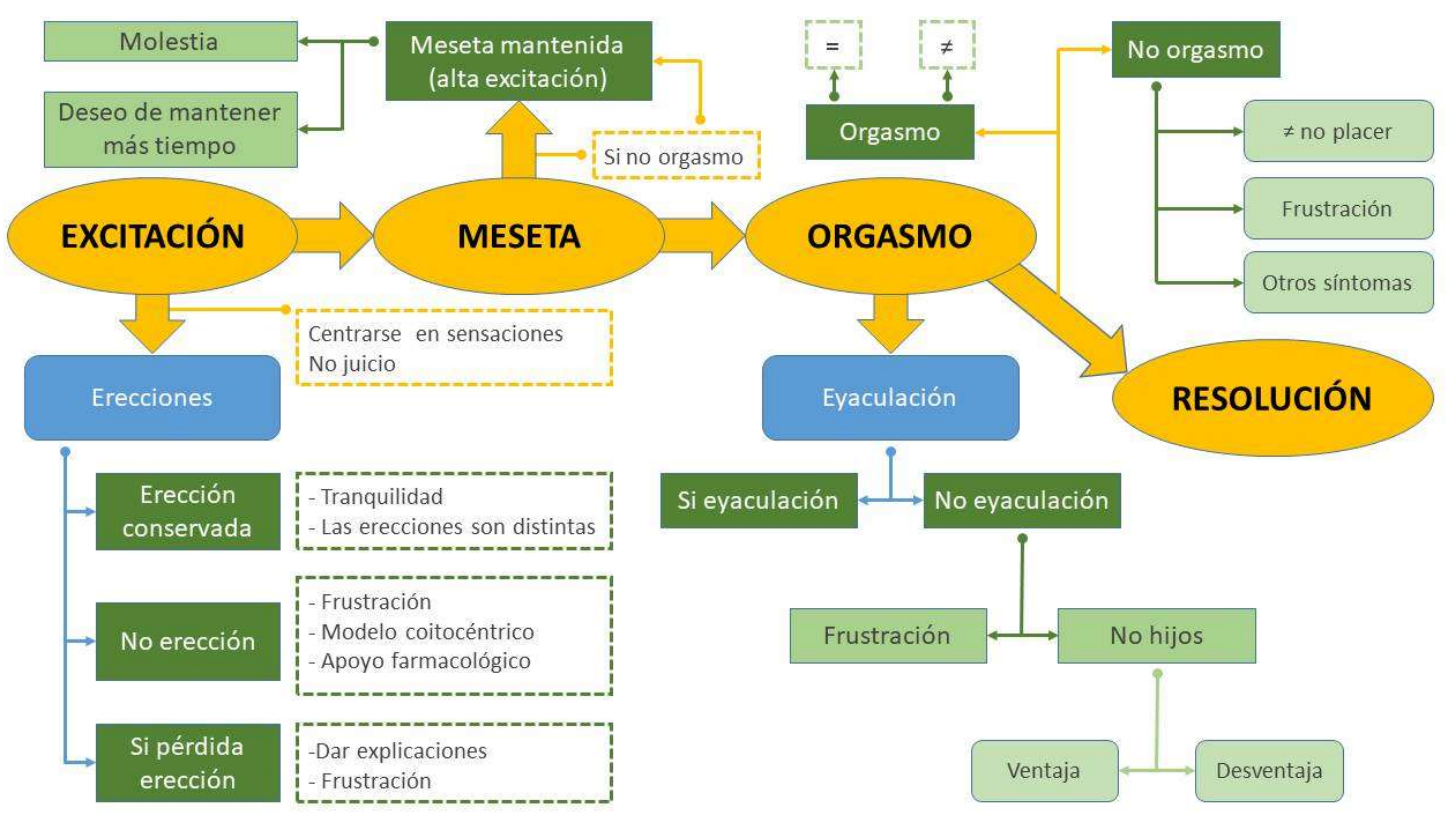

\subsubsection{Percepciones sobre las limitaciones derivadas de la lesión medular y su relación con la erótica}

Las personas con una lesión medular identifican limitaciones para realizar algunas actividades de la vida diaria y algunas dificultades en la interacción erótica: se destaca que es importante conocerlas, ser consciente de ellas y ante el planteamiento de una nueva pareja, que este conocimiento y consciente se produzca también por parte de la pareja.

Porque encima, si tienes tus limitaciones en tu día a día normal. Si tienes tus limitaciones en el tema de sexo, si tienes tus limitaciones... es como madre mía, ¿y esto? (M2-5).

Hay cosas que no puedes hacer, bueno sí, de eso tienes que tener claro que hay cosas que no vas a poder hacer, que no vas a poder hacerlas tan fácilmente. Pero quiero decir, eso, se trata de que esos prejuicios pues, están, los tengas claros ya de mano. $Y$, además, es lógico si yo voy a empezar con una persona, tal, pues tiene que ser consciente de que alguna limitación va a tener. Que luego va a ver, que va a tener menos de las que se imaginaba, pero vas a tener alguna, está claro (H1-23). 


\subsection{Alteraciones en la movilidad}

En cuanto a las alteraciones en la movilidad, en las personas que se desplazan en silla de ruedas, se siente agobio por la sedestación prolongada a lo largo de toda la jornada.

Si se centra la mirada en la erótica, se identifica la idea de que existe una relación entre el nivel de independencia para las actividades de la vida diaria: vestirse, desvestirse, etc., la necesidad de apoyos para realizarlas y la posibilidad de mantener encuentros eróticos.

En la actividad erótica, hay ciertas posturas que no se pueden realizar y para otras, va a necesitarse la ayuda del compañero; se identifica como importante el poder pedir la ayuda necesaria. Si es preciso, también es necesario buscar los espacios y los tiempos que puedan necesitarse.

Tampoco te voy a negar que también tengo mis días malos, de que estoy en la cama y te levantas y es como buf, otra vez todo el día ahí sentada (M2-6).

El problema está, ahora, pues en hacer ciertas posturas que yo cuando estaba bien podía hacer y ahora pues no. Pues a la hora de si me tengo que incorporar hacia arriba o tal, pues a mí me cuesta más, me tengo que coger la pierna, me tienen que ayudar, ese tipo de cosas ¿Entiendes? Entonces para mi resulta un poco... a ver no complicado, porque yo soy bastante liberal no me... oye, que me tienes que ayudar a ponerme así, que yo sola la pierna se me va...Entonces, no me importa decir pues ya está (M2-2).

Una persona en mi situación, yo en este caso, sea capaz de desvestirse, vestirse solo y hacer transferencias tiene mucha implicación a la hora de poder desarrollar encuentros eróticos. Es decir, el hecho de que no sea que te tengan que desnudar entero y vestirte entero después, sino que tengan que colaborar contigo, tengan que ayudarte pero que tú puedas hacer cosas, que tú seas capaz de echarte a la cama solo o con la ayuda de una sola persona ayudándote un poco... a que necesites a 2 personas que te ayuden a echarte a la cama, eso evidentemente para luego mantener un encuentro tiene su importancia porque ya no solamente es buscar, porque tienes que buscar el espacio y tienes que buscar... y si no puedes hacer esas cosas...es como...es como complicado... es como bastante complicado (H3-45). 


\subsection{Espasticidad}

La vivencia de la espasticidad va a ser dependiente del grado que se tenga de la misma. No todos los espasmos son desagradables, incluso a veces pueden forzarse para generar movimiento o descargar una parte del cuerpo que tiene una posición forzada.

Hay espasmos que surgen en momentos de alta excitación, ya sea con el orgasmo, o en el momento en el que sucedería el orgasmo y la eyaculación.

Yo la verdad es que de espasticidad estoy muy bien, puedo tener alguno, pero no me molesta, no ni me impide la vida, de hecho, muchas veces los fuerzo yo, porque yo que sé, fuerzo un espasmo en la pierna porque así me descarga un poco la pierna, a veces de estar la misma posición. Y si es verdad que, cuando cuándo tendría que ser digamos el momento del orgasmo y de eyacular, pues ahí noto yo un espasmo en el abdomen, y entonces ahí ya noto que se acaba, porque si no, siguen los espasmos en el abdomen, ahí es cuando yo paro (H2-42).

El tema espástico, otra cosa importante: hay gente que tiene espasmos. Que los espasmos son malos para algunas cosas (H1-60).

Muchas veces antes de que llegue el momento ese de los espasmos en el abdomen, a veces lo que noto es como que tengo ganas de orinar entonces supongo que sería el momento supongo el semen la eyaculación supongo (H266).

\subsection{Lubricación vaginal}

La disminución de lubricación vaginal se identifica como una alteración común tras una lesión medular. Sin embargo, no todas las mujeres la tienen. Cuando hay consultas relacionadas con la erótica es común recetar lubricantes, sin preguntar si existen problemas en este aspecto.

No tengo problemas de sequedad vaginal, y esas cosas, no tengo problemas (M22).

El doctor [neurólogo] me decía que había lubricantes y tal, pero a mi lubricante me sobra, "tú por eso no te preocupes que a mí eso me sobra" (M3-57). 


\subsection{Alteración en el control de los esfínteres urinario y fecal}

Si se produce una alteración a este nivel, el control de esfínteres es uno de los temas más difíciles de encajar tras una lesión medular. Más aún, cuando se une control de esfínteres y relaciones eróticas: aparece una preocupación por la incontinencia urinaria y fecal, aunque la incontinencia fecal se identifica como más fácil de controlar.

La orina es un líquido corporal que se identifica como algo sucio, por lo que, la idea de tener un escape durante una relación erótica se plantea como algo desagradable y prácticamente terrible.

A veces en parejas con personas incontinentes con necesidad de apoyo, este tema se vivencia como una carga importante.

Va un poco todo ligado: el control de esfínteres y la sexualidad...puf, puf, puf. Ahí hay un tema que es para tratar (H4-133).

Los esfínteres es una de las cosas más chungas a la hora de plantearte volver a tener una relación erótica con alguien, porque claro, normalmente hay incontinencia urinaria y fecal, hombre lo de las heces es más fácil controlarlo, ¿no? Llega un momento que tú coges tus horarios, tal y bueno...pues... pero lo de la incontinencia urinaria, iHostia! (M1-11).

Yo ahora mismo tengo la mala suerte de necesitar sondarme porque no hay..., normalmente no se me escapa la orina por sí sola ¿no? digo la desgracia, pero en ese sentido es una suerte, porque te vas a la cama con alguien y sabes que no te vas a mear encima, pero es algo tan prosaico como eso y tan chungo como eso (M1-11).

Si eres una persona que usas colector, porque yo tengo la vejiga espástica. Yo tengo la sensación de ir al baño, pero tengo la vejiga espástica, y yo cuando me río me meo. (Pequeña risa) O sea, yo puedo hacer movimientos y tal y no me meo, pero como me ría me meo. Y claro, con un colector con toda aquella historia, era un poco hasta traumático para ti, porque claro, te meabas, ibas a mantener relaciones sexuales y te meabas, que es una sensación, pues imaginaros, hasta bastante...cochina por decirlo de... por calificarlo de alguna manera. Muy desagradable por calificarlo de alguna manera (H4-33).

Yo a lo mejor paso a la ducha y de la ducha voy a la cama, y ella acaba de secarme 
o de vestirme. $Y$ cuando me pongo boca abajo al apretar siempre me meo, y a veces se pone a dar voces y cagamentos, y yo pienso: ¿Qué pensará que lo hago adrede? (P1-59).

¿Terminaste de hacer esto? No lo sé, voy al váter, ¿terminaste? No lo sé, ¿cómo pretendes que yo lo sepa? pero bueno, con el paso del tiempo vas más o menos. Yo por ejemplo antes iba muy mal, muy mal, y la última vez que fui a $X$, que me Ilamó, que me dieron un sistema como lavativa, ahora ya sé cuándo acabo más o menos, ahora ya sé si acabé. Antes era muy problemático porque yo pasaba, hasta semanas sin poder hacer nada (P1-61).

Es algo que se plantea como difícil de contar a alguien antes de un encuentro erótico esporádico, sobre todo, incluso llegando a estropear en cierta medida la interacción por el mero hecho de contarlo. Con el tiempo se llega a soluciones como contarlo con naturalidad o simplemente comportarse con espontaneidad sin dar explicaciones sobre la situación.

En el plano erótico, con la incontinencia urinaria, con el tema de las sondas, el tema de pañales, con el tema de cosas de estas... Claro que es una de las cosas de las que más te puede costar contar. Al principio a mí se me hacía un mundo (H3-97).

Pero antes me agobiaba, incluso cuando era algo esporádico, algo que presumiblemente no iba a pasar de aquel día, me agobiaba mucho o que lo viese o tener que contarlo. Me agobiaba y realmente me fastidiaba parte de la interacción (H3-97).

Al principio, me las apañaba para que no se diesen cuenta de muchas cosas hasta que yo quería contarlas, pero me suponía un esfuerzo tremendo. Era un tremendo esfuerzo. Y complicado. Era muy cansado aquello. Y eso ha evolucionado a que, ahora mismo, pero ahora mismo quiero decir hace muchos años, me pueden ocurrir dos cosas: una, que no tenga ningún problema a contárselo a alguien, ya no contarlo, sino actuar con naturalidad y que esa persona lo vea el primera día que aparece por aquí, o, directamente, pasar del tema, es decir, yo no tengo que dar explicaciones a nadie y yo no tengo que contar nada, y si tú ves algo o dejas 
de ver, tampoco es mi historia (H3-57).

Entiendo que te dé cosa sobre todo la primera, conoces a alguien en un bar o lo que sea... si os vais a casa pues entiendo que claro si es alguien de fuera, no es de tu círculo, entiendo que le pueda chocar igual que le tengas que explicar en un momento, me tengo que sondar, entiendo que todas estas cosas sean diferentes pero bueno, es lo que hay ahora mismo así que... (H2-56)

Por otro lado, se percibe la dificultad del manejo y la convivencia durante las relaciones eróticas con los productos de apoyo utilizados para el control de esfínteres: colectores, sondas, pañales, etc. Las dificultades identificadas en el manejo de estos productos son: las personas con sonda vesical permanente que no pueden volver a ponérsela de forma autónoma, teniendo que acudir a un servicio sanitario para ello y la falta de manejo de los productos, llegando incluso a dejarlos puestos ante el miedo de no saber volver a ponerlos.

La gente que lleva sonda permanente, por ejemplo, y el que se puede manejar solo, bueno... se quita se pone, pero ¿Y el que no? (M1-11).

Yo recuerdo en aquella primera situación, pues yo ya había empezado a, yo ya utilizaba colectores y sondas para mear y eso, y lo suyo, evidentemente lo suyo, era haberlo quitado y luego haber puesto uno, pero yo tenía tanto miedo a luego no saber ponerlo, que decidió que con ello puesto... lo cual yo decía [risas] si ya es complicado de por sí lo que estamos haciendo y fíjate que no estoy sondado, que tenemos esa facilidad, que no es cuestión de que haya que quitar ningún catéter ni nada, no, no, no, no.... Ahora entiendo que todavía fuese más desagradable para mí, pero para ella... (H3-12).

Con el tiempo se vivencia un entendimiento con el cuerpo y una adaptación a la nueva situación buscando nuevas formas de amoldarse: ir al baño o sondarse previamente a tener relaciones eróticas, por ejemplo. Surge a veces la necesidad de re-sondarse o de tener que volver a ir al baño (sobre todo asociado a ciertas posturas que aumentan la presión o el golpeteo sobre la vejiga) durante el encuentro, con la importunidad de tener que parar y retomar. 
Utilizar el humor como herramienta, erotizar los productos de apoyo utilizados, quitarle importancia al asunto, si ocurre un accidente, no darle mayor importancia son herramientas útiles para el manejo.

Me sondo antes, porque yo en mi caso tengo la vejiga disrefléxica o algo así, es que los términos médicos, entre el inglés y el español, no sé muy bien cómo es...y entonces claro, claro, muchas veces me ha pasado a lo mejor de...de que a lo mejor estoy tal, y sí que tengo que ir a... me tengo que sondar otra vez, porque claro, como no lo puedo controlar, noto las ganas, pero no lo puedo controlar. Entonces me tengo que hacer otro sondaje o lo que sea. Eso sí, pero muchas veces, llegan antes las ganas de orinar, pues porque a lo mejor la postura en la que se está, pues favorece, hay más golpeo en la vejiga, entonces a veces antes...A veces me sondo y a la media hora tengo que sondarme otra vez, y otras veces estoy toda la noche sin tener que sondarme, entonces depende un poco de cómo... también del día y de cómo me encuentre físicamente antes (H2-48).

Según lo que estés haciendo me estás apretando la vejiga. Y mi vejiga y yo tenemos una relación, pues bueno... Si me aprietas mucho la vejiga me entran ganas de mear. Bastante que soy capaz de avisarte de que me están entrando ganas de mear. Pero es eso de: bueno, estás ahí, tienes que parar la historia... La gente no se mea normalmente, pues no, pues ya... Pero lo que a la gente se le activa para no mear, a mí no se me activa. Con lo cual, pues sí, tienes que parar, o tienes que ir al baño, o ya te has llevado la botella de mear previamente, o se te ha olvidado y encima le tienes que decir a esa persona, que igual es la primera vez que está: oye, vete al baño y cógeme esto porque es que me estoy meando... (H3-97).

Lo positivo, no recuerdo haber tenido nunca una mala experiencia en eso, ni una mala palabra, ni una mala mirada, ni alguien que se haya quedado bloqueado, ni nada de eso. O no ha ocurrido, o lo han sabido disimular muy bien, una de dos. Pero bueno, no ha ocurrido. Pero también tiene su... sobre todo al principio, tiene su cuestión desagradable o... no, desagradable no, incómoda. Porque igual precisamente porque estás ya en un momento álgido y es cuando más golpe hay 
contra la... y dices: pues ya lo siento, sé que te estoy haciendo una putada tremenda, pero tienes que parar. Ahí sí que he recibido malas contestaciones, muy malas contestaciones, pero no por mi... sino por la circunstancia, la... Pero bueno, de hecho, luego eso, la mayoría de las veces se ha convertido en una situación jocosa (H3-97).

Con todo esto juego bastante [hablando del tema de control de esfínteres], bastante con el humor. Me parece que es muy importante, ponerle un poco de humor a las cosas y verlas y transmitirlas con humor. Quitarle el hierro y, sobre todo, cuando ves que encima la otra persona puede ser que, de alguna manera, se esté agobiando porque le ha venido de nuevo, meter alguna broma, alguna pulla, tomarle el pelo, alguna cuestión para bajar la intensidad, quitarle hierro al asunto (H3-98).

Erotizar ciertos elementos, ciertas circunstancias, ir quitándoles hierro, ir transmitiéndolas, y luego que si hay veces que suceden cosas que no estaban programadas que iban a suceder, pues han sucedido. Es decir, si pensábamos que de aquí íbamos a salir tan impolutos como habíamos llegado, pues no nos habríamos metido en esta historia. Y ya está. Que no pasa nada, y si pasa pues se le saluda y ya está. No hay más (H3-98).

\subsection{Cambios en la sensibilidad}

Tras la fase de shock medular, puede haber una percepción de recuperación de sensibilidad, aunque la sensibilidad conseguida puede diferir de la previa a la lesión y a veces vivirse como "insuficiente".

Los primeros días o semanas, yo tengo la sensación de que mi cuerpo todavía no había recuperado esa sensibilidad que recuperó después, esto del shock medular, no sé, pues lo que durase, yo al principio sí que notaba que no tenía esa sensibilidad de pecho para abajo, o al menos no recuerdo tenerla, y sí que recuerdo tenerla en este momento y sí que recuerdo que ya la tenía. Pero, aun así, me di cuenta de que esa sensibilidad que yo tenía no era suficiente, no era suficiente para sentir como yo sentía anteriormente (H3-13). 
La sensibilidad se encuentra afectada según el tipo de lesión y luego en un infinito abanico de posibilidades, no habiendo dos lesionados iguales. La conservación de la sensibilidad se vive como algo muy positivo.

En mi caso en ese sentido no tengo problemas [conservación de la sensibilidad] (H2-23).

$Y$ en el tema de la sensibilidad también he tenido suerte. Es verdad que no noto como antes, pero sí noto, en eso bien (H2-40).

Yo si me acaricias un pie siento como que me acaricias. El otro puedes darle con un martillo que no...que no siento nada (H4-59).

En los discursos adquiere una especial importancia la sensibilidad genital. La diversidad de distintas sensibilidades es infinita: no cambiando, desapareciendo, disminuyendo, o estando parcelada: partes en las que se siente y partes en las que no. En los casos de sensibilidad parcelada, la interacción erótica se adapta a esa peculiaridad sensitiva. La presencia de sensibilidad genital se vivencia como algo positivo.

Cuando se produce una alta excitación, se percibe un incremento en la sensibilidad genital.

Puedes darte con un canto en los dientes que sientes tus genitales. Comparando con la mayoría de la gente que le ocurre esto, no tienen noción de que están ahí. Es decir, si no se los mira, no tiene noción de que están ahí (H3-66).

[Hablando de la disminución de la sensibilidad genital] Hay momentos que sí. Hay momentos que sí. Depende del día, también. Sí que noto, pero, como antes no. $O$ hay días que lo noto como antes y otras veces no noto igual. Sí, que me bajó el nivel de sensibilidad (M2-3).

Menos sensibilidad [genital], sí. Como si, yo que sé, como si me toco el brazo y te hacen cosquillitas y las sientes y luego iay, pues nada! y luego pues pasa esto y te tocas el brazo y no notas las mismas cosquillitas, pues lo mismo (M2-3).

Yo tengo una sensibilidad muy rara porque como tengo una lesión incompleta hay sitios que...por ejemplo por aquí empiezo a perder la sensibilidad, pero por aquí si tengo sensibilidad. Yo en los testículos tengo sensibilidad y en el pene no. 
O sea, explícame eso [risas]. Es una cosa que aprendiste: a los testículos en lugar de al pene (H4-53).

Es curioso... que yo no teniendo sensibilidad, a nivel de piel o teniendo muy poquita, muy limitada, sí que noto sensaciones en los genitales cuando me pongo cachonda, que es una cosa curiosa, ¿no? es como raro, supongo que mi cerebro sigue teniendo las neuronas que estaban ahí, con lo cual, como hay mucha interconexión, si hay un estímulo erótico, esas neuronas se estimulan, aunque a nivel local, pues no haya nada, no haya una... (M1-18).

Hay casos en lo que se presenta lo contrario, una hipersensibilidad que puede conllevar una activación de los puntos dolorosos.

Luego cuando vine para casa ya con la pareja si es verdad que ya antes de rozar "tal" [refiriéndose a los genitales] era como que me daban unos pinchazos que todavía, depende de dónde se me toque y tal, me dan los pinchazos en la lesión y me dejaban con más dolor, activado el dolor que tenía en la espalda. Y si es verdad que ahora me sigue molestando, pero no me molesta tanto como al principio que era dolor (M3-51).

En ocasiones puede producirse un incremento en la percepción sensitiva en este caso genital con el paso del tiempo.

Es verdad que, con el tiempo, yo hay sensaciones que no tenía que he ido ganando, y sobre todo por ejemplo a nivel genital, no tengo sensibilidad como tal, pero sí que siento algunas cosas (M1-5).

Existe un desconocimiento sobre la presencia de sensibilidad genital en otras personas con lesión medular, extrapolando la situación personal al resto.

Lo que no sabíamos era de lo que no teníamos conciencia, era de lo que pasaba el resto o no, yo no, yo la verdad es que hasta tiempo después yo no tuve conciencia de que al resto o a la mayoría del resto no tenía sensibilidad y no se le ponía dura. Yo pensaba que lo mismo que me pasaba a mí les pasaría a los 
demás, y los demás tampoco tenían conciencia de que había alguien que sí tenía sensibilidad y al que sí se le ponía dura (H3-57).

En cuanto al placer que se puede obtener con la estimulación genital, se produce una adaptación según el grado y extensión de la sensibilidad. Puede ser útil la utilización de apoyos como vibradores, que parece que pueden ayudar al estímulo. Se identifica un desconocimiento o un conocimiento parcial por parte de la ciencia respecto al sistema nervioso.

Yo, por ejemplo, eh... a lo mejor...con una estimulación directa del clítoris, siento así, así, [a medias] pero cuando me penetran, sí que tengo más sensibilidad, es una cosa curiosa. Entonces yo encuentro mucho más placer en una penetración que en una estimulación pura y dura del clítoris, o simplemente del clítoris (M128).

Yo creo que también la estimulación, a través de la vibración también hace que se estimulen ciertas...que ayuda que determinadas zonas, que a lo mejor, sí que están un pelín inervadas...Bueno, iclaro! como del tema nervioso no se sabe nada muy bien, y no se sabe cómo...hay zonas que yo creo que si las enseñas a sentir con...[vibradores], nervios que si están inervados, bueno, en fin...pues eso también puede ayudar, por lo menos a mí sí que me ha...me ha ayudado (M1-30).

Se identifica una diferencia entre el sensar (las sensaciones producidas por el contacto de la piel) y el sentir (sensaciones derivadas de los órganos de los sentidos). El placer o el estímulo derivado de la relación erótica se produce por el conjunto de ambos, aun así, desde el modelo tradicional se puede vivenciar una frustración por la ausencia de sensaciones.

Por otro lado, se siente una mejora en las sensaciones con el tiempo, derivada en parte de un mayor conocimiento en lo que gusta y lo que no, y por otra parte debido a un despertar de sensaciones o una mayor conciencia en la percepción de la mismas.

Ante la ausencia de sensibilidad, aparece la idea de la percepción de un placer distinto y de la necesidad de aprender a gestionar ese "nuevo" placer. 
Yo estaba en un lugar que me resultaba agradable sentir lo que estaba sintiendo. Aunque seguía sin llenarme en absoluto sensar lo que estaba sensando. Es decir, todo lo que tenía que ver con la piel, con el contacto, con las sensaciones, con el placer de la piel. Pero bueno, la relación es que, a mí, en cierto modo, sí que la parte erótica se me llenaba por otras vías que no era la vía de la piel, que era la vía de la vista, la vía del gusto, del olfato y tal..., pero yo seguía sintiendo que ese modelo, en la parte sensitiva y en lo global me seguía sin llenar (H3-70).

Todavía no había pasado ni un año. Es decir, yo seguía teniendo esa frustración del tema de mi falta de sensaciones durante el coito (H3-74).

$Y$ es verdad, que...que cuanto más sexo, mejor en el sentido de que, tú primero que aprendes a ver lo que te gusta y lo que no, y luego que sí, yo creo que sí, que se despiertan sensaciones, que hostia, yo no sabía que yo sentía esto, cuando tienes una penetración en determinada postura o... (M1-30).

Es todo como antes, digamos. Al no tener la sensibilidad, sí que sientes un placer, pero es diferente, tienes que aprender a gestionar ese placer ¿no? (H1-10).

A razón de la ausencia de sensibilidad, sumado a otros motivos, puede producirse un abandono de los encuentros eróticos, argumentando que, si no se siente nada, pues la relación pierde sentido, a no ser por la vivencia de la otra persona.

Bueno yo el cambio [hablando del cambio en la sexualidad a raíz de la lesión] la verdad, no volvimos más... ni a pensar en ello. Como yo tampoco sé si lo necesito o no lo necesito porque como no siento... Tampoco sé si...si podría llegar algún día a decir...bueno, lo hice y quedé como estaba, no sé. Ye un tema que tampoco nunca...no llegué a pensar cómo podría ser (P1-49).

Yo pensaba cuando le dije eso al Dr. X, lo de la Viagra $^{\circledR}$, pero claro eso, piensas detenidamente, que, si no vas a notar nada, no vas a sentir nada, lo único por hacer feliz a la otra persona, no lo sé (P1-52).

La importancia de la sensibilidad no se reduce a la sensibilidad genital para un encuentro erótico, sino que se reconoce como importante la sensibilidad y la excitabilidad de todo 
el cuerpo.

Otra cosa es que sintieras o no por ahí. Pero realmente es todo el cuerpo. Hay otra gente que dice que solo es ahí, no perdona: excitas todo el cuerpo, y hay muchas cosas que no solamente follar, como dice ahora mi hijo que está descubriendo "los temas" con 11 años (M3-73).

La sensibilidad, si se ve afectada, está claro que hay que buscar otras vías de placer (M1-7).

La figura 11 muestra el mapa conceptual sobre las percepciones sobre las limitaciones derivadas de la lesión medular.

Figura 11: percepciones sobre las limitaciones derivadas de la lesión medular

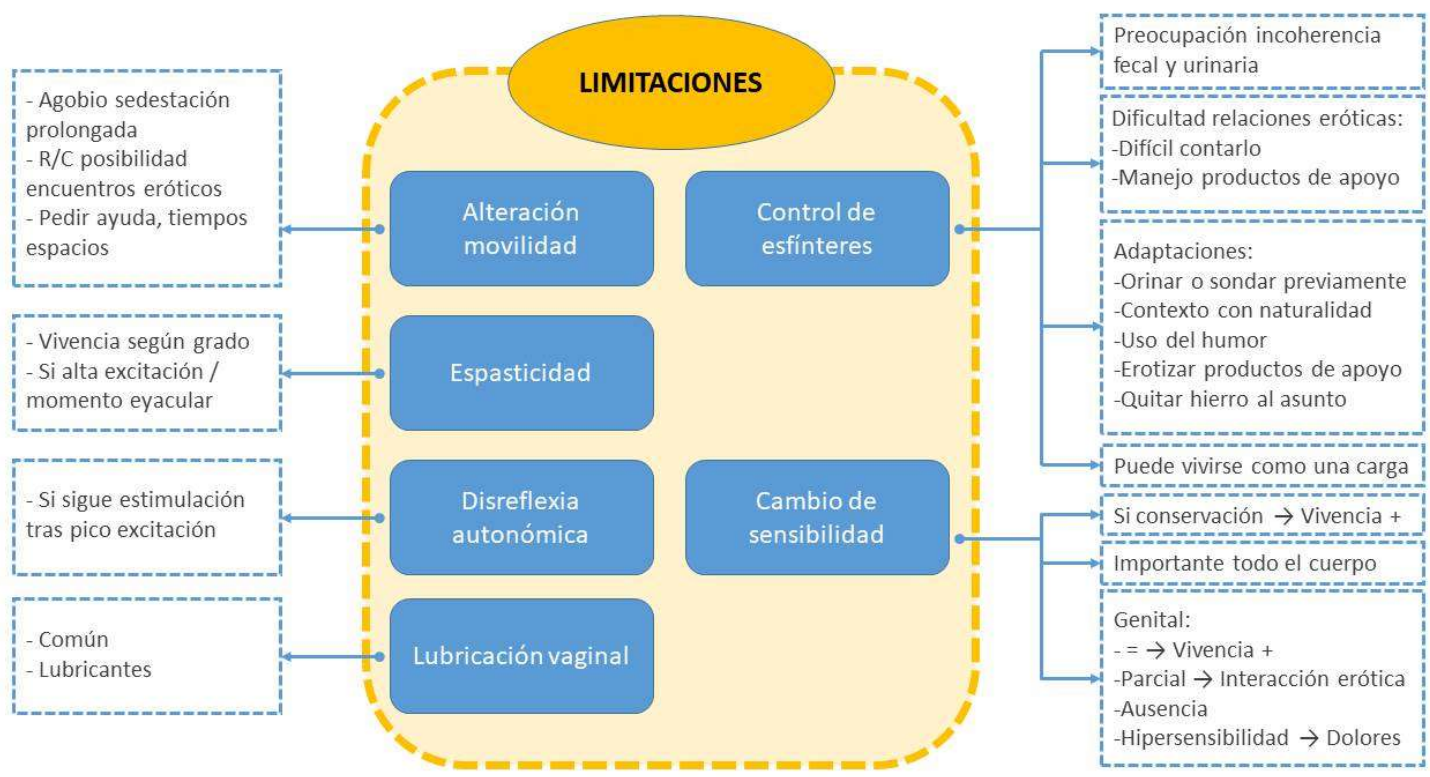

\subsubsection{Experiencias sobre el reaprendizaje erótico tras la lesión medular}

Tras la lesión medular, se produce un reaprendizaje erótico, adaptado al nuevo cuerpo, intentando disminuir o paliar las limitaciones y fomentar las potencialidades. En los discursos se identifican varios puntos a destacar:

\section{a) Aumentar la comunicación, pedir lo que se necesita}

Previo a tener una relación erótica con una persona nueva, se percibe como importante la comunicación, explicando qué va a ocurrir y pedir lo que se necesita para ello. Esto se identifica como una herramienta para disminuir miedos tanto en la persona con lesión 
medular como en su compañero o compañera.

Y yo, lo mismo que tuve que aprender a decir, a explicar a un tío: vamos a follar, pero oye, antes, antes...que no quiero que luego haya malentendidos, va a pasar esto, vamos a necesitar esto, yo necesito esto. No te asustes, yo no me asusto, yo te voy a enseñar, tú tranquilo, porque claro, porque también para la otra persona, no todo el mundo a lo mejor le apetece entrar en ese juego, y decir, es que igual la rompo algo, le hago daño, yo que sé, pues a lo mejor no a todo el mundo le apetece... (M1-27)

\section{b) Apagar el cerebro}

Se identifica como importante el aprender a centrarse en las sensaciones o en el momento, sin pensar ni juzgar lo que está pasando.

Es un aprendizaje el...el... pues eso, qué bien lo estoy pasando y ya está, sin más, sin pensar (M1-37).

\section{c) Explorar}

Explorar, descubrir lo que gusta, descubrir lo que no gusta, buscar las destrezas, experimentar, etc. Cuando hay una pareja estable, se va probando mediante el método de ensayo-error para ir descubriendo las formas y maneras en las que ambos están a gusto.

Y es verdad, que...que cuanto más sexo, mejor en el sentido de que, tú primero que aprendes a ver lo que te gusta y lo que no, y luego que sí, yo creo que sí, que se despiertan sensaciones, que hostia, yo no sabía que yo sentía esto, cuando tienes una penetración en determinada postura o... (M1-30).

También tienes que buscarte las mañas para eso, porque yo no puedo sujetar mis piernas abiertas, o no me puedo poner encima... ¿no? Entonces buscar las mañas para...luego ya depende del tío: los hay más atrevidos, menos, que les da más miedo romperte... Normalmente la primera vez es complicada en ese sentido, ¿no? Pero luego es más divertido, ya cuando te conoces, te agarran, te pin " $p a^{\prime}$ aqui", "pa' allá" (M1-30). 
A muchos niveles influye, el no saber tú mismo cómo. Si tú no te puedes tocar, por ejemplo, ¿Cómo sabes lo que te gusta o lo que no? Uno aprende lo que le gusta y lo que no (M1-15).

Siempre es un poco al principio experimentar y saber hasta dónde puedes llegar, qué puedes hacer ahora de más y cuando no puedes hacer más (H2-25).

Me volví a encontrar con una relación continuada en el tiempo en la que los encuentros ya no eran los encuentros, vamos a decir, esporádicos, sino que eran algo más continuo y con la misma persona. Con lo cual ya era volver a desarrollar el modelo o tener más posibilidades de prueba-error, de por dónde vamos, de qué hacemos, de dónde me encuentro yo mejor, dónde me encuentro peor, qué es lo que puedo o no puedo, o lo que me satisface o me deja de satisfacer (H3-69).

\section{d) Utilización de productos de apoyo para la erótica o uso de juguetes eróticos}

Incorporar el juego a las relaciones eróticas se vive como importante. Incorporar juguetes eróticos como vibradores se identifica como útil para explorar sensaciones y para ayudar a la estimulación; así como para su uso en la reeducación erótica. El uso de otros productos como geles con diferencia de calor, también se ve como otro producto que puede resultar útil para la estimulación.

Con el tiempo yo he... hemos, es decir, diferentes parejas con las que he podido estar, y yo, sobre todo, he aprendido a incorporar lo que es el juego. Pero igual que he aprendido incorporar eso, lo mismo que aprendes a incorporar cualquier otro tipo de vibrador, cualquier otro tipo de juguete erótico (H3-73).

Una cosa que sí que, pues también me ha ayudado a ver lo que siento, lo que no...son algunos vibradores (M1-29).

Yo creo que también la estimulación, a través de la vibración también hace que se estimulen ciertas...que ayuda que determinadas zonas, que, a lo mejor, sí que están un pelín inervadas... (M1-30).

Hay zonas que yo creo que si las enseñas a sentir con... [Vibradores], nervios que, si están inervados, bueno, en fin...pues eso también puede ayudar, por lo menos a mí sí que me ha...me ha ayudado (M1-30). 
Los geles pueden ayudar en determinados casos ¿eh?, los geles estos de calor, de efecto calor y tal, en intensificar un poquillo (M1-36).

Es importante que haya en este caso vibradores, pero sirve como ejemplo, juguetes eróticos adaptados, de manera que se facilite la autonomía para su utilización.

Una cosa que sí que, pues también me ha ayudado a ver lo que siento, lo que no...son algunos vibradores. El buscarte también las mañas, porque claro, yo no me puedo tumbar en una cama, desnudarme sola y utilizar un vibrador. Yo necesito tener determinada ropa, eh... que sea cómoda para mí, que me permita coger el vibrador y metérmelo entre las piernas, que sea ergonómico para que yo lo pueda utilizar ¿no?, porque si no lo puedes usar...Los hay estupendos y maravillosos, pero yo tengo que buscar el vibrador justo que a mí me viene bien en ese sentido: tanto de agarrarlo, de encenderlo, de apagarlo, de cargarlo como de luego que me llegue a donde yo quiero llegar, y eso también me ayuda a ver, como siento, como no siento (M1-29).

\section{e) Erotizar productos de apoyo}

Se identifica como aprendizaje importante el erotizar las situaciones, las circunstancias, los elementos, los productos de apoyo y convertir las dificultades en recursos. Quitar importancia a lo no programado que es posible que, aunque no esperado, suceda.

Partiendo de un modelo pobre, que es el habitual que tiene todo el mundo, vamos a ir expandiendo un poco, quitándonos prejuicios, tratando de quitar prejuicios y expandiendo un poco. Y no de descubrir el Mediterráneo, descubrir nada nuevo, sino cosas que ya sabías... que sabes que están ahí y que la gente las hace, y que tú también las has hecho pero que las has hecho en algún momento, si no es por compromiso, teniendo asimilado no, pero esto es algo... de pasada, esto es algo sin darle igual la entidad que puede tener, sin disfrutar todo lo que puedes disfrutar de ello. Y dándole mucha importancia a las circunstancias, al sacar el morbo, la gracia, lo de excitante que pueden tener las circunstancias de cómo están sucediendo las cosas, y convirtiendo lo que en algún momento puede ser una dificultad, o una resistencia, en un recurso. Erotizando ciertas situaciones o ciertos elementos que en un momento dado eran lo contrario, se cargaban la 
erótica de la escena (H3-79).

Vas viendo cómo le puedes sacar cosas potentes, bonitas... a tu situación de cosas que antes realmente creías que lo que provocaban era totalmente lo contrario: el deserotizar la situación o el momento (H3-80).

Erotizar ciertos elementos, ciertas circunstancias, ir quitándoles hierro, ir transmitiéndolas, y luego que si hay veces que suceden cosas que no estaban programadas que iban a suceder, pues han sucedido (H3-98).

Como ejemplo concreto que ha emergido en los discursos, el Ferti Care ${ }^{\circledR}$, aparte de su utilización para la recogida de muestras y tratamiento para la fertilidad, se puede usar como juguete erótico para lograr una eyaculación durante el encuentro y una sensación que se asimile en cierta manera al orgasmo.

Acabé comprándome el aparato este, el Ferti Care ${ }^{\circledR}$, precisamente por tenerlo como juguete más bien. Pero como juguete también para superar un poco esa frustración también, en mí y en el resto. Pero sigue siendo una forma de conseguir una eyaculación, no un orgasmo, una eyaculación y cierta sensación orgásmica, o cierta sensación de descontrol corporal, vamos a llamarlo así. Pero bueno, continúa siendo muy ortopédica (H3-73).

Para mí esto [el Ferti Care ${ }^{\circledR}$ ] ahora es algo que no es un juguete erótico, sino que es un elemento totalmente antierótico, vamos a decirlo de alguna manera. Yo ya lo he incorporado como lo que es, como es el juguete erótico, con lo cual pues bueno... (H3-73).

\section{f) Redescubrimiento de zonas erógenas}

Cuando se produce una pérdida sensitiva, se produce un redescubrimiento de zonas erógenas: se desarrollan otras nuevas en zonas que tienen la sensibilidad conservada. Este proceso de búsqueda de los nuevos puntos erógenos lleva un tiempo, una exploración.

Al final yo creo que desarrollas otras zonas, zonas erógenas, ¿no? las desarrollas más, zonas donde tengas la sensibilidad al 100\%...(H2-42). 
Antes pensaba que simplemente era...yo creo que lo que el $80 \%$ de la gente entiende por sexo, que es la penetración y ahora he visto, pues que hay mucho más, y yo creo que en ese sentido sí que ha cambiado, buscar otras zonas de placer... (H2-50).

Pero... pero quiero decir que... cuando es una relación, yo creo que ya eso ya pasa a un punto secundario. Aunque también es importante, hay mil partes sexuales, no hace falta tampoco hablar de la película de... ¿Cómo se llama esta...? la del tetra esta, que le gusta que le toquen las orejas... (H1-30).

Vuelves otra vez a otra cosa importante que había, es saber cómo mantener unas relaciones sexuales porque te cambia completamente tus sitios de placer. Antes estabas acostumbrado o tenías en la cabeza el pene como el...el sitio que da el placer, hasta que te das cuenta que no, que hay otras más cosas. Y eso claro, lleva un periodo. Lleva un periodo en el cual te vas, te vas acostumbrando a todo eso (H4-34).

Antes era la penetración y el orgasmo. Ahora no, ahora ya buscas tus puntos erógenos, yo sé cuáles son mis puntos erógenos y lo que yo quiero (H4-37).

Mira, busca tu punto erógeno, búscate uno, búscate tal. O céntrate en dar placer a tu pareja, también puede ser una forma de llegar a tu orgasmo (H4-61).

Yo me enteré que las orejas...pues yo las orejas, qué quieres que te diga, a mí me dan placer las orejas. Fíjate tú quién va a pensar eso...en mi época quién iba a pensar eso, pues sí. Son cosas que...y sobre todo los años de servicio (H4-63).

\section{g) Centrarse en lo que uno puede hacer y no en lo que no puede hacer}

Se identifica como necesario el centrar la mirada en lo que uno puede hacer, en las potencialidades y no en las limitaciones o en lo que no es posible hacer.

Yo en lo único que no me puedo centrar es en las cosas que no puedo hacer, eso está claro ¿Por qué voy yo a... quiero ir a comer a un restaurante que hay mil escaleras para entrar? ¿Por qué me voy a obcecar ahí si hay miles de restaurantes? entonces, me voy a enfocar donde puedo ir y disfrutar de ello, pero así en todo (M2-6). 


\section{h) Uso del humor}

Se identifica como herramienta el uso del humor, tanto para contar cosas que es complicado comentar como para quitar hierro cuando se produce una situación inesperada que puede resultar incómoda.

Con todo esto juego bastante [hablando del tema de control de esfínteres], bastante con el humor. Me parece que es muy importante, ponerle un poco de humor a las cosas y verlas y transmitirlas con humor. Quitarle el hierro y, sobre todo, cuando ves que encima la otra persona puede ser que, de alguna manera, se esté agobiando porque le ha venido de nuevo, meter alguna broma, alguna pulla, tomarle el pelo, alguna cuestión para bajar la intensidad, quitarle hierro al asunto (H3-98).

\section{i) Dar placer como forma de obtener placer}

El proporcionar placer al otro, se identifica como un recurso para obtener el propio placer, pero sin olvidarnos de uno.

Como tampoco sientes muy bien, quieres cumplir expectativas y demás, te centras mucho en el placer del otro y tratas de sentir lo que en el fondo tampoco vas a poder sentir muy bien (M1-27).

Yo encuentro mucho placer en que la otra persona se lo pase bien, que también me excita, no es que yo diga, ay que bien, no, no... me excita, pero... es verdad que también me ha tocado aprender (M1-27).

\subsection{Apoyo farmacológico}

Los fármacos para la disfunción eréctil, se perciben como un apoyo en los encuentros eróticos, ya sea para producir la erección o para ayudar a mantenerla. Se percibe una falta de asesoramiento en la exposición de opciones e información sobre los distintos fármacos.

Se percibe un importante cambio de los fármacos a lo largo de los años. Como hito, el comienzo de los fármacos orales para la disfunción eréctil, el sildenafilo (Viagra ${ }^{\circledR}$ ) como el primero en salir al mercado. 
Te han dicho que no vas a tener una erección, que no vas a tener una eyaculación y que cuando quieras tener algo pues tendrás que apoyarte de algo que te han hablado pero que no te han indicado ni lo que es, ni cómo se toma, ni qué opciones hay, ni nada (H1-1).

Yo cuando estuve en Estados Unidos, allí sí traté con un sexólogo. Y yo claro, imaginaros que todavía, aquí el Viagra ${ }^{\circledR}$ o pastillas que te ayudaran a la erección no había. Y yo me acuerdo que la primera vez era con unas inyecciones, no me acuerdo el nombre (H4-30).

Y empezamos con las inyecciones, pero claro, las inyecciones tenían un problema de aquella, que de aquella no estaba tasado, que podías ponerte mucha cantidad o poca cantidad. Y lo que hacías era ponerte el glande del pene pues como un tomate, si lo usabas (H4-34).

Derivado a la falta de asesoramiento por parte de los profesionales, se producen consejos en el grupo de iguales y se comienzan a tomar estos fármacos con un método de "ensayo-error". Se pueden producir efectos secundarios derivados del fármaco y en ocasiones de la sobredosificación del mismo. En el caso del sildenafilo (Viagra ${ }^{\circledR}$ ) se observa visión azulada y en el caso del alprostadil (Caverject ${ }^{\circledR}$ ) un priapismo importante.

Yo me acuerdo, la primera la Viagra ${ }^{\circledR}$. Pero, claro, la Viagra ${ }^{\circledR}$ primero tenías que tener, que saber la cantidad que tenías que tomar. Eso es importante saber esa cantidad, tenerlo controlado (H4-40).

Esa era una experiencia entre nosotros [el manejo de tratamientos para la disfunción eréctil]. Y yo, gracias a Dios, encontré un grupo de gente maravillosa. Somos más que compañeros, somos amigos, somos familia. $Y$ eso involucra en todos los temas. Claro que...yo a través de esto si sirve para que alguien profesional, que no tenga que ser como nosotros, que era la prueba esa de siempre, ensayo error - ensayo error - ensayo error. Sería genial (H4-48).

$Y$ ya sé lo que tengo que tomar y lo que no tengo que tomar, porque yo tengo compañeros que se pasaron 3 pueblos tomando Viagra ${ }^{\circledR}$. Empezaron a ver azul y esas cosas (H4-45). 
Entonces llegas al doctor y le dices: "oye, es que la Viagra", aparte de que aquello tiene muy poco tiempo de reacción, tiene muy poco margen de maniobra, veo las cosas azules y bah, no me mola mucho ver así, como para arriba azul. Me acuerdo que miraba como para el techo y veía como luces azules y decía... “¿Qué cojones es esto? Si me quiero drogar, me drogo de otra forma" [risas] (H1-3).

Otro tuvo un problema de la hostia, hablando mal y pronto, con el tema de las inyecciones, el tío veía que no se le ponía dura, y venga a meterse para allá, venga a meterse para allá, $p a^{\prime}$ urgencias. Pa' urgencias, casi le tienen que amputar el pene. Luego no bajaba, no bajaba, y... ¿necrosar se puede llamar la palabra? (H445).

En cuanto a las ventajas percibidas de los fármacos orales para la erección, se identifica el un mecanismo de producción de la erección natural: la erección se produce cuando hay un estímulo erótico. El tadalafilo (Cialis ${ }^{\circledR}$ ) se advierte como más duradero. Si el modelo no se encuentra centrado en el coito, se utiliza de forma esporádica, cuando apetece y no como condición sine qua non.

Como inconvenientes de estos fármacos se encuentran que no siempre se produce la erección esperada y que hay que prever el encuentro erótico para tomarla, lo que resulta difícil si no se tiene una pareja estable.

Sí tienes erecciones, pero igual no las tienes tan duraderas como te gustaría y que para que el momento sexual, que es algo que te gusta, no pase a no gustarte...pues decides probar ¿no? Y entonces pruebas, en aquel caso, con una Viagra $^{\circledR}$, porque es lo que siempre has oído. Y dices, bueno, pues vamos a probar ¿Cantidad? Pues no sé, dame la mínima, oye, si esto ya se levanta por sí mismo. La cosa es que dure un poco más ¿no? Y pruebas. Y... ijoder! (H1-2).

“Bueno, hay también el Cialis ${ }^{\circledR}$, si quieres probar, además tiene una duración más larga." Eso me lo dice el..., el..., el urólogo (H1-3).

Con el Cialis ${ }^{\circledR}$, porque llega un momento que vas controlando tú. Vas controlando, sobre todo el nivel de erección y cuando la quieres, porque hay momentos que no te sirve para nada, eso después de mucho tiempo, ¿eh? Te das cuenta y dices tú: 
"pues vamos a jugar un poco y después ya buscamos ese tema". Y ya sé lo que tengo que tomar y lo que no tengo que tomar (H4-43).

"Joder tía, es que he descubierto el Cialis ${ }^{\circledR}$ y esto es una pasada, porque no sé qué..." O sea, yo veía que él estaba feliz por poder tener una erección, y que además la erección era como muy normal entre comillas, ¿no? Él: me excito, me pongo, la veo despelotarse y ya se me pone dura y tal y cual, y yo decía, fíjate ¿no? alguien que en un momento dado decía que eso era una bobada, que, si no hay sensibilidad para qué, que no...(M1-19).

Yo le decía: [conversación con el urólogo] "Bueno, yo es que ahora mismo no tengo una pareja fija. Si se me da la noche bien, vas para casa". "Bueno, tú piensa que, si ves que la noche te va a salir guay, tú llévate la pastillita contigo. Te la tomas de la que estés por ahí y así cuando llegues a casa ya te está haciendo máximo efecto, y tal" Y yo: "Claro hostia, eso está de puta madre. ¿Y si no me salió? Pues jodí $20 €$ en pastillitas. Y vaya guay ¿no?" [Risas] Y decía: "Bueno sí, como si te hubieras tomado dos copas más". No me parece ni medio normal lo que me estás contando. Me parecía todo tan, tan, tan cogido por los pelos, ¿sabes? (H1-3).

Él me decía que probase el Cialis ${ }^{\circledR}$ porque duraba más e iba a ser más rentable, pero no funcionaba, porque claro, eso cada persona... No funcionaba y entonces me cansé de tomar Cialis ${ }^{\circledR}$ para engancharme unos chinazos de la virgen (H1-4). Me gasté en Cialis $^{\circledR}$ lo que no estaba escrito. Porque aquello no funcionaba ni para Dios. Y decía: "Bueno, la tendrá que tomar más a menudo, habrá que...Nada". Entonces, bueno, es que según tal te afecta cero, mucho, poco o según cuadre. Pues eso, tampoco me lo dijo el chico que igual no me podía afectar (H1-19).

Hubo un tiempo en el que yo utilizaba bastante más la Viagra ${ }^{\circledR}$ porque también me centraba bastante más en el coito. Pero luego también hubo un tiempo en el que para mí la Viagra $^{\circledR}$ o cualquier otra historia es como el utilizar un vibrador. Es una cuestión de vamos a darle un puntillo y hoy... venga, hoy toca. Vale, hoy toca y lo disfrutamos y tal, pero no tengo la necesidad de, para tener una relación y tener un encuentro y que el encuentro finalice y poder decir que estaba a gusto, 
me lo he pasado bien, que para mí ha sido placentero, que para mí ha cumplido todas las expectativas... Bueno, para habérnoslo pasado bien para mí no tiene que haber pasado ni por un coito, ni por un orgasmo, ni por una eyaculación (H3100).

En cuanto a los fármacos inyectados en el pene como el Alprostadil (Caverject ${ }^{\circledR}$ ) se percibe un mayor desconocimiento tanto de otros lesionados medulares, como de los profesionales sanitarios, tanto médicos, como enfermeras, como farmacéuticos. Se percibe como algo moderno por parte de los profesionales, a pesar de ser previo a los fármacos orales.

Como ventajas se percibe como algo más eficaz, que asegura la erección. Como desventaja la erección se vive como menos natural, no dependiente de la excitación, sino dependiente exclusivamente de la acción del fármaco.

Entonces en esas reuniones de deporte, mucho lo que haces es hablar ¿no? Entonces, de repente, un día te dice uno "yo uso el Cialis ${ }^{\circledR}$, y tal" ¿no? "pues yo la Viagra $^{\circledR}$, y tal" ¿no? "pues yo me la engancho con una goma y cual". Y ¿no? "pues yo el Caverject ${ }^{\circledR ”-~ “ ¿ E l ~ C a v e r j e c t ~}{ }^{\circledR}$ ?" - "Sí, sí, me la pincho” “¿Qué me estás contando? ¿Qué te estás pinchando?” ¿El qué? ¿Dónde? Tú estás, bueno, claro...y cómo no te han contado nada... (H1-3).

Como la gente te habla de lo del Caverject $^{\circledast}$, y tal, no sé qué, decides un día probar. $Y$ con este mismo doctor, que quiero entender que lleva un montón de años tratando a lesiones medulares y que tiene un montón de conocimientos, se lo digo. Y vamos, le cuento la panacea. Es decir, no ha oído hablar del tema en su puta vida. Y entonces, le pido a la farmacia eso. Digo, vamos a empezar por el de un miligramo, me dice y tal. Cuando llego allí es la revolución del local. (Risas) Es decir, las enfermeras y aquel dicen: "vamos a ver esto, vamos a leer detenidamente el prospecto para tal... iay mira! hay que pincharlo aquí... hay que hacer tal... cual... No sé qué, tal..." Y claro, yo digo, bueno debe ser la bomba esto. Debe ser hipermoderno, cosa que no era para nada moderno (H1-3).

$Y$ entonces digo: "pues vamos a ir a lo seguro porque esto tiene que funcionar sí o si" "Venga, vamos a lo seguro, aunque no me mole tanto, porque lo otro era 
como más natural, ¿no?, tomabas una pastilla y cuando estabas realmente excitado... va; aquello [el Caverject ${ }^{\circledast}$ ] va, sí o sí, porque aquello como lo hinchas, pues... por así decirlo va toda la sangre por cojones. Y entonces, probamos y aquello fue la panacea (H1-4).

Entonces, bueno, decides optar por ese sistema porque te resulta más cómodo [el caverject ${ }^{\circledast}$ ]. Y es cierto que al final tú usas la comodidad en una relación sexual (claro) y si la comodidad significa que 5 minutos antes de empezar con el tema tienes que marchar al baño, hacer lo que tengas que hacer, para hacerlo de una forma autónoma, pues bueno, merece más la pena que no andar jugando con una pastillita que el día que no funciona bien... (H1-4).

Eso que yo tenía erecciones, incluso teniendo erecciones lo que te he contado lo mal que me fue la historia pues para el que no tenía erecciones..., y todavía estamos en un periodo, 96- 97 es un periodo pre-Viagra ${ }^{\circledR}$, porque la Viagra $^{\circledR}$, la Viagra ${ }^{\circledR}$ llegó en ese momento, más o menos en el 97-98 o una cosa así, entonces todavía estábamos con el Caverject ${ }^{\circledast}$ y todas estas historias que eran muy incómodas. Es decir, que tenía que ser, que me he programado que hoy va a ser y hoy me voy a pinchar, con lo cual le quitaba toda la erótica, parte de la erótica al asunto de lo que era el tema de los deseos, no es que esto va a empezar porque tenemos un brote de deseo, no. Va a empezar porque yo me voy a pinchar y encima tenemos que aprovechar lo que dura esto... pues eso... (H3-33).

La figura 12 muestra el mapa conceptual sobre el apoyo farmacológico. 
Figura 12: apoyo farmacológico

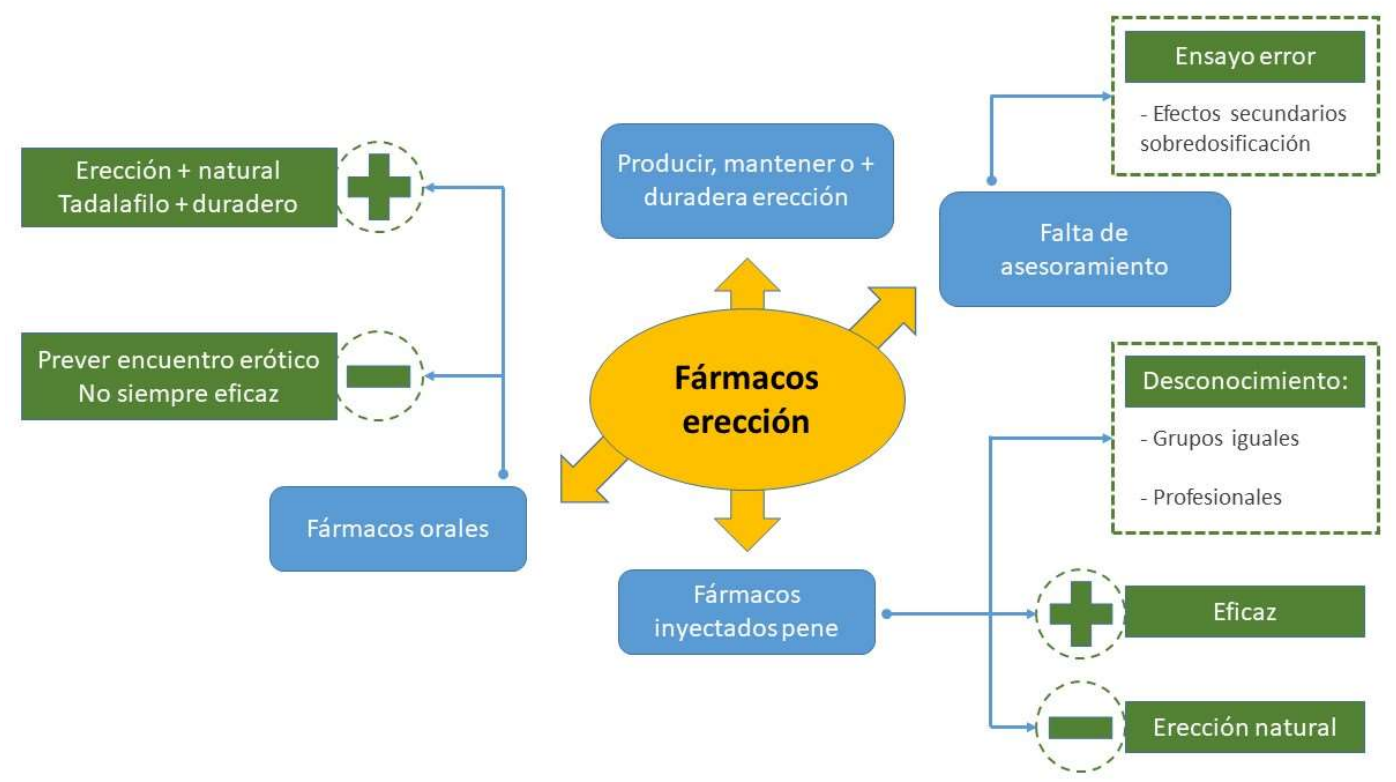

4.3.5.6. Percepciones sobre las potencialidades en la erótica derivadas de la lesión medular

Tras la lesión medular se suele hablar con frecuencia de las limitaciones en general, y en particular, en la erótica. Sin embargo, se identifica la aparición de potencialidades tras la lesión en la interacción erótica.

Al descubrir otras formas de encuentro fuera del coito rápido con la búsqueda de la llegada pronta del orgasmo, se descubren nuevas formas como centrarse más en la pareja, disfrutar más de todo el camino, una apertura a otras opciones que antes no se exploraban o se hacían por cumplir o de forma rápida. Esto en conjunto genera una sensación de más disfrute que antes.

Una de las cosas que me gustó es que yo, por ejemplo, disfruto mucho más ahora con la chica con la que estoy que antes. Porque, igual, como yo no tengo tanta prisa por centrarme en lo mío, me centro mucho más en lo de ella. Y al final es mucho más placentero, porque también estás tú mucho más metido en el tema. Entonces, al final es cierto, que antes tenía ganas aquello, lo que tenías ganas era rápido, rápido, y que llegase pronto, y la luz ¿no? pero ahora dices: "vale, sí, eso también me gusta" pero disfruto mucho más de todo el camino. Pues párate por el camino, que estás de puta madre igual (H1-28). 
A nivel de eso no lo veo tan negativo, sino todo lo contrario. Creo que igual, pues, puedes optar a muchas otras opciones más que antes, porque si no antes pues igual no parabas tanto en esas opciones (H1-28).

Probablemente si conozco a una chica no la pueda sacar en brazos y sacarla por la puerta porque probablemente nos caigamos los dos, pero sí, es lo que tú dices. A lo mejor no sé, un día no puedes tener una erección de horas o de 10 minutos o lo que sea, pero a lo mejor sin erección, puedes seguir dando placer a tu pareja. Entonces yo que sé, aunque no tenga mano, por ejemplo, yo, probando, probando, desarrollas otras habilidades manuales en ese sentido (H2-56).

$Y$ de aquella manera empecé a ver cuáles podían ser mis puntos fuertes. Es decir, qué es lo que puedes... cómo puedes explotarte, qué es lo que puedes entrenar, qué es lo que puedes... que a ti te guste, que se te pueda dar bien, es decir que se den las condiciones/circunstancias para que tú puedas estar cómodo haciéndolo y que le puedas sacar partido y así fue... Así fue eso de ampliar el modelo. Lo que yo llamo cultivar la erótica (H3-78).

Partiendo de un modelo pobre, que es el habitual que tiene todo el mundo, vamos a ir expandiendo un poco, quitándonos prejuicios, tratando de quitar prejuicios y expandiendo un poco. Y no de descubrir el Mediterráneo, descubrir nada nuevo, sino cosas que ya sabías... que sabes que están ahí y que la gente las hace, y que tú también las has hecho pero que las has hecho en algún momento, si no es por compromiso, teniendo asimilado no, pero esto es algo... de pasada, esto es algo sin darle igual la entidad que puede tener, sin disfrutar todo lo que puedes disfrutar de ello. Y dándole mucha importancia a las circunstancias, al sacar el morbo, la gracia, lo de excitante que pueden tener las circunstancias de cómo están sucediendo las cosas, y convirtiendo lo que en algún momento puede ser una dificultad, o una resistencia, en un recurso. Erotizando ciertas situaciones o ciertos elementos que en un momento dado eran lo contrario, se cargaban la erótica de la escena (H3-79).

Lo que para unos puede ser una limitación para otros puede ser una potencialidad: la 
ausencia de eyaculación puede vivirse como una limitación si se desea tener hijos, pero también se puede vivir como una ventaja si no se desean.

Nosotros tenemos un problema muy grande con eyaculación, tú si quieres...yo no eyaculo sino me estimulo. Y entonces ahí está el problema, por una parte, decías: "mira así no tengo, de puta madre... [Risas]...oye hablando mal y pronto...sí, sí, de puta madre... que yo voy a tener... (H4-36).

Otra potencialidad es el tener una mayor preocupación con el placer de la pareja, incluso vivirlo como un recurso para llegar al propio placer.

Otra cosa que aprendí, fijate tú, es a dar placer a los demás. Ahí, eso fue un cambio importante, ¿eh? eso de verdad ¿eh?, porque antes tú llegabas y tenías relaciones y iala!, si tú lo pasas bien, bien, y si tú lo pasas mal, tu problema, claro, y ahora no, y ahora te das cuenta... Y eso vino hasta bien, ¿no? por mi parte me vino bien, porque te sientes y dices: ijoder!, di placer y sé que di placer (H4-38). O céntrate en dar placer a tu pareja, también puede ser una forma de llegar a tu orgasmo (H4-61).

\section{a) Mejor interacción erótica}

La interacción erótica se puede tornar en conjunto como muy positiva, incluso mejor que antes.

-Vuestra sexualidad en ese sentido es mejor.

-Pues posiblemente. Yo, no es por dármelas de súper guay, pero a mi hubo mujeres que me lo dijeron. Te lo puedo garantizar. A mí me pasó (H4-104).

\section{b) Cambio del concepto erótico-amatorio}

El modelo desde el que se parte es un modelo falocéntrico, centrado en la erección y coitocéntrico, en el cual toda relación erótica tiene que pasar por la penetración intravaginal; este modelo está centrado en la consecución de la eyaculación masculina y el orgasmo. Sin cualquiera de estas condiciones: erección-coito-eyaculación masculina-orgasmo la relación no se considera completa. Tras la lesión medular, si hay alteración de la erección o si hay una alteración de la sensibilidad genital, ya sea en el 
hombre o en la mujer, este modelo no encaja bien, produciendo frustración en los encuentros si se perpetúa sin más el modelo.

Bueno, este era el modelo en el que hasta ahora te has sexualizado o socializado sexualmente y has visto que este modelo de la penetración intravaginal, del coito, del cual, del tal, pues bueno, en tu caso funciona como funciona, más menos mal y eso que yo tenía erecciones, incluso teniendo erecciones lo que te he contado lo mal que me fue la historia pues para el que no tenía erecciones... (H3-33).

$Y$ al principio fue, continuó siendo bastante complicado, bastante duro, porque mi intención, es decir, a donde yo iba era la repetición del modelo, la repetición del modelo normativo de... centrado en el coito, centrado en la penetración intravaginal y con ciertos preliminares (H3-69).

Para mí en aquel entonces eran precisamente preliminares. Era algo que se hace porque toca. Eso que se llama "el mojabragas". Porque toca, es decir, toca porque hay que empezar así, no sé qué, no sé cuánto. Es decir, ya sabes dónde vas y cuanto antes llegues mejor. $Y$ ahí continuaba esa frustración de: bueno, me lo paso bien porque estoy en una situación que me resulta agradable y placentera en otros órdenes, vamos a decir, en otros placeres, a otros niveles... (H3-70).

Y mis primeras... porque yo todavía estaba en la vía del coito en aquel momento. Mis primeros coitos, es decir, mis primeras relaciones con esa chica, bueno, mis primeras y casi las últimas en casi toda la relación, fue bastante repetición de modelo (H3-74).

Y me di cuenta que la sexualidad no es solo la penetración, hay más cosas (H436).

Fue lo primero de lo que te das cuenta. Ya te digo, un médico (creo que sexólogo) fue el que me dijo eso. El que me abrió la cabeza: "esto no es meter y sacar" (H4103).

Este modelo falocéntrico y centrado en el coito no es exclusivo de hombres, sino que hay mujeres en las que se produce una frustración en la relación erótica si no se sigue su forma. 
También lo que yo he descubierto a lo largo de estos años... Lo que yo he descubierto a lo largo de estos años es que esto del coitocentrismo y el falocentrismo no es tan de los hombres, sino que es un modelo muy extendido y muy demandado por la mayoría de las mujeres. Igual no en todos sus encuentros y en todos los momentos, pero también necesitan para sentir (necesitáis), en muchas ocasiones que la relación ha sido una relación completa, el hecho de que el pene haya aparecido por algún lado. Bueno, esa es mi conclusión después de las experiencias que yo tengo de esa frustración que veo que se genera, y esa demanda que yo recibo a veces (H3-100).

El modelo centrado en el coito se percibe como que no funciona, o no funciona todo lo bien que es esperable o deseable, obligando a la búsqueda de otros modelos, ampliando el abanico de posibilidades, explorando otras opciones, otras prácticas, nuevas zonas de placer. Este cambio de modelo se percibe como algo positivo, como un aumento de opciones, un aumento del disfrute de todo el camino y no solo de búsqueda de la meta, generando también un mayor placer en la pareja.

A ver, antes la sexualidad con 18 años, yo solo veía digamos el sexo ¿no? y ahora yo creo que hay mucho más, y he explorado mucho más también. y no solo... antes pensaba que simplemente era...yo creo que lo que el $80 \%$ de la gente entiende por sexo, que es la penetración y ahora he visto, pues que hay mucho más, y yo creo que en ese sentido sí que ha cambiado, buscar otras zonas de placer...(H2-50).

Al final, es un poco cambias el concepto ¿no? es decir, a nivel de eso no lo veo tan negativo, sino todo lo contrario. Creo que igual, pues, puedes optar a muchas otras opciones más que antes, porque si no antes pues igual no parabas tanto en esas opciones. Porque ibas más a lo que querías, que era a conseguir en ese momento el morbo, el llegar y pum (H1-28).

Pero en principio el tema sexual, de la cama, no significa ni solo meterla ni solo ponerla contra la pared, pegándole... quiero decir, no sé, hay mil opciones y todas son divertidas (H1-23). 
Una de las cosas que me gustó es que yo, por ejemplo, disfruto mucho más ahora con la chica con la que estoy que antes. Porque, igual, como yo no tengo tanta prisa por centrarme en lo mío, me centro mucho más en lo de ella. Y al final es mucho más placentero, porque también estás tú mucho más metido en el tema. Entonces, al final es cierto, que antes tenía ganas aquello, lo que tenías ganas era rápido, rápido, y que llegase pronto, y la luz ¿no? pero ahora dices: "vale, sí, eso también me gusta" pero disfruto mucho más de todo el camino. Pues párate por el camino, que estás de puta madre igual (H1-28).

El coito es puesto como una práctica más no buscando ser la principal, ni la única, ni la más importante. Otras prácticas consideradas antes "de segunda" reaparecen en el nuevo modelo otorgándoseles un papel más importante. Con el orgasmo ocurre lo mismo, se valora el placer a lo largo de toda la relación sexual, no valorando exclusivamente ese instante que puede ocurrir o no.

Me sirvió para encontrar cosas que me gustaban, momentos, situaciones prácticas... que me llenaban, que me llenaban mucho, con las que ya empecé a dejar al coito en realidad en el lugar en el que debería haber estado siempre, que era el de otra alternativa más. No vamos a hacer la cúspide a la que vas subiendo y tienes que hacer cumbre. Lo mismo con el orgasmo, el mismo paralelismo (H378).

Partiendo de un modelo pobre, que es el habitual que tiene todo el mundo, vamos a ir expandiendo un poco, quitándonos prejuicios, tratando de quitar prejuicios y expandiendo un poco. Y no de descubrir el Mediterráneo, descubrir nada nuevo, sino cosas que ya sabías... que sabes que están ahí y que la gente las hace, y que tú también las has hecho pero que las has hecho en algún momento, si no es por compromiso, teniendo asimilado no, pero esto es algo... de pasada, esto es algo sin darle igual la entidad que puede tener, sin disfrutar todo lo que puedes disfrutar de ello (H3-79).

A partir de ese momento en adelante, digamos que mi modelo está bastante más cultivado y amplificado y, además, ya sabiendo que mi desarrollo erótico a partir de ese momento iba a ser el de seguir cultivando y amplificando, e intentar 
incorporar todo lo que pudiera aprender de todas las relaciones que tuviese y de todo lo que me pudiese llegar, y también intentando incorporárselo a esas personas también. Y la verdad es que nunca he tenido queja (H3-81).

Una chica que dijo, que no se trataba solamente de sexo, sino que...que a veces que una caricia, que un tal, que también valía (P1-78).

Hubo un tiempo en el que yo utilizaba bastante más la Viagra ${ }^{\circledR}$ porque también me centraba bastante más en el coito. Pero luego también hubo un tiempo en el que para mí la Viagra ${ }^{\circledR}$ o cualquier otra historia es como el utilizar un vibrador. Es una cuestión de vamos a darle un puntillo y hoy... venga, hoy toca. Vale, hoy toca y lo disfrutamos y tal, pero no tengo la necesidad de, para tener una relación y tener un encuentro y que el encuentro finalice y poder decir que estaba a gusto, me lo he pasado bien, que para mi ha sido placentero, que para mí ha cumplido todas las expectativas... Bueno, para habérnoslo pasado bien para mí no tiene que haber pasado ni por un coito, ni por un orgasmo, ni por una eyaculación. $Y$ entiendo que a las chicas con las que he estado les pasa lo mismo (H3-100).

La figura 13 muestra el mapa conceptual sobre las percepciones sobre las potencialidades derivadas de la lesión medular.

Figura 13: percepciones sobre las potencialidades derivadas de la lesión medular

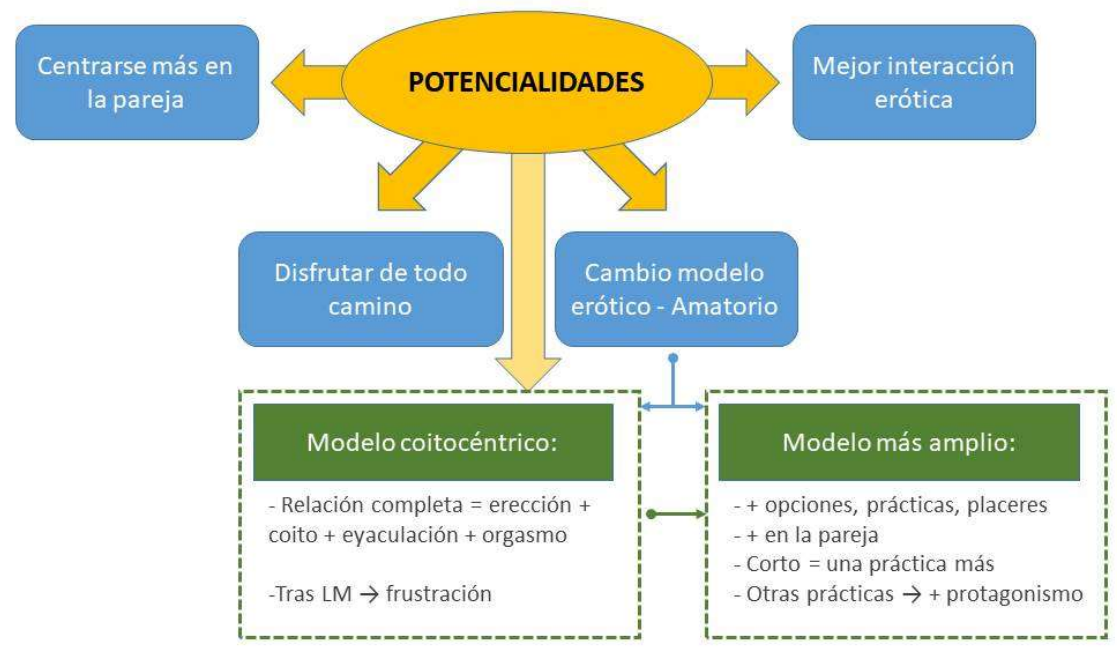




\subsubsection{Vivencias sobre la procreación tras la lesión medular}

\subsection{Deseo de tener hijos}

Hay casos en los que el embarazo puede ser un riesgo para la lesión medular. En estos casos el consejo médico es no tener hijos o no tener más hijos. Se puede producir sentimientos de frustración por el deseo de tener hijos, tanto de la persona con lesión medular, como de la pareja, como de los otros hijos.

Luego también sale un poco el tema de tener más hijos y claro, pues no. El neurólogo me dijo: "averiada la casa no la tienes, pero claro, el cuerpo si" Y claro un embarazo te cambia totalmente, lo primero, lógicamente, por el riego sanguíneo. "Yo no te puedo garantizar que tu cuerpo lo supere, no lo supere o que lo que venga tampoco". Te dicen eso así y bueno pues... Yo no me quiero arriesgar, la verdad. Sí es verdad que cuando pasó estábamos hablándolo [con la pareja] para ver si teníamos otro porque el hijo es mío, no es de él. Y mi hijo también decía que quería un "hermanín". Ahora ya no lo dice. Además, me oyó un día comentar esto y ya no quiere porque "para que te pase a ti algo... pues mejor que no" (M3-43).

Yo lo llevo mejor [el no tener más hijos] porque ya tengo uno y ya supe lo que era el embarazo y de bebé y tal. Sí que es verdad que él [pareja] es muy niñero y le gustaría... que él está encantado eh, que lo tiene como suyo [al hijo], primero es $X$ [el hijo] y luego nosotros. Pero te queda esa cosa (M3-44).

Una cosa es que te digan que hay un mínimo riesgo, que a lo mejor te lo piensas. Pero cuando te dicen tanto, por las dos partes y demás, pues ya te lo planteas un poco más. Vale más aguantar a lo que he llegado y mantenerme aquí, que fastidiarla a lo mejor (M3-45).

Cuando la lesión afecta al mecanismo de la eyaculación, se tiene que recurrir a los estimuladores de la eyaculación; si esto no funciona la siguiente opción es la punción testicular. Cuando no hay un deseo actual de tener hijos, este proceso suele posponerse al momento en que se desee tener hijos.

Yo todavía no he hecho nada de eso, porque tampoco tengo la necesidad ahora mismo, es decir, ni tengo pareja, ni tengo vistas cercanas a formar una familia, y 
entonces, y sé que bueno...hablando con él y sé que puedo ir allí y hacerme una punción o hacerme lo que tengamos que hacer y saber si soy fértil o no, si puedo formar una familia, digamos de mi... de mí (H2-23).

Mi único problema es que yo no eyaculo, entonces digamos, yo no llego a ese clímax, ¿no? por eso te decía antes lo de la punción, se intentó en su día con un estimulador, pero... pero nada, creo que la única opción que queda es la punción, pero era sobre todo, no por el hecho de eyacular si no para ver si soy fértil y puedo formar una familia, y como no me corre prisa tampoco (H2-42).

\subsection{Información o asesoramiento sobre la procreación}

Existe una desinformación derivada de la falta de asesoramiento sobre los recursos que existen en el hospital para ayudar a la procreación. En el caso de menores, no se facilita esa información durante el ingreso, pero tampoco se facilita la información de que existen para cuando en el futuro deseen procrear. Aparece la idea de que puede existir el pensamiento de que una persona con una tetraplejia vaya a querer tener hijos.

Yo llegué muy tarde a la, bueno, tan tarde como que el tiempo que yo estuve en el Hospital de $X$, los 9 meses, a mi nadie en ningún momento me habló de absolutamente de nada, ni siquiera de esa unidad de asistencia. Yo llegué con 17 años, pero creo que no es razón para ello, pero yo creo que no hay razón, yo ya había recibido educación sexual siendo menor, aquella educación sexual que recibíamos, pero a mí ya me habían hablado de estas cosas, y yo era activo sexualmente (H3-34).

A mí nadie me habló de, ni siquiera de...oye...si quieres tener hijos de aquí a unos años...bueno, pues vente (M1-62).

Pero a mí no, (nadie te dijo nada) con 17 años... a lo mejor es porque también obvian que alguien tetrapléjico (vaya a querer) al final [tener hijos]...os hablo de hace 24 años, va a hacer 24 años también ¿ंeh? O sea, yo creo que, en 24 años, creo yo, que las cosas habrán cambiado un poco, creo yo (M1-65).

Yo te digo que fui tarde porque yo, en los 9 meses que estuve en el hospital de $X$, no fui nunca, nunca, a mí nunca se me habló de ello (H3-37). 
Yo fui a la unidad de rehabilitación sexual en la primera revisión que yo tuve en

el hospital de $X$, en la primera revisión que yo tuve, que fue en 2001, espera que quiero ver que te esté diciendo todo bien...- ¿Bastante tiempo después no? ¿2001? 4 años...-(H3-37).

La presencia de los progenitores cuando se da la información a menores es un freno a la hora de solicitar el acudir a algún recurso sobre la sexualidad, aparece el miedo a que se entere, a que se informe, a de que tenga que autorizar.

Luego yo estaba ahí con mi madre, lo cual también era una especie como de freno a la hora de... "¿Y tiene que firmar ella algo? ¿Y tiene que hacer ella algo? ¿Y se va a enterar?" Y no... no me apetecía una mierda... nada... (H3-37).

En el caso de las mujeres, como la fertilidad en principio no se encuentra afectada, no se produce ningún asesoramiento sobre la procreación ni sobre los apoyos existentes.

En el caso de las mujeres, en principio ni eso porque no variaba, es decir, de una lesión medular, no variaba en absoluto la... en absoluto, creo que en absoluto el estado de los óvulos, o el estado de la... había un periodo en el que podías estar o no sin menstruación y luego volvía la menstruación y no, en principio no había ningún... (H3-32).

\subsection{Recursos desde el sistema público de salud (unidades de reproducción asistida)}

Los recursos existentes son las unidades de reproducción asistida, que en el caso de personas con lesión medular se encargan de la extracción del semen para una valoración de la fertilidad y una posible técnica de reproducción asistida, y en el caso de las mujeres, la derivación a ginecología para un seguimiento del embarazo como embarazo de riesgo. Estas unidades de reproducción asistida, pueden tener el nombre engañoso de unidades de rehabilitación sexual, en las cuales los lesionados pueden querer acudir buscando otro tipo de ayudas más relacionadas con la erótica y la amatoria.

En el Hospital de $X$, cuando yo estuve, y estuve en el 96-97. Lo único que existía 
era lo que se llamaba la unidad de rehabilitación sexual, que en realidad era una unidad, por llamarlo así, de reproducción asistida, o de no sé... de asistencia, más que reproducción asistida, de asistencia a la reproducción. Era un lugar en el que tú llegabas allí [a la unidad de rehabilitación sexual] y si eras un hombre, lo único que hacían era coger un... cómo es posible que se me olvidara...Ferti Care ${ }^{\circledR}$, un vibrador de estos para extracción de semen, ordeñarte, que era como lo Ilamábamos todos... "Qué, ¿ya has ido a que te ordeñen?", "tengo que ir a que me ordeñen". Te ordeñaban, lo cogían, tomaban muestras y lo que te decían era un poco en qué situación estaba, en qué condiciones estaba tu semen a la, en el caso de que tú quisieras intentar una... inseminación (H2-31).

Te decían: "hay una unidad de orientación sexual". Y tú oías "sexual" y decías, pues yo tengo que ir, tengo que ir, algo hay que... pero no sabías qué es lo que iba a pasar y llegabas ahí y entrabas y lo único que veías era un despacho bastante pequeño, lleno, repleto hasta los topes de fotos de críos, que eran las fotos de los pacientes que habían nacido allí gracias a la ayuda de la unidad de rehabilitación sexual, pero claro, no, es decir, tú esperabas encontrarte algo que tuviera que ver con... pues eso... con la fisiología sexual, es decir, o con el coito o con como montártelo, o alguien que te viniera a decir como algún tipo de pauta, o como que te explicara qué es lo que te pasaba y qué tenías que hacer para tal...(H3-37).

Pero bueno, yo creo que ahí lo de la reproducción asistida, pues supongo que en hombres-no lo sé, ¿eh? se limitaría a ver cómo podrían sacarles el semen, y en mujeres, bueno, pues nada. Hombre el embarazo implica más riesgos, más movidas, bueno, pues en ese sentido te vigilan en el embarazo, no sé si la gente ingresa y tal, no lo sé. Esta amiga mía, yo creo que no ha estado en ningún lado...imagino que la vigilarían...especialmente (M1-64).

Los cervicales no suelen poder eyacular, entonces hay maneras: puede ser por punción, mediante estimuladores que te sacan, sobre todo para ver si eres fértil (H2-23).

Yo visité esa unidad, al doctor $X$ y el doctor $X$ pues hizo lo que hacía con todos sus pacientes masculinos, me llevó a una camilla, me tumbó me quitó la ropa, cogió 
su maquinita y la cuestión era, pues, vamos a ordeñarte, a ver qué... (H3-42).

\subsection{Vivencias de la maternidad}

En la vivencia de la maternidad se valora como cosas positivas para que los niños lo vivan bien: el mostrar con naturalidad lo que ocurre, explicar las cosas y no ocultar información. Se habla de una vivencia positiva de los niños, los cuales tienen una maduración anticipada y una mayor protección hacia sus madres. Concluyen que si ven a sus madres bien, ellos están bien.

Cuando estás sola para el espacio...el crío venía como si estuviéramos en una habitación de hotel: con la tele, la cama, el baño... Como digo yo, las cosas cuanto más naturales lo hagas, no le van a buscar dos vueltas (M3-20).

El crío lo lleva bastante bien porque yo soy muy sincera con él, no le oculto las $\operatorname{cosas}(\mathrm{M} 2-6)$.

Como él me ve a mi bien, que lo llevo bien, que no dejo de hacer cosas, pues él lo lleva también bien (M2-6).

Es como un poco protector. A ver, yo creo que maduró un poco más en ese aspecto (M2-6).

Él tenía que hacer la compra o cocinar, decir pues acaba tú de cocinar porque yo ya no podía más. Y ese tipo de cosas, pues son cosas que a él le marcan, pero yo creo que es para crecer, para madurar él, y creer que no pasa nada, que yo sigo saliendo a tomar algo con mis amigas, que voy al cine, que voy de compras, yo tengo mi trabajo, que hago cosas. Entonces, si él me ve que estoy a gusto y feliz así, que lo llevo bien que no estoy deprimida, ni llorando, entonces bueno él dice qué más da que tal...(M2-6).

En la figura 14 se muestra el mapa conceptual sobre las vivencias sobre la procreación tras la lesión medular. 
Figura 14: vivencias sobre la procreación tras la lesión medular

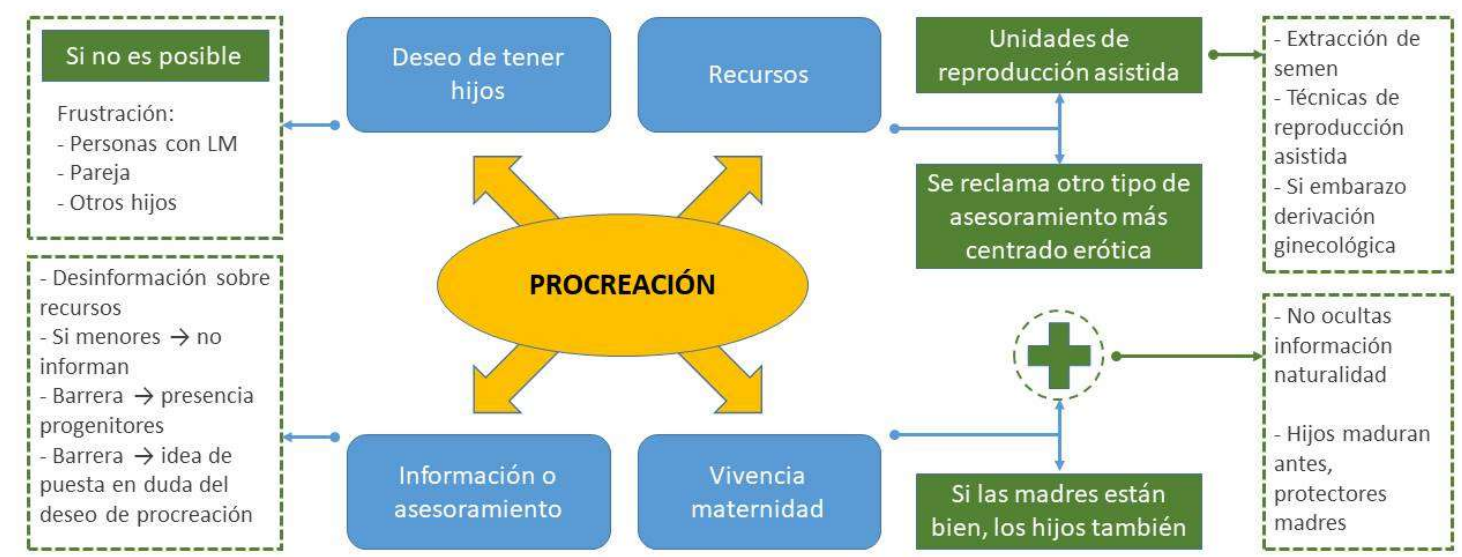

\subsubsection{Vivencias en el ámbito de la pareja tras la lesión medular}

Se percibe una gran diferencia a la hora de afrontar una relación erótica cuando la pareja es estable o esporádica.

Cambiaría mucho si yo tuviese una pareja formal, eso sí (M2-5).

Tú tenías una serie de cortes, te cortabas y tal hasta que llega un momento que...por eso te digo que claro, varía mucho del "aquí te pillo aquí te mato" a tener una pareja estable. Ahí varía muchísimo. Nosotros tenemos el problema ese: una relación así de una noche puede salir mal, muy mal. [Risas] Es verdad porque a lo mejor dice: venga. Pero si ya tienes una relación, ya es completamente diferente y si tu pareja se te inhibe como... [ruidos] ya está. Eso ya depende un poco de la relación que tengas (H4-97).

En las relaciones esporádicas, se percibe una falta de confianza y de complicidad para encontrar los modos y maneras en la interacción erótica para que ambos estén a gusto. La mayor dificultad se identifica a la hora de explicar las peculiaridades derivadas de la lesión medular para poder mantener una relación erótica: sondarse, explicar los apoyos necesarios para actividades como: vestirse, desvestirse, entrar o salir de la cama, mantener ciertas posturas, explicar zonas erógenas o no saber cómo dar placer a la otra 
persona. Esto se puede percibir como una barrera, sobre todo en un primer encuentro, que disminuye en los encuentros sucesivos.

Con la comunicación es todo mucho mejor, más que sí, porque entiendo que te dé cosa sobre todo la primera, conoces a alguien en un bar o lo que sea... si os vais a casa pues entiendo que claro si es alguien de fuera, no es de tu círculo, entiendo que le pueda chocar igual que le tengas que explicar en un momento, me tengo que sondar, entiendo que todas estas cosas sean diferentes pero bueno, es lo que hay ahora mismo así que... (H2-56).

Por eso un lesionado medular eso de "aquí te pillo aquí te mato" ...buf. Es jodido. Es más complicado. ¿Por qué? Por eso, porque tú no sabes cómo dar placer a esa persona (H4-97).

Hay que decirle [si es una pareja esporádica]: "oye, pues tócame una oreja" ...y dice ella: “¿cómo?”. ilmagínate! Yo te digo mi caso... O ráscame la espalda o cualquier cosa que se te pueda ocurrir. $O$ donde tengo sensibilidad es en los testículos y en el pene no, ¿cómo explicas eso? (H4-99)

Ya para empezar ligar una noche y explicarle a un tío: "no mira...cuando nos vayamos a la cama me vas a tener que desnudar tú, me vas a tener que meter en la cama tú, que eso es muy divertido, pero cuando acabemos de follar, me vas a tener que volver a vestir y sentarme tú en la silla". O sea, a esos niveles también, quiero decir, el superar eso buf... a mí me ha costado años, por eso, porque es como... no veo ni siquiera yo la manera, cómo se lo voy a explicar a otra persona (M1-11).

Yo no tengo una pareja estable, con lo cual, a lo mejor el hecho de mantener... de que yo sí que mantuve relaciones sexuales en este tiempo, pero no hay a lo mejor esa complicidad o esa confianza para una persona que yo tenga relaciones sexuales con él, bueno, pues a lo mejor decirle lo que hay, o lo que se puede hacer porque yo también lo ignoro, lo desconozco, también. No es el tema también de que a lo mejor puedes tener una pareja que a lo mejor se puede involucrar más en ello, de que los dos: oye, pues mira hay esto y lo otro, que a lo mejor que uno que sea esporádico es diferente la situación (M2-2). 
A la hora de si me tengo que incorporar hacia arriba o tal, pues a mí me cuesta más, me tengo que coger la pierna, me tienen que ayudar, ese tipo de cosas ¿Entiendes? Entonces para mi resulta un poco... a ver no complicado, porque yo soy bastante liberal no me... oye, que me tienes que ayudar a ponerme así, que yo sola la pierna se me va...Entonces, no me importa decir pues ya está. Pero bueno, hay cierto reparo porque no tengo una pareja estable. Pues esa confianza no hay, esa complicidad, esa confianza y de decir oye pues pasa esto y ya está (M2-2).

Normalmente la primera vez es complicada en ese sentido, ¿no? Pero luego es más divertido, ya cuando te conoces, te agarran, te pin "pa' aqui", "pa' allá" (M130).

Se puede dar el caso de tener relaciones con personas que ya se conocían de forma previa a la lesión, o incluso, con las que se había mantenido relaciones eróticas de forma previa a la lesión. Las vivencias apuntan hacia la no existencia de problemas al respecto.

Yo las relaciones que he tenido este tiempo, fueron con chicos que ya me conocían antes de estar en silla. Entonces pues, para ellos no supuso ningún problema en ese aspecto. Aunque no sean pareja ni nada, hayan sido relaciones sexuales y tal. Pero no supuso ningún impedimento (M2-5).

Entonces, pues sí que chicos con los que estuve, me conocieron, y luego volví a estar con ellos estando en silla y ellos no tienen ningún problema ni me hicieron, bueno, es que ni se les ocurra eso lo primero, vamos faltaría más, pero y luego bueno, pues con otra persona que sí estuve, que mantuve relaciones sexuales y que no me hubiese conocido en silla antes de estar en sillas de ruedas, luego me conoció, siempre me dijo que no tuvo ningún impedimento a la hora de estar conmigo (M2-6).

Otras dificultades identificadas son la toma de fármacos orales para producir la erección y sus tiempos de acción, el no saber si tomarlo o no, por no saber si va a surgir un encuentro y el dar explicaciones si la medicación no hace el efecto deseado y no se produce la erección o esta se pierde. 
"Bueno, yo es que ahora mismo no tengo una pareja fija. Si se me da la noche bien, vas para casa". "Bueno, tú piensa que, si ves que la noche te va a salir guay, tú llévate la pastillita contigo. Te la tomas de la que estés por ahí y así cuando Ilegues a casa ya te está haciendo máximo efecto, y tal" Y yo: "Claro hostia, eso está de puta madre. ¿Y si no me salió? Pues jodí 20 € en pastillitas (H1-3).

Merece más la pena que no andar jugando con una pastillita que el día que no funciona bien... pues estás allí y si todavía tienes una relación estable pues se lo explicas. Pero si no tienes una relación estable, igual no te apetece explicar nada. Porque no te apetece, tampoco, porque son cosas personales ¿no? (H1-4).

Estuve 3 años sin tener una novia estable, tuve muchos picos pardos. Pero, pues, comerte muchos marrones y salir de ahí como podías, porque si no era alguien que conocieses de mucho más, tampoco te apetecía ponerte a explicar tu vida, porque tú te acuestas una noche con alguien, no le explicas porque tienes una teta más baja que otra, o tal, sí fue que tuviste una operación o tuviste un cáncer porque bueno eso lo explicas cuando tienes más confianza (H1-7).

Cuando hay una pareja estable se perciben menos cambios en las relaciones eróticas, estas adquieren un lugar dentro de la globalidad de la relación. La confianza con la pareja permite que en estas relaciones se pueda explorar, probar y utilizar un método de ensayo-error para ver lo que gusta y lo que no.

Yo tengo una relación ahora, por ejemplo, estable. Tengo una relación como la que tenía antes, es decir, sin más, tienes relaciones sexuales cuando te apetece, cuando surge, y cuando todo. Pues como antes, no le veo tampoco... (H1-23).

La persona que esté interesada en ti, si es para una noche para un polvo, pues es para una noche, pa' un polvo. Pero si es para algo más, lo otro va a ser secundario. Incluso habrá casos en los que no le dan esa importancia porque tienes otras maneras sexuales de complacer (H1-30).

Y bueno a partir de ahí tuve una relación con una chica, 4 años, hasta hace...como estaba en el mundo de la medicina y de la sanidad, digamos que para mí era más fácil explicarle las cosas, al principio, sobre todo, porque piensas que al ser personal sanitario piensas que va a saber muchas cosas en este caso de la 
sexualidad, pero ves que tampoco... [risas] (H2-26).

Me volví a encontrar con una relación continuada en el tiempo en la que los encuentros ya no eran los encuentros, vamos a decir, esporádicos, sino que eran algo más continuo y con la misma persona. Con lo cual ya era volver a desarrollar el modelo o tener más posibilidades de prueba-error, de por dónde vamos, de qué hacemos, de dónde me encuentro yo mejor, dónde me encuentro peor, qué es lo que puedo o no puedo, o lo que me satisface o me deja de satisfacer (H3-69).

Yo ahora estoy casado otra vez y ya fue completamente diferente ¿no? Ya tienes una experiencia. Llevamos juntos como 9 años y llevamos casados 1 año y poco. Claro pero ya era diferente, ya tienes tu pareja. Cambia mucho la cosa porque, que yo me acuerdo cuando ibas a las competiciones y uno y otro y tal, y te enrollabas por ahí y eso es aquí te pillo aquí te mato. $Y$ es completamente diferente. La sexualidad con tu pareja es completamente diferente a una de esas de aquí te pillo aquí te mato (H4-50).

Y le pregunté [al neurólogo] y al principio me dijo: "pues no sé, ya veremos porque eso claro hay que ir mirando, depende lo que tu sientas o lo que no. Cómo reacciona el cuerpo. Pero bueno, en sí no habría problema, en el sentido de lo que vas recuperando. Eres joven y encima si tienes una pareja estable todo eso ayuda. No es lo mismo que no tengas y ahora te plantees: ¿Dónde voy ahora a buscar? A ver si sí, a ver si no..." (M3-47).

La comunicación se vive como algo necesario en la pareja para descubrir gustos y posibilidades.

Conjuntamente vais viendo, os vais guiando y si hay comunicación, pues mucho mejor, y si la otra persona lo entiende pues mucho mejor, entonces habláis y tal. Al principio era mucho hablar y luego ya pues, ya se sabe lo que a cada le gusta, hasta dónde puede llegar cada uno y en ese sentido a partir ya de los primeros 6 meses, a partir de ahí ya fue realmente como una pareja normal (H2-26).

Entonces yo que sé, aunque no tenga mano, por ejemplo, yo, probando, probando, desarrollas otras habilidades manuales en ese sentido y eso; pero al final eso es probar, y sobre todo bueno hablarlo con la otra parte y probar los dos 
y sobre todo hablar y decir pues esto sí, esto no, esto me gusta y esto no. Con la comunicación es todo mucho mejor (H2-56).

En las personas con pareja estable previa a la lesión, el reinicio de encuentros eróticos se retrasa más que en personas sin pareja, se identifica la idea de "estar a la altura".

Normalmente, sí me he dado cuenta, que lo que es, lo que yo he vivido: los que tenían novia digamos que lo posponían más que los que no tenían. No sé si es, si era porque por el tema de la presión de no estar a la altura de lo anterior, pero si me di cuenta que los que tenía novia tardaban más en que les picara ese gusanillo de volver a estar con su pareja digamos en la intimidad que los que no teníamos más días que simplemente intentábamos conocer a alguien. Fue mi impresión allí en el hospital (H2-66).

En personas que su lesión les ha ocasionado una pérdida de movilidad importante, aparece el miedo a causarles algún daño en la movilización durante los encuentros eróticos.

Yo si me pongo en el lugar de él, también hay que pensarlo: "tú imagínate que a ti te pasa con tu pareja y estás pensando: a ver si le voy a mancar o la lesión o a ver el cuerpo cómo la muevo o cómo tal, y para encima tal y luego pensar tal... y tengo que estar para probar...". Entonces claro, estás pensando y al final piensas tantas cosas que aquello no va (M3-57).

La exploración del cuerpo y del cuerpo de la pareja se torna importante.

La exploración, conocer tu cuerpo, importantísimo. Conocer tu cuerpo y que tu pareja conozca tu cuerpo. Que no tengas que decir oye hazme esto. Eso es importantísimo (H4-53).

Se percibe que lo aprendido en una relación, sirve para relaciones venideras.

Yo creo que hubo un tremendo cambio con la relación con esta otra chica. Hubo un cambio porque a partir de ese momento en adelante, digamos que mi modelo está bastante más cultivado y amplificado (H3-81). 
Intentar incorporar todo lo que pudiera aprender de todas las relaciones que tuviese y de todo lo que me pudiese llegar, y también intentando incorporárselo a esas personas también (H3-81).

Puede ocurrir un deterioro de la pareja a raíz de la lesión, asociado al cambio en la persona y en la vida derivado de la lesión medular. La pareja pasa por una adaptación a la nueva situación.

Viví con una persona que no estaba en silla, entonces el cambio de vida...de carácter...y de todo no es la misma vida (P1-2).

A ver...no necesita a nadie. No ye "daime", "faime", "traime", X...ahora cuando te pasa a los 62 años, tardes en admitirlo, te ponen tratamiento, y tiras por esta situación (P-2).

El cambio de vida te digo yo que machaca (P1-16).

Yo no superé [enfermedad grave de un nieto] ni aquello ni esto (P1-36).

Se produce frecuentemente la ruptura de la pareja. Cuando ha habido encuentros esporádicos, no suelen repetirse con posterioridad a la lesión con esas personas. El tema de la silla se percibe como causante, el cambio de mirada hacia la persona con lesión medular que se siente menos deseable. También el proceso de adaptación y duelo que está viviendo la persona con lesión medular hace que prefiera romper la relación.

Yo en aquel momento estaba con mi pareja que vivió conmigo el accidente. Pasan los meses y dejo de estar con esa chica con la que estaba (H1-3).

De hecho, cuando el accidente, estaba así, así, con una y a partir del accidente no supe mucho más de ella. La vi alguna vez más y se cortó. Ahí, por alguna indirecta sí que me mandó que podía ser el tema de la silla, del accidente y tal, pero bueno fue hace muchos años, no pasa nada (H2-37).

Alguna con la que haya estado antes del accidente, la verdad es que hay muchas que no he visto más, hay alguna que igual es el grupo de amigos, la verdad es que es como antes, o sea, que en ese sentido bien, tuve suerte (H2-37). 
Yo considero que tuve bastante suerte, porque con esta persona al menos no sentí el rechazo que pude haber sentido con otras de mis amigas, o chicas con las que había estado, que a raíz del accidente pues algunas desaparecieron así, "mutis por el foro" (H3-12).

Aquello pues duró lo que duró, además no es que fuera un esto de... lo dimos por terminado antes del tiempo, porque yo no me hallaba, es decir, yo estaba en ese momento asimilando cosa que estaban sucediendo y no me encontraba a gusto, no era el momento, y creo que por su parte tampoco, pues bueno, fue un poco desastrito aquella vez (H3-16).

Con las chicas con las que había estado esporádicamente no volvió a haber, no volví a notar ningún tipo de interés por el acercamiento, era como si la situación hubiera cambiado el, pues sí, el modo de verme, el modo de percibirme (H3-18). De hecho, todas mis posteriores relaciones, eh..., relaciones de todo tipo pero que tuvieran algún tipo de componente erótico, no volvió a haber ninguna con nadie, con ninguna de las que pudiera haber estado antes... (H3-20).

Mi mujer me ayudó, hasta que la relación acabó, pero bueno acabó por otros temas que no tienen que ver con el aspecto sexual (H4-28).

Yo después me separé, me separé por distintos problemas, nos separamos (H434).

Pero, no es lo mismo, no es lo mismo, cuando tú sabes que conoces ya a una persona ya en esas condiciones, que está rehabilitada, que te hace feliz, a estar un matrimonio, y de repente te llega esta situación y te cambia el carácter y te rebotas, y qué bah. La misma situación no es, la prueba es que la mayoría de matrimonios que están en estas circunstancias-yo conozco dos parejas antes de que X [su marido] estuviera-que se separaron, porque la convivencia es muy difícil (P1-57).

En la figura 15 se muestra el mapa conceptual sobre las vivencias en el ámbito de la pareja tras la lesión medular. 
Figura 15: vivencias de la pareja tras la lesión medular

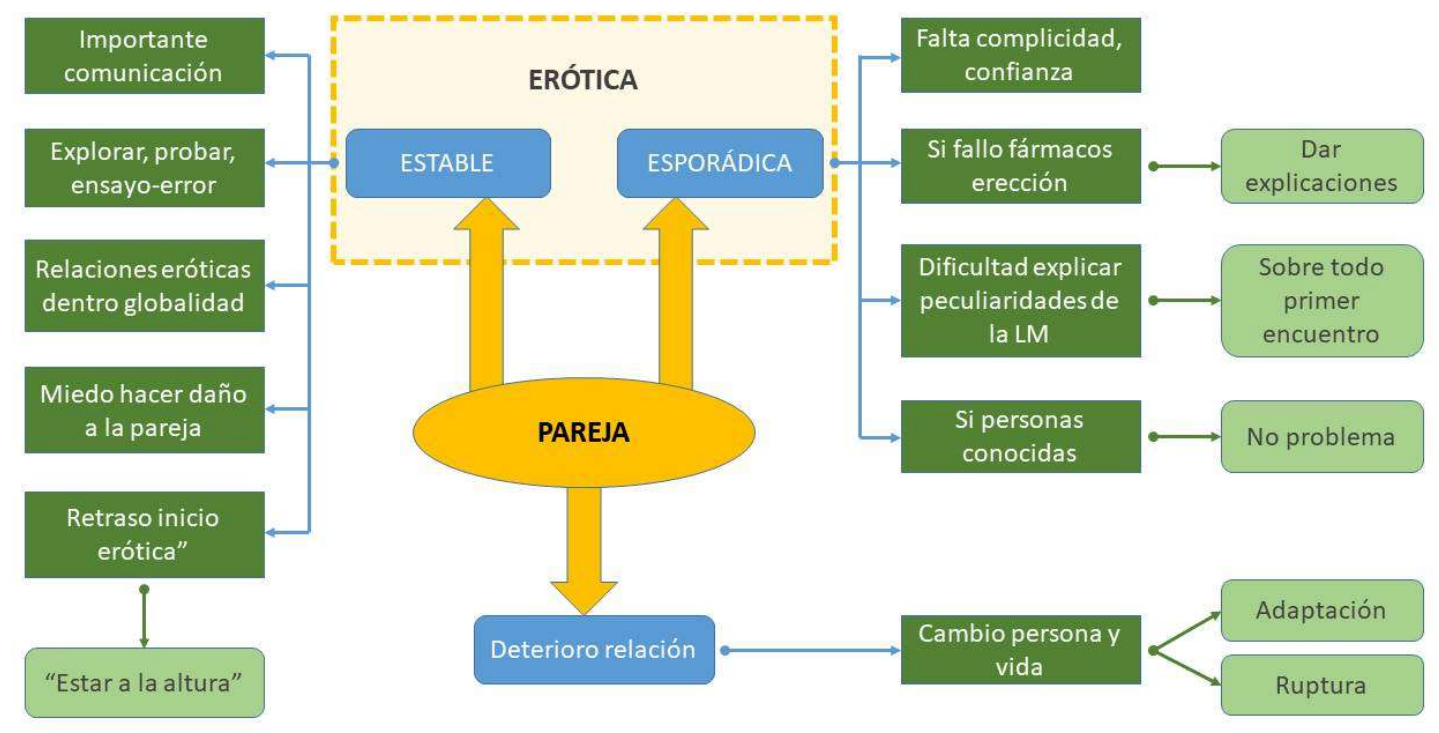

\subsubsection{Experiencias de asesoramiento}

\subsection{Percepciones sobre la necesidad de asesoramiento}

Se tiene la opinión común de que es necesaria la existencia de un asesoramiento y un acompañamiento. Aparecen percepciones de falta de conocimientos derivada de la falta de información; también de falta de empatía, carencia de recursos y sentimiento de soledad.

Te encuentras con que no sabes nada, nadie te ha explicado nada, entonces, bueno, pues bueno, habrá sido así (H1-2).

Es como yo lo recibo y tengo contacto directo con muchísimas personas y gente que no han tenido ningún conocimiento sexual por ningún lado (H1-12).

Yo sabía por lo que había pasado, es decir, por esa completa falta de atención, esa completa falta de empatía, completa falta de transmisión de información, de conocimientos, completa falta de comprensión o de tratar de sobre todo de empatizar, o de tranquilizarte o de acompañarte. La palabra es la falta de acompañamiento y sobre todo esa falta de orientarte o de hacerte ver, de abrirte un poco la mirada a esa infinidad de posibilidades que los que estuvimos en aquellos años, y no sé cómo estarán los que están ahora, creo que estarán parecido, al final lo haces o no lo haces, pero sobre todo es un camino como muy solitario, muy solitario. A veces acompañado por las parejas que puedas tener o 
tal, pero en eso personal es muy solitario (H3-106).

Yo, en el tema de relaciones sexuales, no lo sé, no sé cómo funcionará eso, no tengo ni idea (P1-50).

Que te marquen cuatro pautas. Que te digan: chaval... (H4-110).

Yo a día de hoy tampoco hablé con nadie, ni nadie me informó sobre... oye mira pues hay...libros sobre ello... documentales, no sé qué... se pueden hacer estas posturas uno y otro, a ver... (M2-2).

\subsection{Asesoramiento entre iguales}

Ante la falta de asesoramiento sanitario, aparece la figura del tutor, otra persona con lesión medular, que acompaña y asesora a una persona que acaba de adquirir esta nueva condición.

Que te lo explique un poco, que al final y ahora mismo sabiendo lo que sé, cualquiera de las personas que tengo tuteladas les explico todo, y les digo: "estate tranquilo, vas a tener una vida sexual plena, digo, tendrás una opción, otra opción, o la que sea, pero vas a tener" (H1-19).

Sirve mucho el boca a boca. Para nosotros sirve mucho el boca a boca. Y tú cuando ya tienes...sobre todo tienes que ganarte la confianza del lesionado, incluso hay gente que te habla y que te pregunta. Y tú dices tu experiencia (H461).

Este asesoramiento entre iguales también aborda temas como la sexualidad o los fármacos para el tratamiento de la disfunción eréctil, utilizando el método de ensayoerror.

Y la sexualidad fue así. Y fue más de comentarios entre unos y entre otros que, de verdad, de médicos o de sexólogos. Que eso es también una de las cosas que hay que cambiar (H4-79).

Y aquella noche [reunión de hombres ingresados en el pasillo del hospital] que yo recuerdo nítidamente, uno de los temas que se habló era a quien se le ponía dura y a quién no (H3-57). 
Entonces en esas reuniones de deporte, mucho lo que haces es hablar ¿no? Entonces, de repente, un día te dice uno "yo uso el Cialis ${ }^{\circledR}$, y tal" ¿no? "pues yo la Viagra $^{\circledR}$, y tal" ¿no? "pues yo me la engancho con una goma y cual". Y ¿no? "pues yo el Caverject ${ }^{\circledR ”-~ “ ¿ E l ~ C a v e r j e c t ~}{ }^{\circledR}$ ?” - "Sí, sí, me la pincho" “¿Qué me estás contando? ¿Qué te estás pinchando?” ¿El qué? ¿Dónde? Tú estás, bueno, claro...y cómo no te han contado nada... (H1-3).

Esa era una experiencia entre nosotros [el manejo de tratamientos para la disfunción eréctil]. Y yo, gracias a Dios, encontré un grupo de gente maravillosa. Somos más que compañeros, somos amigos, somos familia. $Y$ eso involucra en todos los temas. Claro que...yo a través de esto si sirve para que alguien profesional, que no tenga que ser como nosotros, que era la prueba esa de siempre, ensayo error - ensayo error - ensayo error. Sería genial (H4-48).

Sin embargo, se percibe una falta de referentes, no siempre existiendo un asesoramiento entre el grupo de iguales e identificando la dimensión sexual de la persona como un tema tabú.

Nadie más habló [sobre la sexualidad], yo por lo menos con nadie, ni con médicos, ni con nadie... No sé si, entre nosotros, o sea, los que estamos allí en A [nombre de asociación], que estamos así... no sé si será un tema tabú, o que nadie tiene por qué contar... (Ella: no, o que cada uno está arreglado...porque son muy jóvenes...) No, porque podía preguntar...oye tú esto, tal...esto tal...pero no, nadie habla (P1-72).

Si nadie te cuenta, eh...como puedes...que hay otras formas de conseguir placer, quiero decir, en mi caso ha sido una búsqueda personal, todo esto, pero no ha habido referentes, porque qué le cuentas a un colega o a una colega: "oye, mira ¿Tú cómo te masturbas?" Pero es que a mí eso no me va a servir, o sea, quiero decir, los referentes de los iguales no sirven porque no tienen nada que ver contigo (-claro) y...y más referentes que los iguales no hay, no existe, no hay ningún sitio... (M1-9). 


\subsection{Asesoramiento sexológico}

El asesoramiento sexológico es muy infrecuente, cuando se produce, se encuentra centrado en desenfocar las relaciones eróticas de los genitales y del coito, producir una apertura del marco erótico y trabajar la identidad sexual.

La gente de X (nombre de asociación) montó unas jornadas de sexualidad para jóvenes y me contactaron para ver si quería participar en una de las mesas contando mis experiencias, contando estas cosas que te estaba contando, cómo las había vivido... Bueno, la experiencia estuvo muy bien, y a mí me sirvió también para reflexionar más sobre el tema y, además, en aquel momento yo ya iba como empoderándome, de alguna manera. Tanto en mi erótica como en mi recuperada, reencontrada, o reinventada masculinidad también (H3-77).

Exactamente. Fue lo primero de lo que te das cuenta. Ya te digo, un médico, creo que sexólogo, fue el que me dijo eso. El que me abrió la cabeza: "esto no es meter y sacar" (H4-103).

Yo creo que eso es importantísimo ya cambiarlo desde la base. Como tienes un terapeuta ocupacional que te coge y tal, pues que te coja un sexólogo y que te abra la cabeza (H4-79).

\subsection{Asesoramiento por Internet}

La utilización de Internet para buscar asesoramiento se reduce a buscar información sobre la lesión, sobre el funcionamiento del cuerpo post-lesional y el visionado de pornografía, que se vive como una forma de estimular el deseo.

Yo ya me había trabajado más las cosas también y ahí ya había mirado, había investigado por mi cuenta, vamos a decir, había empezado, todavía no teníamos Google, pero ya teníamos internet, entonces ya había empezado a mirar un poco por ahí cosas (H3-61).

Internet fue un apoyo, pero en realidad fue un apoyo muy residual. Si a mí internet me apoyó en algo que tuvo que ver con la erótica fue realmente para ver porno. Es decir, para estimular un poco mí deseo de alguna manera. Sí que busqué ciertas cosas [en internet], pero tampoco profundicé mucho en buscar 
cosas porque con lo básico que yo había encontrado, que era básicamente qué es lo que le sucedía a mi cuerpo, no necesitaba profundizar en por qué le sucedía eso y cuáles eran las conexiones neuronales que no funcionaban... Todo eso, como que a mí no me hacía... no me servía saberlo (H3-65).

\subsection{Asesoramiento sanitario}

El no dar educación sexual o asesorar en este tema es también una forma de educación sexual: el obviar que una persona con una lesión medular quiera información sobre sobre su sexualidad.

Si empezando por un hospital donde te rehabilitan en todo y ese aspecto se obvia [el aspecto sexual], pues... (Ya...ese silencio) Deja de ser parte de tu vida (M1-54). Entonces a nivel sexual, directamente, no dijeron nada, no dijeron nada. $Y$ entonces, claro, te encuentras con que has tenido que ir investigando y que desgraciadamente eso te ha ralentizado en tu bienestar, ¿no? (H1-6).

No había ningún tipo de asesoramiento, no había ningún tipo de nadie que te explicaba qué es lo que te había sucedido, qué es lo que te va a suceder y como podías, un poco, apañártelas, nadie que te ayudase a cultivar tu sexualidad (H333).

A nivel de sexualidad ¿alguien te contó algo? - No, no, no. Nada (M3-64).

Yo en aquel momento estaba con mi pareja que vivió conmigo el accidente. $Y$ llegas a casa y en el término sexual pues lo que te han contado es que no puedes hacer nada, básicamente (H1-1).

A veces se identifica un asesoramiento "muy por el libro", etiquetando de forma cerrada a cada lesionado según su tipo de lesión y no valorando la existencia de una diversidad individual derivada de la complejidad del sistema nervioso. En este asesoramiento la información aportada a veces es errónea y no coincide con la realidad.

El tema de la eyaculación. Pues es cierto que yo eyaculo y además me gusta, con lo cual, genial. Pero a mí me dijeron que no, que no, que no, que no, que era imposible. Bueno, pues bien, chica, imposible no, es una lesión medular y ahí hay dos millones de cables y puede estar roto muchos, pocos, todos. Algo cambiará 
(H1-21).

El médico te dijo: "Yo te receto la Viagra" ${ }^{\circledR ”}$ dije yo "no se preocupe, que el médico de cabecera, si la necesitáramos, también nos la da" Dijo: "pero tú ni vas a disfrutar, ni vas a eyacular, ni nada de nada" (P1-22).

Qué dijeron cuando a mí me da... nada, es que a partir de la D6... justo tal... no se cual, era todo como muy del libro. Entonces, de repente, cuando ya vas conociendo tu cuerpo te das cuenta de que llegas al orgasmo, de que el orgasmo te es muy placentero, que es un orgasmo muy largo y si aprendes a reconducir, lo aprendes a controlar: cuándo vas a tener un orgasmo, a cuándo no, a cómo mantenerlo más, a cómo menos.

Se identifica como negativo un asesoramiento excesivamente utópico, basado en el "puedes hacer todo lo que quieras" en el que se dulcifica la realidad y se ocultan las barreras existentes.

Nadie te cuenta cómo es la realidad (M1-9).

Realmente nadie te preparaba para lo que te ibas a encontrar en la calle, a todos los niveles, "no, no, tú puedes hacer una vida normal", pero ¿ Tú qué cojones sabes si tú caminas? Si no es verdad, empezando porque cuando salga a la calle me voy a encontrar barreras arquitectónicas, me voy a encontrar con gente que me mira con condescendencia y me habla con condescendencia (M1-7).

$Y$ de inculcarte que sigas tu vida, que todo puede ser y además es que era muy... [...] pero era muy mundos de Yupi, vamos a ver, tú no...y hablo del servicio de psicología y psiquiatría (M1-7).

Se percibe como negativa la falta de formación de los profesionales, que lleva a dejar de pedir información por la percepción de que no se va a saber responder a sus preguntas. Si yo ahora mismo voy... a un...yo que sé, a un centro de estos de planificación familiar o de educación sexual es que probablemente no sepan lo que decirme, si no hay alguien que sepa de lo que me pasa a mí (M1-9). 
Yo les he preguntado siempre a todos. Todavía a principios de diciembre tuve revisión con el neurólogo y me dijo: "yo de ese tema, la verdad que poco te puedo decir". Está más otro doctor B [el médico rehabilitador] con ese tema. Y yo dije: "ay madre pues si él está más que tú...déjalo". Pues nada, ya iremos investigando poco a poco (M3-78).

El urólogo. Quien me va diciendo, como quien dice: "bah, vete probando y a ver lo que pasa". Pero vamos, dándole la mínima importancia y teniendo la más mínima puta idea, ninguna, vamos (H1-3).

Sobre el tema de sexualidad, analizando los discursos, se percibe como frecuente que sea el propio paciente el que saque el tema o le pregunte al profesional.

Pero es cierto que cuando venías aquí a preguntar no te daban una contestación. No te decían: "tú tranquilo, hombre, que hay esto, hay esto, hay esto o hay no sé qué. No, no, no te decía nada. Era como que yo tenía que preguntar y decir: "Oye, aparte de esto, ¿No hay otra?" (H1-78).

Yo siempre he sacado el tema a todos los médicos y a las fisios (M3-66).

Yo en la consulta que me dio por preguntarle al Dr. X, ¿el tema de la sexualidad? Y fue cuando me dijo, sí, sí, yo te doy si quieres la Viagra ${ }^{\circledR}$, pero no vas a sentir...no vas a tal... (P1-70).

Luego en la reunión de rehabilitación [en unas jornadas de lesionados medulares que hubo en el hospital] decía: me llamará pesada, pero yo sigo con lo mío. Cuando lo hablé luego allí, ya había 2 personas más que si les gustaría saber un poco de ese tema (M3-58).

Sin embargo, se percibe como positivo en el asesoramiento el mostrar preocupación por abordar el tema sexual, el tratarlo con naturalidad, el ofrecer confianza y el sentir que el profesional tiene experiencia.

Ella [médica rehabilitadora de hospital de referencia] estaba también pendiente porque claro, quieras que no 18 años, estaba en la adolescencia, entonces estaba muy pendiente del tema de la sexualidad. Allí [en hospital de referencia] hay un 
departamento de...de...que se llama unidad sexual, y tuve varias, varias consultas cuando estaba ingresado, y luego cada año, volvía en febrero más o menos que es cuando me cuadra, volvía de revisión los años siguientes y siempre, si quería tenía la opción de poder ir a la unidad sexual. O sea que, en ese sentido, Toledo está muy bien (H2-15).

En la unidad sexual, el doctor que hablaba con...te lo trataba con tanta naturalidad que le seguías el rollo y como estabas solo en la consulta...pues... Y luego te da confianza también el hecho de que lleva haciendo eso 20, 30 años y controla, deberá saber algo del tema...y nada...pues te hace preguntas, si tienes novia, si a lo mejor, las erecciones, la sensibilidad... (H2-22).

Se identifica una mejora en el asesoramiento sobre la sexualidad con el paso de los años, percibiendo como los médicos lo valoran en la actualidad como importante.

Yo te puedo decir que antes cuando iba a revisión, que ibas una vez al año al médico rehabilitador y tal, al principio ese tema era lo que os dije: allí no se comentaba nada ni te preguntaba si quiera. Hasta que después a los mismos médicos les interesa. Les interesaba porque, oye, es una forma de volver a realizarte como persona. Porque es importantísimo (H4-67).

Se identifican como temas que hubiesen sido de elección para tratar por parte del sistema sanitario: productos de apoyo, geles o juguetes eróticos, libros de consulta, posturas para las relaciones eróticas en silla de ruedas, etc.

Sobre todo, explicar un poco cosas que se desconocen totalmente [cosas que te hubiera gustado que el sistema sanitario te hubiese contado]. A lo mejor, sobre aparatos, ahora que yo estoy contando, pues mira, sí que a veces pierdo sensibilidad...no es que no note nada, pero sí que noto que no siento lo mismo como podía sentir, por momentos, también es cierto que no me pasa siempre. Pero, pues decir, pues tienes estos aparatos o estos geles que te pueden ayudar (M2-5). 
O también saber que le puede pasar a otras personas, identificarte con ellas también, leer sobre ello. Pues los libros, voy a comprar uno, voy a leer, posiciones que puedes tener a la hora de mantener relaciones sexuales en la silla de ruedas. Yo eso también lo desconocía. Pues no sé, pues muchas cosas. Todo. Porque a mí, en realidad, a mí nadie me explicó absolutamente nada sobre ese tema. $\mathrm{Ni}$ siquiera me preguntaron (M2-5).

El sistema sanitario se percibe con muchas carencias a la hora de abordar la sexualidad en personas con una lesión medular, valorando lo importante que sería un acompañamiento de esta dimensión desde la cama del hospital.

Volvió a ponerme en contacto con cuáles eran todas las carencias que seguía habiendo en el sistema de atención a la sexualidad, pero atención a pacientes cuyo diagnóstico implica totalmente a su dimensión sexual,

Porque yo a lo mejor no digo las palabras adecuadas ni se llegar a la persona como podéis llegar vosotros. Porque yo soy bastante abierto y tal y a lo mejor le suelto cualquier cosa y lo que hace es coger más miedo. Puede llegar así, pero yo creo que un tratamiento ya desde la cama del hospital sería importante (H4-79). Si, fue en la revisión de 2001 la primera vez que yo fui a esa unidad de, la primera vez que alguien, habiendo pasado ya 5 años de mi accidente, la primera vez que alguien me hablaba de... No espera, te lo estoy diciendo mal. No, te lo estoy diciendo bien, sí... no, no era la primera vez que alguien me hablaba de eso porque ya habían pasado varias cosas, bastantes cosas. Pero sí la primera vez que alguien desde el punto de vista sanitario me hablaba o me atendía en algo que tuviera que ver con mi dimensión sexual (H3-39).

En la figura 16 se muestra el mapa conceptual sobre las experiencias de asesoramiento. 
Figura 16: experiencias de asesoramiento

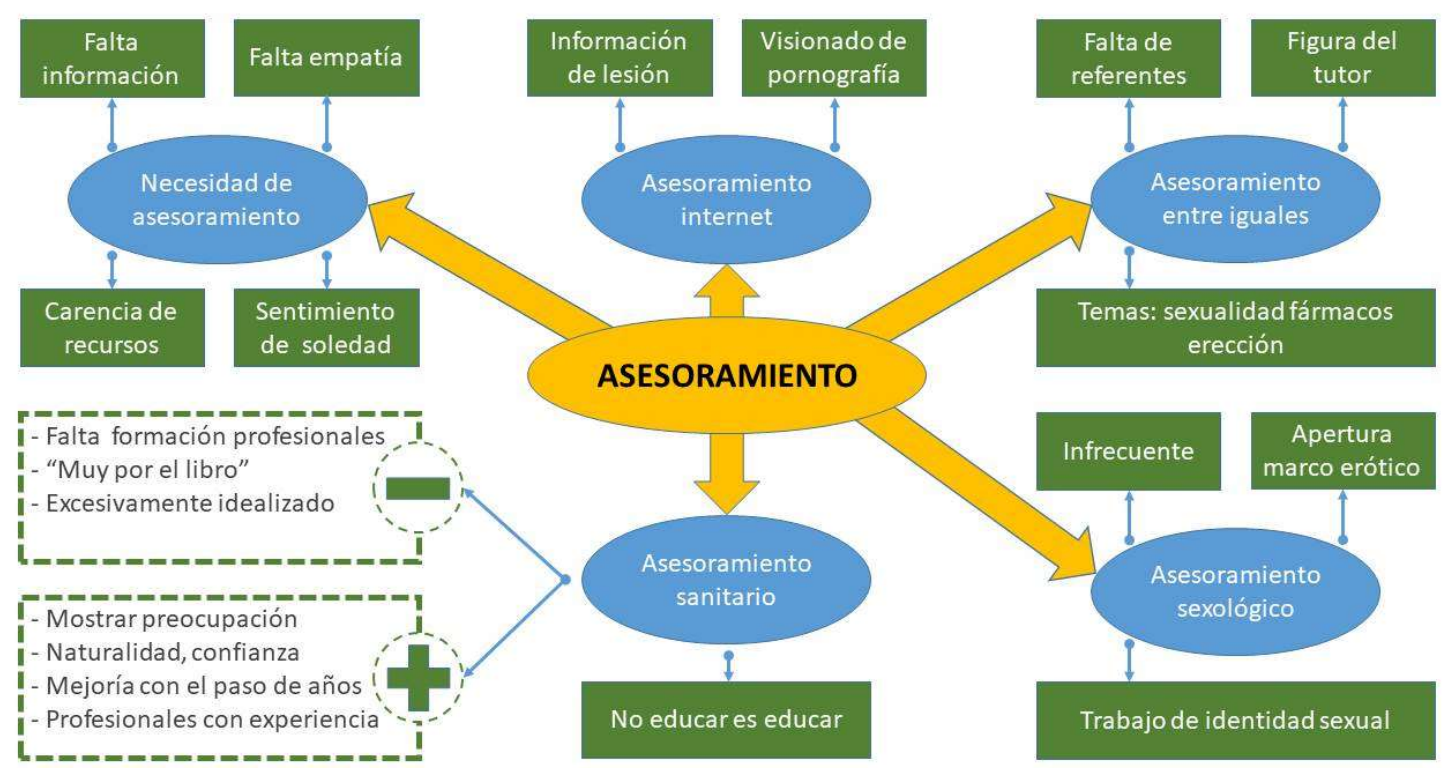

4.3.5.10. Opinión sobre las figuras de apoyo en la sexualidad tras la lesión $\underline{\text { medular }}$

En los casos en los que la erótica es vivida como una necesidad del ser humano se puede recurrir a diversas figuras: la asistencia sexual o la prostitución son dos de ellas.

Yo digamos, oír o he visto o he leído en algún sitio dos figuras en ese sentido: una es pues una prostituta, sin más, o sea sin más una trabajadora sexual o como lo quieras llamar, y otro es más no sabría tampoco explicarlo así, digamos como que...con más cariño, es que no sé cómo decirlo... como que está... ambas figuras para mí hacer un servicio, pero lo que se entiende como asistente sexual lo veo como algo más terapéutico, no sé si es la palabra correcta, pero es lo que yo entiendo cuando se dice la asistencia sexual (H2-72).

En la prostitución o trabajo sexual se encuentran varias desventajas: el no conocer el cuerpo del otro, no sabiendo los puntos erógenos, lo que a veces lleva a no continuar acudiendo a estas figuras.

Porque temas de prostitución yo conozco gente que va. Yo fui un par de veces y digo esto no es lo mío. Para una copa, tomamos una copa y por lo menos nos reímos. $O$ sea que es una experiencia, porque es normal, eres una persona que 
tiene sus necesidades. Y no sabes cómo buscarlas pues, ¿dónde acudes? Sé que está mal decirlo, pero es así eh (H4-51).

Y hay mucha gente que sigue yendo [prostitución] pero...Yo hablando...buf es una tontería. Porque no te van a hacer lo que tú quieres si tú no sabes tus puntos erógenos (H4-53).

La asistencia sexual se percibe como un derecho en el acceso a la sexualidad, para personas que no pueden acceder a su propio cuerpo. Se ve también, aunque con más desconcierto, en la ayuda al encuentro erótico entre dos personas en las que haya un problema en la movilidad.

Sí creo que es un necesarios porque creo que todo el mundo tiene derecho a eso, a la sexualidad, hay gente que no puede llegar a ciertas partes de tu cuerpo porque simplemente es un tetrapléjico súper alto, pero a lo mejor, entonces en esos caso...A mí me choca más lo de la ayuda a la tercera persona, digamos que te ayude a ti y a tu pareja, a mí eso me choca más, eso me choca más, pero creo que son necesarios porque hay mucha gente que no puede (H2-78).

Por otro lado, el asistente sexual se percibe como una figura importante en la reeducación erótica de la persona con lesión medular, en el caso de personas sin pareja. Se visualiza como una figura terapéutica: acompañamiento en la aceptación del nuevo cuerpo y en el volver a sentirse como persona deseable, en el acompañamiento a la reconstrucción identitaria.

Yo es que estoy muy a favor de ese tema [asistentes sexuales], a favor en el sentido de que lo veo parte, en un caso de lesión medular lo veo parte fundamental de una terapia o de una reeducación, ¿no? En el caso de gente que no tiene pareja, que es mucha (M1-49).

Yo es que lo veo fundamental, desde mi punto de vista es parte de la reeducación. Es que por ejemplo hacer un taller de cuerpo es que...es básico en..., yo lo veo ¿no? como talleres de ternura, talleres de aprendizaje de ver tu propio cuerpo otra vez, de mirarte de otra manera, de volver a...de volver a permitirte ser 
deseable. Yo hay veces que en las charlas lo digo: si es que yo empecé a retomar el ser mujer, el día que me permití volver a ser deseable, ¿Por qué no...? (M1-51).

Aparecen en el discurso, la organización de esta figura en otros países, en los cuales hay una unión de la figura del asistente personal y sexual en la misma persona, viéndose como algo poco aconsejable por la dificultad de manejo de las situaciones diarias.

En Holanda también existe la figura de las trabajadoras sociales que a través del Gobierno del Ayuntamiento si estás en una silla, tienes un cierto grado de discapacidad, tienes una serie de requisito, pues tú tienes opción a tantas veces al mes, o algo así, eso en Holanda (H2-72).

Además, hay tantas formas de entender la sexualidad y la figura del asistente...porque claro, en qué momento, si digamos que el asistente personal y la sexual las combinas en una figura... ¿Dónde está la línea que separa cuando es sexual y cuándo...? Quiero decir...imagínate que alguien está en silla... y contrata a un asistente personal que tengan ambas funciones: ¿qué te está limpiando el polvo y tú vas...? por ponerte un ejemplo... es mi opinión (H2-80).

La utilidad de la asistencia sexual no se ve como exclusiva para personas con lesión medular, ni solo para personas con problemas de movilidad, sino que se ve como útil en todas las personas en situación de vulnerabilidad.

Esto hay que abordarlo, hay que hacerlo [hablando sobre la asistencia sexual]...y una de las cosas que nos planteábamos, cualquier persona en situación de vulnerabilidad puede necesitar, tenga o no discapacidad un asistente, y nos planteábamos el caso de personas mastectomizadas, gente que está pasando por un cáncer: volver a abordar tu vida erótica, enfrentarte con tu nueva imagen y volver a sexualizarla, a erotizarla (M1-74).

En la figura 17 se muestra el mapa conceptual de opinión de las figuras de apoyo en la sexualidad tras la lesión medular 
Figura 17: opinión sobre las figuras de apoyo en la sexualidad tras la lesión medular

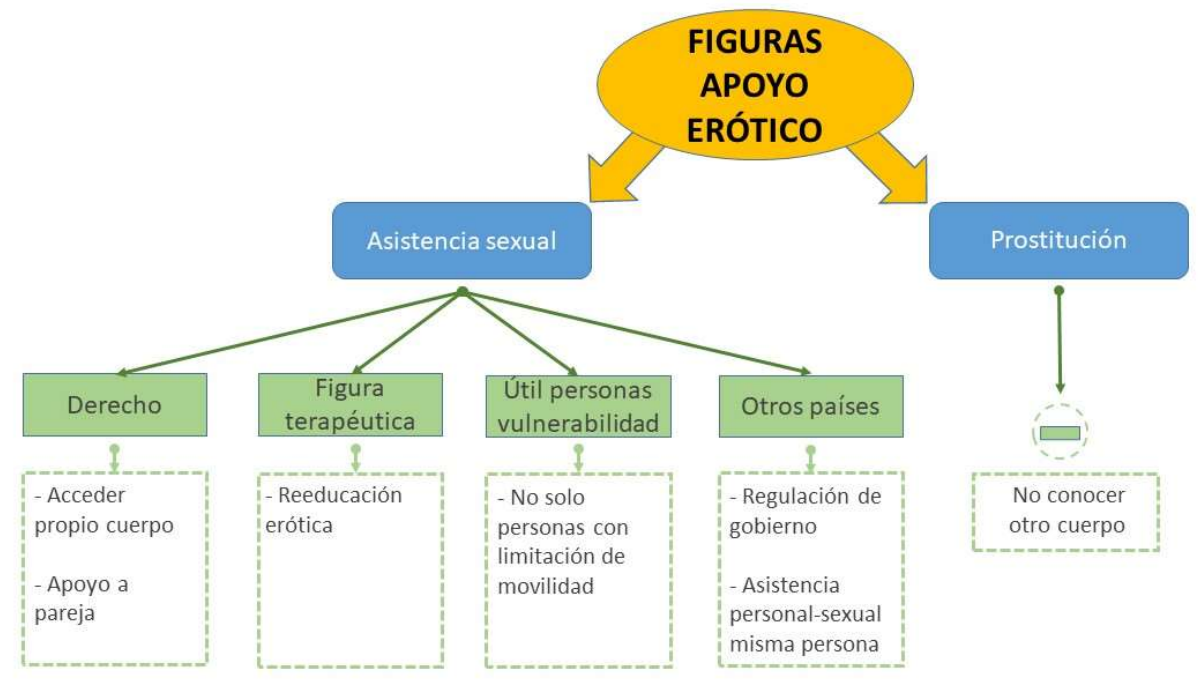


Discusión 


\section{Discusión}

\subsection{Epidemiología}

No existe ningún registro regional ni nacional sobre lesión medular. La incidencia y la prevalencia son halladas a raíz de estudios y existe una variabilidad importante debido a las diferencias de criterio en cada uno de ellos. Son varios los estudios $(13,14,17,108)$ que hablan de dos picos de incidencia: uno entre los 15 y los 29 años debido a accidentes de tráfico, y otro alrededor de los 65 años producido por caídas. En el estudio realizado por Álvarez Pérez(109) en Asturias, se refleja que entre 1951 y 2013, el 13,7\% del total de pacientes con LMT tenían más de 65 años.

En nuestro estudio no se ha podido obtener ese dato, debido a que el criterio de inclusión respecto a la edad era tener entre 18 y 65 años.

Los estudios están reflejando un cambio en el patrón clásico de lesionado medular, aumentando la edad media y con un cambio en su etiología. En nuestro estudio la edad media del paciente en el momento de la lesión fue de 40,2 años, más baja que en el estudio de Torres Alaminos(10) en el Hospital Nacional de Parapléjicos de Toledo que fue de 49 años y que en el de Montoto(14) en Galicia que fue de 50,2 años y algo menor que en el estudio de Bárbara-Bataller(16) en Canarias que fue de 43,7. No se ha encontrado explicación a dicha diferencia.

\subsubsection{Sexo}

En el presente estudio la razón hombre/mujer es de 3,33/1, siguiendo la línea al de Montoto-Marqués(14) en Galicia con un 3,24/1, el de Bárbara-Bataller(16) en Canarias con un 3,8/1 y el de Van den Berg(13) en Aragón con un 3,9/1 y siendo más elevada que en el estudio de Torres Alaminos(10) en el que la razón es de 2/1.

La diferencia entre sexos es atribuida por varios autores, a dos causas: por un lado las mujeres participan menos en las actividades de alto riesgo, y cuando lo hacen, lo realizan con mayor seguridad que los hombres $(10,16)$. 


\subsubsection{Tipo de lesión}

En este estudio la distribución de la lesión según afectación de miembros es: un 38,5\% presenta una paraplejia, un $28,2 \%$ una paraparesia, un $20,5 \%$ una tetraparesia y un $12,8 \%$ una tetraplejia.

Según la extensión de la lesión, el 52,6\% presenta una lesión completa. En el estudio de Torres Alaminos(10), la lesión completa es más baja, del 29\%, aunque incluye las lesiones traumáticas y no traumáticas. En el estudio de Bárbara-Bataller(16) en Canarias el $44,7 \%$ presenta lesión completa, un porcentaje más cercano al de este estudio.

Según el nivel neurológico, el 45,4\% presenta una lesión dorsal, el 30,2\% cervical y el 24,4\% lumbar. Esto es concordante con el estudio de Torres Alaminos(10) en el que un 51\% tiene lesión dorsal, el 36\% cervical y un 13\% lumbo-sacra. En el estudio de BárbaraBataller(16) sin embargo, las lesiones cervicales son las más frecuentes con un $48,9 \%$, seguidas de las dorsales con un $36,9 \%$ y las lumbares con un $14,2 \%$, que corresponde con el estudio de Montoto-Marqués(14), en el que un 54,9\% presenta un nivel cervical, un $32,4 \%$ dorsal y un $12,7 \%$ lumbosacro. Sin embargo, en el estudio de Van den Berg(13), las lesiones torácicas son más frecuentes $(37,4 \%)$, seguidas de las cervicales $(36,9 \%)$, las lumbares $(19,3 \%)$ y las sacras $(4,3 \%)$.

En relación con el tipo de lesión según la escala ASIA al alta, el 50,7\% presenta una ASIA A, EL 27,6\% ASIA D, el 14,5\% un ASIA C, el 4,3\% un ASIA B y un 2,9\% un ASIA E. El orden de prevalencia de los tipos de lesión según la escala ASIA es concordante con el estudio de Bárbara-Bataller(16) en Canarias, siendo la lesión ASIA A la más frecuente con un $47,7 \%$, ASIA D con un $23,8 \%$, la lesión ASIA C con un $16,9 \%$, la lesión ASIA B con un $6,2 \%$, y la lesión ASIA E con un 5,4\%. En el estudio de Montoto-Marqués(14), el ASIA A con un $44,3 \%$, con un ASIA C con un $23,5 \%$, con un ASIA D con un $19,6 \%$ y con el ASIA B con un 12,6\%. En el estudio de Van den Berg(13), la lesión ASIA A es la más frecuente. Todos los estudios concuerdan en que el tipo de lesión más frecuente es el ASIA A.

\subsubsection{Etiología}

En este estudio las causas más frecuentes de LMT son los accidentes de tráfico con un $30,3 \%$, seguido de los accidentes laborales con un $25,9 \%$ y los accidentes fortuitos con un $20,2 \%$. Los accidentes de tráfico como primera causa es concordante con el estudio 
realizado en Aragón por Van der Berg(13), difiriendo de los estudios de Canarias y Galicia en los que los accidentes se sitúan en un segundo lugar tras las caídas.

En el presente estudio aparece el intento autolítico como causa de la lesión medular en un $11 \%$, siendo esto superior a otros estudios encontrados. En la tesis de Álvarez(15) realizada en Asturias en el 2015 los intentos de suicidio fueron la causa de un 4,6\% de las LMT. Esta diferencia tan marcada puede deberse a que Álvarez(15) analiza un período muy amplio, desde 1932 a 2013, lo que puede conllevar a muchas fluctuaciones en las distintas etiologías de la lesión medular traumática. En el estudio de CastañoMonsalve(110), realizado en un hospital de referencia en lesión medular, el intento de autolisis ocasionó el $2 \%$ de las lesiones medulares. Los motivos pueden deberse a un infrarregistro de los suicidios que se pueden considerar como otras causas: por ejemplo, en el estudio de Torres Alaminos(10), el suicidio se clasifica como una subcategoría de las caídas, suponiendo un $11 \%$ de las mismas. En gran parte de los estudios consultados sobre lesión medular, la población con antecedentes en la salud mental es excluida, lo que también podría explicar este dato. Hay que remarcar que Asturias del 2010 al 2015 presenta la tasa de suicidio estandarizada más alta de todas las comunidades autónomas, tanto en hombres como en mujeres, hasta llegar a considerarse un problema de salud pública(111), lo cual podría suponer una explicación al alto porcentaje de LM producidas por esta causa en la comunidad autónoma estudiada.

En el presente estudio, el $100 \%$ de las personas con lesión medular tras un intento autolítico, presentaban antecedentes en la salud mental. Esto concuerda con el estudio de Castaño-Monsalve(110) en el que el porcentaje fue ligeramente más bajo, del 93\%. El artículo de Rech(20) remarca la importancia de analizar los trastornos psiquiátricos que han podido conducir al traumatismo, especialmente si este se produjo por defenestración, para establecer el tratamiento pertinente. En la revisión sistemática de Kennedy(112) se concluye que el principal riesgo asociado con el suicidio en las LMT es la presencia de trastornos psiquiátricos, proponiendo una evaluación tras la lesión medular para poder establecer el tratamiento pertinente. 


\subsection{Complicaciones secundarias}

Las complicaciones secundarias son frecuentes tras una lesión medular. En la investigación de Stillman(113) después del primer año tras el alta, aparece que el $44 \%$ de los lesionados medulares presentan 3 o menos complicaciones, un $34 \%$ de 3 a 7 complicaciones y un $22 \% 8$ o más complicaciones. La prevalencia de las complicaciones es muy variable debido a la heterogeneidad en los estudios a la hora de recoger los datos. Sin embargo, parece que hay consenso en destacar las complicaciones secundarias como un tema importante a estudiar debido al gran impacto que tienen en la calidad de vida, en las hospitalizaciones, y en la morbimortalidad de este colectivo. Sería necesario profundizar en este conocimiento para poder realizar, tanto la prevención de las mismas, como el tratamiento pertinente.

Haisma(23) destaca que los programas educativos deben centrarse en la prevención y la detección temprana de las complicaciones. A través de estas estrategias, junto con el tratamiento oportuno se podrá reducir su impacto.

\subsection{1. Úlceras por presión}

Las personas con lesión de la médula espinal son un grupo particular en el que las UPP son comunes debido a la sensibilidad alterada, la movilidad reducida y la sedestación o el decúbito prolongado(114). La prevalencia de UPP en el presente estudio es concordante en las dos fases: en la revisión de HCE se registra una prevalencia del $43,4 \%$ y en la fase II, los cuestionarios un $41,4 \%$. Estos valores son concordantes con otros estudios que las sitúan entre el 33\% y el 49\%(115-118), aunque existe una diversidad entre los criterios de inclusión en los distintos estudios (población hospitalizada o no, tiempo de recogida, etc.). La revisión sistemática de Di Prinzio(119) muestra que debido a la heterogeneidad de los estudios no ha sido posible metaanalizar la evidencia. En el metaanálisis de Shiferaw(120), la magnitud global de úlceras por presión fue de 23,3\%.

En nuestro estudio el $26,2 \%$ presentaban úlceras en más de un lugar; esto es concordante con el estudio de Deena Lala(118) en el que el $27 \%$ presentaba más de una úlcera por presión.

Respecto a los factores que se encuentran relacionados: en este estudio aparece una relación estadísticamente significativa entre la presencia de antecedentes mentales y la 
presencia de UPP, esto no ha sido encontrado en ningún otro estudio y merecería ser explorado. Sin embargo, sí hay una coincidencia entre la lesión según el grado de afectación de miembros y la presencia de UPP(121). En la revisión sistemática de Di Prinzio(119) aparecen en varios estudios la relación entre la severidad de la lesión según la clasificación ASIA y la presencia de UPP, sin embargo, esto no aparece en nuestras observaciones.

\subsubsection{Complicaciones urológicas}

Las disfunciones genitourinarias son secuelas frecuentes en la lesión medular (20,122125). En el presente estudio un $68,7 \%$ presenta vejiga neurógena y un 33,7\% ITUs de repetición. La infección del tracto urinario sigue siendo el tipo de infección más frecuente en esta población(126), siendo una de las principales causas de atención médica(127). En el estudio de Locke(128) realizado en Canadá, un 73,5\% de los participantes tuvieron al menos una ITU desde el momento de la lesión. Según Stillman (113), las complicaciones notificadas con mayor frecuencia durante el primer año tras la lesión medular fueron las ITUs.

En el presente estudio, el método más común de vaciamiento vesical es el sondaje vesical intermitente (47\%), seguido del vaciado espontáneo (31,8\%). Esto concuerda con el estudio de Bárbara-Bataller(125) realizado en Canarias en el cual, el 42,4\% utilizan catéter intermitente y un $26,4 \%$ micción voluntaria. Esto se ajusta a las recomendaciones actuales, ya que el cateterismo intermitente es el tratamiento más recomendado para personas con lesiones de la médula espinal $(123,126,129)$.

En lo relativo a la interacción de las complicaciones urológicas con la sexualidad, se encuentra una relación estadísticamente significativa entre la preocupación por el escape de orina durante las relaciones eróticas y la calidad de vida sexual. Un 52,3\% de nuestra población refiere sentirse preocupado por el escape de orina durante las actividades eróticas, existiendo una relación estadísticamente significativa entre esta preocupación y el grado de placer en la relación erótica y en el orgasmo. Esto coincide con la revisión de Teplitsky(130), en la que identifica a la presencia del catéter urinario y la preocupación por la incontinencia urinaria, como barreras que enfrentan los lesionados medulares en el campo de la sexualidad; Elmelund(131) identifica también la 
incontinencia urinaria como un problema físico importante con impacto en la actividad erótica, esta idea es refrendada por Cramp(132) en su estudio sobre incontinencia urinaria y sexualidad.

Esta idea aparece también en los discursos, unida a la identificación de la orina como algo sucio y a la idea de que su aparición durante una relación erótica como algo negativo. En el estudio de Santesmases (51) , la falta de control de esfínteres aparece señalado como algo traumático por los informantes. En las entrevistas realizadas por Fritz(133) en Detroit a mujeres con lesión medular, la falta de control vesical e intestinal aparece identificada como problemática unida al riesgo de escapes con la penetración o el orgasmo.

Aparece en los discursos la dificultad del manejo y la convivencia durante las relaciones eróticas con los productos de apoyo utilizados para el control de esfínteres. Esta idea también aparece en el estudio de Santesmases(51), que observa esta difícil relación sobre todo en las mujeres.

Como apunte, destacamos que en la revisión de Barboglio(129), los pacientes con catéteres suprapúbicos tienen mejor imagen corporal y mejor función sexual. Esto no se ha visto reflejado en este estudio, ya que tan solo dos pacientes presentaban una eliminación vesical mediante este dispositivo.

\subsubsection{Complicaciones gastrointestinales}

En la revisión de HCE del presente estudio, se obtiene que el 60,2\% tiene intestino neurógeno, un 8,4\% estreñimiento, un 1,2\% incontinencia fecal y un 1,2\% incontinencia a gases. En la revisión de Vallès(134) entre un 27-46\% presentan estreñimiento, entre el 31-41\% incontinencia fecal, el 31\% patología anorrectal y el 18\% disreflexia autónomica relacionada con la evacuación. Las diferencias pueden deberse a la forma de clasificar las complicaciones gastrointestinales y a que la recogida de datos en este estudio ha sido mediante la revisión de HCE.

La presencia de alteraciones gastrointestinales tiene una relación estadísticamente significativa con el tipo de lesión según afectación de miembros y según extensión. Esto concuerda con la opinión de Vallès(134), que explica que la fisiopatología de la 
incontinencia fecal y el estreñimiento, se correlaciona con las características neurológicas de la lesión en cuanto al nivel neurológico y la gravedad.

El $43,5 \%$ refiere sentirse preocupado por el escape de heces durante las actividades eróticas. Sin embargo, en el estudio de Anderson(135), un 79,4\% no les preocupaba la incontinencia fecal durante el acto sexual. Esta diferencia podría atribuirse a que el estudio de Anderson(135) está realizado en hombres. Sin embargo, en nuestro estudio no aparecen diferencias estadísticamente significativas por sexos en esta preocupación. Siguiendo esta línea, en este estudio aparece una relación entre la preocupación por el escape de heces y el grado de placer sentido durante el orgasmo.

En los discursos aparece preocupación por la incontinencia fecal, aunque se identifica como más fácil de controlar que la incontinencia urinaria. Según Rech(20), solo un 15\% de los pacientes tienen incontinencia fecal habitual, sin embargo, el miedo a que se produzca un episodio, que refiere que está presente en un $75 \%$ de los pacientes, es identificado como una fuente de estrés psicológico y puede dar lugar a una restricción de las actividades sociales. En el estudio de Kreuter(136) enfocado en mujeres uno de los cambios encontrados en la sexualidad tras la lesión medular, es el manejo de las complicaciones intestinales.

\subsubsection{Dolor}

En la fase I de este estudio, se encuentra reflejada la presencia de dolor neuropático en el $30,1 \%$ de las HCE, dolor mecánico en un $19,3 \%$ y ambas afecciones en el $13,3 \%$. En la fase II del estudio, un 52,3\% declara tener dolor crónico.

En la revisión sistemática y metaanálisis de Burke(137), la prevalencia de dolor neuropático en personas con LMT fue del $47 \%$. Este porcentaje es concordante con nuestro estudio, ya que el dolor neuropático fue presentado por el $43,3 \%$.

En la revisión sistemática de Van Gorp(138), la tasa de prevalencia global de dolor tras la lesión medular fue del $61 \%$, similar al dolor reflejado en las HCE y superior al autodeclarado en nuestro estudio, aunque el autor reconoce una gran heterogeneidad entre estudios. 
Según el estudio de Haisma(23), las personas con tetraplejia y con lesión incompleta presentan más dolor musculoesquelético. En el estudio de Burke(137), el dolor neuropático es más común en pacientes con tetraplejia, tras un año después de la lesión y en pacientes mayores. Estas asociaciones no aparecen en este estudio.

En este estudio, las personas con dolor crónico puntuaban más bajo en calidad de vida, tanto social como general. En la revisión de Estores(139), el dolor era una de las preocupaciones importantes para la población con LMT.

Respecto a su influencia en la sexualidad, no ha aparecido influencia en ninguna de las variables estudiadas. Esto concuerda con el estudio de Otero-Villaverde(52) en el que el dolor no afectaba a la actividad sexual y con el de Biering-Sorensen(140) en el que no afectaba a la satisfacción con la misma.

\subsubsection{Espasticidad muscular}

En la fase I del estudio, un 46,4\% de las historias clínicas había registro sobre la presencia de espasticidad muscular. En la fase II del estudio, este número autodeclarado asciende al $67,4 \%$. Es probable que haya un infrarregistro en las HCE. En este estudio las personas con una lesión completa, con una paraplejia y con una lesión dorsal, son las que más espasticidad presentan. Sin embargo, en el estudio de Haisma(23), son las personas con una tetraplejia y una lesión incompleta las que presentan más frecuentemente espasticidad muscular.

No se encuentra relación entre la espasticidad muscular y las variables relacionadas con la sexualidad. Esto concuerda con el estudio de Otero-Villaverde(52) y con el de BieringSorensen(140), en el que tampoco se encontraba afectación de la actividad sexual.

\subsubsection{Disreflexia autonómica}

En la fase I del estudio, había registro en un 3,6\% de las historias de haber sufrido alguna crisis de disreflexia autonómica. En la fase II, un 9,4\% decían haber sufrido una crisis grave de disreflexia autonómica durante las relaciones eróticas. Esta diferencia puede deberse a un infrarregistro en las HCE o a una inadecuada valoración en las consultas de seguimiento. 
En el estudio de Lee(141) en pacientes con lesión medular superior a T6, la tasa de incidencia fue de $92,8 \%$ y la tasa de disreflexia asintomática fue de $42,9 \%$. En el estudio de Andersen(135) un $28,6 \%$ de los hombres son LM tuvieron síntomas de disreflexia autonómica durante la actividad erótica y en un 6,1\% interfirió con ella. Aunque en nuestro estudio se preguntaba por la disreflexia autonómica grave, que interfiriese con las relaciones eróticas, la diferencia de porcentajes respecto a otros estudios es elevada. Esto puede ser debido a la no identificación de las manifestaciones corporales como síntomas de disreflexia autonómica.

Aunque a priori, no es un porcentaje que pueda parecer alarmante, sí que es necesario dar una buena educación sexual para prevenirla, identificarla de forma rápida y explicar qué medidas son necesarias para su tratamiento. Los episodios graves de disreflexia autonómica pueden tener como consecuencia accidentes cerebrovasculares hemorrágicos(142) lo que refuerza la necesidad de educación.

En los discursos, se reconoce la presencia de espasmos en el momento en que se produce la eyaculación real o se produciría una eyaculación hipotética y se identifica la posible disreflexia autonómica si se continúa en este momento con la estimulación erótica.

\subsection{Registro sobre sexualidad en las HCE}

No se ha encontrado constancia de otros estudios que valoren el registro sobre la sexualidad en personas con LMT en las HCE y sus factores relacionados. Es por ello que no se ha podido comparar la correspondencia de este registro con otros estudios.

El registro sobre la sexualidad en las HCE es pobre, tanto en cantidad como en calidad: en la mitad de las HCE no aparece ningún dato sobre la sexualidad en pacientes que han tenido un proceso de rehabilitación hospitalario, revisiones anuales sobre su lesión medular y seguimiento desde atención primaria.

Respecto a los temas registrados, se observa un abordaje desde lo somático y lo patológico, en vez de un abordaje desde la promoción de la salud y el cultivo de la sexualidad de forma holística o con un enfoque amplio o una perspectiva sexológica. El tema que se aborda en hombres es sobre todo la erección con sus consecuentes tratamientos farmacológicos para la disfunción eréctil, y en las mujeres las patologías 
ginecológicas. Esto concuerda con la bibliografía sobre el tema: dice Oliver(143) que cuando se habla de sexualidad en personas con lesión medular es frecuente que se asuma una concepción eminentemente rehabilitadora-biologicista, una visión androcéntrica que se enfoca en los varones y en la búsqueda de la erección. Esto es refrendado por Federici (144) que afirma que "las personas con lesión de la médula espinal tienen que luchar contra sus propias actitudes y estereotipos sociales que limitan la sexualidad a las funciones fisiológicas de los genitales, a la primacía falocéntrica del placer sexual y al atractivo de los cuerpos perfectos".

\subsection{Calidad de vida}

Con referencia a la calidad de vida, se obtuvo una calidad de vida sexual con una media de 6,74 ( $D E=3,17)$, una calidad de vida económica con una media de 8,11 (DE=2,81), una calidad de vida social con una media de 18,42 (DE=3.99) y una calidad de vida global con una media de 33,27 ( $D E=7,97)$. Esto es concordante con los datos obtenidos por CoboCuenca(53) en una muestra de varones con lesión medular en Toledo, obteniendo en el estudio una calidad de vida sexual con una media de 7,62 (DE=2,7), una calidad de vida económica de 7,71 (DE=2,6), una calidad de vida social con una media de 20,16 (DE=2,7) y una calidad de vida total de 34,27 ( $D E=2,8)$. Aunque el estudio de Cobo-Cuenca(53) sea solo de hombres, en este estudio no aparece relación estadísticamente significativa con el sexo. En la tesis de López García-Moreno(145) sobre la lesión medular como factor de riesgo de disfunción sexual en el varón, la calidad de vida sexual tiene una media también concordante, de 7,67 ( $D E=2,67)$.

En el estudio de Cobo-Cuenca(53), no existe relación significativa entre la calidad de vida y la etiología de la lesión, el grado y el tiempo de la lesión. En este estudio tampoco se encuentran estas relaciones.

Las personas con pareja puntúan más alto en la calidad de vida social, sexual y total. Estos datos concuerdan con los datos del estudio de Cobo-Cuenca(53) en los que el grupo que tiene pareja sexual puntúa significativamente más en calidad de vida global.

Las personas con lesiones altas (tetraplejias completas o incompletas) puntúan más alto en calidad de vida social, sexual y total, sin embargo, no se encuentran diferencias entre lesiones completas e incompletas. Este dato muestra que no por tener una lesión alta la 
vivencia de la sexualidad va a ser peor, sino que existen otras variables que influyen en la vivencia de la misma, como la existencia de pareja.

\subsection{Sexualidad}

Al igual que en el estudio de Bahner(146), los participantes entrevistados expresaron su agradecimiento por participar en un estudio sobre sexualidad, ya que en pocos casos se les había preguntado sobre este tema.

La sexualidad es una esfera primordial para las personas que han tenido una lesión medular. En este estudio, el $87,3 \%$ considera que es importante la vida erótica en las relaciones de pareja. Estores(139) realizó una revisión en la que concluía que la función sexual era una preocupación importante para la población con lesión medular. En el estudio de Biering-Sørensen(140) la mejora de la sexualidad es la principal prioridad para los pacientes parapléjicos. En el caso de los pacientes con tetraplejia, es la segunda prioridad, solo superada por la recuperación de la función de sus brazos(147). En la revisión sistemática de Simpson(148), la función sexual se identifica como una de las prioridades de recuperación funcional, junto con la función motora y el control vesical e intestinal. La alteración de la función sexual se considera una de las pérdidas más sentidas por los lesionados medulares y también por sus parejas(149).

Uno de los temas clásicos al abordar la sexualidad en esta población, es definir cuándo comienza la preocupación por esta esfera tras una LMT. En los discursos de este estudio, aparecen preguntas sobre la sexualidad en momentos muy tempranos tras la lesión, en algunos informantes, incluso en la $\mathrm{UCl}$. Esto concuerda con varios estudios: en el estudio sobre sexualidad e incontinencia urinaria en mujeres de $\operatorname{Cramp}(132)$, el sexo fue uno de los primeros temas sobre los que la mayoría de mujeres del estudio preguntaron tras su lesión. Centeno(49) expone que: "desde los primeros días en la UCl y a lo largo de los trece meses de hospitalización, siempre hubo pensamientos sexuales".

Otros estudios sin embargo, recogen que inmediatamente después de una LMT, la mayoría de los pacientes se concentran en la mejora física y es cuando logran aceptar su lesión, cuando comienzan a ocuparse de su sexualidad(22). En el estudio de Kathnelson(150) la mayoría deseaba recibir información sobre la sexualidad justo después de la lesión, sin embargo, otros preferían esperar al menos un año por tener 
primeramente otras prioridades o no sentirse como personas sexuales en un primer momento.

Hay que remarcar que con frecuencia la sexualidad no suele ser abordada en los primeros momentos tras la lesión, hasta que no ha pasado a veces un año, debido a la idea de que en esos momentos las personas con lesión medular están a "otras cosas más prioritarias". También es frecuente su exclusión de los estudios sobre sexualidad durante los primeros seis meses o el primer año tras la lesión(55,151). Reflexiona Centeno(49), que: "La sexualidad no debería ser la guinda de un proceso de rehabilitación, algo que siempre aguarda esperando a que se resuelvan los temas realmente importantes o prioritarios. Como tal, debería ser central y no secundaria en la valoración y evaluación de los apoyos sociales para las personas con diversidad funcional".

\subsubsection{Instrumentos de medida de la sexualidad}

Aparecen en la bibliografía algunas revisiones que exploran la existencia de instrumentos de medida para valorar la sexualidad en población con lesión medular. Las conclusiones son similares en todas ellas: los instrumentos de evaluación son escasos, la mayoría de los cuestionarios son antiguos y habría que valorar si se ajustan a los cambios sociales que se han podido producir en el tema de la sexualidad y la gran parte no se encuentran validados para población con lesión medular(102,104,152). Además, los instrumentos se centran en medir sobre todo aspectos sobre la relación coital y sobre las fases de la respuesta sexual humana. Sin embargo, se olvidan de valorar otros como: deseabilidad, deseo cumplido o no de procreación, imagen corporal, etc.

\subsubsection{Deseabilidad e imagen corporal}

En este estudio, un $68,5 \%$ de las personas con LMT considera que su capacidad de seducción ha disminuido en distinto grado. Las personas sin pareja en el momento actual sienten que su capacidad de seducción es menor que aquellas con pareja. En el estudio de Migaou(55), la percepción de la seducción era uno de los aspectos más afectados en la sexualidad. 
En los discursos aparecen ideas como la elevación de la silla de ruedas a algo simbólico que se visualiza antes que la persona, imbricado a la idea de que, si no existe una sociedad inclusiva, las personas con lesión medular no se ven como iguales y, por tanto, deseables. Según Centeno(34), "la indeseabilidad no es exclusiva ni preponderante en ningún grupo humano, pero sí puede llegar a ser una profecía autocumplida si enseñamos que algunos deseos son inapropiados". Romañach(28) habla de la división de las personas con cualquier tipo de diversidad funcional en "héroes", personas que se sobreponen a todo y se ven como iguales, y por tanto, deseables; y "parias", el resto de personas con diversidad funcional, que se encuentran excluidos socialmente y por tanto son "indeseables".

En este estudio, la imagen corporal se encuentra deteriorada a raíz de la LMT: un $89,8 \%$ se encontraba satisfecho o muy satisfecho con ella antes de la lesión, lo que disminuyó a un 53,4\% tras ella. Según Sinha(67) los cambios en la apariencia física después de una lesión medular pueden afectar la autoestima sexual. Según Hess(153) el cambio y la anticipación de la pérdida pueden amenazar seriamente la autoestima y el sentido del valor de una persona como ser sexual.

En los discursos aparece la vivencia del cuerpo tras la LMT como un "otro" al que hay que conocer y posteriormente, reconocer y aceptar. Esta idea aparece explicada en el estudio de van Diemen(154) denominando a ese proceso como "separación o alienación del cuerpo-yo".

En esta línea, la pérdida de intimidad asociada a la situación, puede favorecer la idea "separación del yo". Allué(155) describe la "okupación" del cuerpo por parte de los objetos y las manos de las personas que le rodean. Según Santesmases(51), las personas con lesión medular, durante el periodo de hospitalización tienen a distanciarse de su cuerpo, concibiéndolo como algo ajeno a su mente, en un intento cartesiano de aislarse de la experiencia corporal. En el estudio de un caso de Bailey(156) la informante expresa que: "durante los cuidados intensivos, su cuerpo fue tratado como un objeto, el tratamiento desconectado de su cuerpo, condujo a la pérdida de su yo privado".

Sería interesante estudiar los factores que ayudan a que este proceso se haga correctamente y el cómo podemos acompañar de forma eficiente en éste los profesionales sanitarios. Bailey(156) concluye que es importante considerar las 
experiencias corporales en transición tras una lesión medular para ayudar a prevenir impactos posteriores en la salud.

En el estudio de Santesmases(51), aparece una diferencia de género entre esta importancia sobre la imagen corporal, no teniendo tanto valor en la identidad masculina. En nuestro estudio, la imagen corporal sí que tiene una mayor asociación en las mujeres a la pérdida identitaria, asociándola a ser "menos mujer", sin embargo, tener una adecuada imagen corporal se identifica como un valor importante, tanto en hombres como en mujeres.

En los discursos es identificado el ejercicio físico como una actividad en la que se mejora la imagen corporal, haciendo que uno se perciba como más deseable. En el estudio de revisión de Lim(142), se concluye que el ejercicio físico a largo plazo es una solución para mejorar directa o indirectamente la función sexual en hombres con LME.

\subsubsection{Cambios en la respuesta sexual humana}

\subsubsection{1. $\quad \underline{\text { Deseo }}$}

El deseo sexual actual comparado con la situación previa a la lesión: en el $41,4 \%$ no se produce cambio, en el $12,6 \%$ está aumentado, en el $32,2 \%$ disminuido y en el $13,8 \%$ es inexistente. En el estudio realizado por Guerrero(151) en 20 hombres con LMT, no hubo afectación del deseo en ninguno de ellos. En el estudio de Migaou(55) el deseo sexual fue el ítem más conservado. En el estudio de Sarah(157) no se encuentran diferencias entre el deseo sexual entre el grupo de personas con LMT y el grupo sin LMT. En el estudio de Cobo-Cuenca(158) que compara hombres con disfunciones sexuales, unos con LMT y otros sin ella, el grupo sin lesión medular tiene más alteraciones del deseo que el grupo con lesión medular. En otro estudio de Cobo-Cuenca(53), el 97,8\% de los participantes del estudio tienen interés por mantener relaciones sexuales.

Un 72,4\% obtiene disfrute al pensar y fantasear con el sexo, lo que hace pensar también en ese mantenimiento del deseo.

Esto concuerda también con los discursos de los informantes, en los que se percibe el deseo conservado, incluso aumentado en ocasiones. 


\subsubsection{Excitación}

En este estudio, los informantes identifican que para lograr la excitación es importante centrarse en las sensaciones, sentimientos y apagar el juicio sobre lo que se debería sentir o no sentir. En el estudio de Hess(153) se muestra que incluso cuando no hay manifestaciones físicas de excitación, las personas con LMT describen la excitación subjetiva como similar a la de las personas sin LM.

Tras la lesión medular se identifica un proceso de reaprendizaje erótico en el que la exploración y el descubrimiento de zonas erógenas, y la erotización de productos de apoyo se identifican como recursos útiles. La maximización de la percepción de las zonas con sensibilidad y la concentración a través de la atención plena y la fantasía son recursos ya identificados en el estudio de Krassioukov(54), en el que resume que "las personas con lesión medular deben estar dispuestas a embarcarse en el viaje del descubrimiento sexual".

\subsection{Erección}

En este estudio, el 85,2\% de los hombres presenta disfunción eréctil de algún grado. Este dato es casi exacto al del estudio de Cobo-Cuenca(53), en el que el $86 \%$ refiere tener disfunción eréctil. Cabe destacar, sin embargo, que su muestra fue obtenida de la consulta de urología a los hombres que acudía por disfunción sexual del Hospital de Toledo.

En nuestro estudio la media sobre el sumatorio de IEEF-5 es de 9,59 con una DE de 8,15, teniendo una mediana de 8. El abanico es amplio en los diferentes estudios: en la tesis de López García-Moreno (145), sobre lesión medular como factor de riesgo de disfunción sexual en el varón, el valor medio del IIEF fue de 13,89 (DE=7,26), en el estudio de Gomes(159) la puntuación media es de 5, aunque incluye a hombres activos sexualmente e inactivos, en el estudio de Miranda, la puntuación media también es de 5(160), en el estudio realizado con población tunecina de Migaou(55), el valor medio del IIEF era de 12,76 (DE=6,01). La explicación a unas puntuaciones tan dispares puede ser debida a que las muestras utilizadas eran muy heterogéneas, en el estudio de López la muestra fue obtenida de una población con algún tipo de disfunción sexual, Enel estudio de Gomes fue en un centro de rehabilitación de Brasil, mientras que el estudio de 
Migaou fue con población tunecina, por lo que no son muestras comparables.

Si dividimos la DE según su gravedad, un 39,3\% de los hombres tenían una DE moderada o grave. En el estudio de Migaou(55) este valor era más elevado, del 53,4\%.

En nuestra población un 14,8\% no tenía DE, en el estudio de Migaou(55) un 23,07\%. En el estudio de Gomes un $24,1 \%$ tenía una DE leve o no tenía DE. En este estudio los hombres con preservación de la sensibilidad genital y anal tienen menos DE, también los que conservan control volitivo intestinal. Esta asociación no se ha encontrado en otros estudios.

Los informantes identifican la capacidad de tener erecciones como una tranquilidad. Sin embargo, esta frecuentemente tiene distinta dureza, duración, precisa de mayor tiempo de excitación para producirse, no se produce siempre que se desea o a veces se pierde. Este suceso es también identificado por Chochina(60), concluyendo que la mayoría de los hombres con lesión medular pueden tener algún tipo de erección, a menudo no es lo suficientemente predecible, rígida o duradera para coitos satisfactorios.

La erección se revela como algo importante para los hombres con lesión medular, asociado a la masculinidad. La no existencia de erección, es vivida con frustración y es extensible en ocasiones a la pareja. Como idea subyacente aparece la erótica entendida como coito, que pasa inexcusablemente por el pene y la erección del mismo(49,51). En la revisión de Hess(153) se destaca que la capacidad de lograr erecciones no es paralela a la habilidad de un hombre de excitarse sexualmente, y no se debe medir el "potencial sexual" de un hombre exclusivamente por la capacidad de obtener y mantener la erección.

\subsection{Apoyos farmacológicos para la erección}

Sobre el uso de ayudas para conseguir o mantener la erección, un 42,6\% utiliza fármacos orales, un 6,6\% fármacos inyectados en el pene y un 1,6\% tiene una prótesis peneana. Los datos son bastante concordantes con los del estudio de Gomes(159), en el que un 37,2\% usaban PED-5, un 3,3\% inyecciones intracavernosas y un 1\% recurrió a la cirugía peneana. Sin embargo, en el estudio de Migaou(55), solo un $23 \%$ utilizaban fármacos orales, inhibidores de la 5-fosfodiesterasa, aunque los propios autores identificaron este número como bajo, debido a las diferencias culturales ya que el estudio está realizado en Túnez. 
En la revisión sistemática y metaanálisis de Jia(161) concluye que los inhibidores de la 5fosfodiesterasa son eficaces y bien tolerados para tratar la DE secundaria a la lesión medular en comparación con el placebo, no habiendo comparado las diferencias entre los distintos fármacos. En la revisión realizada por Ohl (162) con estudios de Europa, Australia y Turquía, todos los estudios del IIEF fueron significativos estadísticamente con sildenafilo frente a placebo. En el estudio realizado por Moemen(163) sobre diferentes tratamientos para la DE en pacientes con lesión medular, el $90 \%$ de los pacientes informó de mejora en la erección después del tratamiento con sildenafil.

En el metaanálisis de García-Perdomo(164), la mejoría con PED-5 fue grande respecto al placebo. En la revisión sistemática de De Forge (165) las erecciones fueron exitosas en el $79 \%$ con sildenafilo.

En el estudio de Sánchez-Ramos (149) no se detectaron diferencias entre el tipo de iFDE5 usado (sildenafilo, vardenafilo y tadalafilo) respecto a las puntuaciones de calidad de vida sexual.

Los efectos adversos más frecuentes del sildenafilo encontrados en la literatura fueron dolor de cabeza, rubor, dispepsia, congestión nasal, hipotensión, ITU y malestar gastrointestinal (161-164), la mayoría de ellos de leves a moderados y transitorios(161). En los discursos de este estudio aparece la visión azulada como un efecto secundario molesto. También la necesidad de previsión del encuentro erótico para tomar la medicación de forma previa se percibe como una dificultad, sobre todo cuando no se tiene pareja estable. La necesidad de planificación para la actividad erótica como dificultad, se encuentra también recogida en la revisión de Lim(142).

Sobre los fármacos inyectados en el pene, los hombres o sus parejas deben aprender cómo inyectarse en el pene la medicación(60). Esta recomendación choca con lo surgido en los discursos sobre la percepción de desconocimiento de los profesionales, a pesar de ser fármacos que surgieron de forma previa a los orales. El primer inhibidor oral de PDE5, el sildenafil, se lanzó en 1998, mientras que los primeros informes sobre el efecto proeréctil de la administración intracavernosa de fármacos fue en 1982(60,161).

Los fármacos inyectados en el pene, se perciben como más eficaces en el logro de la erección, aunque la erección se vivencia como algo menos natural y más mecánica, exclusivamente derivado de la acción del fármaco. Esto es coincidente con la literatura, 
en la que está descrito que la erección suele ocurrir en unos pocos minutos, independientemente de la estimulación sexual $(60,163,165)$. Esto difiere de las erecciones facilitadas por PDE5i en las que la estimulación sexual es obligatoria(60).

Los efectos secundarios más frecuentes encontrados en la literatura con estos fármacos son hematomas, hinchazón y erección prolongada $(66,163)$. La erección prolongada llegando incluso al priapismo ha salido en las entrevistas, aunque asociada a una falta de aprendizaje y a un desconocimiento de la dosis necesaria.

El último recurso en el tratamiento de la disfunción eréctil en esta población es la prótesis de pene implantada quirúgicamente(66). En nuestro estudio tan solo 1 paciente tenía una prótesis de pene.

\subsection{Lubricación}

En este estudio un $19 \%$ de las mujeres no tienen la lubricación deseada nunca o rara vez. En la revisión de Forsythe(166) este porcentaje de lubricación inadecuada era del 23,3\%, en el estudio de Anderson(167), era más elevado, del 27,6\%. Sin embargo en el estudio de Biering-Sorensen(140) solo un 6\% tenía la lubricación alterada.

En este estudio un 19\% usa hidratantes o lubricantes vaginales, lo que corresponde con las mujeres que no obtienen la lubricación deseada. En nuestro estudio no se encuentran variables asociadas, pero se quiere destacar la importancia de la educación sexual en el uso de estos productos, sobre todo, en personas sin sensibilidad genital, que no notan la presencia de lubricación, pudiéndose producir lesiones vaginales con el coito.

Cabe apuntar, que en varios estudios lo que se mide es la lubricación adecuada o inadecuada, pero no hay un estándar para valorar esto, por lo que sería más adecuado medirlo sobre la autopercepción de si la lubricación es satisfactoria.

\subsection{Placer}

En el presente estudio un $56,7 \%$ obtiene mucho o muchísimo placer durante las relaciones eróticas y un $57,7 \%$ con el orgasmo, una cifra casi similar. Sin embargo, el número de personas que sienten poco placer o ninguno, es superior durante el orgasmo 
con un $19,2 \%$, frente al $13,2 \%$ durante la relación erótica. Esto puede ser debido a que un parte de las personas con LMT no tienen orgasmos.

Tienen más placer (tanto en la relación erótica como en el orgasmo) los lesionados medulares con sensibilidad en el área genital y los que no están preocupados por el escape de orina y en el caso de las relaciones eróticas, también de heces. Estas asociaciones no se han encontrado en otros estudios.

Por otro lado, en la mayoría de estudios se suele estudiar el disfrute de la relación erótica a través del orgasmo. Sin embargo, se muestra que hay personas con LMT que tienen placer durante la relación erótica y no durante el orgasmo. El orgasmo no mide el grado de placer sentido durante una relación erótica y es por ello, que debería estudiarse de forma diferenciada en los estudios. También es frecuente el estudio separado durante el coito y durante los preliminares, como si se tratasen de dos relaciones eróticas distintas en lugar de distintas prácticas posibles en una relación erótica.

En los discursos aparece la diferencia entre el sentir (entendido como sentimiento antes algo) y el "sensar" (entendido como sensación). El placer se identifica como un producto de ambos. Esta diferencia existente en el latín entre "sensare" y "sentire", es explicada por el sexólogo Landajarroitajáuregi(48) e identificada como útil para trabajar la educación sexual en esta población. Esta idea se muestra en el estudio de Soler(168), en el que un $42 \%$ de los hombres describieron un placer intenso durante las caricias en todo el cuerpo, incluso en las zonas del cuerpo donde no tenían sensibilidad.

En los temas que les gustaría que fuesen abordados por los profesionales tras la LMT, un 7\% quieren información sobre el placer y el orgasmo. A pesar de que la OMS(42) recoge que los enfoques teóricos sobre la sexualidad incluyen el placer y que el placer se reconoce como uno de los fines de las relaciones eróticas $(151,169)$, la educación sexual en general, y la de las personas con diversidad funcional en particular, no suele tener un abordaje positivo ni un enfoque desde el placer(46). Esto también es confirmado por los informantes de este estudio.

\subsubsection{Orgasmo}

En este estudio, el 42,9\% no tiene nunca orgasmo, el 11,9\% rara vez, el 16,7\% a veces, el 14,3\% a menudo y el 14,3\% siempre. Esto concuerda con la revisión de Alexander(170) 
en el que un 50\% de la población con LME tiene orgasmos. En el estudio de Soler(168), un $42 \%$ informó de orgasmo. Sin embargo, en el estudio de Cobo-Cuenca(53), el 71\% refiere no tener orgasmo ni eyaculación.

El grado de placer sentido en el orgasmo tiene una relación estadísticamente significativa con el nivel neurológico; solo un $7,1 \%$ de las personas con una lesión lumbosacra sienten mucho o muchísimo placer durante el orgasmo. Esto concuerda con la fisiología del orgasmo en la que el arco sacro actúa como elemento importante para su producción.

Por otro lado, de los lesionados medulares que sienten mucho o muchísimo placer durante el orgasmo, un $20 \%$ no tiene sensibilidad genital, esto pone de relieve que puede existir orgasmo sin sensación genital. Es necesario trabajar en esta población con modelos eróticos más amplios y menos genitalizados.

En los discursos aparece que en ocasiones los orgasmos se perciben como distintos a los previos a la lesión. Esto también es identificado por Courtoise(70) que indica que a veces los pacientes no informan el orgasmo cuando describen sensaciones semejantes al orgasmo porque difieren de su percepción pre-traumática. Algunos de ellos asocian este momento a la presencia de espasmos corporales. Esto se refleja también en el estudio de Migaou(55), en el que se identifican sensaciones de espasmos, calambres o temblores en las extremidades inferiores en el momento del orgasmo.

El orgasmo puede ocurrir en hombres que no son capaces de eyacular(153). En el presente estudio, un $6,4 \%$ de los hombres tienen orgasmos, pero no eyaculan. Según Alexander(170) es frecuente que en algunos estudios se equipare el orgasmo a la eyaculación, siendo esto un error.

Krassioukov(54) explica que el potencial orgásmico puede mejorar con diversas intervenciones: a través del mapeo corporal, practicando la atención plena con estimulación sexual y con la utilización de la relajación, la fantasía, el recuerdo de experiencias sexuales positivas y la respiración. Según Courtoise(70), debe fomentarse la rehabilitación sexual enfatizando la autoexploración y el reencuadre cognitivo para maximizar la percepción de las sensaciones eróticas y el clímax. En los discursos de este estudio el aumentar la comunicación en pareja, "apagar el cerebro", explorar el nuevo cuerpo sin juicio sobre lo que se debe y no debe sentir, la utilización de productos de 
apoyo, la erotización de lo cotidiano y uso de juguetes eróticos, el redescubrimiento de zonas erógenas y dar placer, se identifican como recursos para mejorar la vivencia erótica en general, no solo asociadas al momento del orgasmo.

\subsection{Eyaculación}

En este estudio el $25,8 \%$ de los hombres eyaculan a menudo o siempre. En el estudio de Courtois(70), el 30\% de los hombres lograron eyacular con estimulación natural. En el estudio de Migaou(55) en Túnez esta cifra es más elevada, del 46,15\%.Lograron alcanzar la eyaculación con ayudas un $91 \%$, un $49 \%$ con estimulación vibratoria del pene, un 12\% añadiendo además midodrina. En este estudio un 11,9\% $(n=8)$ utiliza vibradores peneanos para facilitar la eyaculación.

La posibilidad de eyacular se vislumbra como importante por varios motivos: por el placer que puede conllevar, por la posibilidad de procreación por medios propios y por el simbolismo asociado. Según Courtoise(70), la mayoría intentan la eyaculación con fines sexuales más que reproductivos.

En este estudio el 9,4\% de los pacientes ha presentado alguna crisis de disreflexia autonómica que necesitase asistencia médica durante las relaciones eróticas. La eyaculación es un disparador conocido para esta reacción, pero las erecciones y la estimulación sexual también pueden precipitarla(153). El clímax de la eyaculación parece estar relacionada con la disreflexia autónoma, se informan pocas sensaciones cuando no se alcanza disreflexia autonómica, se informan sensaciones climáticas placenteras cuando se alcanza de leve a moderada y se informan sensaciones desagradables o dolorosas cuando es grave(70).

Se puede alentar a identificar las sensaciones asociadas con la eyaculación como medio para obtener placer sexual(70). En las entrevistas, los hombres identifican espasmos que surgen en momentos de alta excitación, ya sea con el orgasmo o en el momento en el que sucedería el orgasmo y la eyaculación. Identifican que si en el momento de aparición de los espasmos, se continúa con la excitación es cuando puede ocurrir una crisis de disreflexia autonómica. 


\subsection{Productos de apoyo}

En este estudio alrededor del $80 \%$ de lesionados medulares utilizan como principal medio de transporte la silla de ruedas(9).

Los productos de apoyo se regulan por la norma internacional "ISO 9999. Productos de apoyo para personas con discapacidad. Clasificación y terminología", la última versión del año 2016, está en la actualidad en revisión. Según esta norma, dentro de los productos de apoyo para el cuidado y la protección personal, se encuentran los productos de apoyo para las actividades sexuales. Estos se dividen en: maniquíes para actividades sexuales, productos de apoyo para la erección, vibradores y dispositivos de masaje para actividades sexuales y productos de apoyo para la educación y la reeducación sexual(171). La mayoría de estos productos tienen como fin la ayuda con distintas posturas (camas, sillas, hamacas adaptadas, etc.) o la búsqueda de la ereccióneyaculación o de la dilatación vaginal. Prácticamente la totalidad se centran en dispositivos para su utilización sobre los genitales.

En este estudio, en un $87,3 \%$ de las HCE aparece reflejado el uso de distintos productos de apoyo, sin embargo, en ninguna de ellas aparece ninguno relacionado con la sexualidad. En los discursos aparecen ideas sobre su utilidad centradas en la exploración de sensaciones, como ayuda a la estimulación y como apoyo para la reeducación erótica. También aparece como idea la erotización de otro tipo de productos de apoyo, como por ejemplo la silla de ruedas. La erotización de productos de apoyo se ha trabajado desde el asociacionismo y el activismo, mostrándose en el documental realizado por Centeno, "Yes, we fuck"(172).

Una gran proporción de hombres con lesión medular están en edad fértil(69). Los vibradores peneanos se han mostrado eficaces como apoyo para lograr la eyaculación. Es por ello que la asistencia médica no es imprescindible, sino que pueden autoeyacular en sus domicilios con fines eróticos o incluso reproductivos(70). En la "Guía y Directorio de recursos para la facultad masculina después de una lesión/disfunción de la Espina Dorsal"(173) de la facultad de medicina de la Universidad de Miami, plantea la opción de la inseminación en casa, con extracción de semen con vibroestimulación y depósito de semen en la vagina con la ayuda de una jeringa(173). En el estudio multicéntrico realizado por Sønksen(174) con 140 parejas, este método consiguió una tasa de 
embarazo del $43 \%$, aunque la mediana de tiempo para conseguirlo fue de 22,8 meses. Este procedimiento no es común en España y suele realizarse en el hospital. En los discursos de este estudio aparece el uso del estimulador peneano con fines eróticos, para usarlo como juguete y conseguir la eyaculación durante la interacción erótica. En ningún caso se ha encontrado referencia en los discursos de su uso con fines reproductivos en el ámbito doméstico. Estos dispositivos no se encuentran financiados por el sistema público de salud en España. Su precio es de 399 euros el Viberect-X $3^{\circledR}$ y de 598 euros el Ferti Care ${ }^{\circledR}$, por lo que, aunque son un producto de apoyo interesante, su precio puede resultar elevado.

Teplitsky(130) reflexiona que hay datos limitados sobre el uso de estos productos, particularmente en pacientes con lesión medular. Se precisa investigación en la creación de nuevos productos de apoyo y de juguetes eróticos adaptados para personas con diversidad funcional en general y con lesión medular en particular que puedan ayudar en la vivencia de su erótica.

\subsection{Pareja}

En este estudio tener pareja es una de las variables más relacionadas con diversos aspectos de la sexualidad tras la LMT: las personas con pareja puntúan más alto en calidad de vida social, sexual y total, por otro lado, tienen mayor placer durante las relaciones eróticas, se perciben con mejor capacidad de seducción, tienen mejor puntaje en el cuestionario SIS y su uso de fármacos para conseguir o mantener la erección es menor.

Los informantes identifican como una dificultad importante el poder explicar las peculiaridades de la lesión medular a la hora de mantener una relación erótica, sobre todo en los primeros encuentros. Según Santesmases(51), esta tensión entre ocultar las dificultades invisibles y la necesidad de desvelarlas aparecen como contrapuestas, temiendo la sorpresa o el desagrado del otro. Sin embargo, en este estudio se identifica la pareja como un lugar de confianza, de exploración y de tiempo de adaptación, en el que establecer relaciones eróticas se percibe de una forma más fácil que las esporádicas. En los discursos se identifica que puede ocurrir un deterioro de la pareja a raíz de la lesión que con frecuencia acaba en ruptura de la misma. Esto es identificado por varios 
autores: según Cavalcante(92), hay una dificultad mayor para parejas ya formadas respecto a aceptar la realidad de la lesión medular. En el estudio de Otero-Villaverde(52) un $37,5 \%$ de las mujeres del estudio tuvieron una ruptura de pareja tras la lesión medular. En el estudio de Guerrero Ferreira(151), un 50\% tuvieron una ruptura en su pareja tras la lesión. En el estudio de Cruz Fernández(91), realizado en la Habana, las separaciones fueron significativas en las mujeres.

Alcedo-Rodríguez(175), que escribe sobre el proceso de adaptación en mujeres con lesión medular, comenta que aquellas mujeres que tienen una pareja sentimental previa a la lesión, se sienten más comprometidas y atadas a sus parejas, llegando a considerarlas como cargas más pesadas que los matrimonios que se forman tras la lesión.

El estudio de Jeyathevan(176) identifica varios temas que pueden influir en la diada cónyuge-lesionado medular como las conductas sobreprotectoras que sobrecargan al cuidador y disminuyen la autonomía de la persona con LM, la pérdida de sexo e intimidad debida a la planificación y a la invasión del cuidado en todos los aspectos de la pareja. Este estudio recalca que es necesario el asesoramiento antes del alta para ayudar a las personas con LM y a sus cuidadores adaptarse a una nueva vida de la lesión. Los informantes de este estudio identifican situaciones de sobrecarga respecto a los cuidados que precisa la pareja. En España, la falta de asistentes personales, solo circunscritos a unas comunidades autónomas, hace que los cuidados recaigan más aún en la familia.

\subsection{Procreación}

En la parte cualitativa las mujeres no hacen ninguna mención al tema de la menstruación. Esto puede deberse a que no sea considerado como parte de su sexualidad.

En el presente estudio, un $20 \%$ ha utilizado algún tipo de ayuda para tener hijos, sin embargo, un $37,7 \%$ no ha satisfecho su deseo de procreación y un $5,2 \%$ lo ha satisfecho parcialmente. Un $48,7 \%$ no tiene hijos. La media de edad en la que se produjo la lesión medular es de 30,8 años, por lo que los pacientes se encuentran en un punto álgido de su edad reproductiva, por lo que es imprescindible valorar su deseo procreativo. La revisión de Chéhensse (62) reflexiona que muchos hombres no han cumplido su 
proyecto parental en el momento de la lesión. Tras la lesión, muchos pacientes preguntan sobre su capacidad para procrear, siendo la infertilidad en caso de que exista, una de las secuelas más desalentadoras según Chong(69). En las entrevistas realizadas en este estudio, aparece la idea de frustración en el caso de no poder tener más hijos, tanto de las personas con lesión medular como de sus parejas.

Se identifica una falta de asesoramiento sobre los recursos que existen en el hospital para las ayudas a la procreación.

En las entrevistas en profundidad realizadas a hombres, en ninguna ha aparecido el tema de la procreación. Esto puede ser debido a que ninguno de los participantes tenía hijos, o a que en el hombre no se asocia tener hijos como una idea completamente vinculada a la sexualidad.

En la planificación de la fertilidad, se identifican barreras de acceso, tanto físicas (el acceso a centros de planificación familiar o la desinformación de los profesionales) como actitudinales (que los profesionales consideren que no existe un deseo de tener hijos debido a su situación personal). Estas barreras han sido identificadas por otros autores(177).

\subsection{Fuentes de información sobre sexualidad}

\subsubsection{Internet}

En el presente estudio Internet es la principal fuente de las personas con LMT para obtener información sobre temas relacionados con la sexualidad. Internet se ha convertido en una fuente de información habitual sobre salud. En el informe realizado por el Observatorio Nacional de las Telecomunicaciones y de la Sociedad de la Información(178), en el 2019 un 60\% de individuos buscan en Internet información relacionada con la salud. En el estudio realizado por Bea-Muñoz(179) sobre la legibilidad de los documentos en español dirigidos a lesionados medulares se reflexiona que las necesidades de información sanitaria en personas con lesión medular son elevadas. En el estudio realizado a mujeres sobre sexualidad e incontinencia urinaria en lesión medular realizado por Cramp(132) en Canadá, los participantes utilizaron Internet como recurso, debido a la falta de información aportada por los profesionales. 


\subsubsection{Profesionales sanitarios}

Los profesionales sanitarios se identifican como la segunda fuente de información sobre sexualidad tras una LMT. Sin embargo, en los discursos se percibe a los profesionales sanitarios con poca formación sobre este tema, cayendo en asesoramientos excesivamente idealizados o edulcorados y que no consideran la variabilidad individual de cada persona con lesión medular.

Las ciencias de la salud han vivido a espaldas de la sexualidad humana, no integrándose en la atención sanitaria de los procesos de salud y enfermedad. El enfoque con el que las ciencias de la salud abordan la sexualidad ha sido y aún sigue siendo absolutamente reduccionista, limitándose a su vertiente más biológica-somática y centrado en la problematización de la misma, ya sea por los efectos indeseables de su uso o como fuente de problemas de salud. Por otro lado, la reproducción es una de las manifestaciones sexuales en el ser humano, sin embargo, la atención sanitaria es la que aborda de forma casi exclusiva(180). Reflexiona Hess(153), que la educación sexual suele estar mal integrada en el proceso de rehabilitación, existiendo una gran vacío en abordar la rehabilitación sexual a pesar de la necesidad reconocida de educación y asesoramiento.

En el presente estudio, el $85,1 \%$ de las personas con LMT siente que no ha recibido suficiente información y apoyo por parte del sistema de salud respecto a cómo enfrentar su sexualidad. Esto concuerda con la mayoría de estudios publicados, en los que la atención de esta esfera se muestra como claramente deficiente: en el estudio de New(181) realizado en Australia, solo un $18 \%$ estaba satisfecho o muy satisfecho con la información y la educación sexual recibida tras una LM. En el estudio de Cruz Fernández(91) en pacientes con afecciones neurológicas en un centro de la Habana, un $89,2 \%$ de los pacientes no habían recibido atención de su sexualidad, aunque el 54\% planteaban que esta faceta debía ser atendida. Sin embargo, en el estudio realizado por Guerrero Ferreira(151) realizado en el mismo centro a pacientes con lesión medular, un $55 \%$ de ellos nunca habían tenido atención en este ámbito, pero el $85 \%$ de los pacientes considera la atención como necesaria. Sin embargo, en el estudio de Soler realizado en Francia(168), todos los hombres que participaban en el mismo habían recibido información o asesoramiento sobre la actividad sexual tras la LMT, dentro del propio 
centro de rehabilitación.

Según García Carenas(73), este colectivo demanda y reclama frecuentemente asesoramiento sobre el tema, aunque solo un pequeño porcentaje la recibe. Esto concuerda con este estudio, en el que se identifica como frecuentemente es el propio paciente el que tiene que preguntar sobre el tema, porque si no, el profesional sanitario no lo aborda.

En este estudio tienen más probabilidad de obtener información por parte de los profesionales los hombres, las personas que tienen UPP y los lesionados medulares que no tienen un vaciamiento vesical voluntario. Sin embargo, no tuvo influencia con ninguna variable más. En el estudio de New(181) la variable que influía era la edad, a más años cumplidos, menos probabilidad de información.

Según García Carenas (73), son muchos los profesionales que admiten su desconocimiento sobre el tema de la sexualidad en la lesión medular. Algunos profesionales no consideran el asesoramiento como parte fundamental de su trabajo. A veces estos temas tienden a resultar embarazosos o incómodos para los profesionales, lo que produce que sean obviados en numerosas ocasiones. En ocasiones existe la creencia por parte de los profesionales de que la vida sexual no es un área vital del ser humano a ser recuperada(92). Una de las causas podría ser la falta de formación específica en los currículos, tanto básicos como de especialización(180).

En la guía para profesionales "Sexuality and Reproductive Health in Adults with Spinal Cord Injury: a clinical practice Guideline for health-care professionals"(182) aparece como recomendación la inclusión de preguntas generales sobre sexualidad y función sexual lo antes posible en el proceso de rehabilitación y el brindar acceso a la educación sobre el sexo en entornos formales e informales durante el tratamiento continuo. También la evaluación de la vida sexual tras la lesión se encuentra incluida en la Guía de Buenas Prácticas en la Atención Integral al nuevo lesionado medular(183).

Por otra parte, según Stoffel (65) existe una baja utilización generalizada de la atención de la salud reproductiva y ginecológica para las mujeres con LM. Este déficit es probable que se deba a múltiples factores, como la falta de conocimiento de mujeres con lesión medular y servicios de salud y la presencia de barreras físicas, que reducen el acceso. 
Esto se percibe en las informantes de este estudio, se cree que si se acude a un centro de planificación familiar se va a tener barreras para su acceso y los profesionales no van a saber aportar una información adecuada.

Las enfermeras son los profesionales de la salud que más contacto directo y continuado tienen con estos pacientes, por lo que sería necesario diseñar programas de educación sexual que incluyeran información afectiva y sexual(184). Esto debería ser así, pero ninguno de los informantes del estudio ha identificado a las enfermeras como personas referentes en el abordaje de la sexualidad.

\subsubsection{Grupo de iguales}

Los compañeros, amigos o parejas se identifican como tercera fuente de información. Cabe destacar la figura del tutor o del grupo de iguales que asesora en temas de sexualidad, por la falta de información de los profesionales y a veces se identifica sobre todo en mujeres la falta de referentes. Sobre la figura del tutor o del mentor se ha encontrado bibliografía identificándose como personas que pueden hacer de guías o fuentes de apoyo. Pueden explicar el manejo de los problemas secundarios de una LM y su afrontamiento basada en la experiencia de la adaptación a la vida diaria. El compartir las experiencias personales, los éxitos y fracasos, crea sensación de apoyo(185). En la revisión sistemática y metaanálisis de Divanoglou(186) se destaca como características clave de la tutoría entre pares: un recurso de aprendizaje creíble con un alto grado de afinidad y motivación. El estar con personas en su misma situación es empoderador y el aprendizaje tiene una alta credibilidad debida a la experiencia vital. Sin embargo, se han realizado pocos estudios de evaluación, muy heterogéneos y la mayoría realizados en países no europeos $(186,187)$

Es España, desde la Federación Aspaym(188) existen diversos programas de apoyo entre pares o de tutoría de lesionados medulares veteranos a nuevos lesionados medulares. Estas iniciativas están reconocidas como "buenas prácticas" en la atención a los lesionados medulares en fase subaguda(183). En Asturias, el "programa tutoría del lesionado medular reciente" se lleva a cabo por parte de Aspaym desde el año 1991, pretendiendo la promoción de acciones de apoyo y orientación a los lesionados medulares recientes y a sus familias $(189,190)$. Los tutores pueden ser figuras importantes en el acompañamiento y asesoramiento de las personas con lesión 
medular, pero no deben sustituir el apoyo por parte de los profesionales.

\subsection{Asistencia sexual}

La asistencia sexual es una figura en construcción. No se han encontrado artículos sobre la opinión de las personas con lesión medular sobre la asistencia sexual.

En nuestro estudio, las opiniones son muy parejas entre la asistencia sexual entendida como una persona que ayuda en el acceso al propio cuerpo o al de otra persona y como una persona con quien mantener relaciones eróticas. Esto puede evidenciar la falta de conocimiento y de debate social sobre la definición de esta figura.

Las preguntas que se plantean sobre la mesa respecto a esta figura son: ¿ es la sexualidad una necesidad humana básica? Dentro de la clasificación de las Actividades de la Vida Diaria de la Asociación Americana de Terapeutas Ocupacionales no se encuentra reflejada(87). Sin embargo, para Centeno(49) y Arnau(90), es una necesidad básica de segundo orden, es decir, de alta importancia pero no necesaria para la supervivencia.

La segunda pregunta es si es un servicio que puede regularse a través de las partes contratantes, o por el contrario es un derecho, en el que el Estado tendría que regularlo y surgiría como debate posterior el tema de la financiación. Dentro de este debate se encontraría también el si debe responder al voluntariado o a un trabajo regulado. Hay que destacar que el derecho español, no hay prohibición respecto al ejercicio libre del trabajo sexual, por lo que la asistencia sexual como trabajo no se encontraría prohibida, pero tampoco regulada(87).

La última pregunta a plantear sería si la asistencia sexual conlleva interacción erótica entre asistente y asistido. Sí que parece que hay acuerdo en torno a que la asistencia sexual no es terapia, diferenciándose de la figura del surrogate(83).

Por otro lado, destaca Centeno(29) la importancia de no caer en la idea de que la única forma de mantener relaciones eróticas para una persona con diversidad funcional es a través de un asistente sexual. 


\section{Limitaciones}

Los datos obtenidos de las historias clínicas pueden presentar defectos de precisión e incluso de interpretación de la realidad de quien cumplimentó dichas historias. Además, en el periodo estudiado se ha producido un cambio, pasando las historias de tener formato en papel a ser electrónicas, aquellas fueron digitalizadas en el momento del cambio por lo que en el proceso se pudieron producir pérdidas de información.

Para tratar de captar un mayor número de sujetos y ampliar en todo lo posible el abanico de opiniones y percepciones, la encuesta sobre calidad de vida se ha difundido más allá de la muestra inicial estudiada y correspondiente a la población de LM de Asturias, por tanto, se desconoce la población total a la que representa la muestra obtenida. Esta limitación se ha tratado de paliar haciendo un análisis estadístico de ambas muestras por separado, la correspondiente a Asturias y la correspondiente a los demás, que ha evidenciado una homogeneidad entre ambas al no encontrarse diferencias significativas en sus características, por ello se ha decidido analizar ambas muestras de forma conjunta.

No se han encontrado cuestionarios que abordasen la sexualidad entendida de forma holística y no reduccionista, con una perspectiva sexológica amplia, por ello ha sido necesario utilizar varios cuestionarios validados y completarlos con preguntas complementarias de elaboración propia y que fueron revisadas por un grupo de expertos.

El objetivo del presente estudio ha sido estudiar la realidad de las personas con LM. En las entrevistas en profundidad ha surgido la oportunidad de que participase la pareja de un LM, sin embargo, la información respecto a las vivencias de estas parejas no se puede considerar como saturada, se ha incluido solamente a modo de excepción, podría plantearse como objetivo de futuros estudios.

Al haber pasado un tiempo variable desde que se produjo la lesión, que en ocasiones puede haber sido largo, es posible un sesgo de memoria, de cómo era su cuerpo y su vivencia de la sexualidad antes de la lesión y este sesgo podría condicionar aquellas respuestas en las que se establecía comparación entre el antes y el después. 


\section{Futuras líneas de investigación}

La investigación sobre la sexualidad de las personas con lesión medular ha avanzado en los últimos años, sin embargo, quedan lagunas de conocimiento importantes, que sería interesante estudiar. Se propone:

- Validar instrumentos de valoración de la sexualidad en todas sus dimensiones en la población de lesionados medulares.

- Realizar estudios prospectivos y longitudinales que estudien la adaptación al nuevo cuerpo y a su sexualidad tras una lesión medular traumática.

- Identificar las dificultades y barreras que identifican los profesionales de la salud para tratar este tema con las personas lesionadas y sus parejas.

- Estudiar la adaptación en las parejas de los lesionados medulares, para poder conocer sus necesidades y de qué forma los profesionales sanitarios podrían acompañarlas. 


\section{Conclusiones}




\section{Conclusiones}

1. El registro sobre sexualidad por parte de los profesionales sanitarios en las personas con lesión medular traumática es escaso. Las variables que influyen en este registro se encuentran centradas sobre todo en el tipo de lesión y en la duración del tiempo de hospitalización.

2. Los temas registrados sobre sexualidad en las historias clínicas electrónicas tienen un enfoque desde la genitalidad y la patología, centrándose en el caso de los hombres, en la erección en el tratamiento de su disfunción, y en el caso de las mujeres en las alteraciones ginecológicas. No se encuentran recogidos otros temas más enfocados en la aceptación del nuevo cuerpo, en temas relacionales o en la reconstrucción de la erótica tras la lesión medular traumática. Son escasos los registros de los aspectos sociales como la existencia de pareja, hijos, redes apoyo, etc.

3. Tras una lesión medular, la sexualidad se modifica en varias dimensiones: tanto la sexuación, la vivencia de la sexualidad, la erótica como la amatoria necesitan ser readaptadas.

4. La identidad sexual se tiene que reubicar tras la lesión medular, produciéndose una vivencia del nuevo cuerpo como un extraño y necesitando el conocimiento y la adaptación al mismo. La feminidad y la masculinidad se ponen en duda, la primera por una peor percepción de la imagen corporal y la segunda por una pérdida de fuerza, independencia y una menor sensación de protección a la familia.

5. El deseo, el interés y la importancia otorgada dentro de la relación de pareja a las relaciones eróticas se mantiene, aunque disminuye la satisfacción con las mismas.

6. Las limitaciones en la interacción erótica son derivadas de la lesión medular per se y de las complicaciones secundarias derivadas de la misma: alteraciones en la movilidad y sensibilidad, manejo del control de los esfínteres, espasticidad muscular y manejo de los productos de apoyo en la relación erótica.

7. Existen otras limitaciones extrínsecas a la persona que impactan en la sexualidad de las personas con lesión medular traumática: la no existencia de una sociedad 
inclusiva, la falta de referentes, la falta de accesibilidad y la falta de acompañamiento profesional.

8. Se identifican como recursos adaptativos los fármacos para la erección, los juguetes eróticos adaptados y la erotización de los productos de apoyo.

9. Las potencialidades en la interacción erótica son la adaptación a un modelo sexual más amplio, no centrado en la genitalidad ni en el coito, lo que conlleva una mejor interacción erótica no basada en el orgasmo y con mayor preocupación en el placer del compañero.

10. Internet es la primera fuente de información sobre sexualidad tras una lesión medular traumática, los profesionales sanitarios se encuentran en segundo lugar, seguido de los compañeros, amigos o pareja.

11. La información aportada por los profesionales sanitarios es escasa, incompleta, centrada en el funcionamiento corporal y se da cuando el paciente lo demanda. Las enfermeras no se identifican como educadoras sexuales cuando cuidan a personas que han sufrido una lesión medular traumática. 
Bibliografía 


\section{Bibliografía}

1. Esclarín de Ruz A. Lesión medular. Enfoque multidisciplinario. 1a ed. Madrid: Editorial Médica Panamericana; 2009.

2. Blackman J, Sunshine K. Médula espinal. En: Haaga JR, Dogra VS, Forsting $M$, Gilkenson RC, Hyun Hak K, Sundaram M. TC y RM. Diagnóstico por imagen del cuerpo humano. 5a ed. España: Elsevier; 2011. 731-53.

3. Sapru H. Spinal cord: anatomy, pshysiology and pathophysiology. En: Kirshblum S, Campagnolo D. Spinal Cord Medicine. 2a ed. Philadelphia: Lippincott Williams and Wilkins; 2011

4. Zarranz JJ. Neurología. 6a ed. España: Elsevier; 2018

5. Drake R, Wayne Volg A, Mitchell A. Gray's Anatomy for Students. 4a ed. Philadelphia, PA: Elsevier; 2019

6. Henao-Lema CP, Pérez-Parra JE. Lesiones medulares y discapacidad: revisión bibliográfica. Aquichan. 2010;10(2):157-72

7. Huete García A, Díaz Velázquez E. Análisis sobre la lesión medular en España. Informe de Resultados. [Internet]. Toledo: Federación Nacional Aspaym; 2009 [fecha de consulta 2 de agosto de 2020]. Disponible en: https://www.aspaym.org/pdf/publicaciones/LM_Aspaym_Media.pdf

8. The American Spinal Cord Injury Association. Escala ASIA. [sede Web]. Richmond: American Spinal Cord Injury [fecha de acceso 3 de febrero de 2020]. Disponible en: https://asia-spinalinjury.org/international-standardsneurologicalclassification-sci-isncsci-worksheet/

9. Rostagno S. Evaluación de las lesiones medulares adquiridas del adulto. EMC Kinesiterapia - Med Física. 2019;40(2):1-11

10. Torres Alaminos MA. Aspectos epidemiológicos de la lesión medular en el Hospital Nacional de Parapléjicos. Rev Ene Enfermería [Internet]. 2018 [citado el 5 de octubre de 2020];12(2). Disponible en: http://www.eneenfermeria.org/ojs/index.php/ENE/article/view/652

11. Wyndaele $\mathrm{M}$, Wyndaele JJ. Incidence, prevalence and epidemiology of spinal cord injury: what learns a worldwide literature survey? Spinal Cord [Internet]. 2006 [citado el 5 de octubre de 2020];44(9):523-9. Disponible en: https://www.nature.com/articles/3101893

12. Fitzharris $M$, Cripps RA, Lee BB. Estimating the global incidence of traumatic spinal cord injury. Spinal Cord [Internet]. 2014 [citado el 8 de octubre de 2020];52:117-22. Disponible en: https://www.nature.com/articles/sc2013135

13. Berg M Van Den, Castellote JM, Mahillo-Fernandez I, De Pedro-Cuesta J. Incidence of Traumatic Spinal Cord Injury in Aragón, Spain (1972-2008). J Neurotrauma [Internet]. 2011 [citado el 8 de octubre de 2020];28(3):469-77. Disponible en: http://doi.org/10.1089/neu.2010.1608 
14. Montoto-Marqués A, Ferreiro-Velasco ME, Salvador-De La Barrera $\mathrm{S}$, BalboaBarreiro V, Rodriguez-Sotillo A, Meijide-Failde R. Epidemiology of traumatic spinal cord injury in Galicia, Spain: trends over a 20 -year period. Spinal Cord [Internet]. 2017[citado el 10 de octubre de 2020];55(6):588-94. Disponible en: http://dx.doi.org/10.1038/sc.2017.13

15. Álvarez Pérez MJ. Lesión medular traumática en Asturias: 80 años de historia [tesis doctoral]. Oviedo: Universidad de Oviedo; 2015.

16. Bárbara-Bataller E, Méndez-Suárez JL, Alemán-Sánchez C, Ramírez-Lorenzo T, Sosa-Henríquez M. Epidemiología de la lesión medular de origen traumática en Gran Canaria. Neurocirugia [Internet]. 2017 [citado el 10 de octubre de 2020];28(1):15-21. Disponible en: http://dx.doi.org/10.1016/j.neucir.2016.08.002

17. Sebastià-Alcácer V, Alcanyis-Alberola M, Giner-Pascual M, Gomez-Pajares F. Are the characteristics of the patient with a spinal cord injury changing? Spinal Cord [Internet]. 2014 [citado el 17 de noviembre de 2020];52:29-33. Disponible en: https://www.nature.com/articles/sc2013128

18. Rueda Ruiz MB, Aguado Díaz AL. Estrategias de afrontamiento y proceso de adaptación a la lesión medular. Madrid: Instituto de Migraciones y Servicios Sociales (IMSERSO); 2003. Serie estudios no10.

19. Federación Nacional Aspaym. Estudio del acceso a los centros de referencia estatal de las personas con lesión medular [Internet]. 1aed. Madrid: Federación Nacional Aspaym; 2020 [fecha de consulta 1 de febrero de 2021]. Disponible en: https://www.aspaym.org/pdf/publicaciones/ASPAYM_Estudio_Acc_CRE_LM.pdf

20. Rech F, Civit T. Tratamiento de las complicaciones y de las secuelas neurológicas de los pacientes con traumatismos medulares. EMC - Apar Locomot [Internet]. 2015 [citado el 2 de febrero de 2020];48(3):1-14. Disponible en: http://dx.doi.org/10.1016/S1286-935X(15)72892-3

21. Allué M. El sexo también existe: discapacidad y sexualidad. En: Guasch $O$, Viñuales O. Sexualidades Diversidad y control social. 1a ed. Barcelona: Edicions Bellatera; 2003. 379-402

22. Hagen EM. Acute complications of spinal cord injuries. World J Orthop. 2015;6(1):17-23.

23. Haisma JA, van der Woude LH, Stam HJ, Bergen MP, Sluis TA, Post MW, et al. Complications following spinal cord injury : Occurrence and risk factors in a longitudinal study during and after inpatient rehabilitation. J Rehabil Med. 2007;39(5):393-8

24. Callaway L, Barclay L, Mcdonald R, Farnworth L, Casey J. Secondary health conditions experienced by people with spinal cord injury within community living: implications for a National Disability Insurance Scheme. Aust Occup Ther J. 2015;62(4):246-54

25. Organización Mundial de la Salud. Resumen Informe Mundial sobre la 
Discapacidad [Internet]. 1a ed. Malta: Organización Mundial de la Salud; 2011. [fecha de consulta 2 de febrero de 2021]Disponible en: https://www.who.int/disabilities/world_report/2011/summary_es.pdf?ua=1

26. de la Cruz C. Sexualidades diversas, sexualidades como todas. 1a ed. Madrid: Editorial Fundamentos; 2018.

27. Aguado Díaz AL. Historia de las deficiencias. 1a ed. Madrid: Escuela Libre Editorial; 1995

28. Romañach J. Héroes y parias. La Dignidad de las personas con discapacidad. En: I Ciclo de Conferencias "Discapacidad e Igualdad de Oportunidades". Castellón de la Plana: Función Isonomía para la Igualdad de Oportunidades; 2003. p. 1-12

29. Centeno Ortiz A. Una aproximación a la bioética de la diversidad funcional desde el deseo. Rev Atlántida [Internet]. 2020 [citado el 5 de enero de 2021];(11):2949. Disponible en: https://www.ull.es/revistas/index.php/atlantida/article/view/1898/1377

30. Romañach J, Palacios A. El modelo de la diversidad. La Bioética y los Derechos Humanos como herramienta para alcanzar la plena dignidad en la diversidad funcional. 1a ed. Madrid: Ediciones Diversitas; 2008.

31. Vygotskii LS. Pensamiento y lenguaje: teoría del desarrollo cultural de las funciones psíquicas. 1a ed. Buenos Aires: Ediciones Fausto; 1995

32. Real Academia Española. Diccionario Real Academia Española [sede Web]. Madrid: Real Academia Española [fecha de acceso 1 de enero de 2020]. Disponible en: https://dle.rae.es/

33. Díez Arrese S. Sexología y discapacidad: cómo eliminar la construcción de "individuos con". En sexología no hay discapacidades sino identidades. En: Sexualidad no normativa. Nuevas visiones en torno a las sexualidades de las personas con diversidad funcional (discapacidad). Universidad Internacional del Mar de la Universidad de Murcia; 2014

34. Fundació Víctor Grifols i Lucas. Sexualidad y Diversidad Funcional. 1a ed. Barcelona: Fundació Víctor Grifols i Lucas; 2020

35. Organización Mundial de la Salud. Clasificación Internacional de Deficiencias, Discapacidades y Minusvalías. Madrid: Ministerio de Asuntos Sociales; 1994

36. Organización Mundial de la Salud. Organización Panamericana de la Salud. Clasificación internacional del funcionamiento, de la Discapacidad y de la Salud. Madrid: Instituto de Migraciones y Servicios Sociales (IMSERSO); 2001

37. Página de Oficina de Vida Independiente de Barcelona. OVIBCN. Oficina Vida Independent [sede Web]. Barcelona: OVI Barcelona; [acceso el 4 de enero de 2021] Disponible en: https://ovibcn.org/ca/

38. Oficina de Vida Independicente de Galicia. VI galicia [sede Web]. Santiago de Compostela: VI galicia; [citado el 3 de marzo de 2021] Disponible en: https://vigalicia.org/ 
39. Oficina de Vida Independiente Andalucía. OVIAndalucía [sede Web]. Andalucía: OVIAndalucía; [citado el 4 de marzo de 2021] Disponible en: https://viandalucia.org/

40. Oficina de Vida Independiente de Madrid. OVI [sede Web]. Madrid: Aspaym; [citado el 4 de enero de 2021] Disponible en: https://www.aspaymmadrid.org/oficina-de-vida-independiente-ovi/

41. Federación de Vida Independiente. FEVI. [sede Web]. Santiago de Compostela: Federación de Vida Independiente; [citado el 4 de marzo de 2021] Disponible en: https://federacionvi.org

42. Actas de una Reunión de Consulta convocada por Organización Panamericana de la Salud, Organización Mundial de la Salud, en colaboración con Asociación Mundial de Sexología. Promoción de la salud sexual, recomendaciones para la acción. Guatemala; 19-22 de mayo 2000.

43. Amezúa E. Teoría de los sexos. La letra pequeña de la sexología. 1ạ ed. Madrid: Instituto de Sexología; 1999

44. Amezúa E. Sexologemas. 1ạ ed. Madrid: Instituto de Sexología; 2006.

45. Saéz Sesma S. Sexo Básico. De los genitales al cerebro, de la fecundación a la vejez. 1a ed. España: Editorial Fundamentos; 2007

46. Álvarez García V, Balbona Rodríguez J, Fernández Fernández D, Paredes Álvarez S, Pérez Pazos A, Rodríguez Martín J. Presentes, visibles \& sexuadas. 1a ed. España: Cmpa; 2020.

47. Campo M, Sánchez Ramos A. La mujer con lesion medular: sexualidad y maternidad. Rev Ter Sex y la Pareja [Internet]. 2003 [citado el 15 de diciembre de 2019];16:1-12. Disponible en: http://www.geishad.org.mx/MUJERCONLESIONMEDULAR.pdf

48. Martínez Sola F, coordinador. Discapacidad y vida sexual. La erótica del encuentro. Gijón: Cocemfe Asturias; 2003.

49. Centeno Ortiz A. Simbolismos y alianzas para una revuelta de los cuerpos. Educ Soc Rev d'Intervenció Socioeducativa [Internet]. 2014 [citado el 10 de diciembre de 2019];58:101-18. Disponible en: https://www.raco.cat/index.php/EducacioSocial/article/view/284939

50. Perrouin-Verbe B, Courtois F, Charvier K, Giuliano F. Sexualité de la patiente neurologique. Progrès en Urol [Internet]. 2013 [citado el 19 de diciembre de 2019];23(9):594-600. Disponible en: http://dx.doi.org/10.1016/j.purol.2013.01.004

51. García-Santesmases Fernández A. El cuerpo en disputa : cuestionamientos a la identidad de género desde la diversidad funcional. Intersticios Rev sociológica Pensam crítico [Internet]. 2015 [citado el 4 de abril de 2020];9(1):41-62. Disponible en: https://www.intersticios.es/article/view/14343

52. Otero-Villaverde S, Ferreiro-Velasco ME, Montoto-Marqués A, Salvador de la 
Barrera S, Arias-Pardo Al, Rodriguez-Sotillo A. Sexual satisfaction in women with spinal cord injuries. Spinal Cord [Internet]. 2015 [citado el 15 de marzo de 2020];53(7):557-60. Disponible en: https://www.nature.com/articles/sc201553

53. Cobo-Cuenca Al, Serrano-Selva JP, de la Marta-Florencio M, Esteban-Fuertes $M$, Vírseda-Chamorro M, Martín-Espinosa NM, et al. Calidad de vida del varón con lesión medular traumática y disfunción sexual. Enferm Clínica [Internet]. 2012 [citado el 15 de marzo de 2020];22(4):205-8. Disponible en: http://dx.doi.org/10.1016/j.enfcli.2012.05.002

54. Krassioukov A, Elliott S. Neural control and physiology of sexual function: effect of spinal cord injury. Top Spinal Cord Inj Rehabil. 2017;23(1):1-10

55. Migaou H, Youssef IBH, Boudokhane S, Kilani M, Jellad A, Frih ZBS. Troubles sexuels chez les patients atteints de lésions médullaires. Progrès en Urol [Internet]. 2018 [citado el 4 de abril de 2020];28(17):980-6. Disponible en: https://doi.org/10.1016/j.purol.2018.06.001

56. Masters, W Johnson V. Respuesta sexual humana. 1a ed. Buenos Aires: Editorial Intermédica; 1976.

57. Masters W, Johnson V, Kolodny V. Eros. Los mundos de la sexualidad. 1a ed. Barcelona: Editorial Grijalbo; 1996.

58. Cour F, Droupy S, Faix A, Methorst C, Giuliano F. Anatomie et physiologie de la sexualité. Progrès en Urol [Internet]. 2013 [citado el 5 de mayo de 2020];23(9):547-61. Disponible en: http://dx.doi.org/10.1016/j.purol.2012.11.007

59. Uncilla Vilela $M$, Alonso Olivé $P$, Fernández Fuentes $R$, Jiménez López J, Izquierdo Méndez P. 1a ed. Oviedo: Servicio de Publicaciones del Principado de Asturias; 1994.

60. Chochina L, Naudet F, Chéhensse C, Manunta A, Damphousse $M$, Bonan I, et al. Intracavernous injections in spinal cord injured men with erectile dysfunction, a systematic review and meta-analysis. Sex Med Rev [Internet]. 2016 [citado el 20 de octubre de 2020];4(3):257-69. Disponible en: https://halunivrennes1.archives-ouvertes.fr/hal-01295641

61. Soler JM, Previnaire JG, Mieusset R. Evidence of a new pattern of ejaculation in men with spinal cord injury: ejaculation dyssynergia and implications for fertility. Spinal Cord. 2016;54(12):1210-4.

62. Chéhensse $C$, Bahrami $S$, Denys $P$, Clément $P$, Bernabé J, Giuliano $F$. The spinal control of ejaculation revisited: a systematic review and meta-analysis of anejaculation in spinal cord injured patients. Hum Reprod Update. 2013;19(5):507-26.

63. Hadiji N, Mieusset R, Previnaire JG, Castel-Lacanal E, Soler JM. Ejaculation and sperm characteristics in men with cauda equina and conus medullaris syndromes. Spinal Cord. 2017;55(6):612-7.

64. Courtois F, Alexander M, McLain ABJ. Women's sexual health and reproductive 
function after SCI. Top Spinal Cord Inj Rehabil. 2017;23(1):20-30.

65. Stoffel JT, Van der Aa F, Wittmann D, Yande S, Elliott S. Fertility and sexuality in the spinal cord injury patient. World J Urol. 2018;36(10):1577-85.

66. Ibrahim E, Brackett NL, Lynne CM. Advances in the management of infertility in men with spinal cord injury. Asian J Androl. 2016;18(3):382-90.

67. Sinha V, Elliott S, Ibrahim E, Lynne CM, Brackett NL. Reproductive health of men with spinal cord injury. Top Spinal Cord Inj Rehabil. 2017;23(1):31-41.

68. Kathiresan A, Ibrahim E, Modh R, Abablla T, Lynne C, Brackett N. Semen quality in ejaculates produced by masturbation in men with spinal cord injury. Spinal Cord. 2012;50:891-4.

69. Chong W, Ibrahim E, Aballa TC, Lynne CM, Brackett NL. Comparison of three methods of penile vibratory stimulation for semen retrieval in men with spinal cord injury. Spinal Cord [Internet]. 2017 [citado el 5 de enero de 2021];55(10):921-5. Disponible en: http://dx.doi.org/10.1038/sc.2017.60

70. Courtois F, Charvier K, Leriche A, Vézina JG, Côté I, Raymond D, et al. Perceived physiological and orgasmic sensations at ejaculation in spinal cord injured men. J Sex Med. 2008;5(10):2419-30.

71. Soeterik TFW, Veenboer PW, Oude-Ophuis RJA, Lock TMTW. Electroejaculation in patients with spinal cord injuries: a 21-year, single-center experience. Int J Urol. 2017;24(2):157-61.

72. Declaración Universal de los Derechos Humanos. Asamblea general de la ONU, resolución 217 (III), (10 de diciembre de 1948).

73. García Carenas L, Alcedo Rodríguez MA, Aguado Díaz A-L. La sexualidad de las personas con lesión medular: aspectos psicológicos y sociales. Una revisión actualizada. Interv Psicosoc. 2008;17(2):125-41

74. Organización de Naciones Unidas. Declaración y Programa de Acción de Viena. Viena: Oficina del Alto Comisionado de las Naciones Unidas para los Derechos Humanos; 1993. DPI/1393.

75. World Association for Sexual Health. Declaración de los Derechos Sexuales [Internet] WAS; 1999. [fecha de acceso 17 de abril de 2020] Disponible en: https://worldsexualhealth.net/wpcontent/uploads/2013/08/declaracion_derec hos_sexuales_sep03_2014.pdf

76. Instrumento de Ratificación de la Convención sobre los derechos de las personas con discapacidad, hecho en Nueva York el 13 de diciembre de 2006. Boletín Oficial del Estado, no96, (21 de abril de 2008)

77. Carta de los Derechos Fundamentales de la Unión Europea. Diario Oficial de la Unión Europea, no 83/02, (3 de marzo de 2010).

78. Constitución Española. Boletín Oficial del Estado, nํ311, (29 de 12 de 1978).

79. Ley 51/2003, de 2 de diciembre, de igualdad de oportunidades, no 
discriminación y accesibilidad universal de las personas con discapacidad. Boletín Oficial del Estado, nㅇ289, (3 de 12 de 2003).

80. Ley 38/2006, de 14 de diciembre, de Promoción de la Autonomía Personal y Atención a las personas en situación de dependencia. Boletín Oficial del Estado, no 299, (15 de 12 de 2006).

81. Ley Orgánica $2 / 2010$, de 3 de marzo, de salud sexual y reproductiva y de la interrupción voluntaria del embarazo. Boletín Oficial del Estado, no 55, (04 de 03 de 2010).

82. García-Santesmases Fernández A. Luces, cámara y erección: la asistencia sexual a escena. Encrucijadas Rev Crítica Ciencias Soc. 2019;17:1-19

83. García-Santesmases Fernández A, Branco de Castro Ferreira C. Fantasmas y fantasías: controversias sobre la asistencia sexual para personas con diversidad funcional. Rev Ciencies Soc Apl. 2016;5(1):3-34.

84. Blanco $M$, Centeno A, Rodríguez-Picavea A, Romañach J. Asistencia personal: una inversión en derechos; una inversión eficiente en empleo [monografía en Internet]. Foro de Vida Independiente; 2009. [fecha de consulta 2 de abril de 2020] Disponible en: http://www.valldignaaccessible.org/wpcontent/uploads/2009/05/090513_asist encia_personal_empleo_derecho_preva

I.doc

85. Ministerio de Trabajo y Asuntos Sociales, Secretaría General de Asuntos Sociales. I Plan Nacional De Accesibilidad 2004-2012. Para un nuevo paradigma, el Diseño para Todos, hacia la plena igualdad de oportunidades. España: Ministerio de Trabajo y Asuntos Sociales; 2003

86. Predif. Situación de la Asistencia Personal en España. España: Predif; 2015

87. De Asís R. ¿Es la asistencia sexual un derecho? Rev Española Discapac [Internet]. 2017 [citado el 3 de febrero de 2021];5(2):7-18. Disponible en: https://www.cedd.net/redis/index.php/redis/article/view/368/pdf_86

88. Associació Tándem Team Barcelona. Tándem Team. Diversidad y conciencia. [sede Web]. Barcelona: Tandem Team; [citado el 3 de enero de 2021]. Disponible en: https://www.tandemteambcn.com/copia-deacompanamientointimo

89. Asistencia sexual.org [sede Web]. Barcelona: asistencia sexual.org; [citado el 3 de enero de 2021]. Disponible en: https://asistenciasexual.org/

90. Arnau Ripollés S. El modelo de asistencia sexual como derecho humano al autoerotismo y el acceso al propio cuerpo: un nuevo desafío para la plena implementación de la filosofía de vida independiente. Intersticios Rev Sociológica Pensam Crítico. 2017;11(1):19-37.

91. Cruz Fernández KE, Castillo Cuello JJ, Coronados Valladares Y, Pérez Díaz Y, Martínez Cuba S, Semino García LE. Propuesta de un programa de atención a la sexualidad de pacientes ingresados con afección neurológica. Rev Cuba Med 
Física y Rehabil. 2018;10(2):1-12.

92. Cavalcante KMH, Carvalho ZMDF, Ximenes LB, Freitas GL. Cambios en la vida sexual de la persona con lesión medular. Av en Enfermería. 2006;24(2):54-62

93. Rodríguez M. El profesional de Enfermería en el abordaje sexual de los pacientes con discapacidad: un enfoque fenomenológico. NURE Investig [Internet]. 2017 [citado el 5 de abril de 2021];14(89):1-10. Disponible en: https://dialnet.unirioja.es/servlet/articulo?codigo $=6278361$

94. Rodríguez Alonso A, Oltra Rodríguez E. Sexualidad en hombres y mujeres con lesión medular adquirida: una revisión. En: Atención a las necesidades comunitarias para la salud. Scinfoper; 2017. p 87-95.

95. Post MW, Van Leeuwen CM, Van Koppenhagen CF, De Groot S. Validity of the Life Satisfaction Questions, the Life Satisfaction Questionnaire, and the Satisfaction With Life Scale in Persons With Spinal Cord Injury. Arch Phys Med Rehabil [Internet]. 2012 [citado el 3 de enero de 2020];93(10):1832-7. Disponible en: http://dx.doi.org/10.1016/j.apmr.2012.03.025

96. Fugl-Meyer AR, Eklund M, Fugl-Meyer KS. Vocational Rehabilitation in northern Sweden. III. Aspects of Life Satisfaction. Scand J Rehab Med. 1991;23:83-7.

97. Fugl-Meyer AR, Lodnert G, Branholm IB, Fugl-Meyer KS. On life satisfaction in male erectile dysfunction. Int J Impot Res. 1997;9(3):141-8

98. Rejas J, Gil de Miguel A, San Isidro C, Palacios G, Carrasco P. Adaptación cultural y validación psicométrica del cuestionario de satisfacción con la vida de FuglMayer-LISAT 8 en población española masculina con disfunción eréctil. Pharmacoecoomics Spanish Res Artic. 2004;1:87-9.

99. Rosen R, Cappelleri J, Smith M, Lipsky J, Peña B. Development and evaluation of an abridged, 5-item version of the International Index of Erectile Function (IIEF5) as a diagnostic tool for erectile dysfunction. Int J Impot Res. 1999;11:319-26

100. Rosen RC, Cappelleri JC, Gendrano N. The International Index of Erectile Function (IIEF): a state-of-the-science review. Int J Impot Res. 2002;14:226-44.

101. Rhoden E, Telöken C, Sogari P, Vargas Souto C. The use of the simplified International Index of Erectile Function (IIEF-5) as a diagnostic tool to study the prevalence of erectile dysfunction. Int J Impot Res. 2002;14:245-50.

102. Pinzón-Espinosa A, Gómez-Guevara MC. Instrumentos para evaluación de la salud sexual en pacientes con lesión medular traumática: una revisión narrativa. Rehabilitacion [Internet]. 2018 [citado el 3 de enero de 2020];52(2):125-33. Disponible en: https://doi.org/10.1016/j.rh.2018.02.003

103. Siösteen A, Lundqvist C, Blomstrand C, Sullivan L, Sullivan M. Sexual ability, activity, attitudes and satisfaction as part of adjustment in spinal cord-injured subjects. Paraplegia. 1990;28:285-95.

104. Abramson CE, McBride KE, Konnyu KJ, Elliott SL. Sexual health outcome measures for individuals with a spinal cord injury: a systematic review. Spinal 
Cord. 2008;46:320-4.

105. BG Glasser AS. The discovery of Grounded Theory: Strategies for Qualitative Research. Estados Unidos, Routledge; 2000.

106. Creswell JW, Poth CN. Qualitative inquiry and research design: choosing among five traditions. 4a ed. Los Ángeles: Sage Publications; 1998

107. Tong A, Sainsbury $P$, Craig J. Consolidated criteria for reporting qualitative research (COREQ): A 32-item checklist for interviews and focus groups. Int J Qual Heal Care. 2007;19(6):349-57.

108. Chen Y, Tang Y, Allen V, DeVivo MJ. Fall-induced spinal cord injury: external causes and implications for prevention. J Spinal Cord Med [Internet]. 2016 [citado el 15 de abril de 2020];39(1):24-39. Disponible en: isi:000268290100003\%5CnC:\%5CEMH\%5CScannede artikler referanser\%5CRefMan3841.pdf

109. Álvarez Pérez MJ, López Llano ML. Lesión medular traumática en mayores de 65 años en la provincia de Asturias. Rev Esp Geriatr Gerontol. 2016 [citado el 13 de febrero de 2020];51(6):335-7

110. Castaño-Monsalve B, Benito-Penalva J, Vidal-Samsó J. Spinal cord injury due to suicide attempt, psychiatric profile and functional disability. Rev Neurol [Internet]. 2019 [citado el 15 de febrero de 2020];68(7):290-4. Disponible en: https://www.neurologia.com/articulo/2018210/esp

111. Servicio de Salud del Principado de Asturias. Protocolo de detección y manejo de caso en personas con riesgo de suicidio. Asturias: Unidad de Coordinación del Programa Marco de Salud Mental -SESPA; 2018

112. Kennedy P, Garmon-Jones L. Self-harm and suicide before and after spinal cord injury: a systematic review. Spinal Cord. 2017;55(1):2-7.

113. Stillman MD, Barber J, Burns S, Williams S, Hoffman JM. Complications of Spinal Cord Injury Over the First Year After Discharge From Inpatient Rehabilitation. Arch Phys Med Rehabil [Internet]. 2017 [citado el 26 de octubre de 2020];98(9):1800-5.

Disponible

en: http://dx.doi.org/10.1016/j.apmr.2016.12.011

114. Atkinson RA, Cullum NA. Interventions for pressure ulcers: a summary of evidence for prevention and treatment. Spinal Cord. 2018;56(3):186-98.

115. Nogueira PC, Caliri MHL, Haas VJ. Profile of patients with spinal cord injuries and occurrence of pressure ulcer at a university hospital. Rev Lat Am Enfermagem. 2006;14(3):372-7.

116. Verschueren JHM, Post MWM, De Groot S, Van Der Woude LHV, Van Asbeck FWA, Rol M. Occurrence and predictors of pressure ulcers during primary inpatient spinal cord injury rehabilitation. Spinal Cord. 2011;49(1):106-12.

117. Scheel-Sailer A, Wyss A, Boldt C, Post MW, Lay V. Prevalence, location, grade of pressure ulcers and association with specific patient characteristics in adult 
spinal cord injury patients during the hospital stay: a prospective cohort study. Spinal Cord. 2013;51(11):828-33.

118. Lala D, Dumont FS, Leblond J, Houghton PE, Noreau L. Impact of pressure ulcers on individuals living with a spinal cord injury. Arch Phys Med Rehabil. 2014;95(12):2312-9.

119. Di Prinzio MF, Argento FJ, Barbalaco L, Cazurro ME, Pereyra A, Sanchez Correa C, et al. Factores de riesgo para la aparición y/o recurrencia de úlceras por presión en sujetos con lesión medular: revisión sistemática. Rev Fac Cienc Med Cordoba. 2019;76(4):242-56.

120. Shiferaw WS, Akalu TY, Mulugeta H, Aynalem YA. The global burden of pressure ulcers among patients with spinal cord injury: a systematic review and metaanalysis. BMC Musculoskelet Disord. 2020;21(334):1-11.

121. Correa GI, Fuentes M, Gonzalez X, Cumsille F, Piñeros JL, Finkelstein J. Predictive factors for pressure ulcers in the ambulatory stage of spinal cord injury patients. Spinal Cord. 2006;44(12):734-9.

122. Hamid R, Averbeck MA, Chiang H, Garcia A, Al Mousa RT, Oh SJ, et al. Epidemiology and pathophysiology of neurogenic bladder after spinal cord injury. World J Urol. 2018;36(10):1517-27.

123. Stöhrer M, Blok B, Castro-Diaz D, Chartier-Kastler E, Del Popolo G, Kramer G, et al. EAU Guidelines on Neurogenic Lower Urinary Tract Dysfunction. Eur Urol. 2009;56(1):81-8.

124. Kreydin E, Welk B, Chung D, Clemens Q, Yang C, Danforth T, et al. Surveillance and management of urologic complications after spinal cord injury. World J Urol. 2018;36(10):1545-53.

125. Bárbara-Bataller E, Méndez-Suárez JL, Alemán-Sánchez C, Sánchez-Enríquez J, Miranda-Calderín G, Sosa-Henríquez M. ¿Cómo afecta el nuevo perfil del lesionado medular al manejo vesical? Arch Españoles Urol. 2019;72(7):662-9.

126. Chang S, Zeng S, Tsai S. Outcome of Different Approaches to Reduce Urinary Tract Infection in Patients With Spinal Cord Lesions: A Systematic Review. Am J Phys Med Rehabil. 2020;99(11):1056-66.

127. Skelton-Dudley F, Doan J, Suda K, Holmes SA, Evans C, Trautner B. Spinal cord injury creates unique challenges in diagnosis and management of catheterassociated urinary tract infection. Top Spinal Cord Inj Rehabil. 2019;25(4):331-9.

128. Locke JA, Welk B, Macnab A, Rivers CS, Kurban D, Nigro M, et al. Exploring the relationship between self-reported urinary tract infections to quality of life and associated conditions: insights from the spinal cord injury Community Survey. Spinal Cord [Internet]. 2019 [citado el 26 de septiembre de 2020];57(12):10407. Disponible en: https://www.nature.com/articles/s41393-019-0323-z

129. Barboglio Romo PG, Smith CP, Cox A, Averbeck MA, Dowling C, Beckford C, et al. Non-surgical urologic management of neurogenic bladder after spinal cord 
injury. World J Urol. 2018;36(10):1555-68.

130. Teplitsky S, Murphy A, Shenot PJ. Knowledge gaps in urologic care of female spinal cord injury patients. Curr Urol Rep. 2019;20(5):1-7.

131. Elmelund M, Klarskov N, Biering-Sørensen F. Prevalence of urinary incontinence in women with spinal cord injury. Spinal Cord [Internet]. 2018 [citado el 26 de septiembre de 2020];56(12):1124-33. Disponible en: http://dx.doi.org/10.1038/s41393-018-0157-0

132. Cramp J, Courtois F, Connolly M, Cosby J, Ditor D. The impact of urinary incontinence on sexual function and sexual satisfaction in women with spinal cord. Sex Disabil. 2014;32:397-412

133. Fritz HA, Dillaway H, Lysack CL. "Don't think paralysis takes away your womanhood": sexual intimacy after spinal cord injury. Am J Occup Ther. 2015;69(2):1-10.

134. Vallès $M$, Mearin F. Alteraciones intestinales en pacientes con lesión medular. Gastroenterol Hepatol. 2012;35(5):330-6.

135. Anderson KD, Borisoff JF, Johnson RD, Stiens SA, Elliott SL. Long-term effects of spinal cord injury on sexual function in men: implications for neuroplasticity. Spinal Cord. 2007;45(5):338-348

136. Kreuter M, Taft C, Siösteen A, Biering-Sørensen F. Women's sexual functioning and sex life after spinal cord injury. Spinal Cord [Internet]. 2011 [citado el 4 de octubre de 2020];49(1):154-60. Disponible en: https://www.nature.com/articles/sc201051

137. Burke D, Fullen BM, Stokes D, Lennon O. Neuropathic pain prevalence following spinal cord injury: a systematic review and meta-analysis. Eur J Pain. 2017;21(1):29-44

138. Van Gorp S, Kessels AG, Joosten EA, Van Kleef M, Patijn J. Pain prevalence and its determinants after spinal cord injury: a systematic review. Eur J Pain. 2015;19(1):5-14.

139. Estores IM. The consumer's perspective and the professional literature: What do persons with spinal cord injury want? J Rehabil Res Dev. 2003;40(4 SUPPL. 1):93-8.

140. Biering-Sørensen I, Hansen RB, Biering-Sørensen F. Sexual function in a traumatic spinal cord injured population 10-45 years after injury. J Rehabil Med. 2012;44(11):926-31

141. Lee ES, Joo MC. Prevalence of autonomic dysreflexia in patients with spinal cord injury above T6. Biomed Res Int. 2017;2017:1-6.

142. Lim CAR, Nightingale TE, Elliott S, Krassioukov AV. Lifestyle modifications and pharmacological approaches to improve sexual function and satisfaction in men with spinal cord injury: a narrative review. Spinal Cord. 2020;58:391-401

143. Oliver Susana. Sexualidad, Lesión Medular Y Vida Activa. [sede Web]. Tenerife: 
Iniciativa Múltiple de Atención de Gaps a la Integración, Normalización y Accesibilidad; 2015 [fecha de acceso 3 de enero de 2019]. Disponible en: http://www.imagina.org/archivos/lesion-medular

144. Federici S, Artegiani F, Pigliautile M, Antonelli P, Diotallevi D, Ritacco I, et al. Enhancing psychological sexual health of people with spinal cord injury and their partners in an Italian Unipolar Spinal Unit: A pilot data study. Front Psychol. 2019;10(754):1-12.

145. López García-Moreno A. La lesión medular como factor de riesgo de disfunción sexual en el varón [tesis doctoral]. Salamanca: Universidad de Salamanca; 2013.

146. Bahner J. Legal rights or simply wishes? The struggle for sexual recognition of people with physical disabilities using personal assistance in Sweden. Sex Disabil. 2012;30:337-56.

147. Anderson KD. Targeting recovery: priorities of the spinal cord-injured population. J Neurotrauma. 2004;21(10):1371-83.

148. Simpson LA, Eng JJ, Hsieh JTC, Wolfe DL. The health and life priorities of individuals with spinal cord injury: a systematic review. I Neurotrauma. 2012;29(8):1548-55.

149. Sánchez-Ramos A, Galán-Ruano A, Vargas-Baquero E, Mas M. Calidad de la vida sexual de varones heterosexuales con lesión medular en tratamiento farmacológico para la disfunción eréctil y de sus compañeras. Rev Int Androl [Internet]. 2018 [citado el 5 de febrero de 2021];16(3):95-101. Disponible en: http://dx.doi.org/10.1016/j.androl.2017.06.004

150. Kathnelson JD, Kurtz Landy CM, Ditor DS, Tamim H, Gage WH. Supporting sexual adjustment from the perspective of men living with spinal cord injury. Spinal Cord [Internet]. 2020 [citado el 5 de febrero de 2021];58(11):1176-82. Disponible en: http://dx.doi.org/10.1038/s41393-020-0479-6

151. Guerrero Ferreira NA, Castillo Cuello JJ. Caracterización de la afectación sexual de los pacientes con lesión medular ingresados al Centro de Rehabilitación Julio Díaz de La Habana, Cuba. 2015. Rev Colomb Med Física y Rehabil. 2019;29(1):40-51.

152. Alexander MS, Brackett NL, Bodner D, Elliott S, Jackson A, Sonksen J. Measurement of sexual functioning after spinal cord injury: preferred instruments. J Spinal Cord Med. 2009;32(3):226-36

153. Hess MJ, Hough S. Impact of spinal cord injury on sexuality: broad-based clinical practice intervention and practical application. J Spinal Cord Med [Internet]. 2012 [citado el 15 de febrero de 2021];35(4):211-8. Disponible en: https://www.tandfonline.com/doi/abs/10.1179/2045772312Y.0000000025?jour nalCode=yscm 20

154. Van Diemen T, Van Leeuwen C, Van Nes I, Geertzen J, Post M. Body image in patients with spinal cord injury during inpatient rehabilitation. Arch Phys Med Rehabil [Internet]. 2017 [citado el 15 de febrero de 2021];98(6):1126-31. 
Disponible en: http://dx.doi.org/10.1016/j.apmr.2016.10.015

155. Allué M. DisCapacitados. La reivindicación de la igualdad en la diferencia. Ediciones. Barcelona: Ediciones Bellatera; 2003.

156. Bailey KA, Gammage KL, van Ingen C, Ditor DS. "My body was my temple": a narrative revealing body image experiences following treatment of a spinal cord injury. Disabil Rehabil [Internet]. 2017 [citado el 16 de marzo de 2021];39(18):1886-92. Disponible en: https://www.tandfonline.com/doi/abs/10.1080/09638288.2016.1211753

157. Javier SJ, Perrin PB, Snipes D, Olivera SL, Perdomo JL, Arango JA, et al. The influence of health related quality of life on sexual desire in individuals with spinal cord injury from Colombia, South America. Sex Disabil. 2013;31(4):32535.

158. Cobo Cuenca Al, Sampietro-Crespo A, Virseda-Chamorro M, Martín-Espinosa N. Psychological impact and sexual dysfunction in men with and without spinal cord injury. J Sex Med [Internet]. 2015 [citado el 5 de abril de 2020];12(2):43644. Disponible en: http://doi.wiley.com/10.1111/jsm.12741

159. Gomes CM, Miranda EP, de Bessa J, Suzuki Bellucci CH, Battistella LR, Najjar Abdo $\mathrm{CH}$, et al. Erectile function predicts sexual satisfaction in men with spinal cord injury. Sex Med [Internet]. 2017 [citado el 27 de enero de 2021];5(3):e14855. Disponible en: https://www.smoa.jsexmed.org/article/S20501161(17)30040-5/fulltext

160. Miranda EP, Gomes CM, de Bessa J, Najjar Abdo $\mathrm{CH}$, Suzuki Bellucci $\mathrm{CH}$, de Castro Filho JE, et al. Evaluation of sexual dysfunction in men with spinal cord injury using the Male Sexual Quotient. Arch Phys Med Rehabil. 2016;97(6):94752.

161. Jia D, Shuang W, Cheng T, Jia X, Zhang M. Efficacy and safety of phosphodieterase-5 inhibitors for treatment of erectile dysfunction secondary to spinal cord injury: a systemic review and meta-analysis. Spinal Cord [Internet]. 2016 [citado el 5 de febrero de 2021];54(7):494-501. Disponible en: https://www.nature.com/articles/sc20163

162. OhI DA, Carlsson M, Stecher VJ, Rippon GA. Efficacy and safety of sildenafil in men with sexual dysfunction and spinal cord injury. Sex Med Rev [Internet]. 2017 [citado el 5 de febrero de 2021];5(4):521-8. Disponible en: https://www.smr.jsexmed.org/article/S2050-0521(17)30009-4/abstract

163. Moemen MN, Fahmy I, AbdelAal M, Kamel I, Mansour M, Arafa MM. Erectile dysfunction in spinal cord-injured men: different treatment options. Int J Impot Res. 2008;20(2):181-7.

164. García-Perdomo HA, Echeverría-García F, Tobías A. Effectiveness of phosphodiesterase 5 inhibitors in the treatment of erectile dysfunction in patients with spinal cord trauma: systematic review and meta-analysis. Urol Int. 2017;98(2):198-204. 
165. DeForge D, Blackmer J, Garritty C, Yazdi F, Cronin V, Barrowman N, et al. Male erectile dysfunction following spinal cord injury: a systematic review. Spinal Cord. 2006;44(8):465-73.

166. Forsythe E, Horsewell JE. Sexual rehabilitation of women with a spinal cord injury. Spinal Cord [Internet]. 2006 [citado el 29 de octubre de 2020];44(4):23441. Disponible en: https://www.nature.com/articles/3101844

167. Anderson KD, Borisoff JF, Johnson RD, Stiens SA, Elliott SL. Spinal cord injury influences psychogenic as well as physical components of female sexual ability. Spinal Cord [Internet]. 2007 [citado el 29 de octubre de 2020];45(5):349-59. Disponible en: https://www.nature.com/articles/3101979

168. Soler JM, Navaux MA, Previnaire JG. Positive sexuality in men with spinal cord injury. Spinal Cord [Internet]. 2018 [citado el 5 de septiembre de 2020];56:1199-206. Disponible en: http://dx.doi.org/10.1038/s41393-018-01779

169. Cobo Cuenca Al. Repercusión de la salud sexual en la calidad de vida del varón con y sin lesión medular [tesis doctoral]. España: Universidad de Castilla la Mancha; 2011

170. Alexander M, Marson L. Orgasm and SCl: what do we know? Spinal Cord [Internet]. 2018 [citado el 5 de febrero de 2021];56(6):538-47. Disponible en: http://dx.doi.org/10.1038/s41393-017-0020-8

171. ISO. ISO 9999:2016. Productos de apoyo para personas con discapacidad: clasificación y terminología. [Internet]. Suiza: ISO; 2016. [fecha de consulta 3 de enero de 2021] Disponible en: https://www.iso.org/standard/60547.html

172. Centeno A, De la Morena R. Yes, we fuck [videodocumental]. España: micromecenatge; 2015.

173. Amador MJ, Lynne CM, Brackett NL. Guía y directorio de recursos para la fertilidad masculina después de una lesión/disfunción de la espina dorsal. Miami: Proyecto de Miami para la cura de la Parálisis; 2000.

174. Sønksen J, Fode M, Löchner-Ernst D, OhI DA. Vibratory ejaculation in 140 spinal cord injured men and home insemination of their partners. Spinal Cord [Internet]. 2012 [citado el 10 de febrero de 2021];50(1):63-6. Disponible en: https://www.nature.com/articles/sc2011101

175. Alcedo-Rodríguez MA, García-Carenas L, Fontanil-Gómez Y, Arias-Martínez B, Aguado-Díaz AL. Proceso de adaptación en mujeres con lesión medular: relaciones entre variables psicológicas y sociodemográficas. Aquichan. 2014;14(2):159-69.

176. Jeyathevan G, Cameron JI, Craven BC, Munce SEP, Jaglal SB. Re-building relationships after a spinal cord injury: experiences of family caregivers and care recipients. BMC Neurol [Internet]. 2019 [citado el 23 de abril de 2020];19(117):1-14. Disponible en: https://bmcneurol.biomedcentral.com/articles/10.1186/s12883-019-1347-x 
177. Pebdani RN, Johnson KL, Amtmann D. Personal experiences of pregnancy and fertility in individuals with spinal cord injury. Sex Disabil. 2014;32:65-74.

178. Ministerio de Asuntos Económicos y Transformación Digital. Individuos que usan Internet para buscar información relacionada con la salud [sede Web]. España: ONTSI. [fecha de acceso 1 de febrero de 2021]. Disponible en: https://www.ontsi.red.es/es/indicadores/Comparativa-

europea/Actividadesindividuos/Individuos-que-usan-Internet-para-buscar-0

179. Bea-Muñoz M, Medina-Sánchez M, Flórez-García MT. Legibilidad de los documentos informativos en español dirigidos a lesionados medulares y accesibles por internet. An Sist Sanit Navar. 2015;38(2):255-62.

180. Oltra Rodríguez E, Rodríguez Alonso A. La atención a la sexualidad en enfermería comunitaria. En: Martínez Riera JR, del Pino Casado, R. Manual práctico de enfermería comunitaria. Barcelona: Elsevier; 2020.

181. New PW, Seddon M, Redpath C, Currie KE, Warren N. Recommendations for spinal rehabilitation professionals regarding sexual education needs and preferences of people with spinal cord dysfunction: a mixed-methods study. Spinal Cord [Internet]. 2016;(November 2015):1-7. Disponible en: http://www.nature.com/doifinder/10.1038/sc.2016.62

182. Consortium for Spinal Cord Medicine. Sexuality and reproductive health in adults with spinal cord injury: a clinical practice guideline for health-care professionals. J Spinal Cord Med. 2010; 33(3): 281-336.

183. Aspaym. Guía de buenas prácticas. Atención integral al nuevo lesionado medular. Toledo: Federación Nacional Aspaym.

184. Cobo-Cuenca Al, Martín-Espinosa NM, Píriz Campos RM. Cuidados enfermeros en el varón con lesión medular y disfunción sexual. Enferm Clin. 2013;23(3):12832

185. Gassaway J, Houlihan BV, Everhart Skeels S, Jones ML. Force of peer mentorship for persons with spinal cord injury. Arch Phys Med Rehabil. 2018;99(8):1691-2

186. Divanoglou A, Georgiou M. Perceived effectiveness and mechanisms of community peer-based programmes for Spinal Cord Injuries-a systematic review of qualitative findings. Spinal Cord [Internet]. 2017 [citado el 5 de enero de 2021];55(3):225-34.

Disponible

en: https://www.nature.com/articles/sc2016147

187. Barclay L, Hilton GM. A scoping review of peer-led interventions following spinal cord injury. Spinal Cord [Internet]. 2019;57(8):626-35. Disponible en: http://dx.doi.org/10.1038/s41393-019-0297-x

188. Aspaym. Federación Nacional Aspaym [sede Web]. Toledo: Aspaym. [fecha de consulta 2 de marzo de 2020] Disponible en: https://www.aspaym.org/lesionmedular

189. Alonso Fernández M, Aguado-Díaz AL. El programa tutoría del nuevo lesionado medular. Psychosoc Interv. 1995;4(12):109-11. 
190. Aguado Díaz AL, Alcedo-Rodríguez MA, Alonso Fernández M, Santos González A. Valoración del programa "tutoría" del lesionado medular reciente. En: III Jornadas Científicas de Investigación sobre Personas con Discapacidad. Salamanca; 1999. 


\section{Anexos}




\section{Anexos}

Anexo I: Tabla de variables de Fase I

\begin{tabular}{|c|c|c|}
\hline VARIABLE & DESCRIPCIÓN & CLASIFICACIÓN \\
\hline \multicolumn{3}{|c|}{ VARIABLES SOCIODEMOGRÁFICAS } \\
\hline Sexo & $\begin{array}{l}\text { Cualitativa } \\
\text { dicotómica }\end{array}$ & Hombre/mujer \\
\hline Edad & Cuantitativa & En años \\
\hline Estado civil & Cualitativa nominal & $\begin{array}{l}\text { Casado o en pareja/ soltero/ separado o } \\
\text { divorciado/ viudo }\end{array}$ \\
\hline Número de hijos & Cuantitativa & \\
\hline Nivel de estudios & Cualitativa ordinal & Básicos/ secundarios/ universitarios \\
\hline $\begin{array}{l}\text { Ocupación previa a la } \\
\text { lesión }\end{array}$ & Cualitativa nominal & $\begin{array}{l}\text { Trabajador/ desempleado/ jubilado/ } \\
\text { estudiante/ labores del hogar }\end{array}$ \\
\hline $\begin{array}{l}\text { Aportación farmacéutica } \\
\text { según tarjeta sanitaria } \\
\text { individual }\end{array}$ & Cualitativa ordinal & TSI 1/ TSI 2/ TSI 3/ TSI 4/ TSI 5/ TSI 6 \\
\hline \multicolumn{3}{|c|}{ VARIABLES RELACIONADAS CON LA LESIÓN MEDULAR } \\
\hline Etiología & Cualitativa nominal & $\begin{array}{l}\text { Tráfico coche/ tráfico moto/ otros } \\
\text { tráficos/laboral/ fortuito/ intento } \\
\text { autolisis/ deportivos/ zambullida/ } \\
\text { agresión/ traumatismo directo/ } \\
\text { desconocido }\end{array}$ \\
\hline $\begin{array}{l}\text { Presencia de antecedentes } \\
\text { en la salud mental }\end{array}$ & $\begin{array}{l}\text { Cualitativa } \\
\text { dicotómica }\end{array}$ & Sí/ No \\
\hline $\begin{array}{l}\text { Patología de base de salud } \\
\text { mental }\end{array}$ & Cualitativa nominal & $\begin{array}{l}\text { Trastorno ansioso-depresivo/trastorno de } \\
\text { personalidad/ adicción a drogas/ enolismo } \\
\text { crónico/ esquizofrenia/trastorno bipolar/ } \\
\text { otras enfermedades mentales }\end{array}$ \\
\hline Edad al lesionarse & Cuantitativa & En años \\
\hline Tiempo de lesión & Cuantitativa & En meses \\
\hline $\begin{array}{l}\text { Estación del año en la que } \\
\text { se produjo }\end{array}$ & Cualitativa nominal & Invierno/ primavera/ verano/ otoño \\
\hline $\begin{array}{l}\text { Tipo de lesión según } \\
\text { afectación de miembros }\end{array}$ & Cualitativa nominal & $\begin{array}{l}\text { Paraparesia/ paraplejia/ tetraparesia/ } \\
\text { tetraplejia }\end{array}$ \\
\hline $\begin{array}{l}\text { Tipo de lesión según } \\
\text { extensión }\end{array}$ & $\begin{array}{l}\text { Cualitativa } \\
\text { dicotómica }\end{array}$ & Completa/ incompleta \\
\hline $\begin{array}{l}\text { Tipo de lesión según nivel } \\
\text { neurológico }\end{array}$ & Cualitativa nominal & Cervical/ dorsal/ lumbar \\
\hline Nivel óseo & Cualitativa nominal & $\begin{array}{l}\text { C1/C2/C3/C4/C5/C6/C7/D1/D2/D3/D4/D5 } \\
\text { D6/D7/D8/D9/D10/D11/D12/L1/L2/L3/L4/ } \\
\text { L5 }\end{array}$ \\
\hline ASIA al alta & Cualitativa nominal & $\mathrm{A} / \mathrm{B} / \mathrm{C} / \mathrm{D} / \mathrm{E}$ \\
\hline
\end{tabular}




\begin{tabular}{|c|c|c|}
\hline $\begin{array}{l}\text { Síndromes clínicos } \\
\text { específicos }\end{array}$ & Cualitativa nominal & $\begin{array}{l}\text { Brown-Séquard/ centro medular/ de cola } \\
\text { de caballo/de cono medular/ no síndrome }\end{array}$ \\
\hline $\begin{array}{l}\text { Realización de intervención } \\
\text { quirúrgica para la } \\
\text { estabilización de la lesión. }\end{array}$ & $\begin{array}{l}\text { Cualitativa } \\
\text { dicotómica }\end{array}$ & 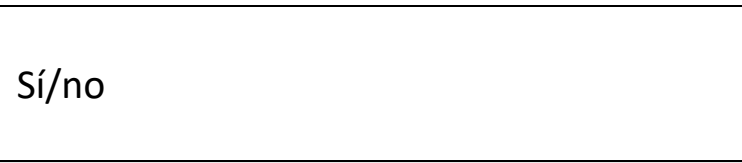 \\
\hline \multicolumn{3}{|c|}{ VARIABLES RELACIONADAS CON LA HOSPITALIZACIÓN } \\
\hline Ingreso en $\mathrm{UCl}$ & $\begin{array}{l}\text { Cualitativa } \\
\text { dicotómica }\end{array}$ & Sí/no \\
\hline Tiempo de estancia en $\mathrm{UCl}$ & Cuantitativa & En días \\
\hline $\begin{array}{l}\text { Tiempo de estancia en } \\
\text { unidad de hospitalización }\end{array}$ & Cuantitativa & En días \\
\hline $\begin{array}{l}\text { Tiempo total de } \\
\text { hospitalización }\end{array}$ & Cuantitativa & En días \\
\hline $\begin{array}{l}\text { Derivación de otros } \\
\text { hospitales }\end{array}$ & $\begin{array}{l}\text { Cualitativa } \\
\text { dicotómica }\end{array}$ & Sí/no \\
\hline Hospitales de derivación & Cualitativa nominal & $\begin{array}{l}\text { Área I/ área II/ área III/ área IV/ área V/ } \\
\text { área VI/ área VII/ área VIII/ extranjero/ } \\
\text { otros }\end{array}$ \\
\hline $\begin{array}{l}\text { Derivación a otros } \\
\text { hospitales de referencia }\end{array}$ & Cualitativa nominal & $\begin{array}{l}\text { Hospital Nacional de Parapléjicos de } \\
\text { Toledo/ Institut Guttman/ Hospital de } \\
\text { origen/ mutuas/ otros/ no derivación }\end{array}$ \\
\hline \multicolumn{3}{|c|}{$\begin{array}{l}\text { VARIABLES RELACIONADAS CON LAS COMPLICACIONES SECUNDARIAS RELACIONADAS CON LA } \\
\text { LESIÓN MEDULAR }\end{array}$} \\
\hline Presencia de UPP & Cualitativa nominal & $\begin{array}{l}\text { Sacras/ talones/ isquion/trocánter/ dedos } \\
\text { del pie/ múltiples localizaciones/ no UPP }\end{array}$ \\
\hline Alteraciones urológicas & Cualitativa nominal & $\begin{array}{l}\text { Vejiga neurógena/ ITUs/ urgencia } \\
\text { miccional/ incontinencia urinaria/ no } \\
\text { complicaciones urológicas }\end{array}$ \\
\hline $\begin{array}{l}\text { Alteraciones } \\
\text { gastrointestinales }\end{array}$ & Cualitativa nominal & $\begin{array}{l}\text { Intestino neurógeno/ estreñimiento/ } \\
\text { incontinencia fecal/ incontinencia a gases/ } \\
\text { no complicaciones intestinales }\end{array}$ \\
\hline Presencia de dolor & Cualitativa nominal & $\begin{array}{l}\text { Dolor neuropático/ dolor nociceptivo/ } \\
\text { ambos/ no dolor }\end{array}$ \\
\hline Espasticidad muscular & $\begin{array}{l}\text { Cualitativa } \\
\text { dicotómica }\end{array}$ & (n) \\
\hline $\begin{array}{l}\text { Episodio de disreflexia } \\
\text { autonómica }\end{array}$ & $\begin{array}{l}\text { Cualitativa } \\
\text { dicotómica }\end{array}$ & Sí/ no \\
\hline $\begin{array}{l}\text { Complicaciones } \\
\text { respiratorias }\end{array}$ & $\begin{array}{l}\text { Cualitativa } \\
\text { dicotómica }\end{array}$ & Sí/no \\
\hline $\begin{array}{l}\text { Alteraciones de la salud } \\
\text { mental }\end{array}$ & Cualitativa nominal & $\begin{array}{l}\text { Síndrome ansioso-depresivo/ intento } \\
\text { autolítico/insomnio/ otras enfermedades } \\
\text { de salud mental/ enfermedades mentales } \\
\text { previas a la lesión/ no enfermedad mental }\end{array}$ \\
\hline Alteraciones de la marcha & Cualitativa nominal & $\begin{array}{l}\text { No camina/ camina pequeños trayectos } \\
\text { con apoyos/ marcha Pareto-espástica/ } \\
\text { marcha en steppage/ otras alteraciones } \\
\text { de la marcha no definidas }\end{array}$ \\
\hline
\end{tabular}




\begin{tabular}{|l|l|l|}
\hline \multicolumn{2}{|c|}{ VARIABLES RELACIONADAS CON LOS APOYOS TRAS LA LESIÓN MEDULAR } \\
\hline Uso de productos de apoyo & $\begin{array}{l}\text { Cualitativa } \\
\text { dicotómica }\end{array}$ & Sí/ no \\
\hline $\begin{array}{l}\text { Utilización de ayudas para } \\
\text { la movilidad personal }\end{array}$ & Cualitativa nominal & $\begin{array}{l}\text { Silla de ruedas/ muletas o bastón inglés/ } \\
\text { otras ayudas/ no ayudas para el } \\
\text { desplazamiento }\end{array}$ \\
\hline $\begin{array}{l}\text { Asociacionismo } \\
\text { relacionado con la lesión }\end{array}$ & Cualitativa nominal & Aspaym/ Cocemfe/ no asociacionismo \\
\hline \multicolumn{2}{|c|}{ VARIABLES RELACIONADAS CON LA ATENCIÓN A LA SEXUALIDAD POR PARTE DE LOS } \\
PROFESIONALES
\end{tabular}


Anexo II: Tabla de variables de Fase II

\begin{tabular}{|c|c|c|}
\hline VARIABLE & DESCRIPCIÓN & CLASIFICACIÓN \\
\hline \multicolumn{3}{|c|}{ VARIABLES SOCIODEMOGRÁFICAS } \\
\hline Sexo & $\begin{array}{l}\text { Cualitativa } \\
\text { dicotómica }\end{array}$ & Hombre/ mujer \\
\hline Edad & Cuantitativa & En años \\
\hline Estado civil & Cualitativa nominal & $\begin{array}{l}\text { Casado o en pareja/ soltero/ separado o } \\
\text { divorciado/ viudo/ otro tipo de relación } \\
\text { de pareja }\end{array}$ \\
\hline Número de hijos & Cuantitativa & \\
\hline Orientación sexual & Cualitativa nominal & $\begin{array}{l}\text { Heterosexual/ homosexual/ bisexual/ } \\
\text { otra orientación del deseo }\end{array}$ \\
\hline Núcleo de convivencia & Cualitativa nominal & $\begin{array}{l}\text { Pareja/solo/ padres/ institución } \\
\text { residencial/ otras situaciones de } \\
\text { convivencia }\end{array}$ \\
\hline Nivel de estudios & Cualitativa ordinal & Primarios/ medios/ universitarios \\
\hline \multicolumn{3}{|c|}{ VARIABLES RELACIONADAS CON LA LESIÓN MEDULAR } \\
\hline Causa de la lesión medular & Cualitativa nominal & $\begin{array}{l}\text { Accidente tráfico/ accidente laboral/ } \\
\text { accidente fortuito/ zambullida/ } \\
\text { enfermedad/ accidente deportivo/ } \\
\text { agresión/ intento autolisis }\end{array}$ \\
\hline Tiempo de lesión & Cuantitativa & En años \\
\hline $\begin{array}{l}\text { Tipo de hospitales de primera } \\
\text { atención }\end{array}$ & Cualitativa nominal & $\begin{array}{l}\text { Hospital regional/ hospital nacional de } \\
\text { referencia/ ambos dispositivos/ } \\
\text { extranjero/ ambos dispositivos }\end{array}$ \\
\hline $\begin{array}{l}\text { Tipo de lesión según } \\
\text { afectación de miembros }\end{array}$ & Cualitativa nominal & $\begin{array}{l}\text { Paraparesia/ paraplejia/ tetraparesia/ } \\
\text { tetraplejia/ no sabe su tipo de lesión }\end{array}$ \\
\hline $\begin{array}{l}\text { Tipo de lesión según } \\
\text { extensión }\end{array}$ & Cualitativa nominal & $\begin{array}{l}\text { Completa/ incompleta/ no sabe su tipo } \\
\text { de lesión }\end{array}$ \\
\hline $\begin{array}{l}\text { Tipo de lesión según nivel } \\
\text { neurológico }\end{array}$ & Cualitativa nominal & $\begin{array}{l}\text { Cervical/ dorsal/ lumbar-sacra/ no sabe } \\
\text { su tipo de lesión }\end{array}$ \\
\hline Presencia de UPP & $\begin{array}{l}\text { Cualitativa } \\
\text { dicotómica }\end{array}$ & Sí/ no \\
\hline Espasticidad muscular & $\begin{array}{l}\text { Cualitativa } \\
\text { dicotómica }\end{array}$ & Sí/ no \\
\hline $\begin{array}{l}\text { Dolor crónico asociado a la } \\
\text { lesión }\end{array}$ & $\begin{array}{l}\text { Cualitativa } \\
\text { dicotómica }\end{array}$ & Sí/ no \\
\hline $\begin{array}{l}\text { Presencia de sensibilidad en } \\
\text { el área genital }\end{array}$ & Cualitativa nominal & Sí/ no/ parcialmente \\
\hline $\begin{array}{l}\text { Presencia de sensibilidad en } \\
\text { el área anal }\end{array}$ & Cualitativa nominal & Sí/ no/ parcialmente \\
\hline $\begin{array}{l}\text { Método de vaciamiento } \\
\text { vesical }\end{array}$ & Cualitativa nominal & $\begin{array}{l}\text { Espontáneo/ sondaje vesical } \\
\text { intermitente/ sondaje vesical } \\
\text { permanente/ maniobra de Credé/ sonda } \\
\text { suprapúbica/ pañal/ otros }\end{array}$ \\
\hline
\end{tabular}




\begin{tabular}{|c|c|c|}
\hline $\begin{array}{l}\text { Método de vaciamiento } \\
\text { intestinal }\end{array}$ & Cualitativa nominal & $\begin{array}{l}\text { Voluntario/ estimulación digital/ enema- } \\
\text { supositorios/ pañal/ otros }\end{array}$ \\
\hline \multicolumn{3}{|c|}{ VARIABLES RELACIONADAS CON LA CALIDAD DE VIDA } \\
\hline $\begin{array}{l}\text { Satisfacción con la vida en } \\
\text { general }\end{array}$ & Cualitativa ordinal & $\begin{array}{l}\text { Muy insatisfactoria/ insatisfactoria/ un } \\
\text { poco insatisfactoria/ un poco } \\
\text { satisfactoria/ satisfactoria/ muy } \\
\text { satisfactoria }\end{array}$ \\
\hline $\begin{array}{l}\text { Satisfacción con la vida } \\
\text { sexual }\end{array}$ & Cualitativa ordinal & $\begin{array}{l}\text { Muy insatisfactoria/ insatisfactoria/ un } \\
\text { poco insatisfactoria/ un poco } \\
\text { satisfactoria/ satisfactoria/ muy } \\
\text { satisfactoria }\end{array}$ \\
\hline $\begin{array}{l}\text { Satisfacción con la relación } \\
\text { en pareja }\end{array}$ & Cualitativa ordinal & $\begin{array}{l}\text { Muy insatisfactoria/ insatisfactoria/ un } \\
\text { poco insatisfactoria/ un poco } \\
\text { satisfactoria/ satisfactoria/ muy } \\
\text { satisfactoria }\end{array}$ \\
\hline $\begin{array}{l}\text { Satisfacción con la vida } \\
\text { familiar }\end{array}$ & Cualitativa ordinal & $\begin{array}{l}\text { Muy insatisfactoria/ insatisfactoria/ un } \\
\text { poco insatisfactoria/ un poco } \\
\text { satisfactoria/satisfactoria/ muy } \\
\text { satisfactoria }\end{array}$ \\
\hline $\begin{array}{l}\text { Satisfacción con la relación } \\
\text { con amigos y conocidos }\end{array}$ & Cualitativa ordinal & $\begin{array}{l}\text { Muy insatisfactoria/ insatisfactoria/ un } \\
\text { poco insatisfactoria/ un poco } \\
\text { satisfactoria/satisfactoria/ muy } \\
\text { satisfactoria }\end{array}$ \\
\hline $\begin{array}{l}\text { Satisfacción con la vida de } \\
\text { ocio }\end{array}$ & Cualitativa ordinal & $\begin{array}{l}\text { Muy insatisfactoria/ insatisfactoria/ un } \\
\text { poco insatisfactoria/ un poco } \\
\text { satisfactoria/ satisfactoria/ muy } \\
\text { satisfactoria }\end{array}$ \\
\hline $\begin{array}{l}\text { Satisfacción con la situación } \\
\text { laboral }\end{array}$ & Cualitativa ordinal & $\begin{array}{l}\text { Muy insatisfactoria/ insatisfactoria/ un } \\
\text { poco insatisfactoria/ un poco } \\
\text { satisfactoria/satisfactoria/ muy } \\
\text { satisfactoria }\end{array}$ \\
\hline $\begin{array}{l}\text { Satisfacción con la situación } \\
\text { económica }\end{array}$ & Cualitativa ordinal & $\begin{array}{l}\text { Muy insatisfactoria/ insatisfactoria/ un } \\
\text { poco insatisfactoria/ un poco } \\
\text { satisfactoria/ satisfactoria/ muy } \\
\text { satisfactoria }\end{array}$ \\
\hline Dimensión sexual & Cuantitativa & \\
\hline Dimensión social & Cuantitativa & \\
\hline Dimensión económica & Cuantitativa & \\
\hline $\begin{array}{l}\text { Sumatorio de calidad de vida } \\
\text { global }\end{array}$ & Cuantitativa & \\
\hline \multicolumn{3}{|c|}{ VARIABLES RELACIONADAS CON LA SEXUALIDAD } \\
\hline \multicolumn{3}{|c|}{ Comunes para ambos sexos } \\
\hline $\begin{array}{l}\text { Preocupación por el escape } \\
\text { involuntario de orina durante } \\
\text { las relaciones eróticas }\end{array}$ & $\begin{array}{l}\text { Cualitativa } \\
\text { dicotómica }\end{array}$ & Sí/ no \\
\hline $\begin{array}{l}\text { Preocupación por el escape } \\
\text { involuntario de heces }\end{array}$ & $\begin{array}{l}\text { Cualitativa } \\
\text { dicotómica }\end{array}$ & Sí/ no \\
\hline
\end{tabular}




\begin{tabular}{|c|c|c|}
\hline $\begin{array}{l}\text { durante las relaciones } \\
\text { eróticas }\end{array}$ & & \\
\hline $\begin{array}{l}\text { Presencia de crisis de } \\
\text { disreflexia autonómica } \\
\text { durante las relaciones } \\
\text { eróticas }\end{array}$ & $\begin{array}{l}\text { Cualitativa } \\
\text { dicotómica }\end{array}$ & Sí/ no \\
\hline $\begin{array}{l}\text { Uso de libros, películas o arte } \\
\text { con contenido erótico }\end{array}$ & Cualitativa ordinal & $\begin{array}{l}\text { Nunca/ rara vez/ a veces/ a menudo/ } \\
\text { diariamente }\end{array}$ \\
\hline $\begin{array}{l}\text { Grado de placer o disfrute al } \\
\text { pensar y fantasear acerca del } \\
\text { sexo }\end{array}$ & Cualitativa ordinal & $\begin{array}{l}\text { Ninguno/poco/ algo/ mucho/ } \\
\text { muchísimo }\end{array}$ \\
\hline $\begin{array}{l}\text { Grado de importancia de la } \\
\text { vida erótica en las relaciones } \\
\text { de pareja }\end{array}$ & Cualitativa ordinal & $\begin{array}{l}\text { No importante/ muy poco importante/ } \\
\text { relativamente importante/ importante/ } \\
\text { muy importante }\end{array}$ \\
\hline $\begin{array}{l}\text { Frecuencia de obtención del } \\
\text { orgasmo }\end{array}$ & Cualitativa ordinal & $\begin{array}{l}\text { Nunca/ rara vez/ a veces/ a menudo/ } \\
\text { siempre/ }\end{array}$ \\
\hline $\begin{array}{l}\text { Grado de placer o disfrute } \\
\text { obtenido durante el orgasmo }\end{array}$ & Cualitativa ordinal & $\begin{array}{l}\text { Muchísimo placer/ mucho placer/ algo } \\
\text { de placer/ poco placer/ ningún placer }\end{array}$ \\
\hline $\begin{array}{l}\text { Grado de placer o disfrute a } \\
\text { lo largo de la relación erótica }\end{array}$ & Cualitativa ordinal & $\begin{array}{l}\text { Muchísimo placer/ mucho placer/ algo } \\
\text { de placer/ poco placer/ ningún placer }\end{array}$ \\
\hline $\begin{array}{l}\text { Percepción de la imagen } \\
\text { corporal previa a la lesión }\end{array}$ & Cualitativa ordinal & $\begin{array}{l}\text { Muy insatisfecho/ insatisfecho/ } \\
\text { satisfecho/ muy satisfecho }\end{array}$ \\
\hline $\begin{array}{l}\text { Percepción de la imagen } \\
\text { corporal en la actualidad }\end{array}$ & Cualitativa ordinal & $\begin{array}{l}\text { Muy insatisfecho/ insatisfecho/ } \\
\text { satisfecho/ muy satisfecho }\end{array}$ \\
\hline $\begin{array}{l}\text { Percepción sobre el cambio } \\
\text { en la capacidad de seducción } \\
\text { tras la lesión medular }\end{array}$ & Cualitativa ordinal & $\begin{array}{l}\text { Ha aumentado mucho/ ha aumentado } \\
\text { un poco/ se ha mantenido igual/ ha } \\
\text { disminuido un poco/ ha disminuido } \\
\text { mucho/ ha desaparecido completamente }\end{array}$ \\
\hline $\begin{array}{l}\text { Cambios en la satisfacción } \\
\text { con la vida erótica tras la } \\
\text { lesión medular }\end{array}$ & Cualitativa ordinal & $\begin{array}{l}\text { Ha aumentado mucho/ ha aumentado } \\
\text { un poco/ se ha mantenido igual/ ha } \\
\text { disminuido un poco/ ha disminuido } \\
\text { mucho/ ha desaparecido completamente }\end{array}$ \\
\hline $\begin{array}{l}\text { Percepción sobre el grado de } \\
\text { satisfacción a la pareja }\end{array}$ & Cualitativa ordinal & $\begin{array}{l}\text { Casi nunca/ pocas veces/ algunas veces/ } \\
\text { muchas veces/ casi siempre }\end{array}$ \\
\hline $\begin{array}{l}\text { Satisfacción sobre el deseo } \\
\text { de procreación }\end{array}$ & Cualitativa nominal & $\begin{array}{l}\text { Sí/ no/ parcialmente/ no deseaba tener } \\
\text { hijos }\end{array}$ \\
\hline $\begin{array}{l}\text { Uso de ayudas para tener } \\
\text { hijos }\end{array}$ & Cualitativa nominal & $\begin{array}{l}\text { Sin ayuda/ inseminación artificial/ } \\
\text { inseminación artificial con donante/ } \\
\text { fertilización in vitro/ fertilización in vitro } \\
\text { con donante/ uso de vibradores/ otros }\end{array}$ \\
\hline \multicolumn{3}{|c|}{ Cuestionario SIS } \\
\hline $\begin{array}{l}\text { Deseo sexual actual } \\
\text { comparado con la situación } \\
\text { previa a la lesión }\end{array}$ & Cualitativa ordinal & $\begin{array}{l}\text { Inexistente/ disminuido/ sin cambio/ } \\
\text { aumentado }\end{array}$ \\
\hline $\begin{array}{l}\text { Importancia dada a la } \\
\text { sexualidad en comparación }\end{array}$ & Cualitativa ordinal & $\begin{array}{l}\text { Inexistente/ disminuida/sin cambio/ } \\
\text { aumentada }\end{array}$ \\
\hline
\end{tabular}




\begin{tabular}{|c|c|c|}
\hline $\begin{array}{l}\text { con la situación previa a la } \\
\text { lesión }\end{array}$ & & \\
\hline $\begin{array}{l}\text { Satisfacción con las } \\
\text { relaciones sexuales de pareja } \\
\text { tras la lesión }\end{array}$ & Cualitativa ordinal & $\begin{array}{l}\text { Muy satisfactorias/ parcialmente } \\
\text { satisfactorias/ parcialmente } \\
\text { insatisfactorias/ muy insatisfactorias }\end{array}$ \\
\hline $\begin{array}{l}\text { Satisfacción con las } \\
\text { relaciones sexuales de pareja } \\
\text { previas a la lesión }\end{array}$ & Cualitativa ordinal & $\begin{array}{l}\text { Muy satisfactorias/ parcialmente } \\
\text { satisfactorias/ parcialmente } \\
\text { insatisfactorias/ muy insatisfactorias }\end{array}$ \\
\hline $\begin{array}{l}\text { Posibilidades y habilidades } \\
\text { para satisfacer sexualmente a } \\
\text { su pareja }\end{array}$ & Cualitativa ordinal & $\begin{array}{l}\text { Muy satisfactorias/ parcialmente } \\
\text { satisfactorias/ parcialmente } \\
\text { insatisfactorias/ muy insatisfactorias }\end{array}$ \\
\hline $\begin{array}{l}\text { Posibilidades y habilidades } \\
\text { para disfrutar de su propia } \\
\text { sexualidad }\end{array}$ & Cualitativa ordinal & $\begin{array}{l}\text { Muy satisfactorias/ parcialmente } \\
\text { satisfactorias/ parcialmente } \\
\text { insatisfactorias/ muy insatisfactorias }\end{array}$ \\
\hline Sumatorio total SIS & Cuantitativa & \\
\hline \multicolumn{3}{|c|}{ Sexualidad en hombres } \\
\hline $\begin{array}{l}\text { Uso de ayudas para } \\
\text { conseguir o mantener la } \\
\text { erección }\end{array}$ & Cualitativa nominal & $\begin{array}{l}\text { Fármacos orales/ fármacos inyectados } \\
\text { en el pene/ prótesis peneana/ no ayudas }\end{array}$ \\
\hline $\begin{array}{l}\text { Frecuencia de capacidad de } \\
\text { eyacular cuando se } \\
\text { encuentra muy excitado }\end{array}$ & Cualitativa ordinal & $\begin{array}{l}\text { Nunca/ rara vez/ a veces/ a menudo/ } \\
\text { siempre }\end{array}$ \\
\hline $\begin{array}{l}\text { Uso de ayudas para facilitar } \\
\text { la eyaculación }\end{array}$ & $\begin{array}{l}\text { Cualitativa } \\
\text { dicotómica }\end{array}$ & Vibradores peneanos/ no ayudas \\
\hline \multicolumn{3}{|c|}{ Cuestionario IEEF-5 } \\
\hline $\begin{array}{l}\text { Confianza en poder tener y } \\
\text { mantener una erección }\end{array}$ & Cualitativa ordinal & $\begin{array}{l}\text { Muy baja/ baja/ moderada/ alta/ muy } \\
\text { alta }\end{array}$ \\
\hline $\begin{array}{l}\text { Frecuencia de erecciones con } \\
\text { dureza suficiente para la } \\
\text { penetración }\end{array}$ & Cualitativa ordinal & $\begin{array}{l}\text { Casi nunca/ pocas veces/ algunas veces/ } \\
\text { muchas veces/ casi siempre }\end{array}$ \\
\hline $\begin{array}{l}\text { Frecuencia de } \\
\text { mantenimiento de erección } \\
\text { tras la penetración }\end{array}$ & Cualitativa ordinal & $\begin{array}{l}\text { Casi nunca/ pocas veces/ algunas veces/ } \\
\text { muchas veces/ casi siempre }\end{array}$ \\
\hline $\begin{array}{l}\text { Dificultad en mantenimiento } \\
\text { de erección hasta el final del } \\
\text { acto sexual }\end{array}$ & Cualitativa ordinal & $\begin{array}{l}\text { Extremadamente difícil/ muy difícil/ } \\
\text { difícil/ ligeramente difícil/ nada difícil }\end{array}$ \\
\hline $\begin{array}{l}\text { Frecuencia de relaciones } \\
\text { sexuales satisfactorias }\end{array}$ & Cualitativa ordinal & $\begin{array}{l}\text { Casi nunca/ pocas veces/ algunas veces/ } \\
\text { muchas veces/ casi siempre }\end{array}$ \\
\hline Sumatorio IIEF-5 & Cuantitativa & \\
\hline Grado de disfunción eréctil & Cualitativa ordinal & $\begin{array}{l}\text { Grave/ moderada/ de leve a moderada/ } \\
\text { leve/ no DE }\end{array}$ \\
\hline \multicolumn{3}{|c|}{ Sexualidad en mujeres } \\
\hline Grado de excitabilidad & Cualitativa ordinal & $\begin{array}{l}\text { Nunca/ rara vez/ a veces/ a menudo/ } \\
\text { siempre }\end{array}$ \\
\hline $\begin{array}{l}\text { Frecuencia en la consecución } \\
\text { de excitación y pérdida } \\
\text { posterior del interés }\end{array}$ & Cualitativa ordinal & $\begin{array}{l}\text { Nunca/ rara vez/ a veces/ a menudo/ } \\
\text { siempre }\end{array}$ \\
\hline
\end{tabular}




\begin{tabular}{|c|c|c|}
\hline $\begin{array}{l}\text { Frecuencia de lubricación } \\
\text { vaginal satisfactoria durante } \\
\text { las relaciones sexuales }\end{array}$ & Cualitativa ordinal & $\begin{array}{l}\text { Nunca/ rara vez/ a veces/ a menudo/ } \\
\text { siempre }\end{array}$ \\
\hline $\begin{array}{l}\text { Uso de ayudas para la } \\
\text { lubricación vaginal }\end{array}$ & $\begin{array}{l}\text { Cualitativa } \\
\text { dicotómica }\end{array}$ & $\begin{array}{l}\text { Ninguna/ hidratantes o lubricantes } \\
\text { vaginales }\end{array}$ \\
\hline \multicolumn{3}{|c|}{ VARIABLE RELACIONADA CON LAS FUENTES DE INFORMACIÓN UTILIZADAS } \\
\hline $\begin{array}{l}\text { Medios de información sobre } \\
\text { sexualidad tras la lesión } \\
\text { medular }\end{array}$ & Cualitativa nominal & $\begin{array}{l}\text { Profesionales sanitarios/ internet/ } \\
\text { compañeros, amigos o pareja/ } \\
\text { asociaciones/libros y revistas/ otros }\end{array}$ \\
\hline \multicolumn{3}{|c|}{$\begin{array}{l}\text { VARIABLES RELACIONADAS CON LAS NECESIDADES SANITARIAS PERCIBIDAS EN RELACIÓN A LA } \\
\text { SEXUALIDAD }\end{array}$} \\
\hline $\begin{array}{l}\text { Percepción sobre la } \\
\text { adecuación de información } \\
\text { por parte del sistema de } \\
\text { salud }\end{array}$ & $\begin{array}{l}\text { Cualitativa } \\
\text { dicotómica }\end{array}$ & ( \\
\hline $\begin{array}{l}\text { Temas sobre los que se ha } \\
\text { informado sobre la } \\
\text { sexualidad por parte de los } \\
\text { profesionales de salud }\end{array}$ & Cualitativa nominal & $\begin{array}{l}\text { Pregunta abierta categorizada } \\
\text { posteriormente }\end{array}$ \\
\hline $\begin{array}{l}\text { Temas sobre los que se } \\
\text { hubiera precisado } \\
\text { información }\end{array}$ & Cualitativa nominal & $\begin{array}{l}\text { Pregunta abierta categorizada } \\
\text { posteriormente }\end{array}$ \\
\hline \multicolumn{3}{|c|}{ VARIABLES RELACIONADAS CON LA VALORACIÓN DE LA FIGURA DEL ASISTENTE SEXUAL } \\
\hline $\begin{array}{l}\text { Opinión sobre la asistencia } \\
\text { sexual entendida como un } \\
\text { apoyo para poder acceder } \\
\text { sexualmente al propio } \\
\text { cuerpo o al de una pareja }\end{array}$ & Cualitativa nominal & $\begin{array}{l}\text { Pregunta abierta categorizada } \\
\text { posteriormente }\end{array}$ \\
\hline $\begin{array}{l}\text { Opinión sobre la asistencia } \\
\text { sexual entendida como } \\
\text { alguien con quien mantener } \\
\text { relaciones sexuales }\end{array}$ & Cualitativa nominal & $\begin{array}{l}\text { Pregunta abierta categorizada } \\
\text { posteriormente }\end{array}$ \\
\hline
\end{tabular}




\section{Anexo III: Cuestionario para mujeres}

Como ya ha sido informada, el siguiente cuestionario forma parte de un estudio que pretende conocer la realidad sobre la sexualidad en las mujeres con lesión medular adquirida de cara a mejorar la atención a este aspecto de la vida.

Las respuestas al cuestionario son anónimas y confidenciales. En ningún caso serán analizadas individualmente si no mediante estadística de forma global y conjunta de todos los cuestionarios recibidos.

Para que los resultados sean válidos es necesario que responda a las preguntas de forma sincera, eligiendo la respuesta que más se aproxime a sus circunstancias, ideas o sentimientos.

Si lo considera oportuno le agradecemos su colaboración remitiéndolo cubierto al equipo investigador dentro del sobre pre-franqueado (envío gratuito) que le adjuntamos. Cualquier duda puede consultarla en el contacto de la investigadora principal que le indicamos en la carta adjunta.

Muchas gracias por su colaboración, es de gran importancia.

En cada pregunta marque con una cruz o una equis $(X)$ el cuadro que corresponde a la respuesta con la que esté más de acuerdo o refleje mejor sus circunstancias.

Nota previa: en este cuestionario, cuando hablamos de sexo o relaciones sexuales nos referimos a cualquier expresión de la sexualidad: besos, caricias, tocamientos, sexo oral, etc. y no solo a las relaciones con penetración.

Fecha de nacimiento:

día.

mes. año.

Nivel de estudios

Primarios (primarios, CEP, GE, Bachiller elemental, EGB, FP I, FP grado medio)

Medios (BUP, COU, PREU, ESO, Bachiller, FP II, FP grado superior)

Universitarios (diplomatura, grado, licenciatura)

Comunidad Autónoma donde vive:

Estado civil actual:

\begin{tabular}{|c|c|c|c|}
\hline Soltera & En pareja/casada & Separada/divorciada & Viuda \\
\hline & & & \\
\hline
\end{tabular}

$\square \quad$ Otro tipo de relación. ¿Cuál?

Número de hijos:

Orientación sexual:

\begin{tabular}{|c|c|c|c|}
\hline Heterosexual & Homosexual & Bisexual & Otros. Especificar \\
\hline & & & \\
\hline
\end{tabular}

¿Con quién vive?

\begin{tabular}{|c|c|c|c|c|}
\hline Pareja & Padres & Sola & Residencia & Otros. Especificar. \\
\hline & & & & \\
\hline
\end{tabular}




\begin{tabular}{|c|c|c|c|c|c|c|}
\hline & $\begin{array}{c}1 \text { - Muy } \\
\text { insatisfactoria }\end{array}$ & $\begin{array}{c}2- \\
\text { Insatisfactoria } \\
\end{array}$ & $\begin{array}{c}3 \text { - Un poco } \\
\text { insatisfactoria }\end{array}$ & $\begin{array}{l}4 \text { - Un poco } \\
\text { satisfactoria }\end{array}$ & $\begin{array}{c}5 \text { - } \\
\text { Satisfactoria } \\
\end{array}$ & $\begin{array}{c}\text { 6- Muy } \\
\text { satisfactoria }\end{array}$ \\
\hline Mi vida general es: & $\square$ & $\square$ & $\square$ & $\square$ & $\square$ & $\square$ \\
\hline Mi vida sexual es: & $\square$ & $\square$ & $\square$ & $\square$ & $\square$ & $\square$ \\
\hline $\begin{array}{c}\text { Mi relación en } \\
\text { pareja es: }\end{array}$ & $\square$ & $\square$ & $\square$ & $\square$ & $\square$ & $\square$ \\
\hline Mi vida familiar es: & $\square$ & $\square$ & $\square$ & $\square$ & $\square$ & $\square$ \\
\hline $\begin{array}{c}\text { Mi relación con mis } \\
\text { amigos y conocidos } \\
\text { es: }\end{array}$ & $\square$ & $\square$ & $\square$ & $\square$ & $\square$ & $\square$ \\
\hline Mi vida de ocio es: & $\square$ & $\square$ & $\square$ & $\square$ & $\square$ & $\square$ \\
\hline $\begin{array}{l}\text { Mi situación } \\
\text { laboral es: }\end{array}$ & $\square$ & $\square$ & $\square$ & $\square$ & $\square$ & $\square$ \\
\hline $\begin{array}{l}\text { Mi situación } \\
\text { económica es: }\end{array}$ & $\square$ & $\square$ & $\square$ & $\square$ & $\square$ & $\square$ \\
\hline
\end{tabular}

Fecha en la que se produjo la lesión medular:

día mes. año.

Causa de la lesión:

Accidente de tráfico

Accidente laboral

Accidente deportivo

Accidente fortuito

Zambullida
Intento de suicidio

Agresión

Enfermedad

Otras

¿En qué hospital/es ha sido atendida de la lesión medular?

Tipo de lesión

\begin{tabular}{|c|c|c|c|c|}
\hline Paraplejia & Paraparesia & Tetraplejia & Tetraparesia & No lo sé \\
\hline & & & & \\
\hline
\end{tabular}

Tipo de lesión según extensión:

\begin{tabular}{|c|c|c|}
\hline Completa & Incompleta & No lo sé \\
\hline & & \\
\hline
\end{tabular}

Nivel de la lesión

\begin{tabular}{|c|c|c|c|c|}
\hline Cervical & Dorsal o torácico & Lumbar & Sacro & No lo sé \\
\hline & & & & \\
\hline
\end{tabular}

¿Tiene o ha tenido úlceras por presión?

$\square \quad$ Sí $\quad \square$ No

¿Tiene o ha tenido espasticidad?

$$
\text { Sí } \square \text { No }
$$

¿Presenta dolor crónico (de más de 6 meses de duración) asociado a la lesión medular?

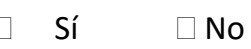


Indique si presenta sensibilidad en el área genital:

$$
\text { Sí } \square \text { No } \quad \square \text { Parcialmente }
$$

Indique si presenta sensibilidad en el área anal:

$$
\text { Sí } \square \text { No } \quad \square \text { Parcialmente }
$$

Indique el método mediante el cual realiza vaciamiento de su vejiga:

Espontáneo (sin ayuda)

Sondaje vesical intermitente

Sondaje vesical permanente

Sonda suprapúbica

Con maniobra de Credé (compresión manual de la parte baja del abdomen para ayudar al vaciamiento de la vejiga)

Pañal por vaciamiento involuntario

Otro ¿Cuál?

Indique el método mediante el cual realiza vaciamiento de su intestino:

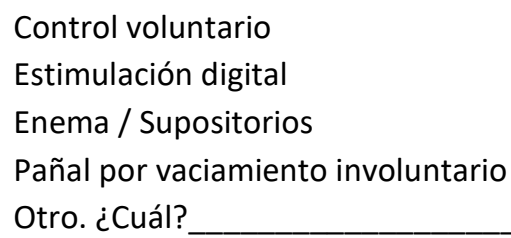

¿Le preocupa el escape involuntario de orina durante la actividad sexual?

$$
\square \text { Sí } \quad \square \text { No }
$$

¿Le preocupa el escape involuntario de heces durante la actividad sexual?

$$
\square \text { Sí } \quad \square \text { No }
$$

¿Ha presentado alguna crisis de disreflexia autonómica (encontrarse mal con crisis de sudoración, taquicardia, dolor de cabeza y aumento de la tensión que necesitara asistencia sanitaria) durante las relaciones sexuales?
$\square$ Sí
$\square$ No

¿Utiliza libros, películas, música o arte con contenido sexual?

\section{Nunca}

Rara vez (menos de una vez al mes)

A veces (una vez al mes pero menos de 2 veces/semana)

A menudo (2 veces/semana o más)

Diariamente

¿Cuánto placer o disfrute obtiene de pensar y fantasear acerca del sexo?

Ningún disfrute o placer

Poco disfrute o placer

Algo de disfrute o placer

Mucho disfrute o placer

Muchísimo disfrute o placer 
¿Es su vida sexual un aspecto importante en sus relaciones de pareja?

No tiene importancia

Es un aspecto muy poco importante

Es un aspecto relativamente importante

Es un aspecto importante

Es un aspecto muy importante

¿Se excita fácilmente? (con lo que le gusta)

\begin{tabular}{|c|c|c|c|c|}
\hline Nunca & $\begin{array}{c}\text { Rara vez (la } \\
\text { minoría de las } \\
\text { veces) }\end{array}$ & $\begin{array}{c}\text { A veces (la mitad } \\
\text { de las veces) }\end{array}$ & $\begin{array}{c}\text { A menudo (la } \\
\text { mayoría de las } \\
\text { veces) }\end{array}$ & Siempre \\
\hline & & & & \\
\hline
\end{tabular}

¿Tiene lubricación vaginal satisfactoria durante la actividad sexual?

\begin{tabular}{|c|c|c|c|c|}
\hline Nunca & $\begin{array}{c}\text { Rara vez (la } \\
\text { minoría de las } \\
\text { veces) }\end{array}$ & $\begin{array}{c}\text { A veces (la mitad } \\
\text { de las veces) }\end{array}$ & $\begin{array}{c}\text { A menudo (la } \\
\text { mayoría de las } \\
\text { veces) }\end{array}$ & Siempre \\
\hline & & & & \\
\hline
\end{tabular}

¿Utiliza alguna ayuda para la lubricación?

\begin{tabular}{|c|c|c|}
\hline No & Fármacos & Lubricantes \\
\hline & & \\
\hline
\end{tabular}

$\square \quad$ Otros. Especificar:

¿Con qué frecuencia llega a la excitación y luego pierde el interés?

\begin{tabular}{|c|c|c|c|c|}
\hline Nunca & $\begin{array}{c}\text { Rara vez (la } \\
\text { minoría de las } \\
\text { veces) }\end{array}$ & $\begin{array}{c}\text { A veces (la mitad } \\
\text { de las veces) }\end{array}$ & $\begin{array}{c}\text { A menudo (la } \\
\text { mayoría de las } \\
\text { veces) }\end{array}$ & Siempre \\
\hline & & & & \\
\hline
\end{tabular}

¿Es capaz de tener un orgasmo cuando está muy excitada?

\begin{tabular}{|c|c|c|c|c|}
\hline Nunca & $\begin{array}{c}\text { Rara vez (la } \\
\text { minoría de las } \\
\text { veces) }\end{array}$ & $\begin{array}{c}\text { A veces (la mitad } \\
\text { de las veces) }\end{array}$ & $\begin{array}{c}\text { A menudo (la } \\
\text { mayoría de las } \\
\text { veces) }\end{array}$ & Siempre \\
\hline & & & & \\
\hline
\end{tabular}

¿Cuánto placer o disfrute obtiene en sus orgasmos? Si no tiene orgasmos, deje la pregunta en blanco.

\begin{tabular}{|c|c|c|c|c|}
\hline $\begin{array}{c}\text { Ningún disfrute o } \\
\text { placer }\end{array}$ & $\begin{array}{c}\text { Poco disfrute o } \\
\text { placer }\end{array}$ & $\begin{array}{c}\text { Algo de disfrute o } \\
\text { placer }\end{array}$ & $\begin{array}{c}\text { Mucho disfrute o } \\
\text { placer }\end{array}$ & $\begin{array}{c}\text { Muchísimo } \\
\text { disfrute o placer }\end{array}$ \\
\hline & & & & \\
\hline
\end{tabular}

¿Cuánto placer o disfrute obtiene a lo largo de la relación sexual (no valorando exclusivamente el momento del orgasmo)?

\begin{tabular}{|c|c|c|c|c|}
\hline $\begin{array}{c}\text { Ningún disfrute o } \\
\text { placer }\end{array}$ & $\begin{array}{c}\text { Poco disfrute o } \\
\text { placer }\end{array}$ & $\begin{array}{c}\text { Algo de disfrute o } \\
\text { placer }\end{array}$ & $\begin{array}{c}\text { Mucho disfrute o } \\
\text { placer }\end{array}$ & $\begin{array}{c}\text { Muchísimo } \\
\text { disfrute o placer }\end{array}$ \\
\hline & & & & \\
\hline
\end{tabular}


¿Cómo se sentía con su imagen corporal antes de tener la lesión?

\begin{tabular}{|c|c|c|c|}
\hline Muy satisfecha & Satisfecha & Insatisfecha & Muy insatisfecha \\
\hline & & & \\
\hline
\end{tabular}

¿Cómo se siente con su imagen corporal actual?

\begin{tabular}{|c|c|c|c|}
\hline Muy satisfecha & Satisfecha & Insatisfecha & Muy insatisfecha \\
\hline & & & \\
\hline
\end{tabular}

Tras la lesión medular, siente que su capacidad de seducción...
Ha aumentado mucho
Ha aumentado un poco
Se ha mantenido igual
Ha disminuido un poco
Ha disminuido mucho
Ha desaparecido completamente

Tras la lesión, su satisfacción con tu vida sexual...
Ha aumentado mucho
Ha aumentado un poco
Se ha mantenido igual
Ha disminuido un poco
Ha disminuido mucho
Ha desaparecido completamente

¿Cómo es su deseo sexual ahora comparado con la situación previa a su lesión?

\begin{tabular}{|l|l|l|l|}
\hline Aumentado & Sin cambio & Disminuido & Inexistente \\
\hline & & & \\
\hline
\end{tabular}

¿Qué importancia le da usted a la sexualidad en comparación con la situación previa a la lesión?

\begin{tabular}{|c|c|c|c|}
\hline Aumentado & Sin cambio & Disminuido & Inexistente \\
\hline & & & \\
\hline
\end{tabular}

¿Cómo son, en general, las relaciones sexuales de pareja después de la lesión? (Si no tiene pareja deje la pregunta en blanco)

\begin{tabular}{|l|l|l|l|}
\hline Muy insatisfactorias & Parcialmente insatisfactorias & Parcialmente satisfactorias & Muy satisfactorias \\
\hline & & & \\
\hline
\end{tabular}

¿Cómo eran, en general, las relaciones sexuales de pareja antes de la lesión? (si no tenía pareja deje la pregunta en blanco)

\begin{tabular}{|l|l|l|l|}
\hline Muy insatisfactorias & Parcialmente insatisfactorias & Parcialmente satisfactorias & Muy satisfactorias \\
\hline & & & \\
\hline
\end{tabular}


¿Cómo son sus posibilidades y sus habilidades para disfrutar de su propia sexualidad?

\begin{tabular}{|l|l|l|l|}
\hline Muy insatisfactorias & Parcialmente insatisfactorias & Parcialmente satisfactorias & Muy satisfactorias \\
\hline & & & \\
\hline
\end{tabular}

¿Cómo son sus posibilidades y sus habilidades para satisfacer sexualmente a su pareja? (si no tiene pareja deje la pregunta en blanco)

\begin{tabular}{|l|l|l|l|}
\hline Muy insatisfactorias & Parcialmente insatisfactorias & Parcialmente satisfactorias & Muy satisfactorias \\
\hline & & & \\
\hline
\end{tabular}

¿Cree que satisface a su pareja? (si no tiene pareja deje la pregunta en blanco)

\begin{tabular}{|c|c|c|c|c|}
\hline Casi nunca & Pocas veces & Algunas veces & Muchas veces & Casi siempre \\
\hline & & & & \\
\hline
\end{tabular}

Si desea/deseaba tener hijos/as, ¿̇ha podido satisfacer su deseo de procreación?

\begin{tabular}{|c|c|c|c|}
\hline Si & No & Parcialmente (he tenido menos hijos/as de las que deseaba) & No deseaba tener hijos \\
\hline & & & \\
\hline
\end{tabular}

¿Ha utilizado alguna ayuda para poder tener hijos/as? (Si no deseaba tener hijos/as, deje la pregunta en blanco)

No

Inseminación artificial con donantes

Inseminación artificial sin donantes

Fertilización in vitro sin donantes

Fertilización in vitro con donantes

Uso de vibradores (Ferticare ${ }^{\circledR}$ )

Otros. Especificar:

¿De dónde ha obtenido información o consejo sobre sexualidad tras la lesión medular?

Internet (blogs, redes sociales, ...)

Libros, revistas sobre el tema

Asociaciones

Compañeros/as, amigos/as o parejas

Profesionales sanitarios

Otros (especificar):

¿Siente que el sistema de salud le ha dado suficiente información y apoyo respecto a cómo enfrentar su sexualidad?

$$
\square \text { Sí } \quad \square \text { No }
$$

¿Sobre qué temas relacionados con la sexualidad le han hablado los y las profesionales de la salud? 
¿Sobre qué temas relacionados con la sexualidad le hubiera gustado que le hablaran los y las profesionales de la salud?

¿Qué opina de la asistencia sexual entendida como un apoyo para poder acceder sexualmente al propio cuerpo o al de una pareja?

¿Qué opina de la asistencia sexual entendida como alguien con quien mantener relaciones sexuales?

Si hay algo más que quiera aportar o comentar, puede incluirlo a continuación:

Muchas gracias por su colaboración. La información aportada será de gran ayuda para la investigación. 


\section{Anexo IV: Cuestionario para hombres}

Como ya ha sido informado, el siguiente cuestionario forma parte de un estudio que pretende conocer la realidad sobre la sexualidad en los hombres con lesión medular adquirida de cara a mejorar la atención a este aspecto de la vida.

Las respuestas al cuestionario son anónimas y confidenciales. En ningún caso serán analizadas individualmente si no mediante estadística de forma global y conjunta de todos los cuestionarios recibidos.

Para que los resultados sean válidos es necesario que responda a las preguntas de forma sincera, eligiendo la respuesta que más se aproxime a sus circunstancias, ideas o sentimientos.

Si lo considera oportuno le agradecemos su colaboración remitiéndolo cubierto al equipo investigador dentro del sobre pre-franqueado (envío gratuito) que le adjuntamos. Cualquier duda puede consultarla en el contacto de la investigadora principal que le indicamos en la carta adjunta.

Muchas gracias por su colaboración, es de gran importancia.

En cada pregunta marque con una cruz o una equis $(X)$ el cuadro que corresponde a la respuesta con la que esté más de acuerdo o refleje mejor sus circunstancias.

Nota previa: en este cuestionario, cuando hablamos de sexo o relaciones sexuales nos referimos a cualquier expresión de la sexualidad: besos, caricias, tocamientos, sexo oral, etc. y no solo a las relaciones con penetración.

Fecha de nacimiento:

día.......... mes año

Comunidad Autónoma donde vive:

Nivel de estudios

Primarios (primarios, CEP, GE, Bachiller elemental, EGB, FPI, FP grado medio)

Medios (BUP, COU, PREU, ESO, Bachiller, FP II, FP grado superior)

Universitarios (diplomatura, grado, licenciatura)

Estado civil actual:

\begin{tabular}{|l|l|l|l|}
\hline Soltero & En pareja/casado & Separado/divorciado & Viudo \\
\hline & & & \\
\hline
\end{tabular}

Otro tipo de relación. ¿Cuál?

Número de hijos:

Orientación sexual:

\begin{tabular}{|c|c|c|c|}
\hline Heterosexual & Homosexual & Bisexual & Otros. Especificar \\
\hline & & & \\
\hline
\end{tabular}

¿Con quién vive?

\begin{tabular}{|c|c|c|c|c|}
\hline Pareja & Padres & Solo & Residencia & Otros. Especificar \\
\hline & & & & \\
\hline
\end{tabular}




\begin{tabular}{|c|c|c|c|c|c|c|}
\hline & $\begin{array}{c}1 \text { - Muy } \\
\text { insatisfactoria }\end{array}$ & $\begin{array}{c}2- \\
\text { Insatisfactoria } \\
\end{array}$ & $\begin{array}{c}3 \text { - Un poco } \\
\text { insatisfactoria }\end{array}$ & $\begin{array}{l}4 \text { - Un poco } \\
\text { satisfactoria }\end{array}$ & $\begin{array}{c}5 \text { - } \\
\text { Satisfactoria } \\
\end{array}$ & $\begin{array}{c}\text { 6- Muy } \\
\text { satisfactoria }\end{array}$ \\
\hline Mi vida general es: & $\square$ & $\square$ & $\square$ & $\square$ & $\square$ & $\square$ \\
\hline Mi vida sexual es: & $\square$ & $\square$ & $\square$ & $\square$ & $\square$ & $\square$ \\
\hline $\begin{array}{c}\text { Mi relación en } \\
\text { pareja es: }\end{array}$ & $\square$ & $\square$ & $\square$ & $\square$ & $\square$ & $\square$ \\
\hline Mi vida familiar es: & $\square$ & $\square$ & $\square$ & $\square$ & $\square$ & $\square$ \\
\hline $\begin{array}{c}\text { Mi relación con mis } \\
\text { amigos y conocidos } \\
\text { es: }\end{array}$ & $\square$ & $\square$ & $\square$ & $\square$ & $\square$ & $\square$ \\
\hline Mi vida de ocio es: & $\square$ & $\square$ & $\square$ & $\square$ & $\square$ & $\square$ \\
\hline $\begin{array}{l}\text { Mi situación } \\
\text { laboral es: }\end{array}$ & $\square$ & $\square$ & $\square$ & $\square$ & $\square$ & $\square$ \\
\hline $\begin{array}{l}\text { Mi situación } \\
\text { económica es: }\end{array}$ & $\square$ & $\square$ & $\square$ & $\square$ & $\square$ & $\square$ \\
\hline
\end{tabular}

Fecha en la que se produjo la lesión medular:

día mes. año.

Causa de la lesión:

Accidente de tráfico

Accidente laboral

Accidente deportivo

Accidente fortuito

Zambullida
Intento de suicidio

Agresión

Enfermedad

Otras

¿En qué hospital/es ha sido atendido de la lesión medular?

Tipo de lesión

\begin{tabular}{|c|c|c|c|c|}
\hline Paraplejia & Paraparesia & Tetraplejia & Tetraparesia & No lo sé \\
\hline & & & & \\
\hline
\end{tabular}

Tipo de lesión según extensión:

\begin{tabular}{|c|c|c|}
\hline Completa & Incompleta & No lo sé \\
\hline & & \\
\hline
\end{tabular}

Nivel de la lesión

\begin{tabular}{|c|c|c|c|c|}
\hline Cervical & Dorsal o torácico & Lumbar & Sacro & No lo sé \\
\hline & & & & \\
\hline
\end{tabular}

¿Tiene o ha tenido úlceras por presión?

$\square \quad$ Sí $\quad \square$ No

¿Tiene o ha tenido espasticidad?

$$
\text { Sí } \square \text { No }
$$

¿Presenta dolor crónico (de más de 6 meses de duración) asociado a la lesión medular?

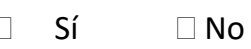


Indique si presenta sensibilidad en el área genital:

$$
\text { Sí } \square \text { No } \quad \square \text { Parcialmente }
$$

Indique si presenta sensibilidad en el área anal:

$$
\square \text { Sí } \quad \square \text { No } \quad \square \text { Parcialmente }
$$

Indique el método mediante el cual realiza vaciamiento de su vejiga:

Espontáneo (sin ayuda)

Sondaje vesical intermitente

Sondaje vesical permanente

Sonda suprapúbica

Con maniobra de Credé (compresión manual de la parte baja del abdomen para ayudar al vaciamiento de la vejiga)

Pañal por vaciamiento involuntario

Otro ¿Cuál?

Indique el método mediante el cual realiza vaciamiento de su intestino:

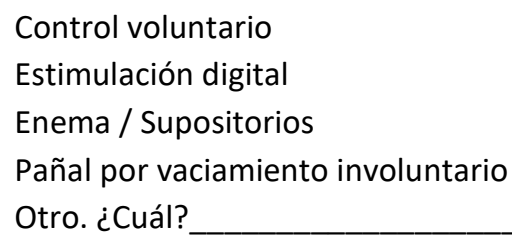

¿Le preocupa el escape involuntario de orina durante la actividad sexual?

$$
\square \text { Sí } \quad \square \text { No }
$$

¿Le preocupa el escape involuntario de heces durante la actividad sexual?

$$
\square \text { Sí } \quad \square \text { No }
$$

¿Ha presentado alguna crisis de disreflexia autonómica (encontrarse mal con crisis de sudoración, taquicardia, dolor de cabeza y aumento de la tensión que necesitara asistencia sanitaria) durante las relaciones sexuales?
$\square$ Sí
$\square$ No

¿Utiliza libros, películas, música o arte con contenido sexual?

\section{Nunca}

Rara vez (menos de una vez al mes)

A veces (una vez al mes pero menos de 2 veces/semana)

A menudo (2 veces/semana o más)

Diariamente

¿Cuánto placer o disfrute obtiene de pensar y fantasear acerca del sexo?

Ningún disfrute o placer

Poco disfrute o placer

Algo de disfrute o placer

Mucho disfrute o placer

Muchísimo disfrute o placer 
¿Es su vida sexual un aspecto importante en sus relaciones de pareja?

No tiene importancia

Es un aspecto muy poco importante

Es un aspecto relativamente importante

Es un aspecto importante

Es un aspecto muy importante

Durante los últimos 6 meses, ¿cómo califica la confianza que tiene en poder tener y mantener una erección?

\begin{tabular}{|c|c|c|c|c|}
\hline Muy baja & Baja & Moderada & Alta & Muy alta \\
\hline & & & & \\
\hline
\end{tabular}

Durante los últimos 6 meses, cuando tiene erecciones mediante estimulación sexual, ¿con qué frecuencia sus erecciones han tenido la dureza suficiente para la penetración?

\begin{tabular}{|c|c|c|c|c|}
\hline Casi nunca & Pocas veces & Algunas veces & Muchas veces & Casi siempre \\
\hline & & & & \\
\hline
\end{tabular}

Durante los últimos 6 meses, durante las relaciones sexuales, ¿con qué frecuencia ha podido mantener su erección después de haber penetrado a su pareja?

\begin{tabular}{|c|c|c|c|c|}
\hline Casi nunca & Pocas veces & Algunas veces & Muchas veces & Casi siempre \\
\hline & & & & \\
\hline
\end{tabular}

Durante los últimos 6 meses, durante las relaciones sexuales, ¿cuánto de difícil le ha sido mantener su erección hasta el final del acto sexual?

\begin{tabular}{|c|c|c|c|c|}
\hline $\begin{array}{c}\text { Extremadamente } \\
\text { difícil }\end{array}$ & Muy difícil & Difícil & Ligeramente difícil & Nada difícil \\
\hline & & & & \\
\hline
\end{tabular}

Durante los últimos 6 meses, cuando ha intentado tener relaciones sexuales, ¿con qué frecuencia han sido satisfactorias para usted?

\begin{tabular}{|c|c|c|c|c|}
\hline Casi nunca & Pocas veces & Algunas veces & Muchas veces & Casi siempre \\
\hline & & & & \\
\hline
\end{tabular}

¿Utiliza alguna ayuda para conseguir o mantener la erección?

No $\square$ Sí. ¿Cuál?

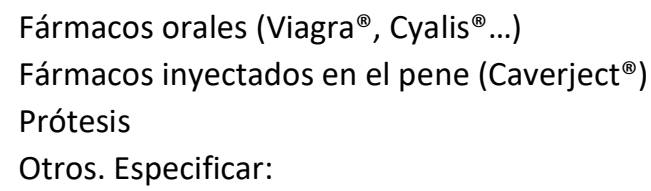

¿Es capaz de eyacular cuando está muy excitado?

\begin{tabular}{|c|c|c|c|c|}
\hline Nunca & $\begin{array}{c}\text { Rara vez (menos } \\
\text { de la mitad de las } \\
\text { veces) }\end{array}$ & $\begin{array}{c}\text { A veces (la mitad } \\
\text { de las veces más } \\
\text { o menos) }\end{array}$ & $\begin{array}{c}\text { A menudo (más } \\
\text { de la mitad de las } \\
\text { veces) }\end{array}$ & Siempre \\
\hline & & & & \\
\hline
\end{tabular}


¿Utiliza alguna ayuda para facilitar la eyaculación?

\begin{tabular}{|l|l|}
\hline No & Vibradores (Ferticare $^{\circledR}$ ) \\
\hline & \\
\hline
\end{tabular}

Otros. Especificar:

¿Es capaz de tener un orgasmo cuando está muy excitado?

\begin{tabular}{|c|c|c|c|c|}
\hline Nunca & $\begin{array}{c}\text { Rara vez (la } \\
\text { minoría de las } \\
\text { veces) }\end{array}$ & $\begin{array}{c}\text { A veces (la mitad } \\
\text { de las veces) }\end{array}$ & $\begin{array}{c}\text { A menudo (la } \\
\text { mayoría de las } \\
\text { veces) }\end{array}$ & Siempre \\
\hline & & & & \\
\hline
\end{tabular}

¿Cuánto placer o disfrute obtiene en sus orgasmos? Si no tiene orgasmos, deje la pregunta en blanco.

\begin{tabular}{|c|c|c|c|c|}
\hline $\begin{array}{c}\text { Ningún disfrute o } \\
\text { placer }\end{array}$ & $\begin{array}{c}\text { Poco disfrute o } \\
\text { placer }\end{array}$ & $\begin{array}{c}\text { Algo de disfrute o } \\
\text { placer }\end{array}$ & $\begin{array}{c}\text { Mucho disfrute o } \\
\text { placer }\end{array}$ & $\begin{array}{c}\text { Muchísimo } \\
\text { disfrute o placer }\end{array}$ \\
\hline & & & & \\
\hline
\end{tabular}

¿Cuánto placer o disfrute obtiene a lo largo de la relación sexual (no valorando exclusivamente el momento del orgasmo)?

\begin{tabular}{|c|c|c|c|c|}
\hline $\begin{array}{c}\text { Ningún disfrute o } \\
\text { placer }\end{array}$ & $\begin{array}{c}\text { Poco disfrute o } \\
\text { placer }\end{array}$ & $\begin{array}{c}\text { Algo de disfrute o } \\
\text { placer }\end{array}$ & $\begin{array}{c}\text { Mucho disfrute o } \\
\text { placer }\end{array}$ & $\begin{array}{c}\text { Muchísimo } \\
\text { disfrute o placer }\end{array}$ \\
\hline & & & & \\
\hline
\end{tabular}

¿Cómo se sentía con su imagen corporal antes de tener la lesión?

\begin{tabular}{|c|c|c|c|}
\hline Muy satisfecho & Satisfecho & Insatisfecho & Muy insatisfecho \\
\hline & & & \\
\hline
\end{tabular}

¿Cómo se siente con su imagen corporal actual?

\begin{tabular}{|c|c|c|c|}
\hline Muy satisfecho & Satisfecho & Insatisfecho & Muy insatisfecho \\
\hline & & & \\
\hline
\end{tabular}

Tras la lesión medular, siente que su capacidad de seducción...

Ha aumentado mucho

Ha aumentado un poco

Se ha mantenido igual

Ha disminuido un poco

Ha disminuido mucho

Ha desaparecido completamente

Tras la lesión, su satisfacción con su vida sexual...

Ha aumentado mucho

Ha aumentado un poco

Se ha mantenido igual

Ha disminuido un poco

Ha disminuido mucho

Ha desaparecido completamente 
¿Cómo es su deseo sexual ahora comparado con la situación previa a su lesión?

\begin{tabular}{|c|c|c|c|}
\hline Aumentado & Sin cambio & Disminuido & Inexistente \\
\hline & & & \\
\hline
\end{tabular}

¿Qué importancia le da usted a la sexualidad en comparación con la situación previa a la lesión?

\begin{tabular}{|c|c|c|c|}
\hline Aumentado & Sin cambio & Disminuido & Inexistente \\
\hline & & & \\
\hline
\end{tabular}

¿Cómo son, en general, las relaciones sexuales de pareja después de la lesión? (Si no tiene pareja deje la pregunta en blanco)

\begin{tabular}{|l|l|l|l|}
\hline Muy insatisfactorias & Parcialmente insatisfactorias & Parcialmente satisfactorias & Muy satisfactorias \\
\hline & & & \\
\hline
\end{tabular}

¿Cómo eran, en general, las relaciones sexuales de pareja antes de la lesión? (Si no tenía pareja deje la pregunta en blanco)

\begin{tabular}{|l|l|l|l|}
\hline Muy insatisfactorias & Parcialmente insatisfactorias & Parcialmente satisfactorias & Muy satisfactorias \\
\hline & & & \\
\hline
\end{tabular}

¿Cómo son sus posibilidades y sus habilidades para disfrutar de su propia sexualidad?

\begin{tabular}{|l|l|l|l|}
\hline Muy insatisfactorias & Parcialmente insatisfactorias & Parcialmente satisfactorias & Muy satisfactorias \\
\hline & & & \\
\hline
\end{tabular}

¿Cómo son sus posibilidades y sus habilidades para satisfacer sexualmente a su pareja? (Si no tiene pareja deje la pregunta en blanco)

\begin{tabular}{|l|l|l|l|}
\hline Muy insatisfactorias & Parcialmente insatisfactorias & Parcialmente satisfactorias & Muy satisfactorias \\
\hline & & & \\
\hline
\end{tabular}

¿Cree que satisface a su pareja? (Si no tiene pareja deje la pregunta en blanco)

\begin{tabular}{|c|c|c|c|c|}
\hline Casi nunca & Pocas veces & Algunas veces & Muchas veces & Casi siempre \\
\hline & & & & \\
\hline
\end{tabular}

Si desea/deseaba tener hijos/as, ¿ha podido satisfacer su deseo de procreación?

\begin{tabular}{|c|c|c|c|}
\hline $\mathrm{Si}$ & No & Parcialmente (he tenido menos hijos/as de las que deseaba) & No deseaba tener hijos \\
\hline & & & \\
\hline
\end{tabular}

¿Ha utilizado alguna ayuda para poder tener hijos/as? (Si no deseaba tener hijos/as, deje la pregunta en blanco)

No

Inseminación artificial con donantes

Inseminación artificial sin donantes

Fertilización in vitro sin donantes

Fertilización in vitro con donantes

Uso de vibradores (Ferticare ${ }^{\circledR}$ )

Otros. Especificar: 
¿De dónde ha obtenido información o consejo sobre sexualidad tras la lesión medular?

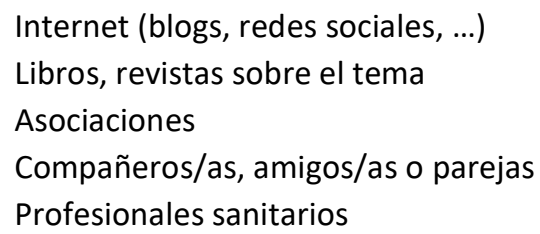

¿Siente que el sistema de salud le ha dado suficiente información y apoyo respecto a cómo enfrentar su sexualidad?

$\square$ Sí $\quad \square$ No

¿Sobre qué temas relacionados con la sexualidad le han hablado los y las profesionales de la salud?

¿Sobre qué temas relacionados con la sexualidad le hubiera gustado que le hablaran los y las profesionales de la salud?

¿Qué opina de la asistencia sexual entendida como un apoyo para poder acceder sexualmente al propio cuerpo o al de una pareja?

¿Qué opina de la asistencia sexual entendida como alguien con quien mantener relaciones sexuales?

Si hay algo más que quiera aportar o comentar, puede incluirlo a continuación.

\section{Muchas gracias por su colaboración. La información aportada será de gran ayuda para la investigación.}




\section{Anexo V: Carta de presentación}

Estimado señor/a:

Nos dirigimos a usted para informarle que en el marco de los estudios de doctorado de la Universidad Jaume I de Castellón y en colaboración con la Universidad de Oviedo a través de su centro adscrito Facultad de Enfermería de Gijón, se está realizando un estudio sobre la vivencia de la sexualidad en hombres y mujeres con lesión medular adquirida. Este es un aspecto que consideramos muy importante en la vida de las personas aquejadas por este tipo de lesión y sobre el que no se conoce mucho puesto que ha sido muy poco investigado, esto dificulta que el sistema sanitario ofrezca la ayuda necesaria.

La investigación cuenta con la aprobación del Comité de Ética de la Investigación del Principado de Asturias así como de la dirección del Hospital Universitario de Asturias (HUCA). Este estudio cumple con todos los requisitos exigidos en la Ley Orgánica 3/2018, de 5 de diciembre, de protección de datos personales y garantía de los derechos digitales. El equipo investigador le garantiza que esta dirección no será cedida bajo ningún concepto a ninguna otra entidad ni el propio equipo se dirigirá a usted para ninguna otra cuestión.

Desearíamos y agradeceríamos poder contar con su colaboración que consistiría en cumplimentar el cuestionario que encontrará junto a esta carta y enviarlo en el sobre prefranqueado que se adjunta (sin coste alguno) lo antes que le sea posible. Contestar a las preguntas es sencillo y le llevará muy poco tiempo, en torno a unos 10-15 minutos.

El cuestionario es voluntario y anónimo (no consta la identidad de quien lo contesta). Todos los datos aportados se tratarán en conjunto mediante técnicas estadísticas y no de forma individual.

Un informe de los resultados globales obtenidos en esta investigación le será reportado si lo desea, para ello y para no romper el anonimato del cuestionario deberá comunicar su interés al correo electrónico andrearodriguezalonso@gmail.com así mismo se enviará el informe a la Asociación de Lesionados Medulares y Grandes Discapacitados de Asturias (Aspaym) y a la gerencia del Servicio de Salud de Principado de Asturias (SESPA) para que puedan ser tomados en cuenta para la mejora de la atención a las personas con lesión medular.

Para aclarar cualquier duda o para hacer llegar cualquier comentario puede dirigirse a la investigadora principal, Andrea Rodríguez Alonso andrearodriguezalonso@gmail.com o al director de la investigación, Enrique Oltra Rodríguez (985 185041 - Facultad de Enfermería de Gijón)

Su colaboración es clave para la investigación, por lo que queremos agradecerle profundamente su participación.

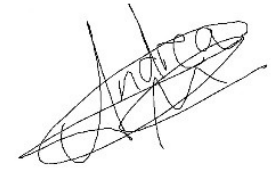

Andrea Rodríguez Alonso.

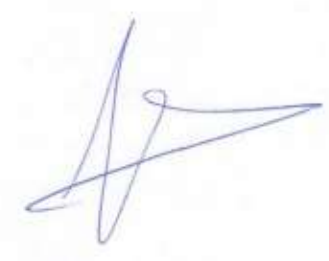

Enrique Oltra Rodríguez (RN, MSc, PhD). 


\section{Anexo VI: Autorización del Comité de Ética de la Investigación del Principado de Asturias}

SERVICIO DE SALUD

HOSPTAL UNIVERST ARIO CENTRUL. DE ASTURIAS \

DEL PRINCIPADO DE ASTUFIAS

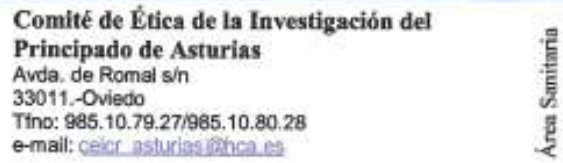

Oviedo, 08 de Mayo de 2017

El Comité de Etica de la investigación del Principado de Asturias, ha revisado el Proyecto de Investigación $n^{\circ} 78 / 17$, titulado. "SEXUALIDAD EN HOMBRES Y MUJERES CON LESION MEDULAR ADQUIRIDA*. Investigadora Principal Dina Andrea Rodriguez Alonso. Tesis Doctoral.

El Comité ha tomado el acuerdo de considerar que el citado proyecto reùne las condiciones éticas necesarias para poder reatizarse y en consecuencia emite su autorización.

Le recuerdo que deberá guardarse la máxima confidencialidad de los datos utilizados en este proyecto.

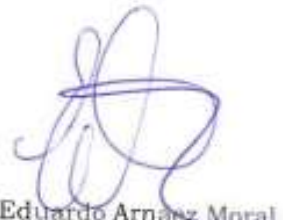

Fdo: Edurato Arnatiz Moral

Secretario del Comité de Ética de la Investigación

del Principado de Asturias 


\section{Anexo VII: Autorización de la Gerencia del HUCA}

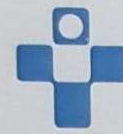

SERVICIO DE SALUD

GERENCIA AREA SANITARIA IV

HOSPITAL UNIVERSITARIO CENTRAL DE ASTURIAS

Oviedo, 12 de Julio de 2017

Asunto: Respuesta a solicitud de permiso para realización trabajo de investigación

Da. Gloria Herias Corral, Directora de Gestión de Cuidados y Enfermería del Área Sanitaria IV, autoriza a:

\section{Da. ANDREA RODRÍGUEZ ALONSO}

Matrona del Área IV para la recogida de datos destinado al trabajo para Tesis Doctoral, que lleva por título "SEXUALIDAD EN HOMBRES Y MUJERES CON LESIÓN MEDULAR ADQUIRIDA".

Se recuerda al solicitante que en la utilización de estos datos debe mantenerse en todo momento la confidencialidad y privacidad de los mismos, tal como está previsto en el L.O. 15/1999, de 13 de diciembre, de Protección de Datos de Carácter Personal, y del R.D. 1720/2007, de 21 de diciembre, por el que se aprueba el Reglamento de desarrollo de la Ley Orgánica 15/1999.

Asimismo le informamos que deberá ponerse en contacto, con el supervisor/a o responsable del servicio para presentarse y exponerle su proyecto.

Consideramos que este estudio puede ser de interés para la organización, por lo que le pedimos que una vez haya concluido el trabajo nos haga llegar los resultados.

Un saludo,

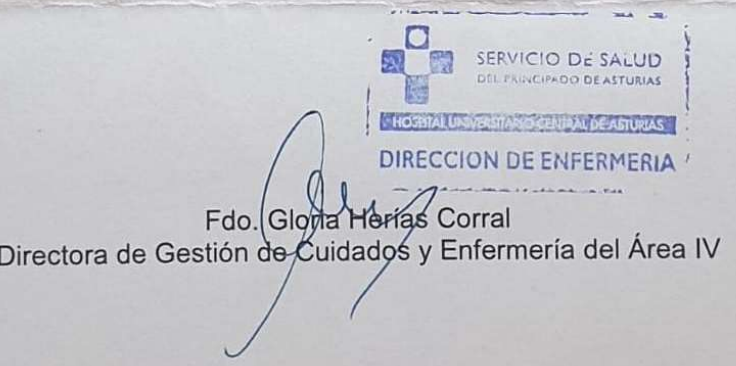




\section{Anexo VIII: Acta Beca al Mejor Proyecto de Tesis Doctoral en Enfermería Familiar y Comunitaria}

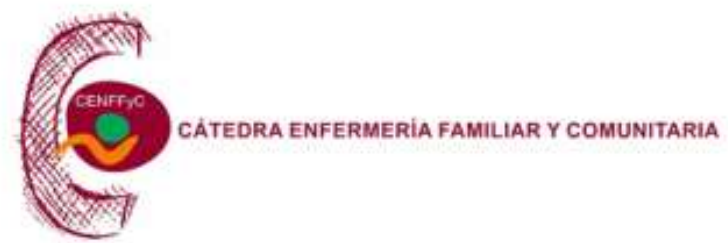

Reunidos en la Universidad de Alicante con fecha 18 de junio de 2018 los miembros del Jurado de la Beca al Mejor Proyecto de Tesis Doctoral en Enfermería Familiar y Comunitaria convocado por la Cátedra de Enfermería Familiar y Comunitaria. Una vez revisadas y evaluadas las propuestas recibidas en base a los criterios establecidos al efecto en la convocatoria publicada en el Boletín Oficial de la Universidad de Alicante (BOUA) de 28 de marzo de 2018, la Beca al Mejor Proyecto de Tesis Doctoral en Enfermería Familiar y Comunitaria al Trabajo:

"Sexualidad en hombres y mujeres con lesión medular adquirida", cuya autora es:

\section{Do Andrea Rodríguez Alonso}

Siendo el Director de la Tesis:

\section{Enrique Oltra Rodríguez}

Para lo cual firman la presente ACTA, en Alicante a 18 de junio de dos mil dieciocho.

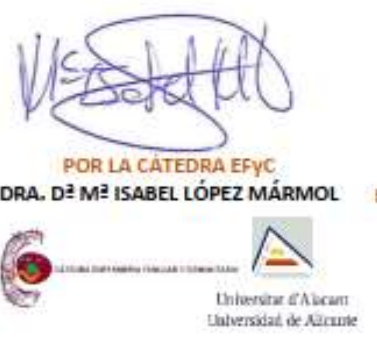

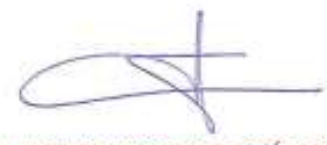

EN NOMBRE Y REPRESENTACIÓN DE LOS HOSPITALES UNIVERSITARIOS DE TORREVIEIAY VINALOPÓ-RIBERA SALUD

DR. D. ANTONIO RUIZ HONTANGAS

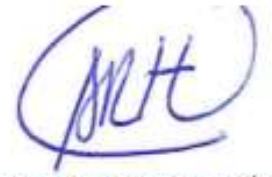

EN NOMBRE Y REPRESENTACIÓN DELA ASOCIACIÓN DE ENFERMERIA COMUNITARIA AEC DR. D. VICENTE GEA CABALLERO 

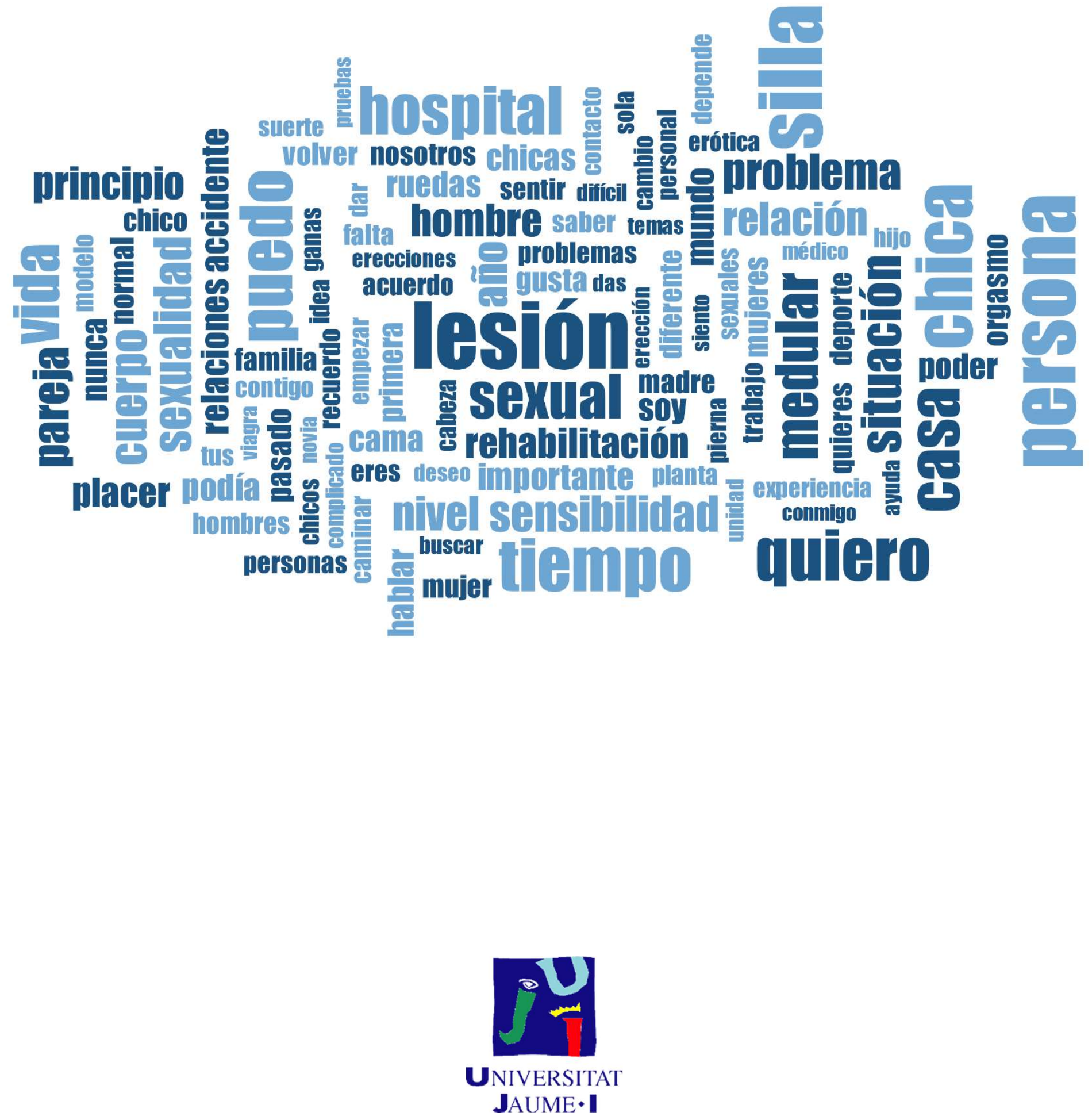